\title{
eSPAN140 performance assessment: V-65 Jesup South Bridge (Buchanan County, lowa)
}

Bryan R. Gallion

Follow this and additional works at: https://researchrepository.wvu.edu/etd

\section{Recommended Citation}

Gallion, Bryan R., "eSPAN140 performance assessment: V-65 Jesup South Bridge (Buchanan County, lowa)" (2016). Graduate Theses, Dissertations, and Problem Reports. 5642.

https://researchrepository.wvu.edu/etd/5642

This Thesis is protected by copyright and/or related rights. It has been brought to you by the The Research Repository @ WVU with permission from the rights-holder(s). You are free to use this Thesis in any way that is permitted by the copyright and related rights legislation that applies to your use. For other uses you must obtain permission from the rights-holder(s) directly, unless additional rights are indicated by a Creative Commons license in the record and/ or on the work itself. This Thesis has been accepted for inclusion in WVU Graduate Theses, Dissertations, and Problem Reports collection by an authorized administrator of The Research Repository @ WVU. For more information, please contact researchrepository@mail.wvu.edu. 


\title{
ESPAN140 PERFORMANCE ASSESSMENT: \\ V-65 JESUP SOUTH BRIDGE (BUCHANAN COUNTY, IOWA)
}

\author{
Bryan R. Gallion \\ Thesis submitted to the \\ College of Engineering and Mineral Resources \\ at West Virginia University \\ in partial fulfillment of the requirements \\ for the degree of
}

Master of Science

in

Civil and Environmental Engineering

Karl E. Barth, Ph.D., Chair

Gregory K. Michaelson, Ph.D., Co-Chair

P. V. Vijay, Ph.D.

Yoojung Yoon, Ph.D.

Department of Civil and Environmental Engineering

Morgantown, West Virginia

2016

Keywords: steel bridge, experimental testing, finite element analysis, eSPAN140 


\section{AbStract \\ ESPAN140 PERformAnCE ASSESSMENT: V-65 JESUP SOUTH BRIDGE (BUCHANAN COUNTY, IOWA)}

\section{Bryan R. Gallion}

The Short Span Steel Bridge Alliance (SSSBA) is a group of bridge and culvert industry leaders (including steel manufacturers, fabricators, service centers, coaters, researchers, and representatives of related associations and government organizations) who have joined together to provide educational information on the design and construction of short span steel bridges in installations up to 140 feet in length. Arguably, one of the crowning achievements of SSSBA is the development and implementation of a series of short-span steel bridge design standards. eSPAN140 is a complimentary web-based design tool which provides customized steel solutions for bridges up to 140 feet.

Working with members of SSSBA, the Secondary Roads Department of Buchanan County, Iowa, headed by Brian Keierlieber, P.E., agreed to be the first owner agency to utilize eSPAN140 to design and construct a short span steel bridge, specifically the new V-65 Jesup South Bridge in Jesup, Iowa. Various members of SSSBA volunteered time, materials, and expertise to assist in delivering the first documented short-span bridge designed using eSPAN140. In addition, the demonstration served significant research objectives: data collected from field investigations during deck casting as well as during live load testing will serve as analytical benchmarks for future analytical studies in short-span steel bridge behavior.

The scope of this thesis is to discuss the development of eSPAN140 and its associated design standards along with how eSPAN140 was utilized during its first documented application, the V65 Jesup South Bridge. In addition, a comprehensive overview of the experimental and analytical testing program is provided, along with a presentation of testing results. As discussed, it is clear that eSPAN140 is quite capable of producing efficient and economical solutions in the short-span range. This efficiency and economy stems largely from the use of commonly available plate and member sizes and the standardization of designs. For this project, eSPAN140 provided all the necessary parameters for county engineers to refine and synthesize an effective short-span steel bridge design. 


\section{ACKNOWLEDGEMENTS}

I would like to thank the American Iron and Steel Institute's Short Span Steel Bridge Alliance for funding this research project and providing the materials for the V-65 Jesup South Bridge. I would also like to thank my advisor Dr. Karl Barth for his guidance and support throughout my undergraduate and graduate career. The knowledge and experience I gained under his guidance is invaluable and will never be forgotten. Also, I would like to thank Dr. P. V. Vijay and Dr. Yoojung Yoon for their participation on this thesis' graduate advisory committee.

Additionally, I would like to thank Dr. Gregory Michaelson for lending his bridge testing expertise and guiding me through rigorous calculations as well as his unending help in the typing of this thesis. I would also like to thank my fellow graduate students of B-11 for their moral and technical support, specifically Pasha Kozhokin. Mr. Kozhokin worked alongside me for most of my graduate career and without him there to bounce ideas around with, I would not have made it this far.

Lastly, I would like to thank my family. My parents instilled in me an importance and persistence in the field of education and continued to offer guidance and support throughout my college career. Furthermore, my girlfriend provided her love, patience, and support that have been essential in my pursuit of my master's degree. 


\section{TABLE OF CONTENTS}

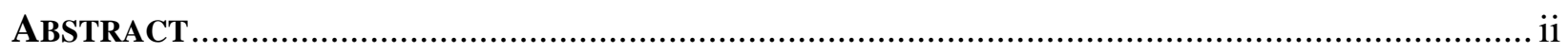

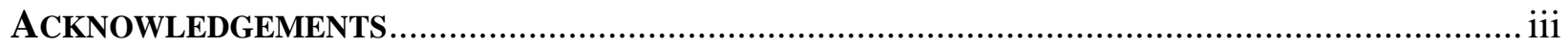

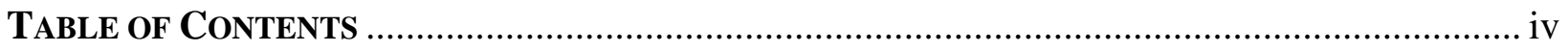

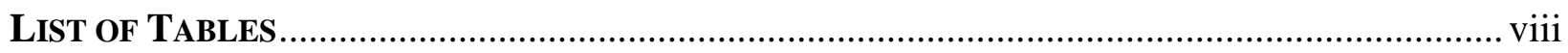

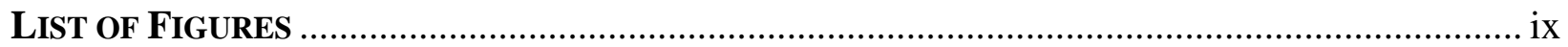

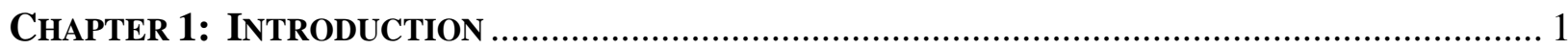

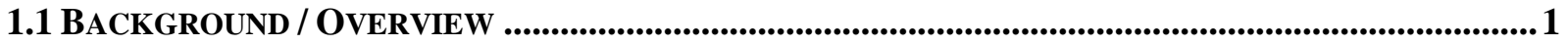

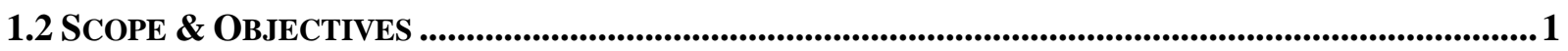

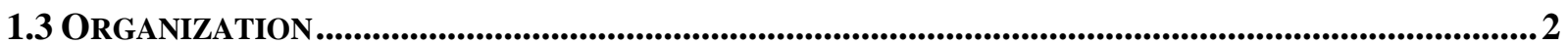

CHAPTER 2: OVERVIEW OF ESPAN140 DeVELOPMENT ..................................................... 3

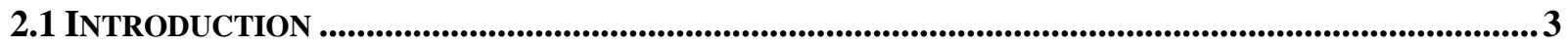

2.3 GOALS OF STEEL BRIDGE STANDARD DEVELOPMENT ......................................................................3

2.3 BRIEF OVERVIEW OF ALTERNATIVE STANDARD STEEL BRIDGE DESIGNS.................................... 4

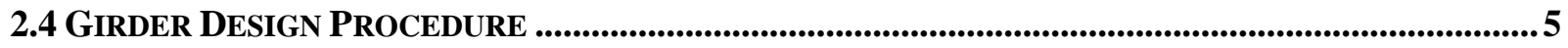

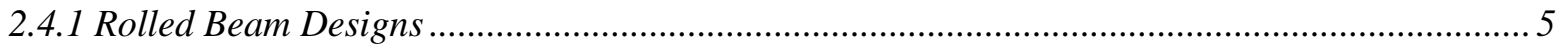

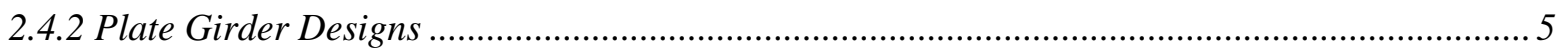

2.4.3 Common Design Parameters .............................................................................................. 7

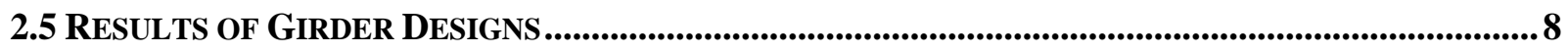

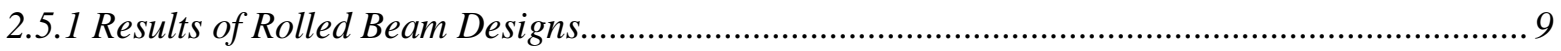

2.5.2 Results of Plate Girder Designs.......................................................................................... 11

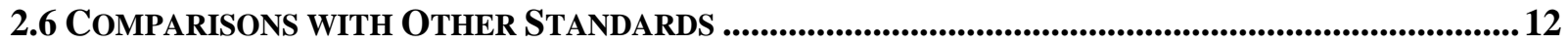

2.7 ESPAN140: INTERACTIVE WEB-BASED DESIGN TOOL ..........................................................

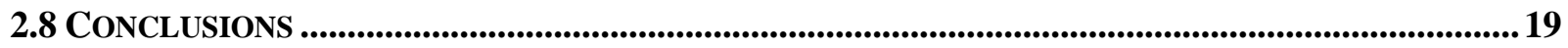

Chapter 3: Design Of NeW V-65 Jesup South Bridge.............................................. 20

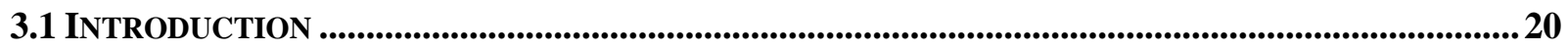

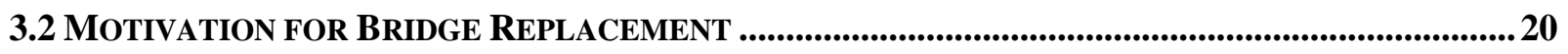

3.3 COMPARISON OF PRODUCED BRIDGE DESIGNS.....................................................................................22

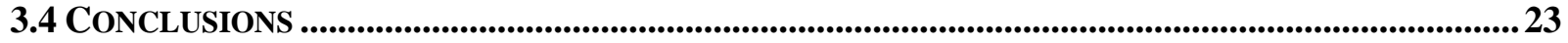




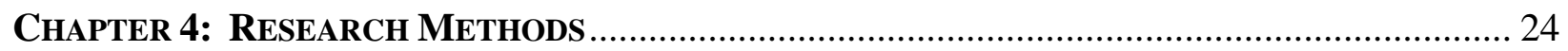

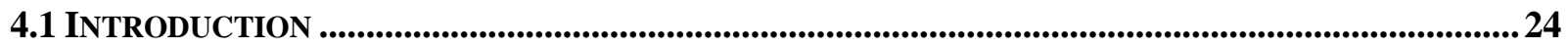

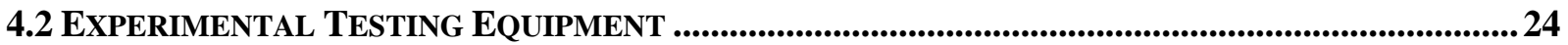

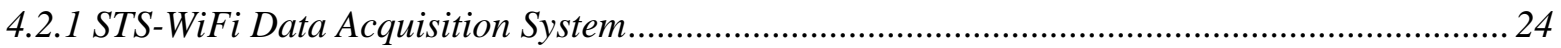

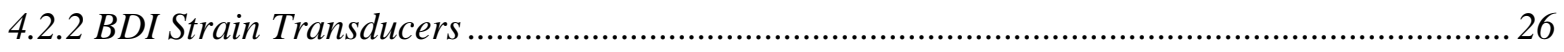

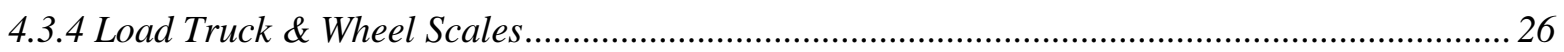

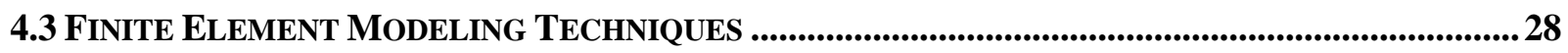

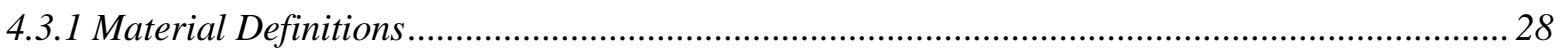

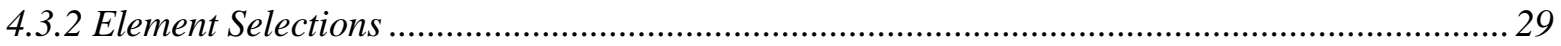

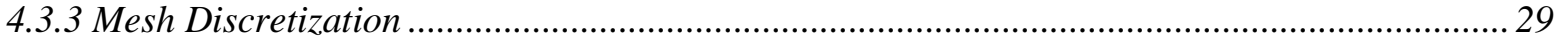

4.3.4 Boundary Conditions and Multiple-Point Constraints .......................................................... 30

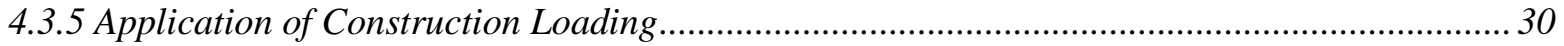

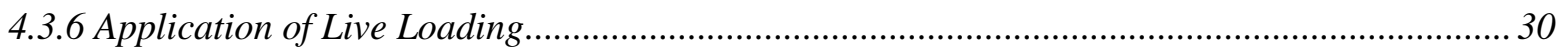

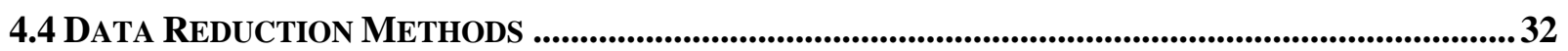

4.4.1 Computation of Lateral Flange Bending Stresses (Construction Loading)............................. 32

4.4.2 Computation of Bending Moment \& Live Load Distribution Factors (Live Loading) ............... 33

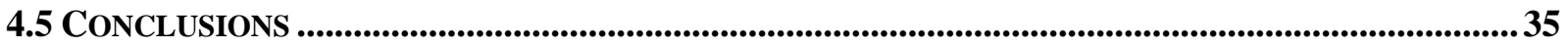

Chapter 5: Field TeSting OF V-65 Jesup South BRIDge ............................................ 36

5.1 INTRODUCTION ...........................................................................................................................................36

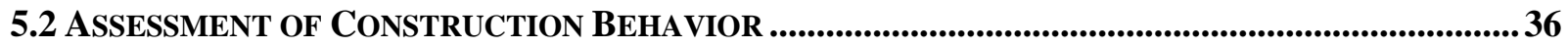

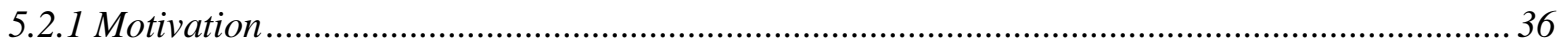

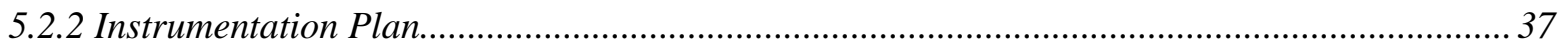

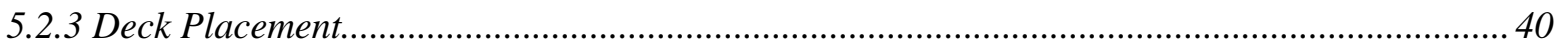

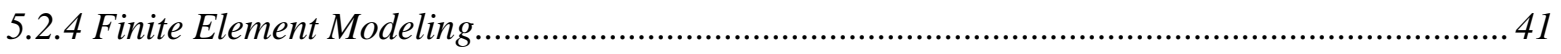

5.3 ASSESSMENT OF IN-SERVICE PERFORMANCE ......................................................................................42

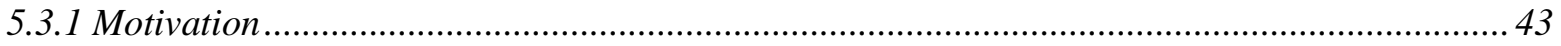

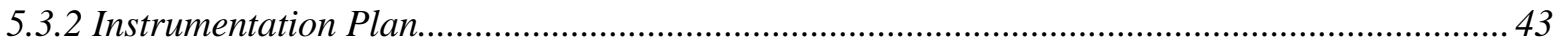

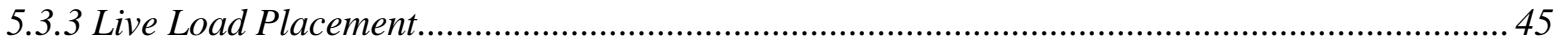

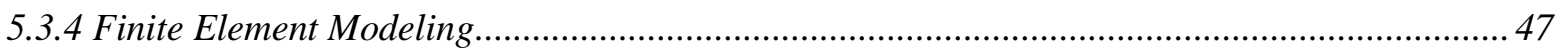

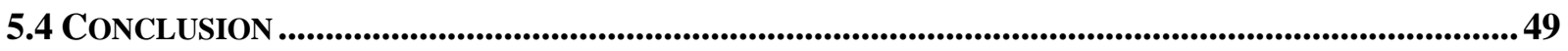

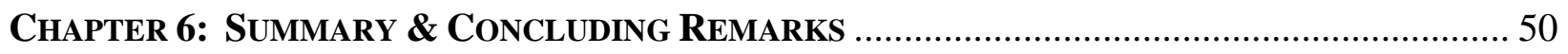

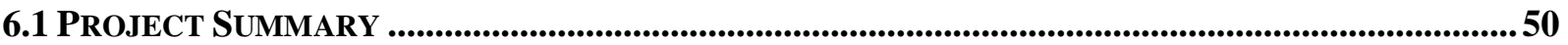




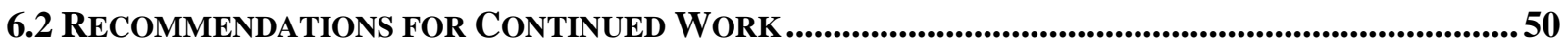

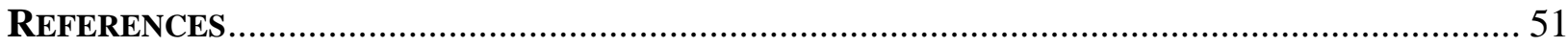

Appendix A： eSPAN140 Output …………………........................................................ 55

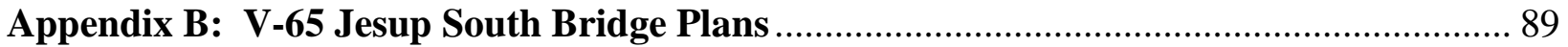

Appendix C: AASHTO Design Calculations ……………………………………….... 110

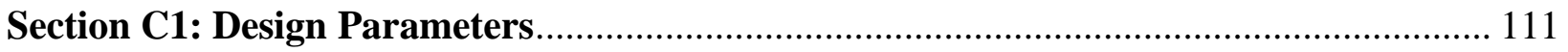

C1.1 INTRODUCTION ........................................................................................................................111

C1.2 BRIDGE LAYOUT ................................................................................................................111

C1.3 DESIGN PARAMETERS............................................................................................................................112

C1.3.1 Loads \& Load Combinations ………………………………………………………... 112

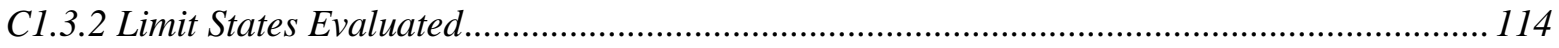

C1.3.2.1 Cross-Section Proportion Limits (Article 6.10.2) .......................................................114

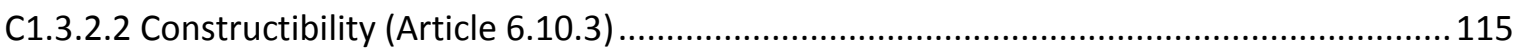

C1.3.2.3 Service Limit State (Article 6.10.4) ..........................................................................117

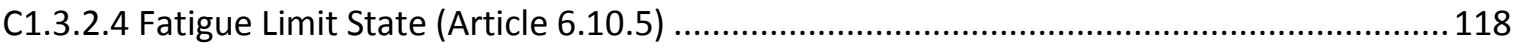

C1.3.2.5 Strength Limit State (Article 6.10.6) .....................................................................118

C1.4 COMMON PARAMETERS \& CALCULATIONS ...................................................................................118

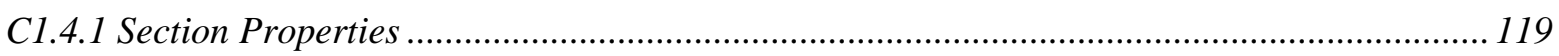

C1.4.2 Multiple Presence Factors \& Live Load Distribution Factors ......................................... 119

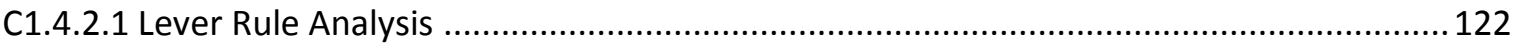

C1.4.2.2 Special Analysis (Article C4.6.2.2.2d) .....................................................................123

C1.4.2.3 Distribution Factor for Live Load Deflection (Article 2.5.2.6.2) .................................... 125

C1.4.3 Nominal Fatigue Resistance ........................................................................................ 126

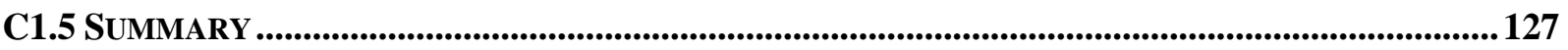

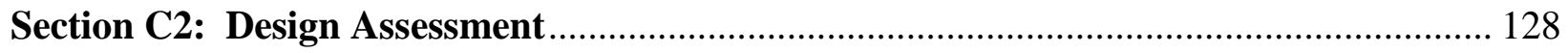

C2.1 INTRODUCTION ............................................................................................................................ 128

C2.2 GIRDER GEOMETRY ....................................................................................................... 128

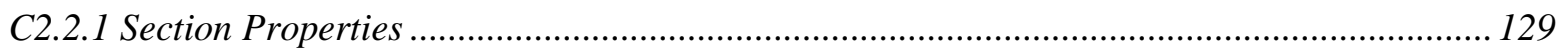

C2.2.2 Cross-Section Proportion Limits............................................................................ 130

C2.3 DEAD LOADS ......................................................................................................................... 131

C2.3.1 Component and Attachment Dead Load (DC) ............................................................. 131 


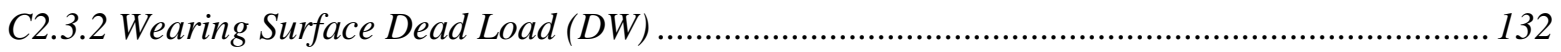

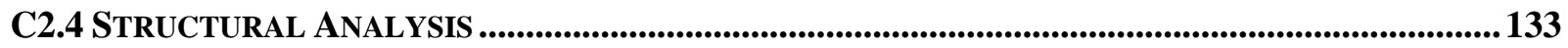

C2.4.1 Live Load Distribution Factors (Article 4.6.2.2) ............................................................... 133

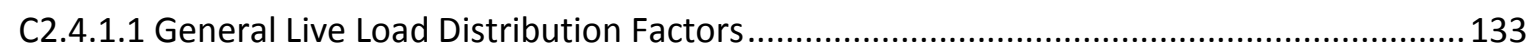

C2.4.1.2 Fatigue Live Load Distribution Factors................................................................. 134

C2.4.1.3 Live Load Distribution Factor Summary .............................................................. 135

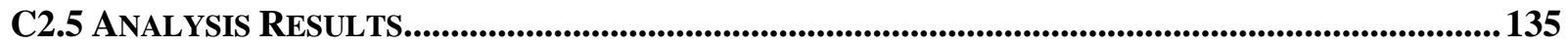

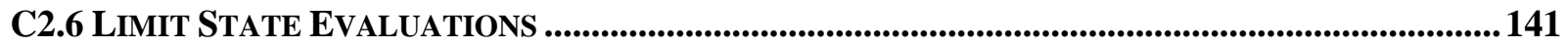

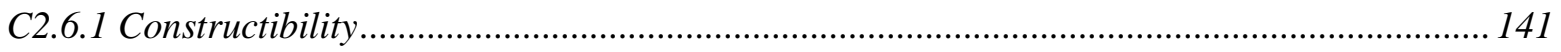

C2.6.1.1 Compression Flange Resistance ........................................................................... 141

C2.6.1.2 Major Axis and Lateral Flange Bending Stresses ..................................................... 146

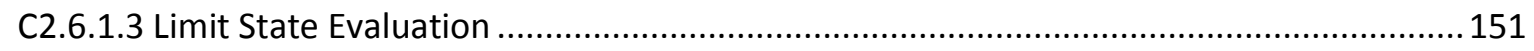

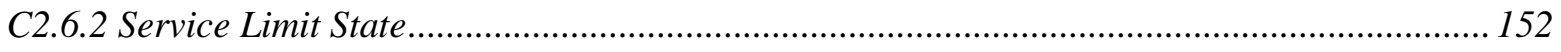

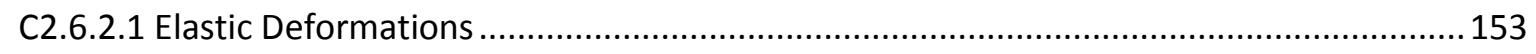

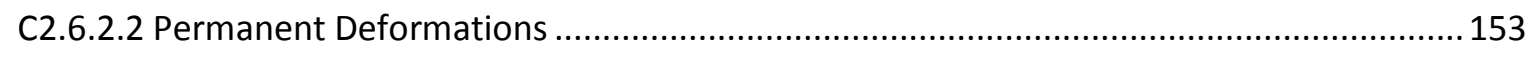

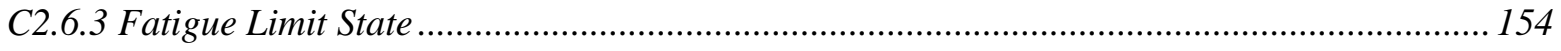

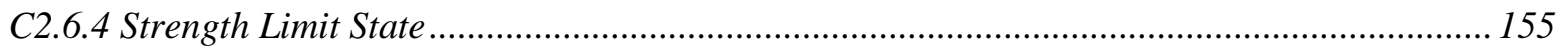

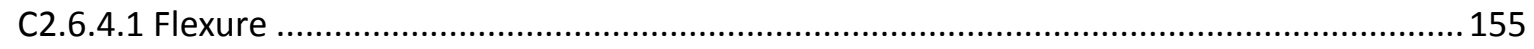

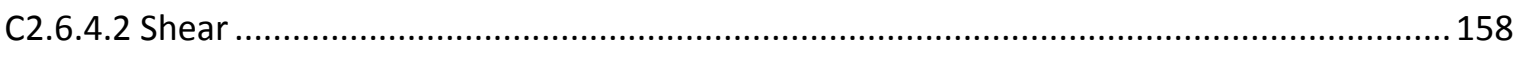

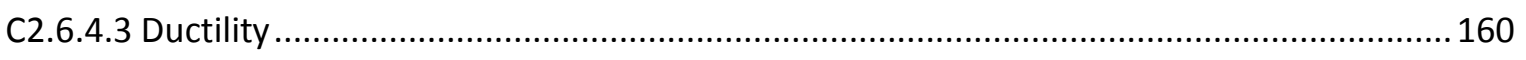

C2.7 PERFORMANCE SUMMARY ...........................................................................................................160 


\section{LIST OF TABLES}

Table 2.1: Lightest Weight Rolled Beam Designs ................................................................ 10

Table 2.2: Limited Depth Rolled Beam Designs............................................................... 11

Table 3.1: Comparison of Bridge Design Parameters ............................................................ 22

Table 5.1: Data Obtained from Deck Placement .................................................................... 41

Table 5.2: Experimental Bending Moments Obtained from Live Load Placement (ft-kip) .......... 47

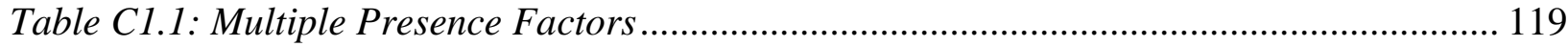

Table C1.2: Girder Eccentricities ................................................................................... 124 


\section{LIST OF FIGURES}

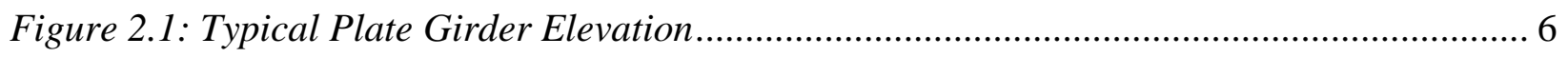

Figure 2.2: Typical Interior Plate Girder Cross-Section ..................................................... 7

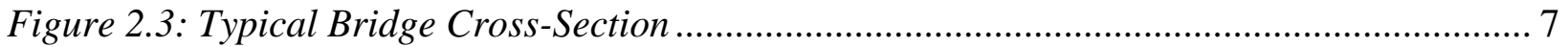

Figure 2.4: Comparison of Design Alternative (9'-0”' Girder Spacing) .................................... 9

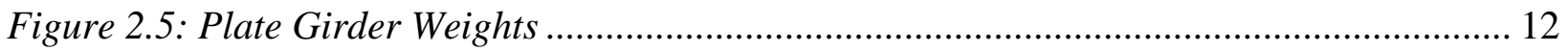

Figure 2.6: Comparison with AISI Standard Designs for a 9'-0” Girder Spacing..................... 13

Figure 2.7: Comparison with OklaDOT Standard Designs for an 11'-10” Girder Spacing ....... 13

Figure 2.8: Comparison with TxDOT Standard Designs for an 8'-8”, Girder Spacing ............... 14

Figure 2.9: eSPAN140 Typical Data Input Window ........................................................... 15

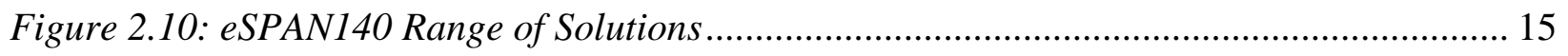

Figure 2.11: eSPAN140 Bridge Cross-Section View............................................................. 17

Figure 3.1: Old Jesup South Bridge, Constructed in 1947 (Case Study) .................................. 20

Figure 3.2: Newly-Completed Jesup South Bridge, Constructed in 2013 (Case Study) ............. 21

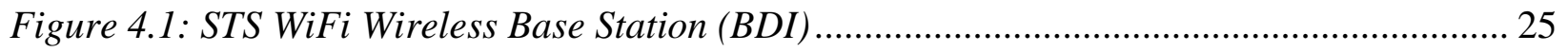

Figure 4.2: STS WiFi 4-Channel Node (BDI) ............................................................... 25

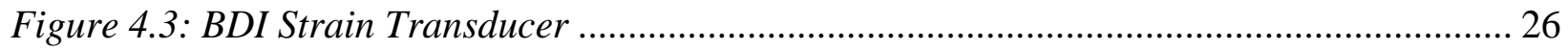

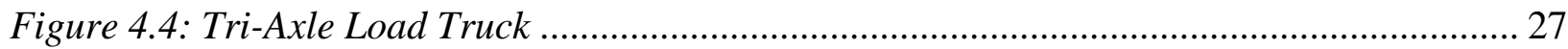

Figure 4.5: Wheel Load Weigher (Intercomp) ................................................................... 27

Figure 4.6: Schematic of Nodal Distribution of Point Loads (Michaelson, 2010)..................... 31

Figure 4.7: Schematic of Nodal Distribution of Point Loads (Galindez, 2009)......................... 32

Figure 4.8: Total Girder Moment and Discretized Components (Michaelson, 2010) ................ 33

Figure 5.1: Gage Locations along Girder Cross-Section ..................................................... 38

Figure 5.2: Longitudinal Placement of Strain Gages ........................................................... 38

Figure 5.3: Bottom Flange Gage Locations (10' from Abutment Face) .................................... 39

Figure 5.4: Web Gage Locations (10'from Abutment Face, Exterior Gages Visible) ................ 39

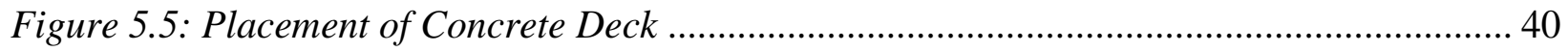


Figure 5.6: Finite Element Modeling Results of Construction Loading .................................. 41

Figure 5.7: Results from Construction Loading Assessment ................................................. 42

Figure 5.8: Gage Locations along Bridge Cross-Section (Looking North) .............................. 44

Figure 5.9: Gage Locations (1' from South Diaphragm) ....................................................... 44

Figure 5.10: Tri-Axle Load Truck ........................................................................................ 45

Figure 5.11: Truck Dimensions and Wheel Loads ............................................................. 45

Figure 5.12: Live Load Truck Placements (Looking North) ................................................. 46

Figure 5.13: Finite Element Modeling Results of Live Loading ............................................ 48

Figure 5.14: Results from Live Loading Assessment ........................................................... 49

Figure C1.1: V-65 Jesup South Bridge Cross Section...................................................... 111

Figure C1.2: Lever Rule Truck Placement ..................................................................... 123

Figure C1.3: Special Analysis Truck Placement ............................................................. 124 


\section{CHAPTER 1: INTRODUCTION}

\subsection{BACKGROUND / OVERVIEW}

The Short Span Steel Bridge Alliance (SSSBA) is a group of bridge and culvert industry leaders (including steel manufacturers, fabricators, service centers, coaters, researchers, and representatives of related associations and government organizations) who have joined together to provide educational information on the design and construction of short span steel bridges in installations up to 140 feet in length. Arguably, one of the crowning achievements of SSSBA is the development and implementation of a series of short-span steel bridge design standards. eSPAN140 is a complimentary web-based design tool which provides customized steel solutions for bridges up to 140 feet.

Working with members of SSSBA, the Secondary Roads Department of Buchanan County, Iowa, headed by Brian Keierlieber, P.E., agreed to be the first owner agency to utilize eSPAN140 to design and construct a short span steel bridge, specifically the new V-65 Jesup South Bridge in Jesup, Iowa. Various members of SSSBA volunteered time, materials, and expertise to assist in delivering the first documented short-span bridge designed using eSPAN140. In addition, the demonstration served significant research objectives: data collected from field investigations during deck casting as well as during live load testing will serve as analytical benchmarks for future analytical studies in short-span steel bridge behavior.

\subsection{SCOPE \& OBJECTIVES}

The scope of this thesis is to:

- Discuss the development of eSPAN140 and its associated design standards

- Provide an overview of the design of the V-65 Jesup South Bridge

- Describe the research methods and field tests conducted on the V-65 Jesup South Bridge 


\subsection{ORgANIZATION}

A brief overview of the organization of this thesis is as follows:

- Chapter 2

- This chapter provides an overview of the development of eSPAN140, detailing the design methodologies employed as well as the user interface within the web-based design tool.

- $\quad$ Chapter 3

- This chapter briefly summarizes the design of the new V-65 Jesup South Bridge and outlines a comparison between eSPAN140 output and actual design parameters.

- Chapter 4

- The experimental and analytical methods used for this research is discussed in this chapter. Specifically, the chapter focuses on the testing program and instrumentation as well as finite element modeling and data reduction techniques.

- $\quad$ Chapter 5

- This chapter provides a summary of the two field investigations performed on the V-65 Jesup South Bridge as well as an evaluation of experimentallyobtained test data using finite element analyses.

\section{- $\quad$ Chapter 6}

- This chapter provides a summary of the scope of work conducted for this study and highlights the key findings. 


\section{CHAPTER 2: OVERVIEW OF ESPAN140 DEVELOPMENT}

\subsection{INTRODUCTION}

There are a large number of bridges in the United States that are considered structurally deficient or functionally obsolete. In response to the deteriorating infrastructure, the Federal Highway Association (FHWA) has introduced an initiative titled Highways for LIFE in an effort to help in reducing these issues. This FHWA focus area promotes the development of bridge design and construction that leads to Long-lasting bridges that are Innovative, have Fast construction times, and are economically Efficient. This research, performed in conjunction with the Short Span Steel Bridge Alliance (SSSBA) of the American Iron and Steel Institute (AISI), has taken these principles into account and has looked into methods of increasing the efficiency of steel girder bridge design through the use of stockpiled common steel plate sizes and a limited suite of rolled steel girders.

This chapter will summarize the efforts of Bridge Technology Center researchers over several years to develop (in conjunction with SSSBA) a series of economical steel solutions for use in the short span bridge market. Specifically, the types of girders designed along with design assumptions and standardization principles will be discussed. In addition, an overview of eSPAN140, the chief online resource for the dissemination of these standards, is provided.

\subsection{GoAls OF STEEL BRIDGE STANDARd DEVELOPMENT}

The goal of this effort was to develop a set of standardized designs that increase the design efficiency of short-span steel bridge designs. The standardized designs were developed based on optimized girder designs, which employ different bridge parameters and design approaches. There are four major sets of bridge designs in this work: "limited depth" rolled beam sections, "lightest weight" rolled beam sections, homogeneous plate girder sections, and hybrid plate girder sections. From the optimized rolled girder designs, limited suites of rolled steel girder sections were selected to investigate the efficiency of using stockpiled girder sections 
for short span steel bridges. Also, the benefits of stockpiling common steel plate sizes were investigated in the design of steel plate girders.

The scope of this work was to develop optimized steel girder designs for bridges with spans between 40 and 140 feet. The girders designed to make up this wide range of bridge spans were designed for all spans between 40 and 140 feet in 5 foot increments. To develop a wide variety of steel girders that encompass the different bridge design parameters and practices of practicing bridge engineers, four different girder spacings and four different girder design approaches were investigated. Based on the designs developed for the different bridge spans, girder spacings, and design approaches, an analysis of efficiency gained from using stockpiled common steel plate sizes and available rolled sections was performed.

\subsection{Brief Overview Of Alternative Standard Steel Bridge DesignS}

In these design efforts, other sets of state bridge design standards were investigated for comparative purposes:

- Oklahoma had one set of steel girder designs for bridges with span lengths between 30 and 100 feet, roadway width of 40 feet and a girder spacing of $11 \mathrm{ft}$. $-10 \mathrm{in}$.

- Texas has three sets of standard girder designs with bridge span lengths between 30 and 120 feet. Each of these sets has a different overall roadway width and girder spacing: 24 foot roadway width with $7 \mathrm{ft}$. -4 in. spacing, 28 foot roadway width with $8 \mathrm{ft}$. -8 in. spacing and 30 foot roadway width with $7 \mathrm{ft}$. spacing.

- Virginia had a large design aid package of pre-designed steel girder bridges that have become outdated. This design package considered a wide variety of bridge span lengths, girder spacings, roadway widths, and bridge skew angles.

- In addition, AISI published a series of standard designs for short-span steel bridges in 1994. These standards served as a benchmark for comparisons with the suite of girders designed in this study.

For a more in-depth review of previously published steel bridge standards, the reader is referred to Nagy (2008). 


\subsection{Girder Design Procedure}

The short-span steel girders in this effort were designed in accordance with the 5th Edition of the AASHTO LRFD Bridge Design Specifications (AASHTO, 2010) and evaluated using Version 6.5 of MDX's Line Girder Rating Software (MDX Software, 2009), a popular steel girder design and rating package used by many state DOTs in the United States.

\subsubsection{Rolled Beam Designs}

The rolled beam sections were designed using two different design approaches, termed "limited depth" and "lightest weight". The "limited depth" rolled girder sections were designed to meet a target L/D (Length/Depth) ratio of 25. Wide-flange sections of the given depth were evaluated until the most economic section for the given span length and girder spacing was found. The "lightest weight" rolled girder sections were developed in the same manner, however without the restriction on the L/D ratio.

\subsubsection{Plate Girder Designs}

The plate girder sections were designed using two different material configurations: homogeneous and hybrid. For both material configurations target L/D ratios were used to determine the depth of the web plate. Web thickness was determined to optimize web stiffener requirements. The compression and tension flanges were selected to create the trial section to begin the evaluation process. Based on the evaluation of the section, dimensions of the flange plates were modified to find a girder section that was both adequate and economical.

In designing the steel plate girder sections, a limited selection of common steel plate dimensions were used to take advantage of stockpiling materials. In addition, to account for flame cutting/torching of plates, all plate depths/widths selected for design were reduced by $1 / 4$ inch during design. The following dimensions were employed for the steel plates: 
- Web plates:

○ Depths: 24 in., 32 in., 40 in., 46 in., 48 in., and 54 in.

○ Thicknesses: all web plates are $1 / 2$ in. thick.

- Flange plates:

○ Widths: 12 in., 14 in., 16 in., 18 in., and 20 in.

○ Thicknesses: 3/4 in., 1 in., 1 1/2 in., and 2 in.

A typical girder elevation is shown in Figure 2.1, where $\mathrm{L}$ is the span length, $\mathrm{C}$ represents the cross-brace spacing and the lengths of the bottom flange transitions are presented. Interior girders were designed for the girder spacing arrangements of 6 feet, 7 feet -6 inches, 9 feet and 10 feet -6 inches. In the designs, it was assumed that there were 5 girders in the bridge system and that the bridge deck consisted of 3 lanes. The typical interior girder cross-section layout is shown in Figure 2.2, and the typical bridge cross-section layout is shown in Figure 2.3. Full composite action between the designed steel girder sections and the concrete slab was assumed to be created through the use of headed shear studs.

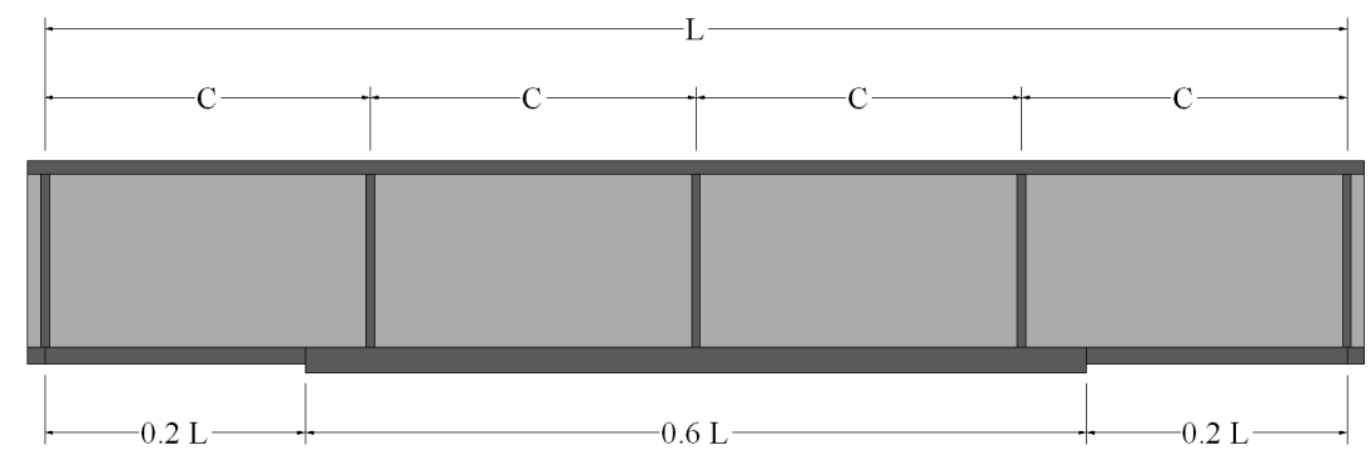

Figure 2.1: Typical Plate Girder Elevation 


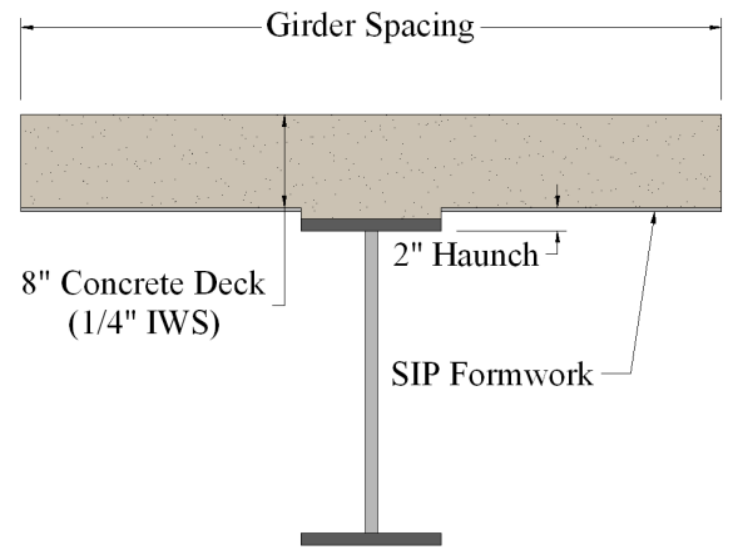

Figure 2.2: Typical Interior Plate Girder Cross-Section

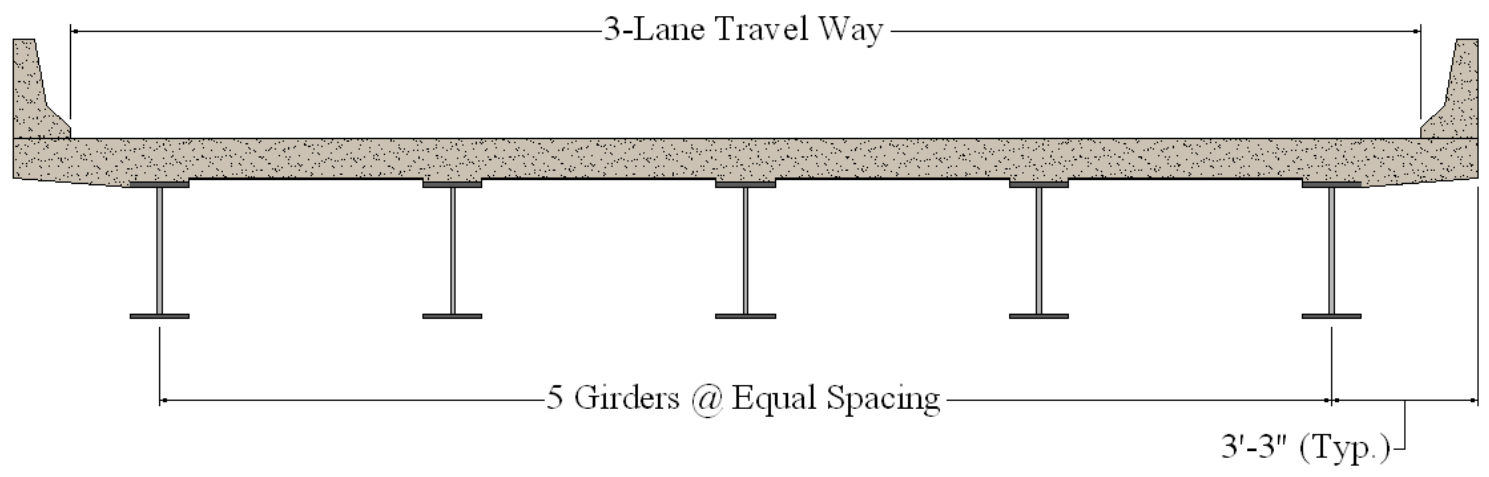

Figure 2.3: Typical Bridge Cross-Section

\subsubsection{Common Design Parameters}

The rolled beam sections and the homogeneous plate girder sections in these designs employ 50-ksi steel. The hybrid steel plate girder sections have 50-ksi steel in the compression flange and web plates and 70-ksi steel in the tension flange plate. For all girder sections, excluding the rolled beam sections of the "lightest weight" suite of girders, an L/D (Length/Depth) ratio of 25 was assumed. The depth in this ratio includes the entire depth of the bridge superstructure (i.e. bridge deck depth plus the concrete haunch thickness plus the girder depth). The concrete haunch is defined as the distance from the bottom of the compression flange to the bottom of the concrete deck. 
The following parameters were assumed for each bridge girder design:

- Steel stay-in-place (SIP) formwork unit weight: 15 psf

- Future wearing surface: $25 \mathrm{psf}$

- Concrete barriers: $305 \mathrm{lbs} / \mathrm{ft}$.

- Miscellaneous steel weight increase: $5 \%$

- Compressive strength of concrete: 4,000 psi

- Concrete unit weight: $150 \mathrm{pcf}$

- Steel unit weight: $490 \mathrm{pcf}$

- Concrete haunch thickness: 2 in

- Concrete deck thickness: 8.25 in (including a 0.25 in sacrificial wearing surface)

- Constant flange width

- Constant web height

\subsection{ReSUltS OF GIRDER DESIGNS}

Figure 2.4 shows a comparison of the design results of the four previously mentioned design methods (homogeneous plate, hybrid plate, limited depth rolled, and lightest weight rolled) for a $9 \mathrm{ft}$. girder spacing. As shown, in the higher span ranges, the economy of rolled beam solution is diminished. This is due to the discrete number of rolled beams available; in the higher span ranges, the discrete range of rolled beams causes the weight of the girders to increase whereas, for plate girders, the sizes of the individual plates can be tailored to meet a given span requirement. Therefore, in the final set of solutions selected, rolled beam solutions are only provided for span lengths from 40 feet to 100 feet. For plate girder solutions, homogeneous girders are provided for span lengths from 60 feet to 140 feet and hybrid girders are provided for span lengths from 80 feet to 140 feet. These limitation ranges were selected by the members of the SSSBA technical working group (a group of fabricators, engineers, plate producers, service centers, and researchers within SSSBA) to deliver the most economical solutions possible from the suite of designed girders. 


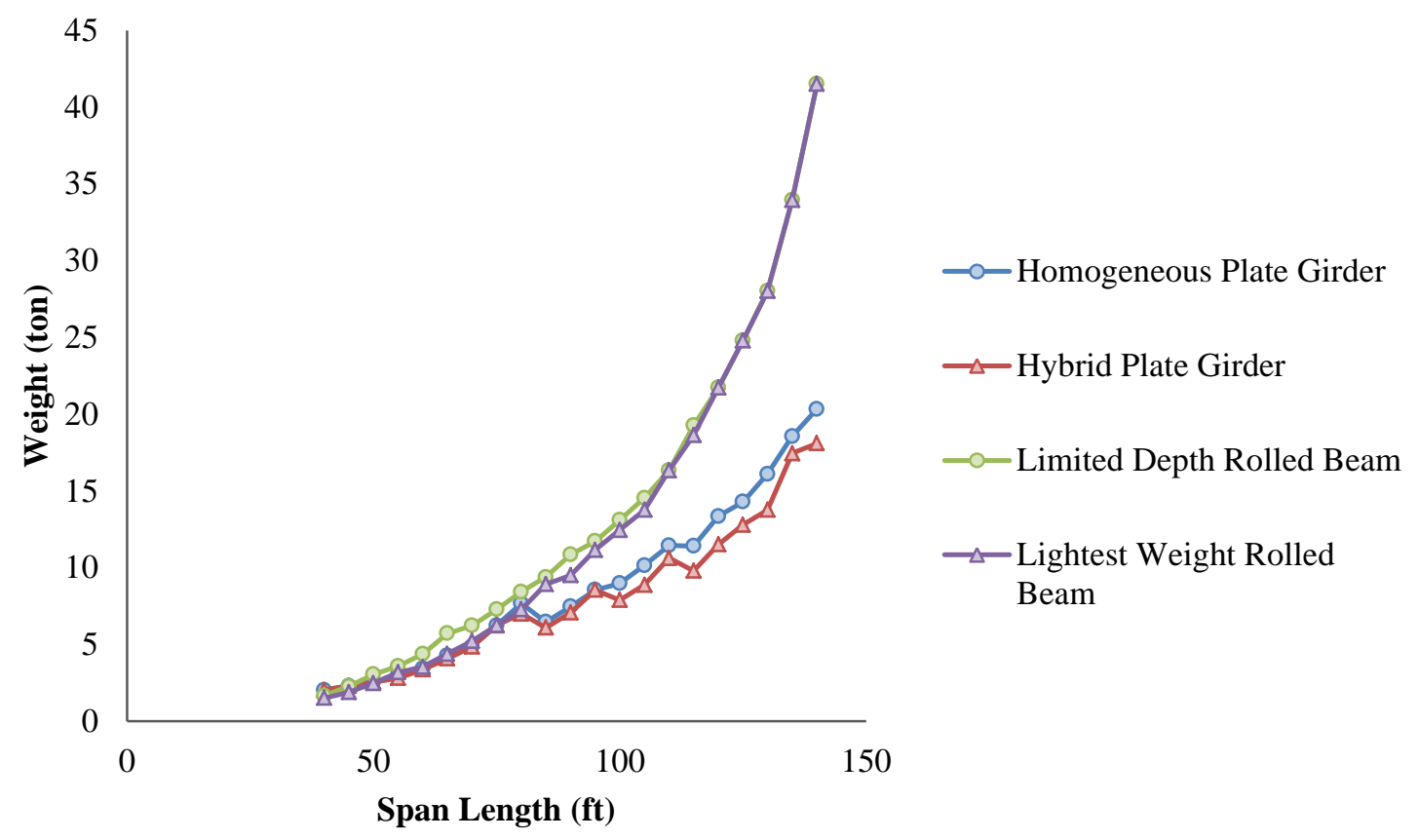

Figure 2.4: Comparison of Design Alternative (9'-0” Girder Spacing)

\subsubsection{Results of Rolled Beam Designs}

Tables 2.1 and 2.2 show the selected rolled beam sections for the lightest weight and limited depth configurations, respectively. The tables provide a selected rolled shape for each 5 foot increment in span lengths between 40 and 100 feet for each of the girder spacings employed. Additionally, the right hand column provides a section selected to meet the requirements for a given span length for all girder spacings. For example, for a $50 \mathrm{ft}$. span length, the W30×108 in Table 2.1 would be satisfactory for all girder spacings from 6 feet to 10.5 feet. Ongoing efforts are focused on collaboration with steel mills to provide more rapid availability of these sections, thus better insuring the success of time-sensitive projects. It should also be noted, for example, that at the 50 foot span range with a 6 foot girder spacing, a W27×84 could be employed, whereas the section that fits all girder spacings in the $50 \mathrm{ft}$. span is a W30 $\times 108$, or a per foot weight difference of 24 pounds. 
Table 2.1: Lightest Weight Rolled Beam Designs

\begin{tabular}{|c|c|c|c|c|c|}
\hline \multirow{2}{*}{$\mathrm{L}, \mathrm{ft}$} & \multicolumn{4}{|c|}{ Girder Spacing } & \multirow{2}{*}{$\begin{array}{c}\text { Selected } \\
\text { Section }\end{array}$} \\
\hline & 6'-0' & 7'-6"' & 9'-0’' & $10^{\prime}-6 "$ & \\
\hline 40 & W21×62 & W21×73 & W24×76 & W24×84 & W24×84 \\
\hline 45 & W24×68 & W21×101 & W27×84 & W30×90 & $\mathrm{W} 30 \times 90$ \\
\hline 50 & $\mathrm{~W} 27 \times 84$ & $\mathrm{~W} 21 \times 111$ & W30×99 & W30×108 & $\mathrm{W} 30 \times 108$ \\
\hline 55 & $\mathrm{~W} 30 \times 90$ & $\mathrm{~W} 24 \times 117$ & W30×116 & W33×118 & $\mathrm{W} 33 \times 118$ \\
\hline 60 & W30×108 & $\mathrm{W} 27 \times 129$ & $\mathrm{~W} 33 \times 118$ & W36×135 & W36×135 \\
\hline 65 & $\mathrm{~W} 33 \times 118$ & $\mathrm{~W} 30 \times 132$ & W36×135 & $\mathrm{W} 40 \times 149$ & $\mathrm{~W} 40 \times 149$ \\
\hline 70 & $\mathrm{~W} 33 \times 130$ & W30×148 & $\mathrm{W} 40 \times 149$ & W40×167 & $\mathrm{W} 40 \times 167$ \\
\hline 75 & W36×135 & $\mathrm{W} 36 \times 150$ & $\mathrm{~W} 40 \times 167$ & W36×182 & $\mathrm{W} 36 \times 210$ \\
\hline 80 & $\mathrm{~W} 40 \times 149$ & $\mathrm{~W} 36 \times 160$ & $\mathrm{~W} 36 \times 182$ & $\mathrm{~W} 36 \times 210$ & W36 2110 \\
\hline 85 & W40×167 & W36×182 & $\mathrm{W} 36 \times 210$ & W36×231 & W36 $\times 247$ \\
\hline 90 & $\mathrm{~W} 40 \times 183$ & $\mathrm{~W} 40 \times 183$ & $\mathrm{~W} 40 \times 211$ & W36×247 & W36 247 \\
\hline 95 & $\mathrm{~W} 40 \times 211$ & W40×199 & $\mathrm{W} 40 \times 235$ & $\mathrm{~W} 40 \times 249$ & $\mathrm{~W} 44 \times 262$ \\
\hline 100 & $\mathrm{~W} 44 \times 230$ & $\mathrm{~W} 40 \times 211$ & $\mathrm{~W} 40 \times 249$ & $\mathrm{~W} 44 \times 262$ & $\mathrm{~W} 44 \times 262$ \\
\hline
\end{tabular}


Table 2.2: Limited Depth Rolled Beam Designs

\begin{tabular}{|c|c|c|c|c|c|}
\hline \multirow{2}{*}{$\mathrm{L}, \mathrm{ft}$} & \multicolumn{4}{|c|}{ Girder Spacing } & \multirow{2}{*}{$\begin{array}{l}\text { Selected } \\
\text { Section }\end{array}$} \\
\hline & $6^{\prime}-0^{\prime \prime}$ & 7'-6" & 9'-0" & $10^{\prime}-6 "$ & \\
\hline 40 & W21×62 & $\mathrm{W} 21 \times 73$ & W21×83 & $\mathrm{W} 21 \times 93$ & W21×93 \\
\hline 45 & W21×83 & $\mathrm{W} 21 \times 101$ & $\mathrm{~W} 21 \times 101$ & $\mathrm{~W} 21 \times 111$ & W21×111 \\
\hline 50 & $\mathrm{~W} 21 \times 111$ & W21×111 & $\mathrm{W} 21 \times 122$ & W $21 \times 132$ & $\mathrm{~W} 21 \times 132$ \\
\hline 55 & $\mathrm{~W} 24 \times 117$ & $\mathrm{~W} 24 \times 117$ & $\mathrm{~W} 24 \times 131$ & $\mathrm{~W} 24 \times 146$ & $\mathrm{~W} 24 \times 146$ \\
\hline 60 & W24×162 & W $27 \times 129$ & W24×146 & W24×162 & W24×162 \\
\hline 65 & W24×192 & $\mathrm{W} 30 \times 132$ & W24×176 & W24×192 & W24×192 \\
\hline 70 & W27×194 & W $30 \times 148$ & W27×178 & W27×194 & W27×194 \\
\hline 75 & W27×217 & $\mathrm{W} 36 \times 150$ & W27×194 & W27×217 & $\mathrm{W} 27 \times 217$ \\
\hline 80 & W30×211 & W36×160 & W30×211 & W $30 \times 235$ & W30×235 \\
\hline 85 & W33×221 & W36×182 & $\mathrm{W} 33 \times 221$ & $\mathrm{~W} 33 \times 241$ & W33×241 \\
\hline 90 & $\mathrm{~W} 33 \times 241$ & $\mathrm{~W} 40 \times 183$ & W33×241 & W33×291 & W33×291 \\
\hline 95 & W36×247 & W40×199 & W36×247 & W $36 \times 282$ & W36×282 \\
\hline 100 & W36×282 & W40×211 & W36×262 & W36×302 & $\mathrm{W} 36 \times 302$ \\
\hline
\end{tabular}

\subsubsection{Results of Plate Girder Designs}

Previous design studies (Morgan, 2010) have shown that the use of a reduced readily available set of plate sizes, as opposed to the use of the exhaustive set of possible plates, has a minimal impact on final girder weight. For specific dimensions of the selected plate girders the reader is referred to Nagy (2008). A plot of the final weight versus span length for both the hybrid and homogeneous sections for each of the girder spacings is provided in Figure 2.5. Several key observations can be made from this figure:

- There is little difference, particularly in the shorter span ranges, in total girder weight as a function of girder spacing.

- In the shorter span ranges there is little benefit provided by the use of hybrid configurations. This is due to the fact that many of the sections start to be controlled 
as a function of minimum allowable plate dimensions as opposed to various design limit states.

- For the longer span lengths (particularly for the wider girder spacings) the hybrid girder configuration does provide some weight benefit.

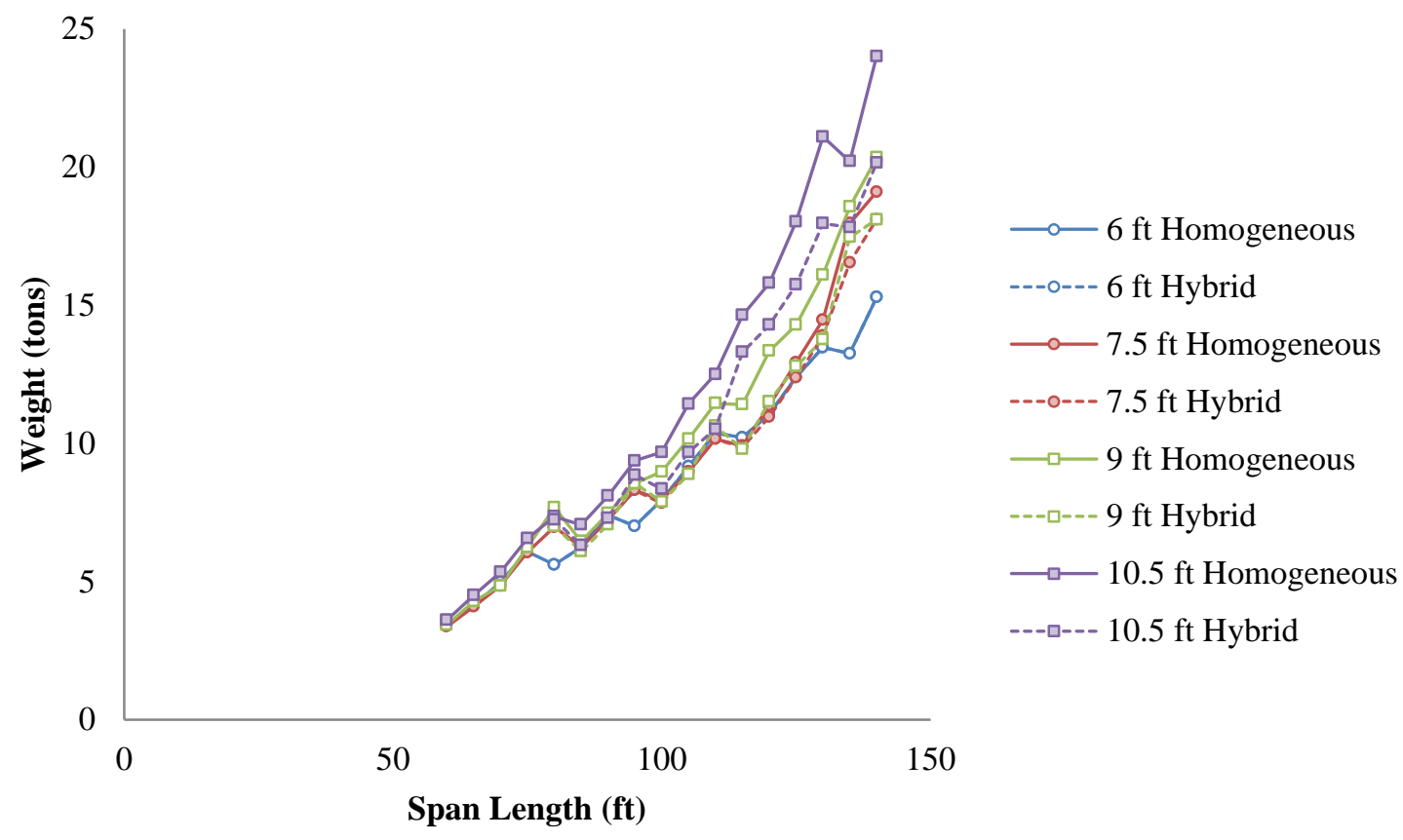

Figure 2.5: Plate Girder Weights

\subsection{COMPARISONS WITH OTHER STANDARDS}

Figures 2.6 through 2.8 detail comparisons with the standard designs developed in this study with those from the standards discussed earlier. It should be noted that, since these standard designs incorporate rolled beam solutions, the comparisons in these figures are for rolled beams only. As shown, the proposed solutions are competitive with other standardized steel bridge designs. 


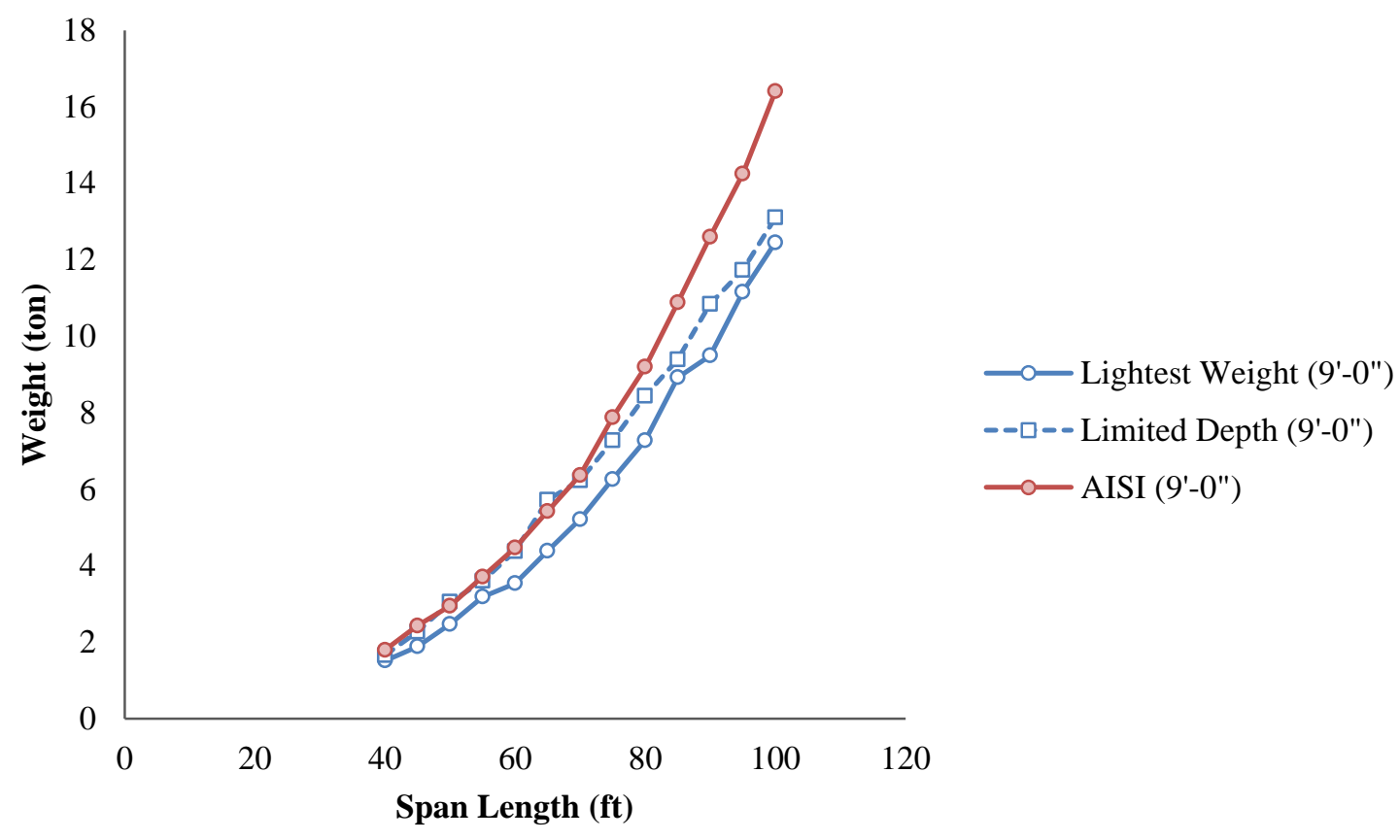

Figure 2.6: Comparison with AISI Standard Designs for a 9'-0" Girder Spacing

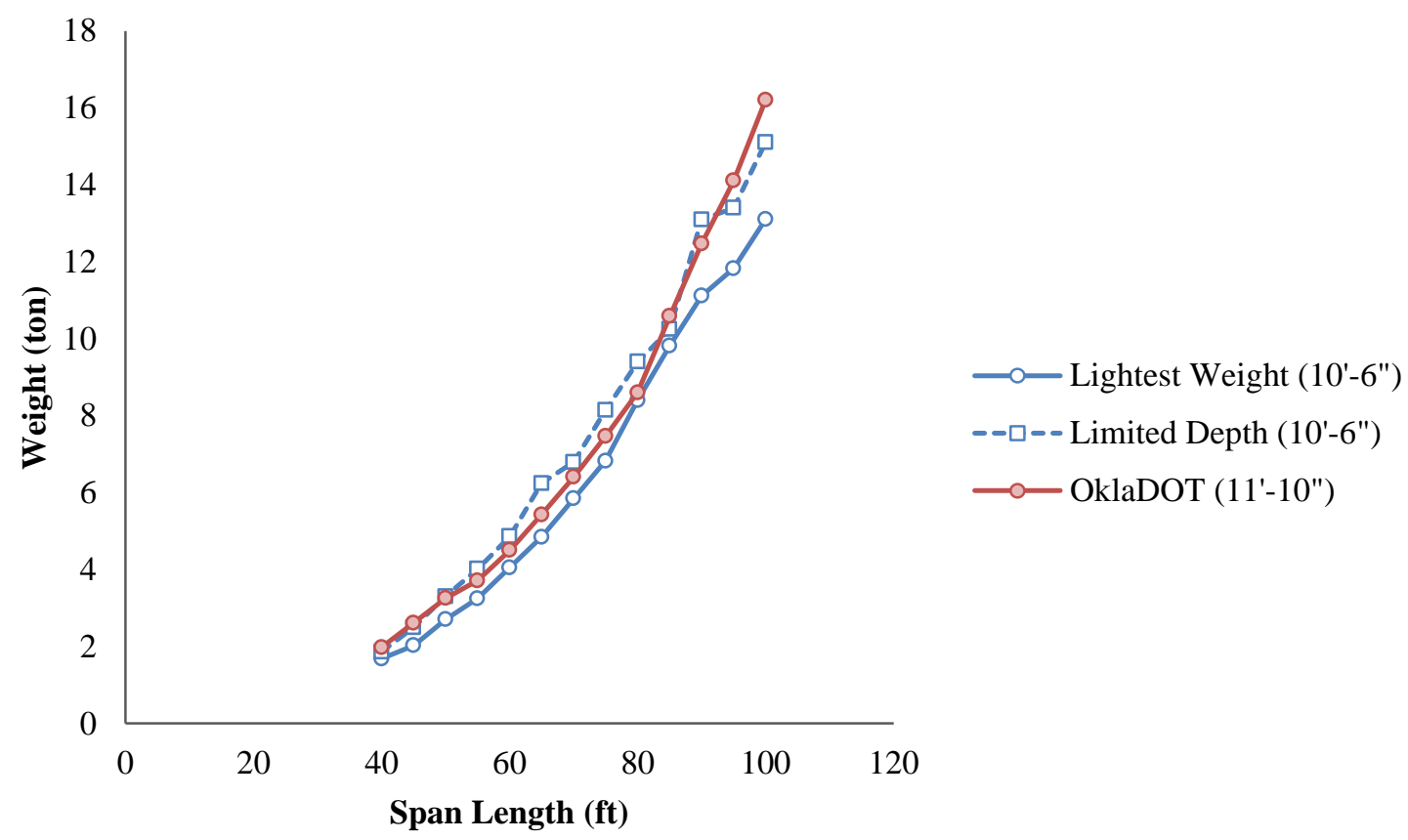

Figure 2.7: Comparison with OklaDOT Standard Designs for an 11'-10” Girder Spacing 


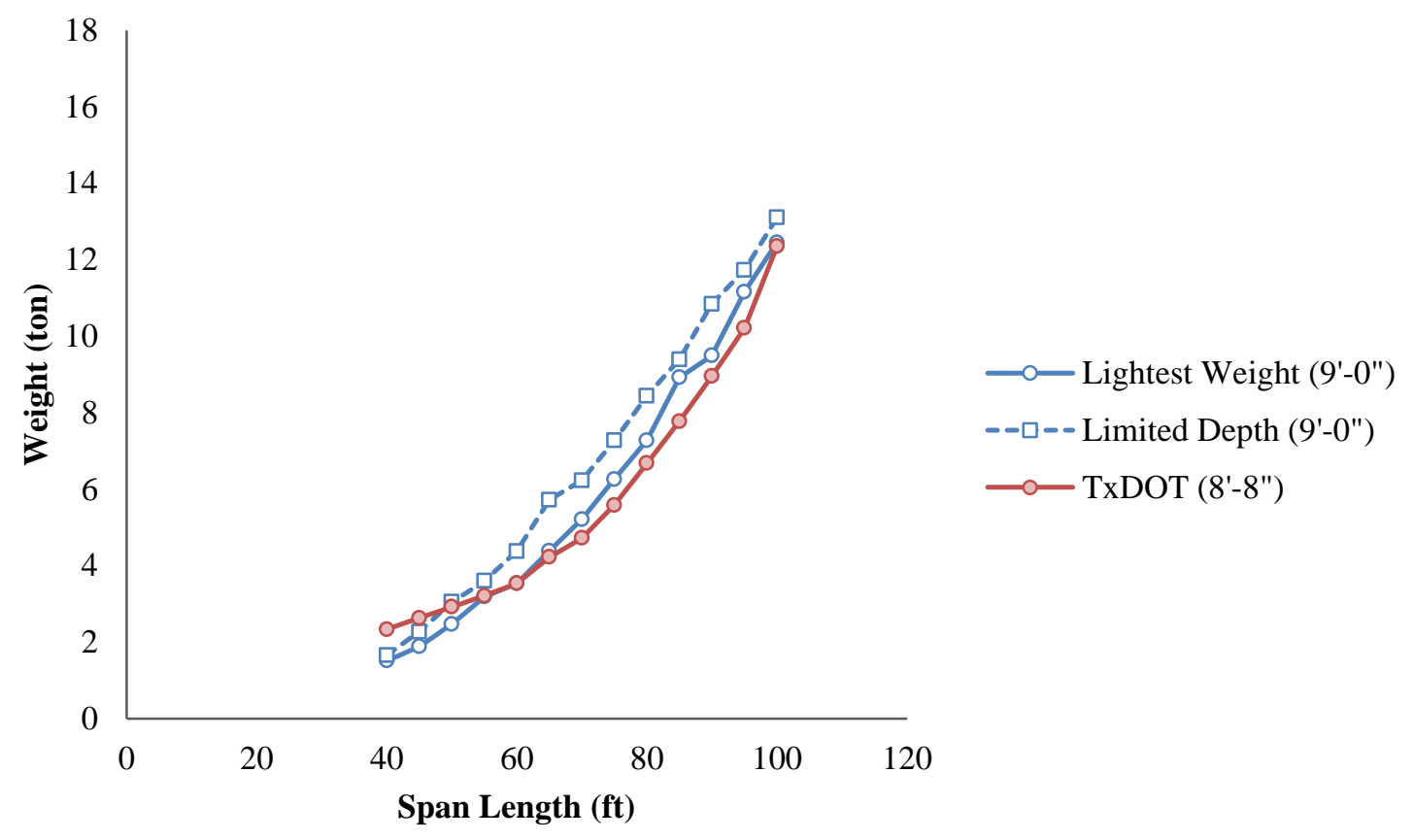

Figure 2.8: Comparison with TxDOT Standard Designs for an 8'-8” Girder Spacing

\subsection{ESPAN140: INTERACTIVE WEB-BASED DESIGN TOOL}

In order to ease the process of steel girder selection and provide state DOTs and owners with a more efficient means of conducting preliminary designs of short-span steel bridges, the SSSBA technical working group, the Steel Market Development Institute (SMDI), the National Association of County Engineers (NACE) Structures Committee, FHWA, and the AASHTO T14 Technical Committee for Structural Steel Design, have developed eSPAN140, an interactive web-based design tool. eSPAN140 is a free, easy-to-use application which generates a customized Solutions Book (in .pdf format) for a given set of bridge parameters, complete with girder dimensions, cross-section information, and associated details.

To begin to use eSPAN140, all the user has to do is go to http://www.eSPAN140.com/ and create a free user's account. Once an account is created, the user will have the ability to edit/review/duplicate previous projects as well as to share previously-generated Solutions Books with colleagues. 
To begin a new project, the user logs into his/her eSPAN140 account. There, the user will find a list of all of the previous projects the user has completed, along with a "Start New Project" button. Clicking this button will open up eSPAN140's data entry screen, where the user inputs various parameters necessary to define a given project. Figure 2.9 shows a typical data input screen in eSPAN140. In addition, eSPAN140 will display Figure 2.10, which defines the range of solutions available in eSPAN140. It should be noted that eSPAN140 will also generate corrugated steel plate solutions along with a series of fabricator and manufacturer solutions.

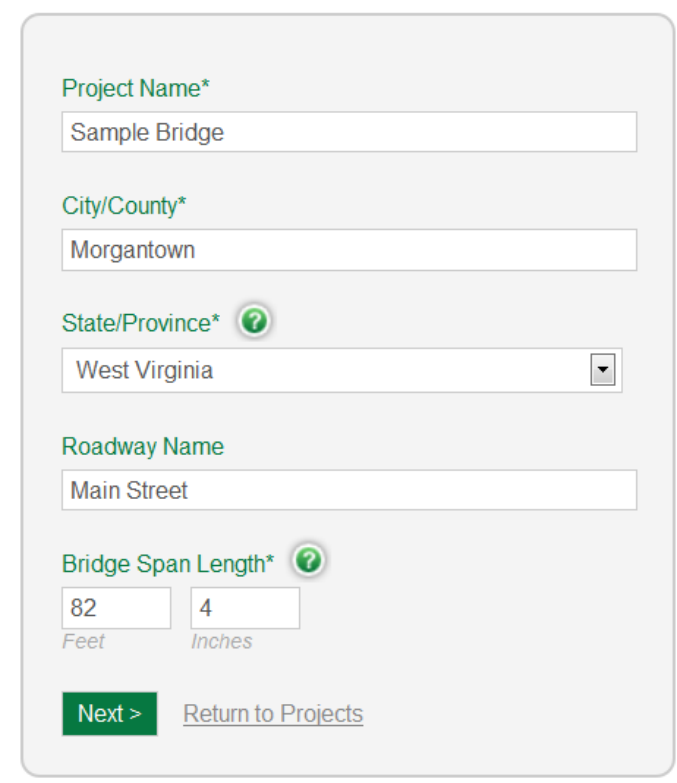

Figure 2.9: eSPAN140 Typical Data Input Window

\begin{tabular}{|c|c|c|c|c|c|c|c|c|c|c|}
\hline \multirow[b]{2}{*}{ Solution Type ${ }^{*}$} & \multicolumn{8}{|c|}{ Bridge Span Length } & \multirow[b]{2}{*}{ Skew Angle } & \multirow[b]{2}{*}{ Overhang Width } \\
\hline & $0^{\prime}$ & $20^{\prime}$ & $40^{\prime}$ & $60^{\prime}$ & $80^{\prime}$ & $100^{\prime}$ & $120^{\prime}$ & $140^{\prime}$ & & \\
\hline Rolled Beam $\left(40^{\prime} \text { to } 100^{\prime}\right)^{\star \star}$ & & & & & & & & & $+1-20$ degrees & $3^{\prime} 3^{\prime \prime}$ or less \\
\hline Homogeneous Plate Girder $\left(60^{\prime} \text { to } 140^{\prime}\right)^{\star \star}$ & & & & & & & & & +/- 20 degrees & $3^{\prime} 3^{\prime \prime}$ or less \\
\hline Hybrid Plate Girder $\left(80^{\prime} \text { to } 140^{\prime}\right)^{\star \star}$ & & & & & & & & & +/- 20 degrees & $3^{\prime} 3^{\prime \prime}$ or less \\
\hline Corrugated Steel Pipe/Structural Shape ( $0^{\prime}$ to $85^{\prime}$ ) & & & & & & & & & All & All \\
\hline Manufacturer's Steel Solutions (all) & & & & & & & & & All & All \\
\hline
\end{tabular}

Figure 2.10: eSPAN140 Range of Solutions 
A project is defined in three steps. The first step is where the user defines general project information. Specifically, the user must input the following parameters:

- Project Name

- City/County

- State/Province

- Roadway Name

- Span Length

- It should be noted that eSPAN140 will round the span length value to the next highest 5 foot increment (U.S.C.S. units are listed since these are the units that eSPAN140 employs) and report the girder solution for this rounded value. For example, if the user specifies a span length of 82 feet and 4 inches, eSPAN140 will generate a Solutions Book containing designs for a span length of 85 feet.

- It should also be noted that, if the user specifies a span length longer than 140 feet, the generated Solutions Book will not include steel girder designs since the girder designs are only valid for span lengths up to 140 feet.

After this, the user advances to step two, where details regarding the bridge cross-section are input. These details are described graphically in Figure 2.11. Specifically, the user must input the following parameters:

- Number of Striped Traffic Lanes

- Roadway Width

- Individual Parapet Width

- Individual Deck Overhang Width 


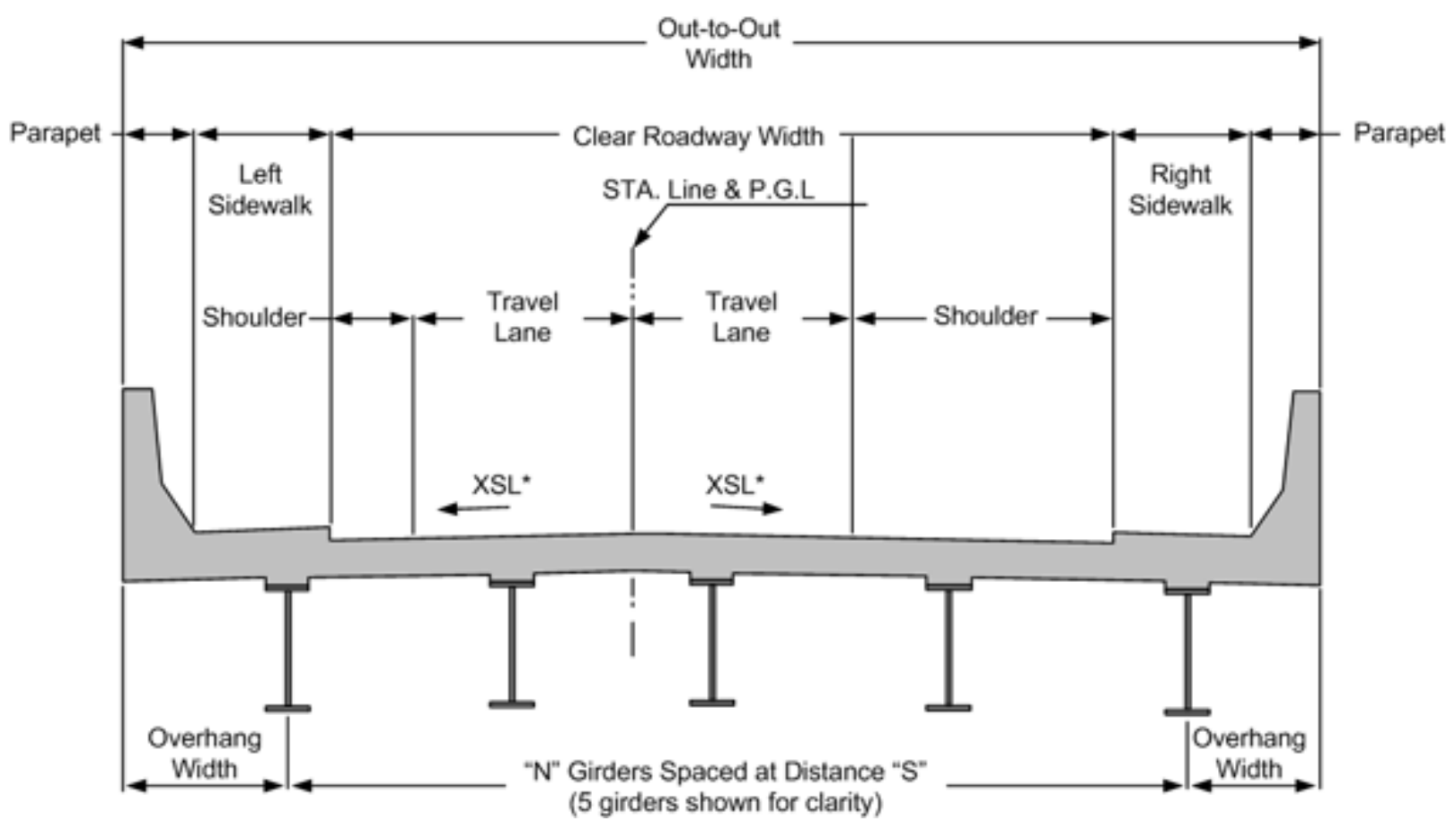

Figure 2.11: eSPAN140 Bridge Cross-Section View

In addition, the user can specify whether sidewalks are present; the user simply has to indicate the number of sidewalks and their individual widths. Once these cross-sectional parameters are defined, the user has to input three last parameters:

- Skew Angle

- It should be noted that, if the user specifies a skew angle larger than $20^{\circ}$, the generated Solutions Book will not include steel girder designs since the girder designs are only valid for skew angles up to $20^{\circ}$.

- Average Daily Traffic, selected from the following:
○ "1 $1-500 "$
○ “501-2000”
○ "Over 2000"

- Design Speed, selected from the following (it should be noted that U.S.C.S. units are listed since these list entries are taken directly from eSPAN140):
○ "0 - $45 \mathrm{mph}$ "
○ "46+ mph" 


\section{○ "Don't know" \\ ○ "Not applicable"}

The user then advances to step three, where the user inputs data related to corrugated steel plate solutions. Specifically, the user has to input the waterway area and height of cover, or the distance from the top of the corrugated steel plate to the bottom of the layer of pavement.

After these three steps, eSPAN140 will generate a customized Solutions Book (in .pdf form). To generate a girder design, eSPAN140 will calculate the out-to-out width between exterior girders (using data input for the cross-section) and then iterate even spaces between exterior girders in order to generate a valid design (i.e. a design with a girder spacing less than 10 '-6" as this is the maximum girder spacing employed in the standards) with the fewest number of girder lines. eSPAN140 then reports the details and dimensions for the girder designed for the next highest girder spacing. For example, if eSPAN140 calculates an interior girder spacing of 8'-10', it will report girder designs for a girder spacing of 9'-0'”.

In addition to the details regarding girder sizes, all of the details necessary to fabricate and erect a short-span steel bridge superstructure are included in the eSPAN140-generated Solutions Book. These include:

- Cambers (both for steel dead weight and total dead weight)

- Stiffener sizes and spacings

- Shear stud layouts

- Individual girder weight

- Girder fabrication details, including weld sizes

- Diaphragm sizes and details

- Framing plan

- Typical cross-section details

- Rebar layout for deck design

- Elastomeric bearing pad details and steel plate sizes

- Customized manufacturer solutions and contact information for SSSBA members 
The Solutions Book also provides contact information for The Bridge Technology Center. The Bridge Technology Center is a complimentary resource available for questions specific to standard design and detail solutions of short-span steel bridges. It is a resource provided by West Virginia University, the University of Wyoming, and Marshall University.

\subsection{CONCLUSIONS}

The efforts of the AISI Short Span Steel Bridge Alliance have great promise for improved economy and competitiveness of steel alternatives in the short-span bridge market. This work has provided an overview of the objectives and design process employed for the development of standard plate girder and rolled beam designs for span lengths between 40 and 140 feet. With preselected members and details, the design process may be expedited, and a more streamlined process for shop drawing review may be created, thus eliminating many weeks in the timeline of a given bridge project. 


\section{ChAPTER 3: DESIGN OF NEW V-65 JESUP SOUTH BRIDGE}

\subsection{INTRODUCTION}

The following chapter discusses the design of the new V-65 Jesup South Bridge in Buchanan County, Iowa. Specifically, a discussion of the previous structure, along with a comparison of eSPAN140 output and as-built conditions is provided.

\subsection{Motivation FOR BRIDGE REPLACEMENT}

The old Jesup South Bridge, located on Buchanan County V65 (located at approximately $42^{\circ} 23^{\prime} 17^{\prime \prime} \mathrm{N}, 92^{\circ} 03^{\prime} 21^{\prime}$ ' W and shown in Figure 3.1), carried traffic (over 2000 ADT) on one of the busiest roads in Buchanan County, Iowa. With a sufficiency rating of 49 , this bridge was a prime candidate for replacement. County engineers sought to replace the existing 22-foot-wide bridge with a modern 40-foot-wide bridge with galvanized steel rolled beams and galvanized rebar.

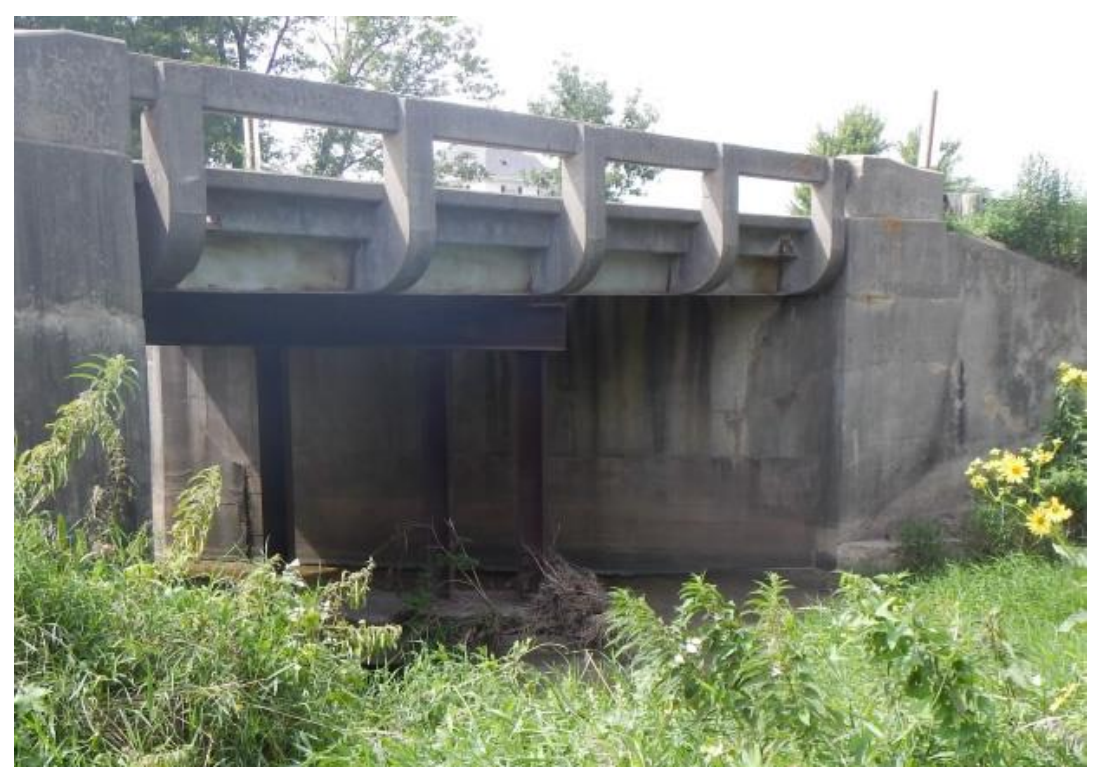

Figure 3.1: Old Jesup South Bridge, Constructed in 1947 (Case Study) 
The newer Jesup South Bridge design, as shown in Figure 3.2, includes a 63-foot span, with two striped traffic lanes, that is supported by five girders. The beams were delivered to the bridge construction site and set on October 2, 2013. The completed Jesup South Bridge opened to traffic on November 19, 2013.

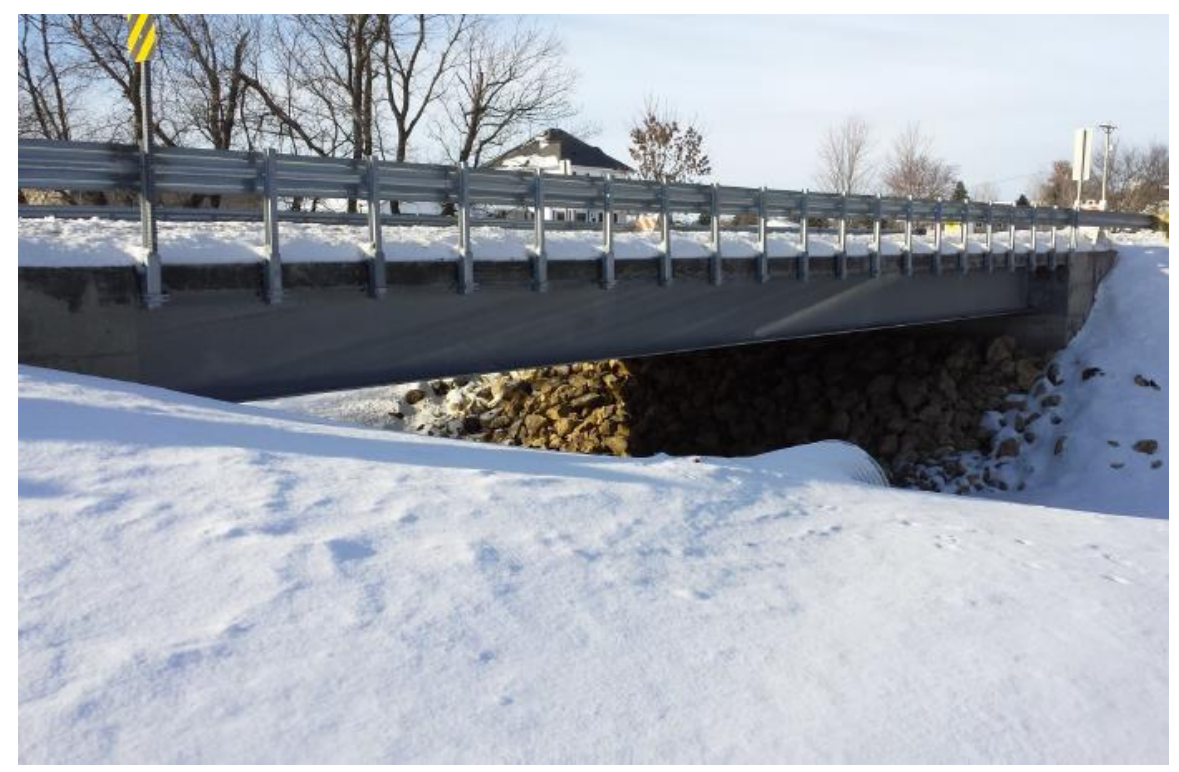

Figure 3.2: Newly-Completed Jesup South Bridge, Constructed in 2013 (Case Study)

The support of the following organizations who contributed to the construction of the V65 Jesup South Bridge are acknowledged below:

- AZZ Galvanizing Services (Galvanizing)

- BlueArc Stud Welding (Shear Studs)

- D-MAC Industries (Steel Bridge Form)

- Gerdau-Memphis (Reinforcing Steel: Rebar)

- Nucor Fastener/Ziegler Bolt \& Part Co. (Fasteners)

- Nucor-Yamato Steel Company (Rolled Beams)

- Skyline Steel (H-Piles)

- St. Louis Screw \& Bolt (Shear Studs)

- U.S. Bridge (Fabrication Railing Materials, Steel Detailing) 


\subsection{Comparison of Produced Bridge DesignS}

Utilizing eSPAN140, county engineers were able to generate a Customized Steel Bridge Solutions Book containing all necessary information to fabricate and construct the new Jesup South Bridge. A comparison of relevant eSPAN140 output and final design parameters is presented in Table 3.1.

\section{Table 3.1: Comparison of Bridge Design Parameters}

\begin{tabular}{|c|c|c|}
\hline Design Parameter & eSPAN140 & Iowa DOT \\
\hline Roadway Width & $39^{\prime}-5 "$ & $40 ’ 0 ”$ \\
\hline Girder Spacing & $8 '-8.4 ”$ & $8^{\prime}-8.5^{\prime \prime}$ \\
\hline Overhang Width & $2^{\prime}-7.2 ”$ & $2^{\prime}-7^{\prime \prime}$ \\
\hline $\begin{array}{l}\text { Bearing Selections } \\
\quad \text { (Substructure) }\end{array}$ & $\begin{array}{l}\text { Elastomeric Bearings } \\
\text { (Traditional Abutment) }\end{array}$ & $\begin{array}{l}\text { Rocker Bearings } \\
\text { (Integral Abutment) }\end{array}$ \\
\hline $\begin{array}{l}\text { Beam Selections } \\
\text { (Design Suite) }\end{array}$ & $\begin{array}{c}\mathrm{W} 40 \times 149 \\
\text { (Selected Sections) }\end{array}$ & $\begin{array}{c}\text { W36 } 6135 \\
\text { (Lightest Weight Sections, } S=9 \text {, }\end{array}$ \\
\hline Diaphragm Spacing & Even (e.g. $\left.21^{\prime}-21^{\prime}-21^{\prime}\right)$ & $21.5^{\prime}-20^{\prime}-21.5^{\prime}$ \\
\hline Connection Plate & PL5×1/2 & PL5 $\times 1 / 2$ \\
\hline $\begin{array}{l}\text { Total Camber } \\
\text { (Location Found) }\end{array}$ & $\begin{array}{c}1.983 ” \\
\text { (eSPANI40.pdf) }\end{array}$ & $\begin{array}{c}\text { 2" } \\
\text { (Shop Drawings) }\end{array}$ \\
\hline $\begin{array}{c}\text { Shear Studs } \\
\text { (Longitudinal Spacing) }\end{array}$ & $\begin{array}{l}3 \text { studs per row } \\
\text { (Variable Spacing) }\end{array}$ & $\begin{array}{l}2 \text { studs per row } \\
\text { (Constant 11" Spacing) }\end{array}$ \\
\hline Total Deck Thickness & $8.25 "$ & $8.50 ”$ \\
\hline $\begin{array}{l}\text { Deck Reinforcement } \\
\text { (Top Transverse Layer) } \\
\text { (Top Longitudinal Layer) } \\
\text { (Bottom Transverse Layer) } \\
\text { (Bottom Longitudinal Layer) }\end{array}$ & $\begin{array}{l}\text { \#6 Rebar } \\
\text { (18" Spacing) } \\
\text { (8" Spacing) } \\
\text { (18" Spacing) } \\
\text { (8" Spacing) }\end{array}$ & $\begin{array}{l}\text { \#6 Rebar } \\
\text { (9" Spacing) } \\
\text { (8.75" Spacing) } \\
\text { (9" Spacing) } \\
\text { (8.75" Spacing) }\end{array}$ \\
\hline
\end{tabular}


In regards to the data presented in Table 3.1:

- Parameters describing the bridge's cross-section show no major deviation in dimensions or details.

- Since Buchanan County engineers decided to employ an integral abutment in lieu of a traditional abutment with elastomeric bearings, it was decided that a small S-shape was to be used as a rocker bearing.

○ Due to this decision, the diaphragm spacing was slightly altered to account for the clear span length between the faces of each abutment.

- In lieu of using the all girder spacing envelope section reported by eSPAN140, Buchanan County engineers elected to use the lightest weight girder option for a $9 \mathrm{ft}$. girder spacing.

○ Utilizing a different girder resulted in different dead loads and different section properties, thereby slightly altering applied cambers.

- In addition, due to altered loads and section properties, a revised shear stud layout was employed (an independent design check validated this design).

- Buchanan County engineers also elected to utilize a deck reinforcement pattern that incorporated a slightly larger amount of steel reinforcement.

\subsection{CONCLUSIONS}

The preceding chapter discusses the design of the new V-65 Jesup South Bridge in Buchanan County, Iowa. Using eSPAN140 as a valid preliminary design, the Buchanan County engineers applied their local customization practices to develop the final design to be constructed. The remaining chapters of this report will discuss the research program conducted on the behavior of this bridge under construction and live loading conditions. 


\section{CHAPTER 4: RESEARCH METHODS}

\subsection{INTRODUCTION}

Contained in this chapter is an overview of the experimental and analytical methods used to assess the V-65 Jesup South Bridge. Specifically, an overview of the testing equipment and finite element modeling techniques used to validate physical test data is discussed.

\subsection{EXPERIMENTAL TESTING EQUIPMENT}

The following section contains an overview of the equipment used to perform field investigations of the V-65 Jesup South Bridge.

\subsubsection{STS-WiFi Data Acquisition System}

Strains were collected and recorded by a suite of wireless instruments, devices, and software from Bridge Diagnostics, Incorporated (BDI). The BDI wireless system can accommodate several different types of instruments and incorporates 4-channel nodes and a wireless base station. Each instrument generally comes equipped with BDI's "Intelliducer" chip that allows it to identify itself within the software. This eliminates confusion during postprocessing when trying to distinguish between data collected by various gages. The instruments used during this field test were BDI strain transducers (see Sections 4.2.2).

The wireless base station shown in Figure 4.1 is used to monitor real-time wireless broadband signals that are transmitted over several hundred feet from the 4-channel nodes (shown in Figure 4.2). The nodes also monitor and power the instruments when online. The base station is capable of taking readings at 500 samples per second $(500 \mathrm{~Hz})$ and has an expandable channel capacity ranging from 4 to 128 channels (in multiples of four). 


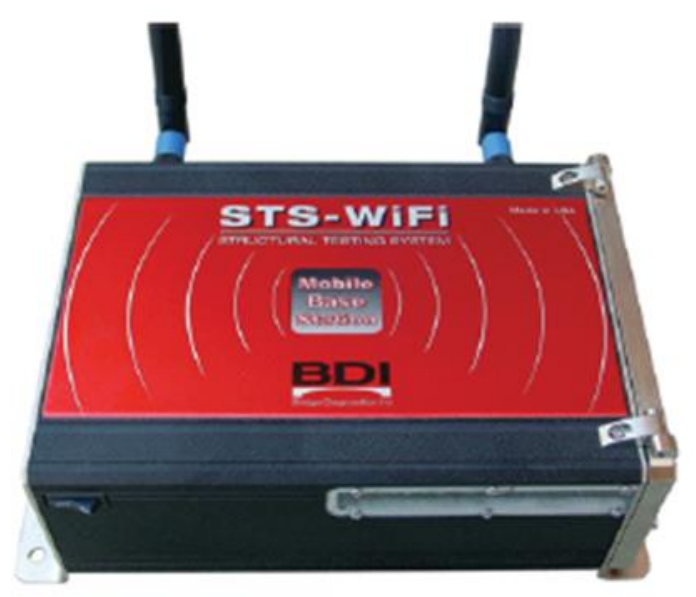

Figure 4.1: STS WiFi Wireless Base Station (BDI)

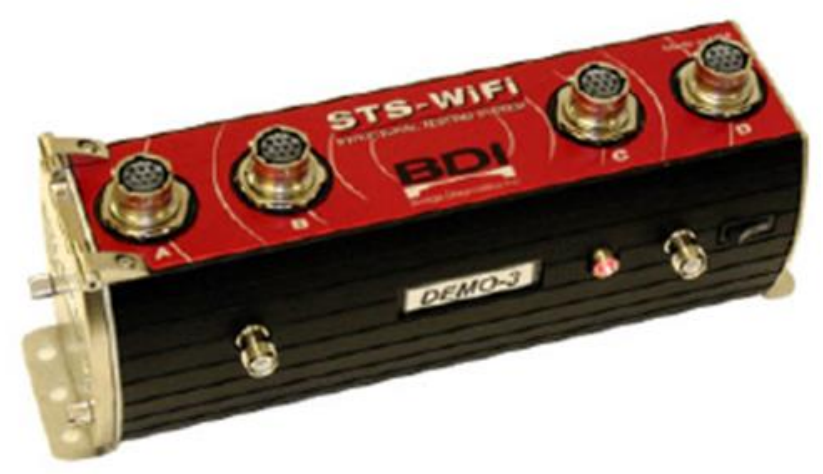

Figure 4.2: STS WiFi 4-Channel Node (BDI)

This test system saves significant time during testing because it requires no wiring between the base station and the instruments. The nodes and base station are powered by rechargeable 9.6V Makita Ni-MH batteries that can last up to six hours under continuous use. The BDI software also has a standby function that allows users to put all or some of the nodes into a hibernation mode for a given amount of time. This allows users to run tests all day on a single battery charge without having to spend valuable time retrieving the nodes to replace batteries. 


\subsubsection{BDI Strain Transducers}

The strain gages selected for the field test were BDI's re-usable strain transducers (Figure 4.3). They are ideal for field-testing because they require minimal surface preparation and take very little time to install. The gages have a temperature range of $-60^{\circ} \mathrm{F}$ to $+250^{\circ} \mathrm{F}$ and connect to the nodes with military style quick connect plugs requiring no solder. Each gage has a range of $\pm 2000 \mu \varepsilon$ with an accuracy of \pm 2 percent. Reusable mounting studs are glued to the bridge with an instant adhesive and mounted with a jig to ensure proper stud spacing. The jig also reduces the risk of damaging the gages while tightening the nuts. The mounting studs fit through two holes on either end of the gage and are tightened with two 7/16-in. nuts. The recommended adhesive is Loctite 410 Black Toughened Adhesive. The gage locations are first marked using black permanent markers and then prepped with a hand grinder to remove galvanization and any corrosion present. The adhesive is then applied to the bottom of the transducer tabs and pressed against the member at the marked locations and held in place for approximately one minute until secure.

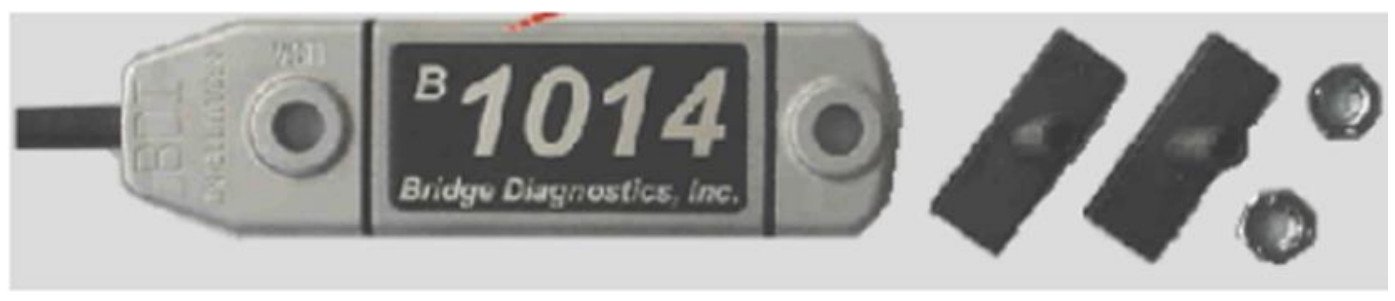

Figure 4.3: BDI Strain Transducer

\subsubsection{Load Truck \& Wheel Scales}

A tri-axle dump truck was used to simulate live loading during in-service testing. The truck was loaded with shale for additional weight to induce various structural behaviors (see Figure 4.4). The truck was weighed with Intercomp Wheel Load Weigher scales on the day of the test (see Figure 4.5). 


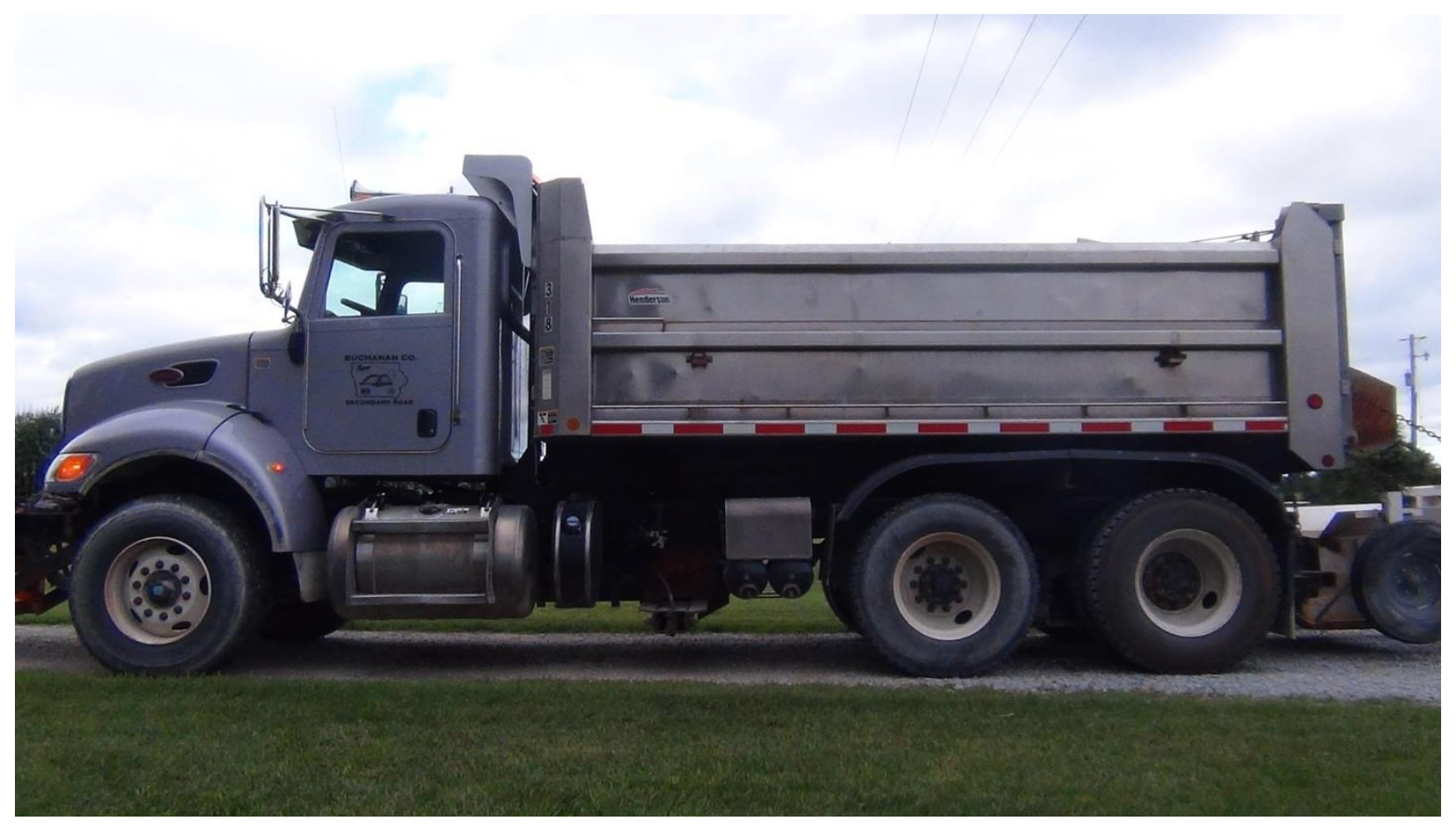

Figure 4.4: Tri-Axle Load Truck

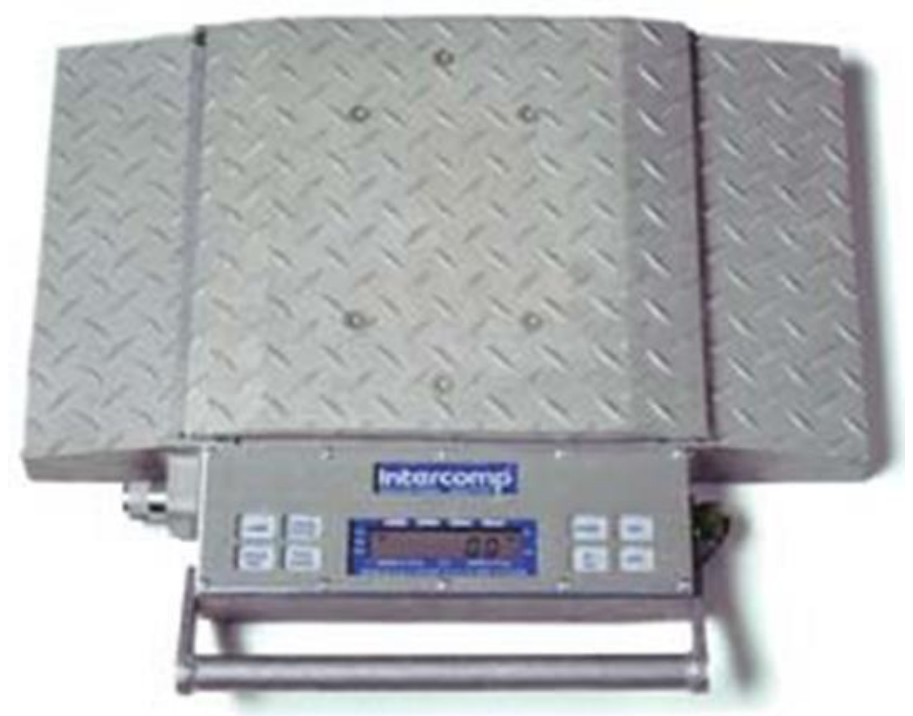

Figure 4.5: Wheel Load Weigher (Intercomp) 


\subsection{Finite Element Modeling TeChNiQueS}

Abaqus 6.10-1/CAE (Dassault Systèmes, 2014) was used for the modeling and analysis of the V-65 Jesup South Bridge in this project. The appropriate elements, mesh densities, and other associated model parameters (boundary conditions, material definitions, etc.) were adapted from previous research to achieve accurate results (Galindez, 2009). Loads applied are representative of typical construction sequences, including overhangs, formwork, screed/rail, walkway, and the finishing machine.

A parametric algorithm was formulated in MATLAB that develops finite element meshes using input parameters defined by a user. Using the appropriate input data, the algorithm calculates loads, assigns node and element information associated with the bridge's geometry, and generates a inp file necessary for analysis in ABAQUS. Once the inp file is generated and analyzed using ABAQUS/Standard, the algorithm post-processes the results of the finite element analysis and computes the bridge response (including primary and lateral flange bending) from finite element analysis as well as the associated AASHTO approximations.

\subsubsection{Material Definitions}

The incorporation of nonlinear behavior would create difficulties in predicting live load distribution and behavior during construction since strain values would be somewhat unpredictable once stresses breached the yield point. Therefore, all materials were only modeled as linear, elastic, isotropic mediums. It should also be noted that the maximum stress values for both the steel and concrete in all of the models once analyzed were found to be well below the

yield stress for steel or the compressive strength of concrete, respectively, indicating that the modeling of the materials as linear elastic mediums was sound. This conclusion has also been made by other researchers. Eom and Nowak (2001) concluded, after testing 17 steel I-girder bridges in Michigan, that the observed response of these bridges under the application of live load was linear throughout their study.

Specifically, the following material properties were employed:

- For reinforced concrete, which was taken to have a compressive strength of $4.0 \mathrm{ksi}$, according to the previsions of AASHTO LRFD Section 5.4.2.4, the modulus of 
elasticity of concrete was determined to be $3640 \mathrm{ksi}$. Also, according to AASHTO LRFD Section 5.4.2.5, Poisson's ratio was taken to be 0.2 .

- For steel, which was taken to have a yield strength of $50 \mathrm{ksi}$, according to the previsions of AASHTO LRFD Section 6.4.1, the modulus of elasticity of steel was taken to be 29000 ksi. Also, Poisson's ratio was taken to be 0.3 .

\subsubsection{Element Selections}

Element selection for the finite element models included a 4-node, doubly-curved, finitemembrane-strain, general-purpose shell with reduced integration (known in the Abaqus/Standard User's Manual as an S4R element) and a 2-node linear beam in space (known in the Abaqus/Standard User's Manual as a B31 element). S4R elements were used to simulate the concrete deck, the girder webs, and the girder flanges; B31 elements were used to simulate the diaphragm members. To model the composite action between both the girders and the deck, node-to-node multiple point constraints were used such that the degrees of freedom between nodes were restrained (these constraints are known in the Abaqus/Standard User's Manual as an MPC Beam).

\subsubsection{Mesh Discretization}

AASHTO LRFD Section 4.6.3.3 describes certain guidelines that should be adhered to with modeling beam-slab bridges. For example, the aspect ratio of finite elements should not exceed 5.0. Also, for finite element analyses involving plate and beam elements, it is preferable to maintain the relative vertical distances between various elements.

The mesh discretization for the finite element models was designed both to attain accurate results as well as to adhere with AASHTO LRFD specifications. For the bridges modeled in this study, mesh discretization of the girders consisted of six elements along the flanges and eight elements along the web. For the deck, the mesh was discretized such that elements were approximately 8 to 10 inches long transversely. As for discretization along the longitudinal axis, all elements were discretized to be one foot long, i.e. one element per foot of 
span length. This scheme of discretization ensured that all of the AASHTO specifications were met as well as that the results that were attained were accurate.

\subsubsection{Boundary Conditions and Multiple-Point Constraints}

Boundary conditions on the models represented common "hinge-roller" conditions. Also, as is common with bridge construction, the girder ends were also restrained from lateral movement as well. These boundary conditions were placed on the nodes along the edges of the bottom flange of each girder.

\subsubsection{Application of Construction Loading}

Loads were applied to the model's construction loading to mimic the stresses acting on the girders during a deck casting sequence. These loads consist of permanent dead loads and construction loads. The permanent loads consisted of the self-weight of the structural member system; whereas additional construction loads consisted of the following loads, taken from NSBA (2012):

- Overhang Brackets : $50 \mathrm{lbs}$ each on $3 \mathrm{ft}$ spacing

- Formworks: $10 \mathrm{lb} / \mathrm{ft}^{2}$

- Screed Rail: $85 \mathrm{lb} / \mathrm{ft}^{2}$

- Railing: $25 \mathrm{lb} / \mathrm{ft}^{2}$

- Walkway: $50 \mathrm{lb} / \mathrm{ft}^{2}$

\subsubsection{Application of Live Loading}

Once the load truck placement position was determined for the experimental testing (see Section 5.3.3), the wheel point loads on the elements were linearly distributed to the neighboring nodes. A schematic of this loading is shown in Figure 4.6. Also, Equations 4.1 through 4.4 describe the nodal loads shown in Figure 4.6. 


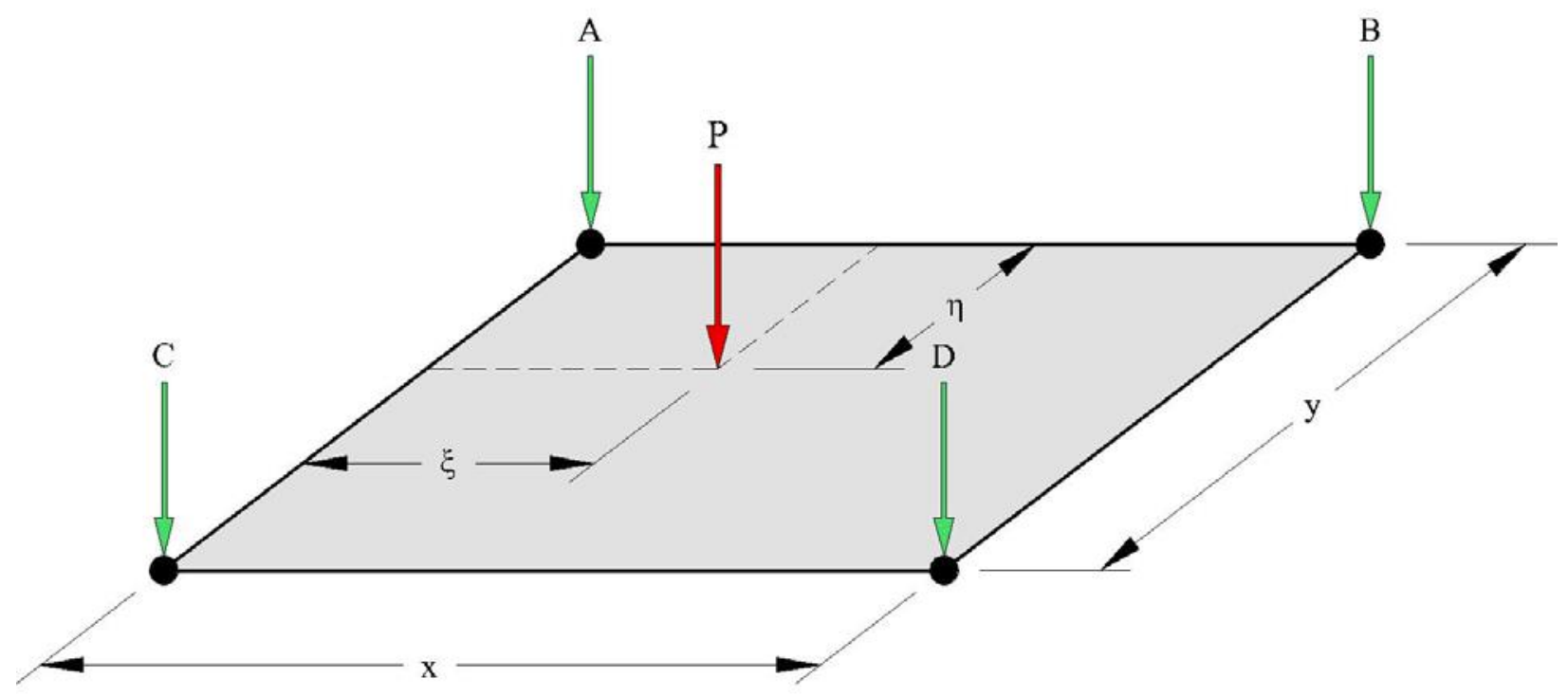

Figure 4.6: Schematic of Nodal Distribution of Point Loads (Michaelson, 2010)

$$
\begin{aligned}
& A=P\left(1-\frac{\xi}{x}\right)\left(1-\frac{\eta}{y}\right) \\
& B=P\left(\frac{\xi}{x}\right)\left(1-\frac{\eta}{y}\right) \\
& C=P\left(1-\frac{\xi}{x}\right)\left(\frac{\eta}{y}\right) \\
& D=P\left(\frac{\xi}{x}\right)\left(\frac{\eta}{y}\right)
\end{aligned}
$$

According to AASHTO LRFD Section 4.6.3.3.1, nodal loads shall be statically equivalent to the actual loads being applied. It can be easily shown that the equations corresponding to Figure 4.6, once summed, will equal the applied point load. 


\subsection{Data Reduction Methods}

Using data from both the physical field tests of the V-65 Jesup South Bridge as well the analysis of finite element models simulating the experiments, a series of standardized bridge responses were assessed. This section describes the methods behind the calculation of those responses.

\subsubsection{Computation of Lateral Flange Bending Stresses (Construction Loading)}

Galindez (2009) proposed a simplified method for isolating the lateral flange bending stresses present in steel I-girder bridges. This method utilizes stresses measured on either side of the flange (i.e. $f_{1}$ and $f_{2}$ ) to compute both major-axis bending stress $\left(f_{b u}\right)$ and lateral flange bending stress $\left(f_{\ell}\right)$. The plan view of the bottom flange in Figure 4.7 and Equations 4.5 through 4.6 illustrate these calculations.

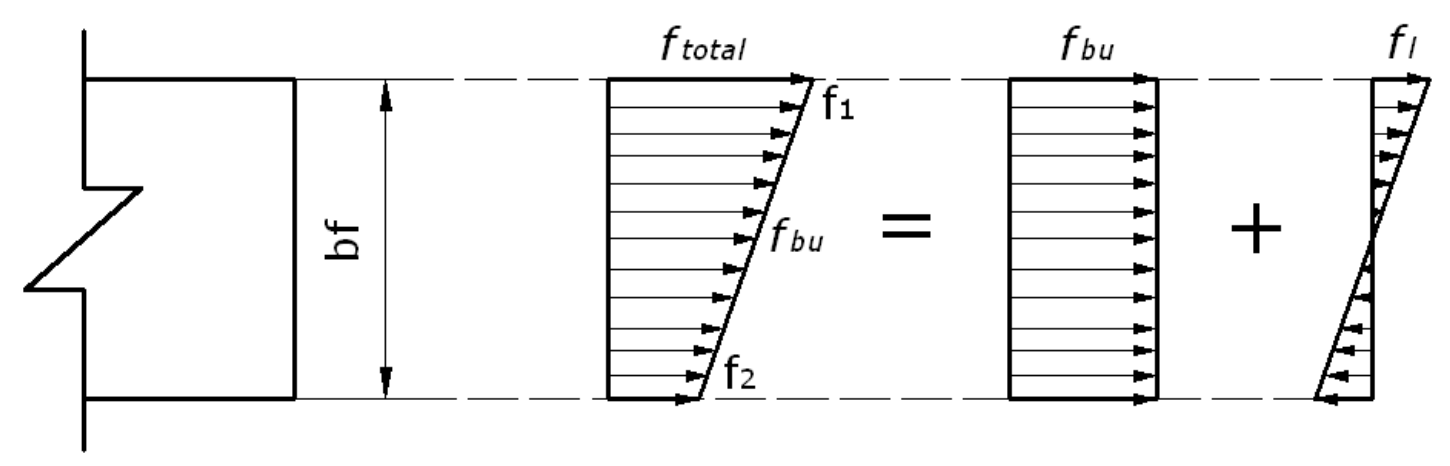

Figure 4.7: Schematic of Nodal Distribution of Point Loads (Galindez, 2009)

$$
\begin{aligned}
& f_{b u}=\frac{f_{1}+f_{2}}{2} \\
& f_{\ell}=f_{\text {total }}-f_{b u}
\end{aligned}
$$

Eq. 4.6 


\subsubsection{Computation of Bending Moment \& Live Load Distribution Factors (Live Loading)}

In order to calculate the bending moment in the girder, the relationship shown in Figure 4.8 and in Equation 4.7 was employed. This relationship is adopted from bridge field testing research by Barker et al. (1999). The total moment in the girder is separated into a pure steel girder couple, $M_{L}$, a pure concrete deck couple, $M_{U}$, and a couple moment between the two that represents the composite action, $M_{A}$.

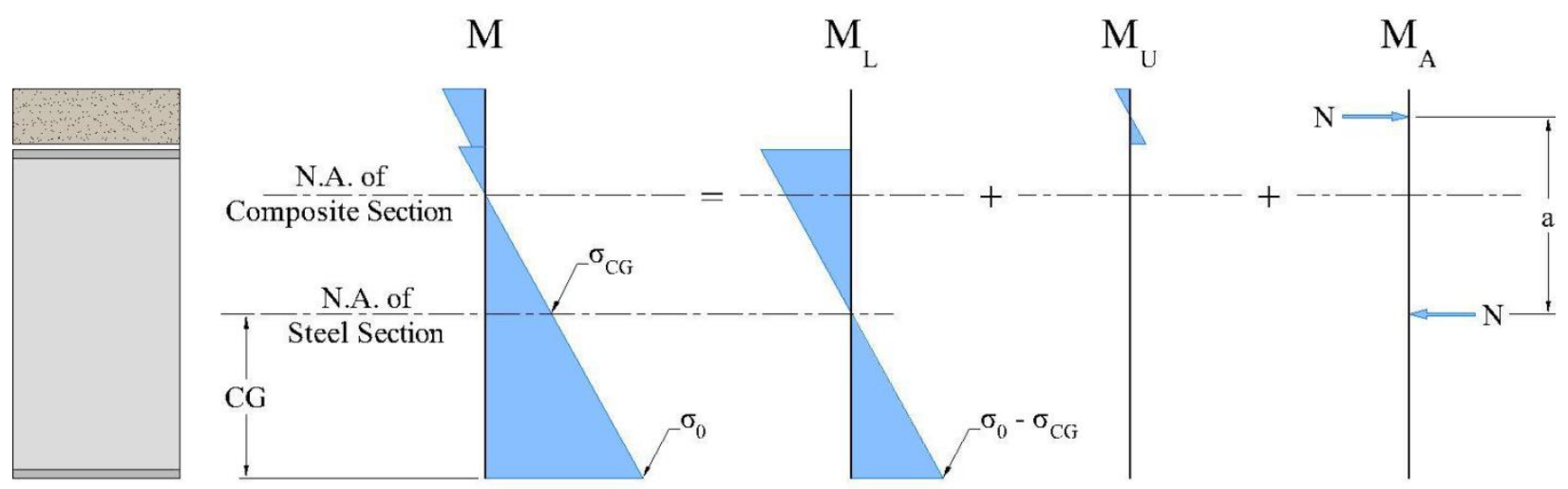

Figure 4.8: Total Girder Moment and Discretized Components (Michaelson, 2010)

$$
M=M_{L}+M_{U}+M_{A} \quad \text { Eq. } 4.7
$$

To adequately represent the stress profile of the composite section, three bending stress quantities were measured: 1) at the bottom of the bottom flange, 2) at a quarter of the web depth, and 3) at half of the web depth. For the finite element analysis, the linear profile of stress along the depth of the girder can be determined. Knowing the stress profile from either experimental tests or finite element analysis, Barker et al. (1999) presents the moment components with Equations 4.8 through 4.10 : 


$$
\begin{array}{ll}
M_{L}=\left(\sigma_{0}-\sigma_{C G}\right) S_{\text {steel }} & \text { Eq. } 4.8 \\
M_{U}=\left(\frac{E I_{\text {slab }}}{E I_{\text {steel }}}\right) M_{L} & \text { Eq. } 4.9 \\
M_{A}=\sigma_{C G} A_{\text {steel }}\left(d_{\text {steel }}-C G+\text { haunch }+\frac{t_{\text {slab }}}{2}\right) & \text { Eq. } 4.10
\end{array}
$$

For these equations:

- $S_{\text {steel }}=$ section modulus of the steel girder

- $E I_{\text {slab }}=$ flexural stiffness of the concrete slab

- $E I_{\text {steel }}=$ flexural stiffness of the steel girder

- $A_{\text {steel }}=$ cross-sectional area of the steel girder

- $d_{\text {steel }}=$ depth of the steel girder

- haunch $=$ distance between steel girder and concrete slab

- $t_{\text {slab }}=$ thickness of concrete slab

When calculating distribution factors, as demonstrated by Michaelson (2010), the simplest approach is to divide the moment in the beam in question by the sum of the moments in all the beams for a given bridge. This method will be referred to hereafter as the Stallings/Yoo method, as it is presented in their research (Stallings \& Yoo, 1993), and is presented in Equation 4.11, where $M_{i}$ is the bending moment in the $i^{\text {th }}$ girder and $N_{b}$ is the number of girders.

$$
D F_{i}=\frac{M_{i}}{\sum_{j=1}^{N_{b}} M_{j}}
$$




\subsection{CONCLUSIONS}

The preceding chapter outlined the experimental and analytical techniques used for this research project. Specifically, details such as equipment selection and finite element modeling parameters were discussed. These techniques were used to collect and assess data from field tests of the V-65 Jesup South Bridge, discussed in Chapter 5. 


\section{ChAPTER 5: FieLD TESTING OF V-65 JESUP SOUTH BRIDGE}

\subsection{INTRODUCTION}

In addition to assisting with design efforts, the Bridge Technology Center (led by WVU), in conjunction with SSSBA, conducted field testing and finite element modeling stress monitoring of the V-65 Jesup South demonstration bridge. The following chapter details two separate field tests performed on the V-65 Jesup South Bridge. The first test focused on monitoring the behavior of the structure during placement of the concrete deck. The second test focuses on assessing the structures in-service performance using vehicular live loading.

\subsection{ASSESSMENT OF CONSTRUCTION BEHAVIOR}

Described in this section is an overview of the field test performed on the structure on October 24, 2013. The focus of the field test was to assess the structure's performance during the placement of the concrete deck.

\subsubsection{Motivation}

Lateral flange bending (LFB) is a torsional effect in flanges of an I-section that is caused by lateral loading on the flange and results from cross-section warping. Since the St. Venant torsional stiffness for an open cross-section is low, torsional loads are resisted by the development of LFB stresses in the girder flanges. AASHTO LRFD Specifications use a fixedend moment approximation to account for LFB in the design phase, as described in Equations 5.1 and 5.2, where $L_{b}$ is the distance between diaphragms, $w_{\ell}$ is the distributed load acting along $L_{b}, F_{\ell}$ is the concentrated load acting along $L_{b}$, and $M_{\ell}$ is the LFB moment resulting from these applied loads. 


$$
\begin{aligned}
& M_{\ell}=\frac{F_{\ell} L_{b}^{2}}{12} \\
& M_{\ell}=\frac{P_{\ell} L_{b}}{8}
\end{aligned}
$$

Eq. 5.2

Previous studies (Galindez, 2009; Jackson, 2013) have shown that the AASHTO approximation for lateral flange bending can significantly overestimate these stresses during deck placement. However, these studies are largely analytical in nature. Due to a lack of experimental data to validate these studies, the focus of this research effort is to assess LFB stresses during the deck placement of a typical simply-supported steel I-girder bridge.

\subsubsection{Instrumentation Plan}

The first field test of the V-65 Jesup South Bridge consisted of two days of preparation and one day of physical testing. During the first two days on location, the main task was to measure and mark out the locations for each strain gage to be placed on the $\mathrm{W} 36 \times 135$ girders along with adhering reusable tabs to the girders at the gage locations. This also included the necessary surface preparation required to adhere the aforementioned reusable tabs (i.e. grinding away galvanizing and surface roughness). The third day consisted of installing the strain indicators onto the reusable tabs, collecting strain data during the placement of the concrete deck, and removing instrumentation after deck placement was complete.

In total, 14 independent gage locations were chosen for physical investigation. Gages were placed along the western exterior girder between the southern abutment and the first diaphragm location. Specifically, seven gages were placed along a cross-section 10 feet from the face of the southern abutment and seven gages were placed 1 foot south of the first diaphragm location. This was chosen as it was the locations determined by analytical studies to generate the largest magnitudes of LFB stresses present during deck casting while simultaneously eliminating stress concentrations at connection regions.

For each cross-section, three gages were placed along the bottom flange (one at the center and one at each end), two gages were placed along the web (one on either side) at a distance $d / 4$ 
from the bottom flange, where $d$ is the girder depth, and two gages were placed along the web (one on either side) at a distance $d / 4$ from the top flange. This instrumentation pattern was chosen to measure both major-axis bending as well as lateral flange bending stresses while providing redundant data readings for all critical values. All gages were oriented to measure stress along the girder's longitudinal axes. Instrumentation locations are shown in Figures 5.1 through 5.4.

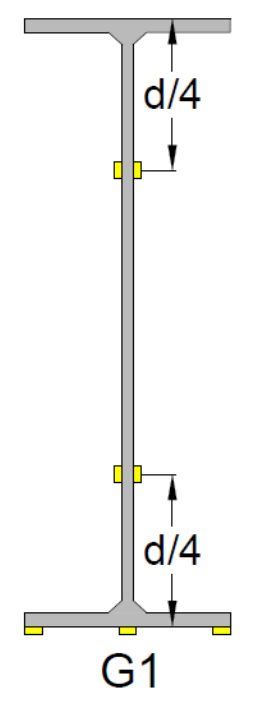

Figure 5.1: Gage Locations along Girder Cross-Section

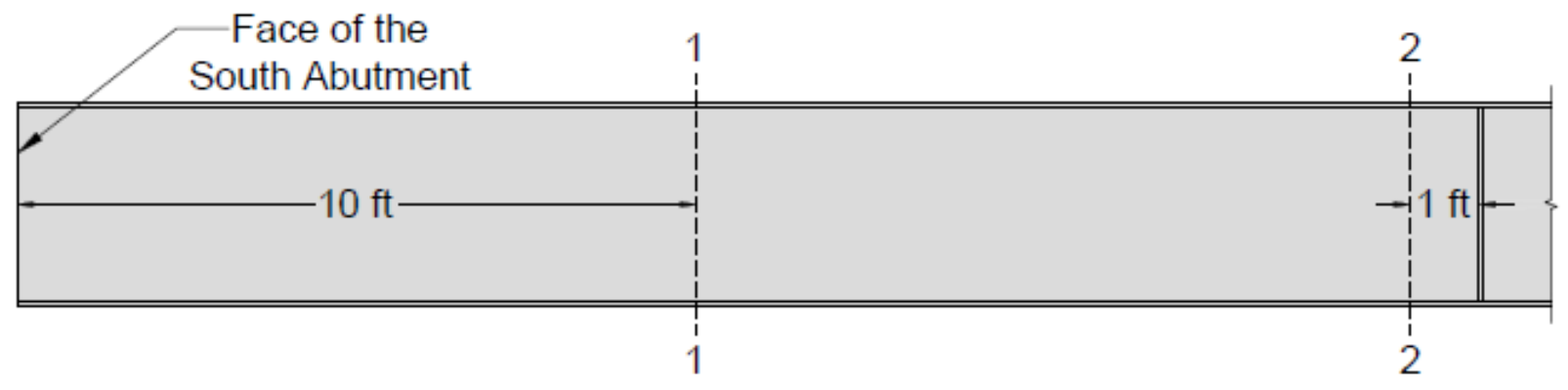

Figure 5.2: Longitudinal Placement of Strain Gages 


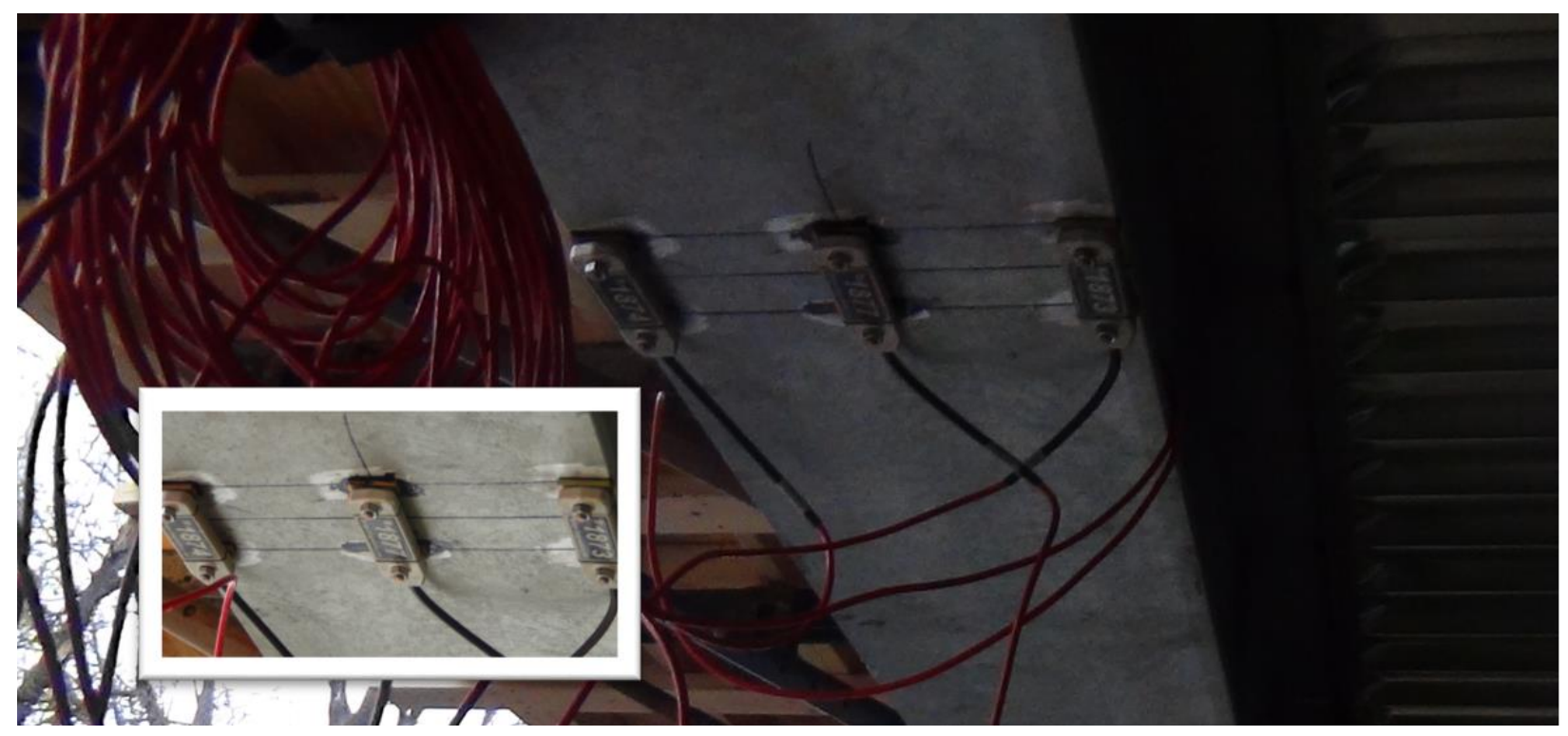

Figure 5.3: Bottom Flange Gage Locations (10' from Abutment Face)

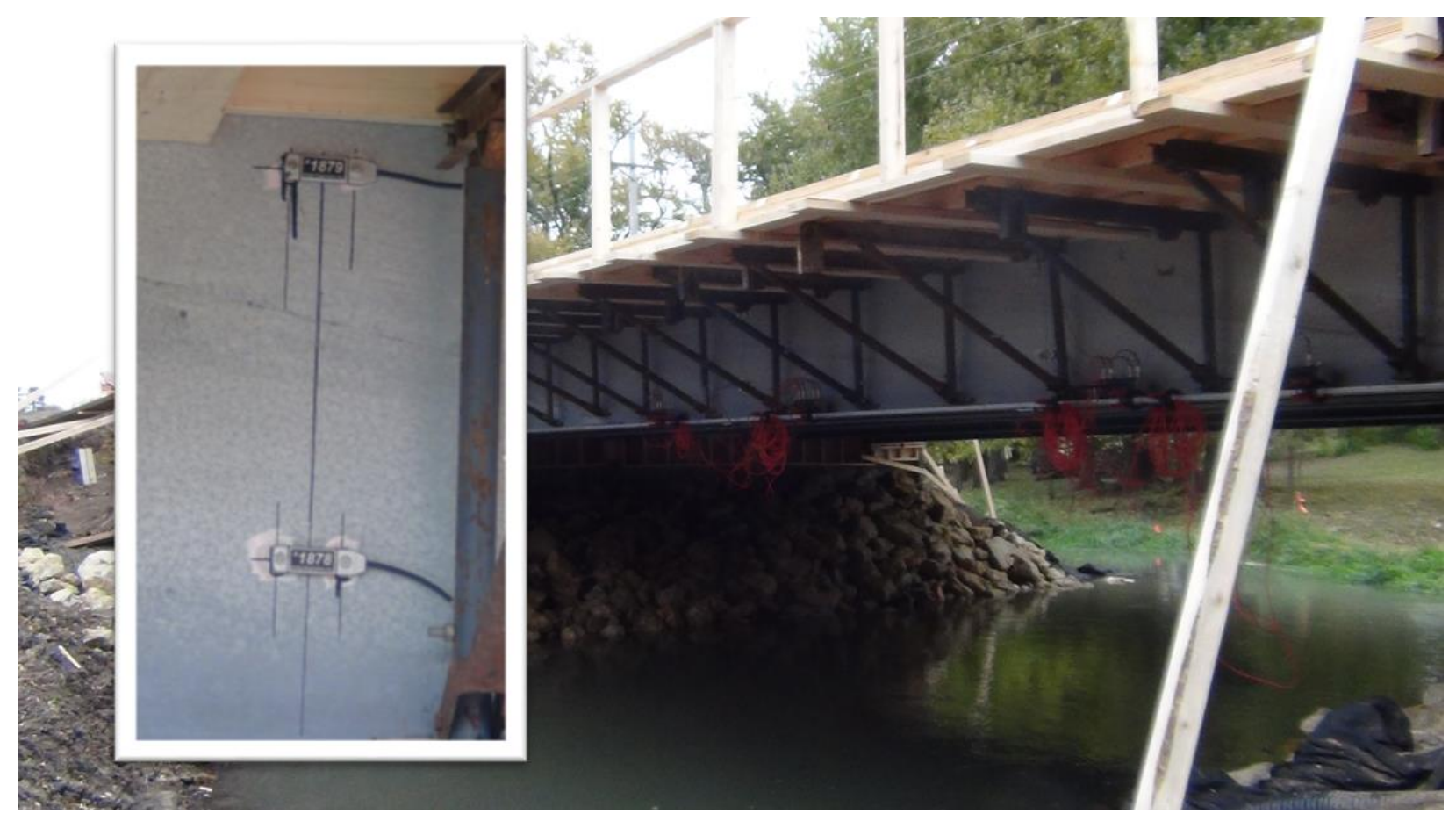

Figure 5.4: Web Gage Locations (10' from Abutment Face, Exterior Gages Visible) 


\subsubsection{Deck Placement}

Deck placement began on the north abutment and proceeded south along the span. A concrete conveyor truck was used to transport concrete (delivered to the southern end of the span) to the northern end during deck placement. During a placement, a crew of approximately 12 county workers utilized a Morrison Super Screed Rail, bull floats, concrete vibrators, and other tools to assist in properly placing the concrete deck (Figure 5.5).

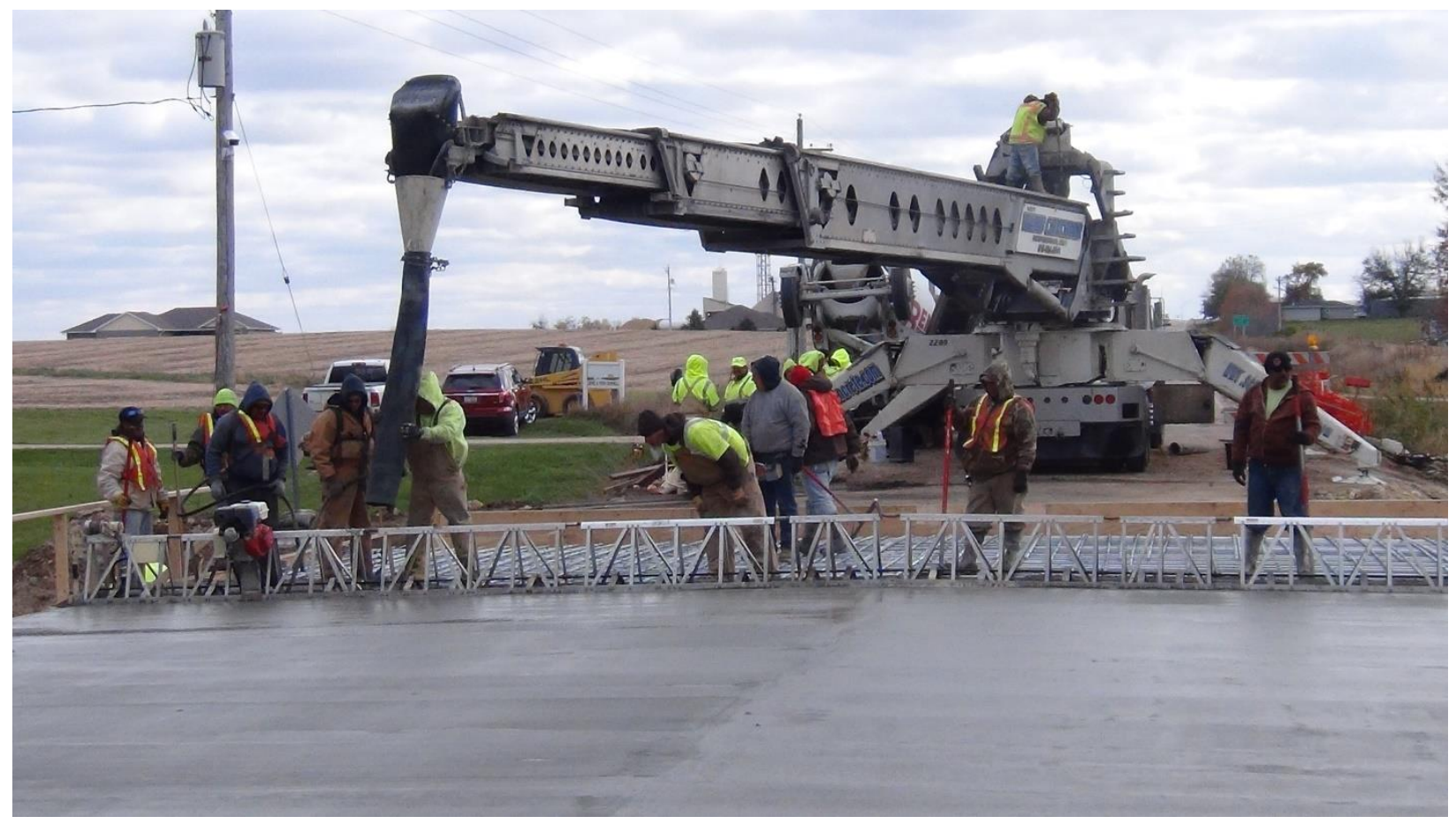

Figure 5.5: Placement of Concrete Deck

During data collection, initial readings were taken before deck placement was started and after deck placement was completed. The difference between these readings indicate the change in stress/strain caused by the placement of the concrete deck. Utilizing the data reduction methods discussed in Chapter 4, the reduced readings in Table 5.1 were obtained. Cross sections referred to in Table 5.1 are described in Figure 5.2. Note that due to the instrumentation plan selected, both major axis bending and lateral flange bending readings were obtained. 
Table 5.1: Data Obtained from Deck Placement

\begin{tabular}{ccc}
\hline Cross Section & Major-Axis Bending Stress & Lateral Flange Bending Stress \\
\hline Section $1-1$ & $+4.99 \mathrm{ksi}$ & $+1.80 \mathrm{ksi}$ \\
\hline Section $2-2$ & $+8.97 \mathrm{ksi}$ & $-2.20 \mathrm{ksi}$ \\
\hline
\end{tabular}

\subsubsection{Finite Element Modeling}

Using the finite element modeling techniques discussed in Chapter 4, a finite element model simulating the construction loading of the V-65 Jesup South Bridge was created and analyzed. Figure 5.6 illustrates the results of the analysis (specifically longitudinal bending stress) on the exterior girder that was instrumented. Note the variation present in the stress contours along the flanges; this indicates the presence of lateral flange bending.

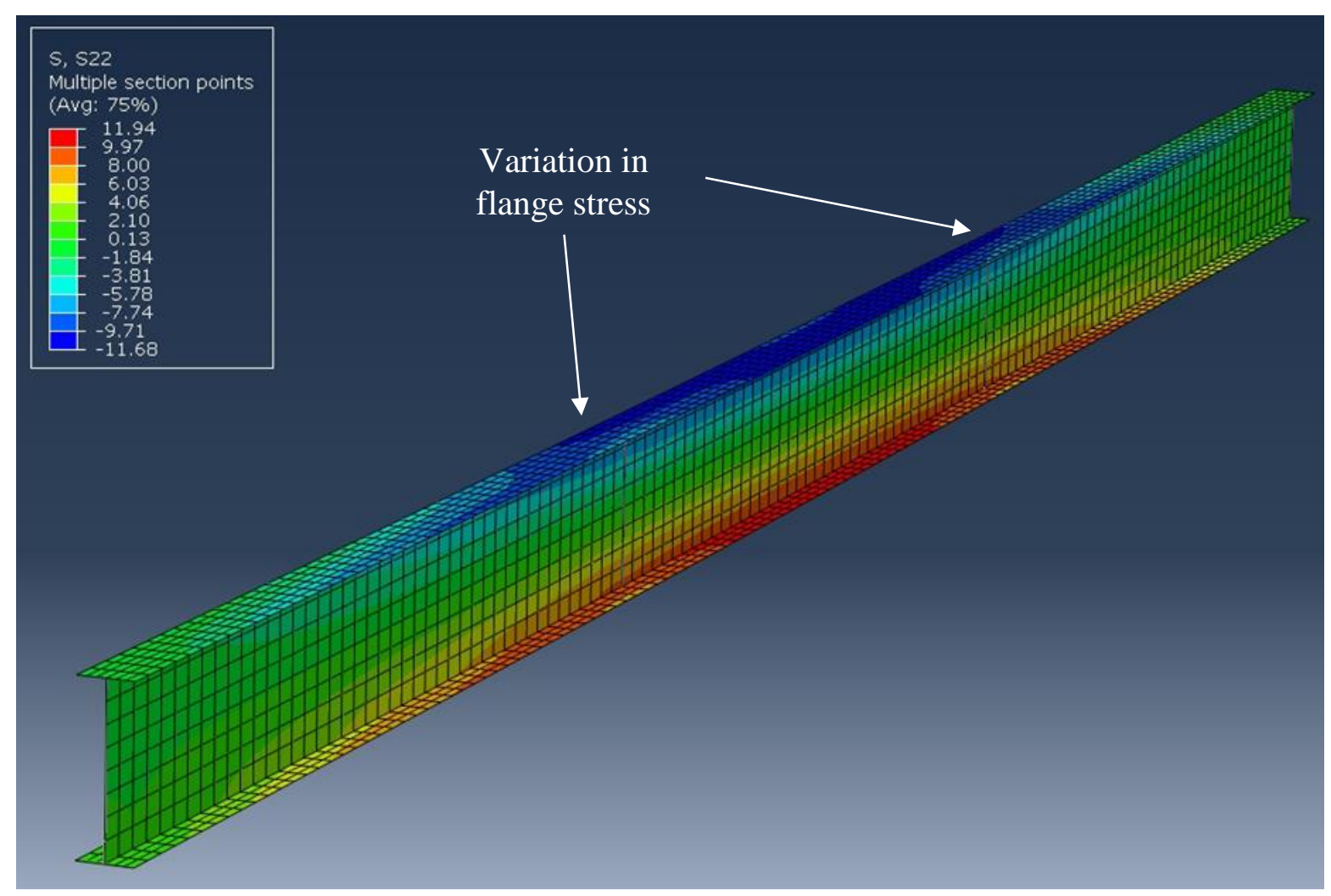

Figure 5.6: Finite Element Modeling Results of Construction Loading 
Utilizing the data reduction methods discussed in Chapter 4, a comparison of the experimentally-obtained data from the field test along with the results of the aforementioned finite element model are plotted in Figure 5.7. In addition, the AASHTO LRFD approximation for LFB is plotted. As shown, experimentally-obtained data and finite element results correlate quite well. In addition, the comparison of AASHTO and finite element LFB stresses reiterates the need for improved approximations for lateral flange bending effects in steel I-girders.

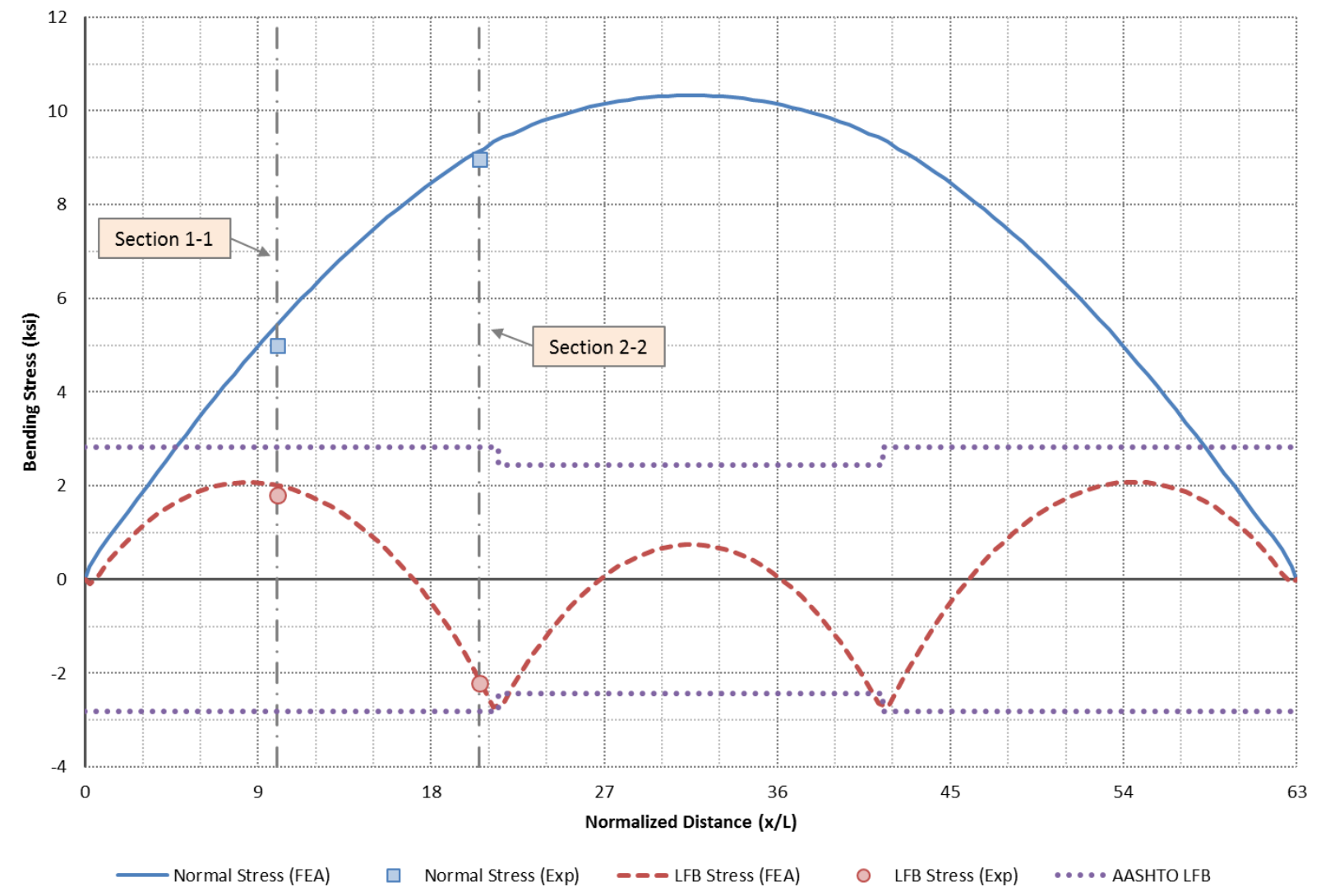

Figure 5.7: Results from Construction Loading Assessment

\subsection{Assessment of In-Service Performance}

Described in this section is an overview of the field test performed on the structure on July 16, 2014. The focus of the field test was to assess the structure's performance during its inservice state (i.e. under vehicular live load). 


\subsubsection{Motivation}

In lieu of a complex three-dimensional analysis, live load distribution factors are commonly employed by bridge engineers to simplify the analysis of a bridge system. Specifically, instead of looking at the bridge system as a whole, these factors allow for a designer or analyst to consider bridge girders individually by determining the maximum number of trucks that may act on a given girder. The development of the relatively new distribution factors for beam-and-slab bridges incorporated in AASHTO LRFD Specifications are primarily the result of NCHRP Report 12-26 (Nutt, Schamber, \& Zokaie, 1988). This report, however, does not take into account the different live load responses of interior and exterior girders. Numerous research studies have shown that the distribution of live load in a bridge system differs between interior girders and exterior girders. In addition, there is little research on the live load distribution to exterior girders on steel I-girder bridges with integral-cast abutments. Therefore, the focus of this research effort is to assess live load distribution characteristics of a typical simply-supported steel I-girder bridge with an integral abutment.

\subsubsection{Instrumentation Plan}

The second field test of the V-65 Jesup South Bridge consisted of two days of preparation and one day of physical testing. During the first two days on location, the main task was to measure and mark out the locations for each strain gage to be placed on the W36 $\times 135$ girders along with adhering reusable tabs to the girders at the gage locations. This also included the necessary surface preparation required to adhere the aforementioned reusable tabs (i.e. grinding away galvanizing and surface roughness). The third day consisted of installing the strain indicators onto the reusable tabs, collecting strain data during live load testing, and removing instrumentation after the live load tests were complete.

In total, 15 independent gage locations were chosen for physical investigation. Gages were placed along each girder 1 foot south of the first diaphragm location from the southern abutment. This was chosen since it used tab locations from the previous field test. Specifically, three gages were placed along each girder: one gage along the center of the bottom flange, one along the web at a distance $d / 4$ from the bottom flange, where $d$ is the girder depth, and one gage 
along the web at a distance $d / 2$ from the bottom flange. This instrumentation pattern was chosen to measure major-axis bending in all of the girders while providing redundant data readings for all critical values. All gages were oriented to measure stress along the girder's longitudinal axes. Instrumentation locations are shown in Figures 5.8 and 5.9.
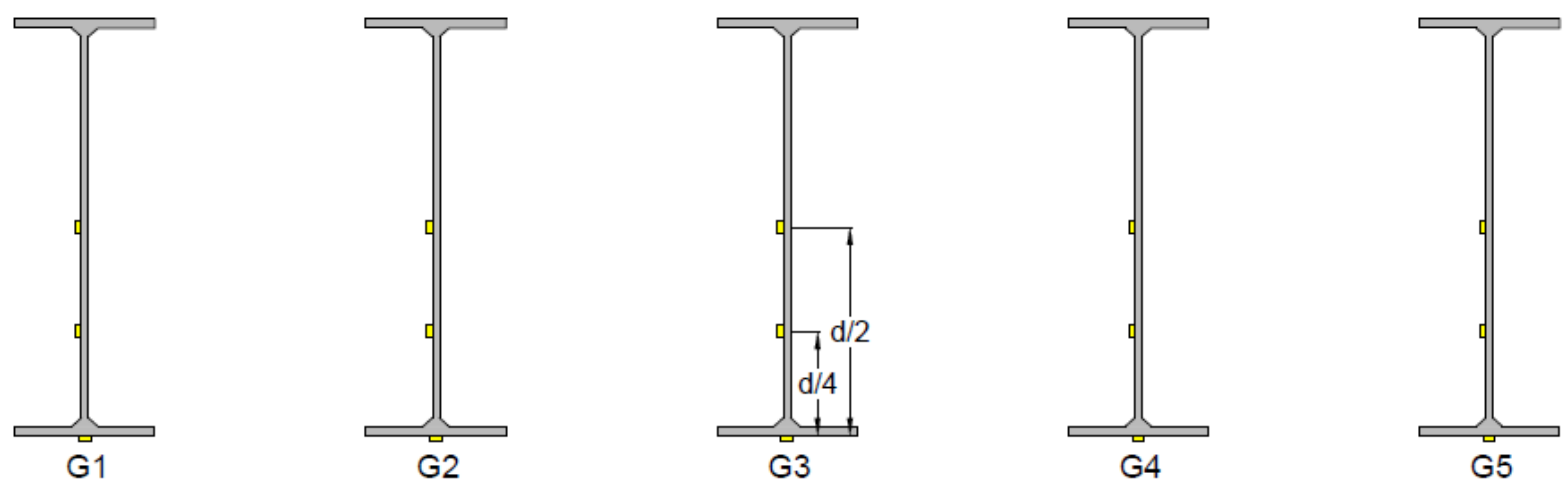

Figure 5.8: Gage Locations along Bridge Cross-Section (Looking North)

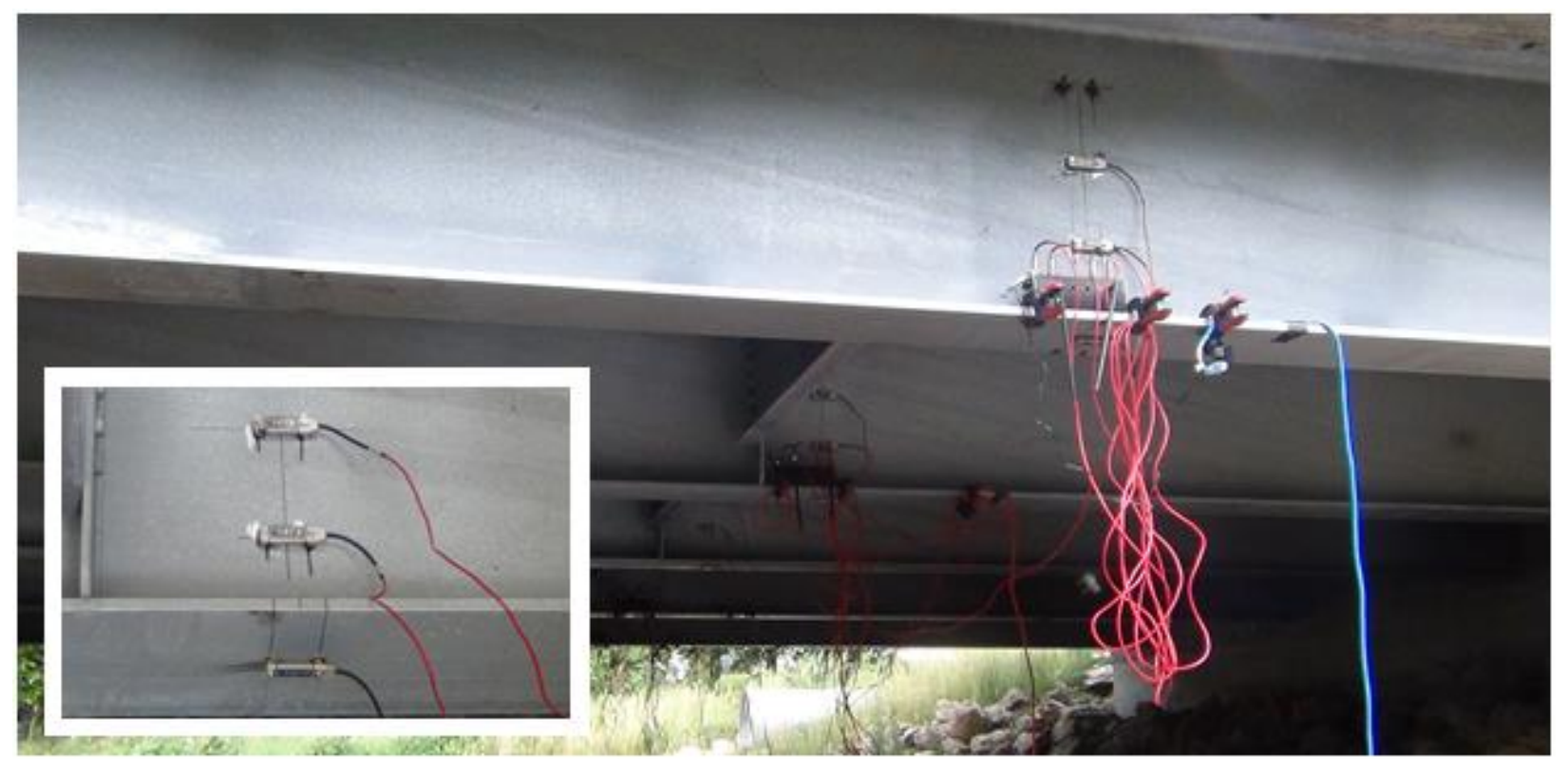

Figure 5.9: Gage Locations (1'from South Diaphragm) 


\subsubsection{Live Load Placement}

The live load used for testing was a tri-axle dump truck made available by the Buchanan County Secondary Roads Department. The truck was weighed and measured with wheel-load scales and a tape measure. The truck is shown in Figure 5.10, and dimensions and wheel weights are shown in Figure 5.11.

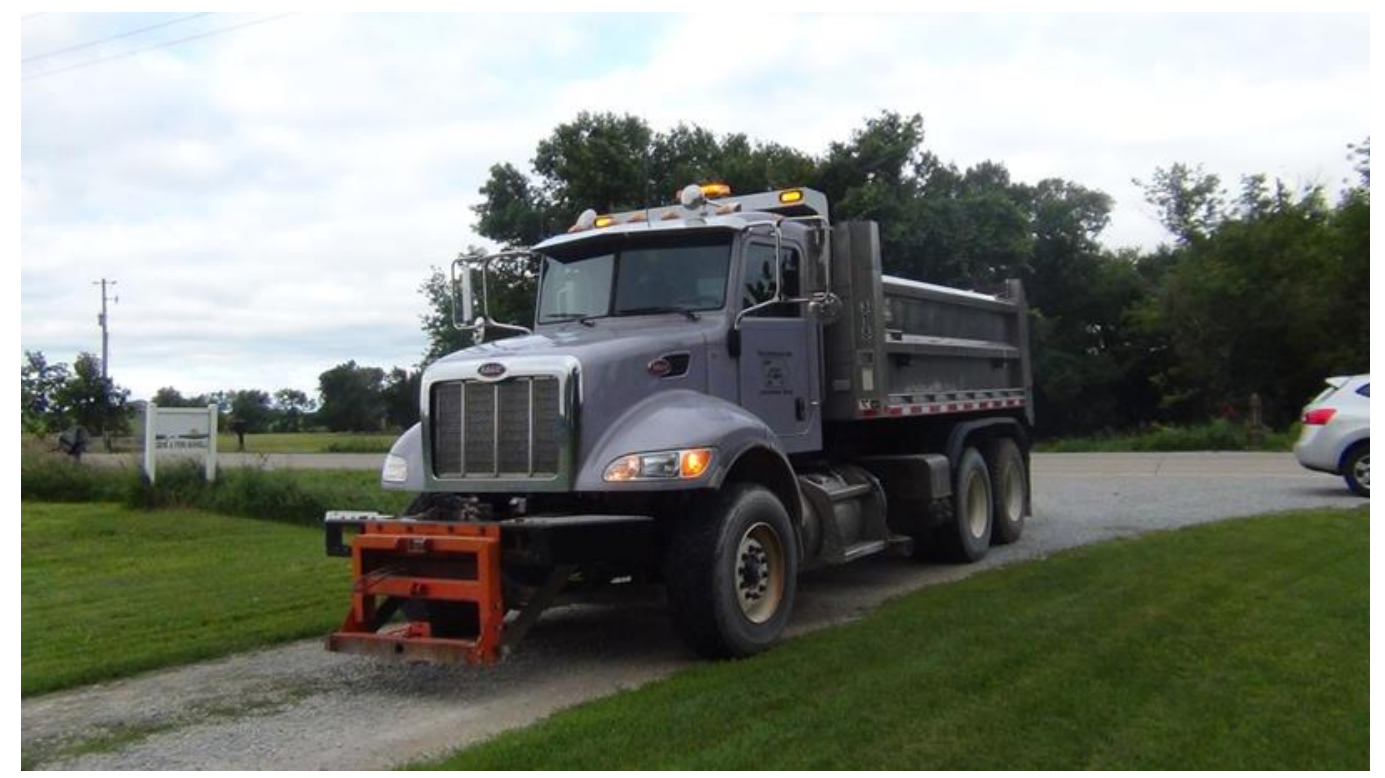

Figure 5.10: Tri-Axle Load Truck

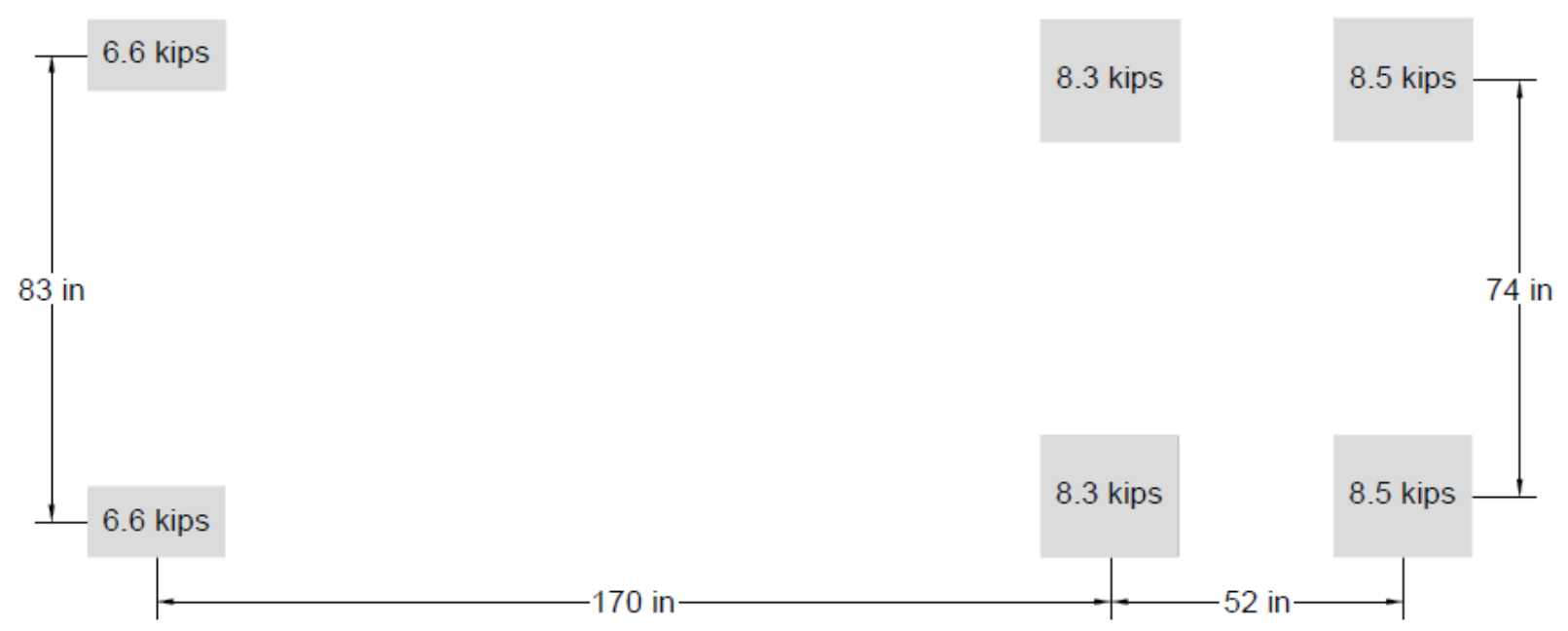

Figure 5.11: Truck Dimensions and Wheel Loads 
The truck placements used during physical testing were intended to generate the maximum response in each girder with the fewest number of runs while also exploiting symmetry (since the bridge has no skew angle). By taking advantage of symmetry, it was determined that only five truck runs needed to be completed. Those truck runs are detailed in Figure 5.12.

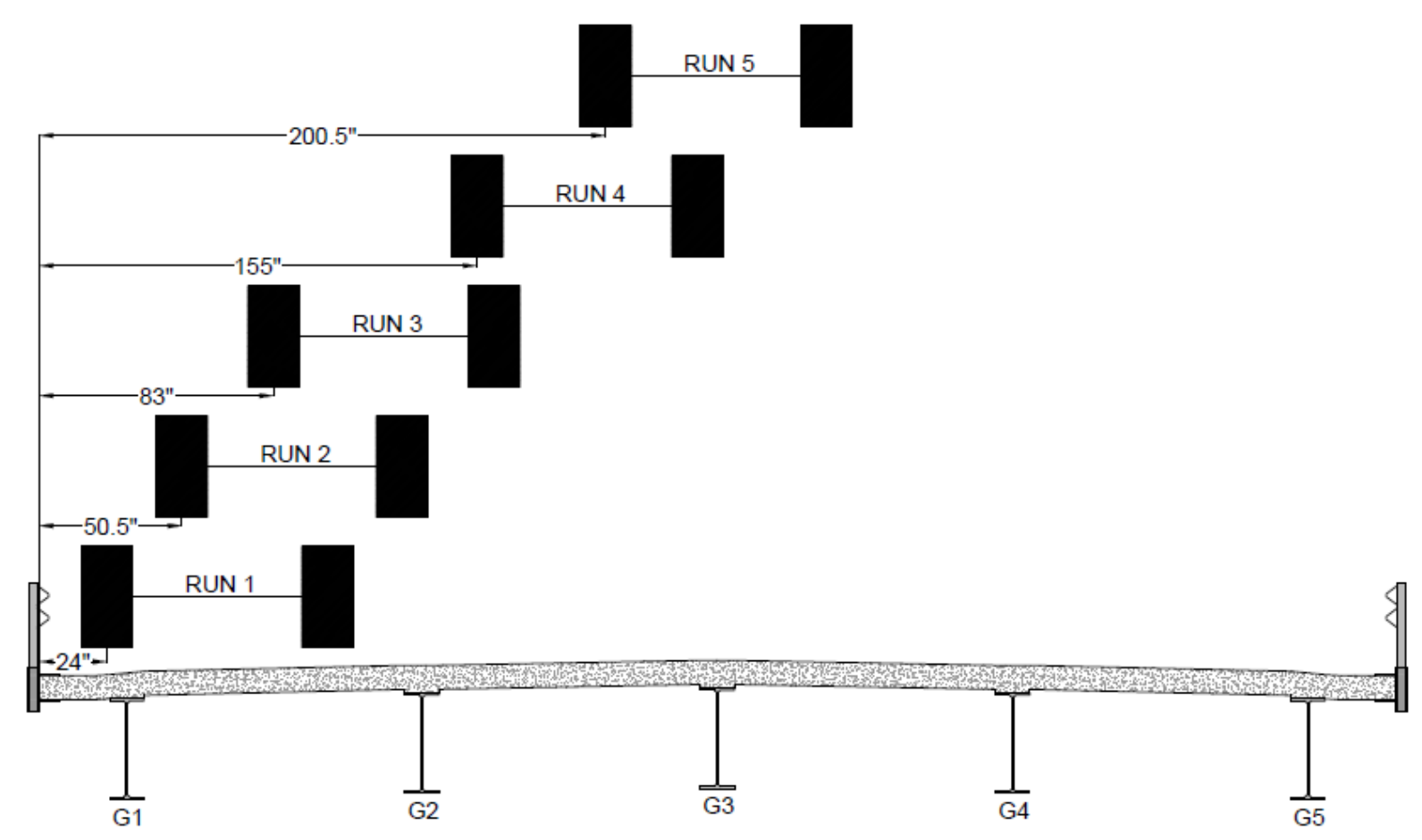

Figure 5.12: Live Load Truck Placements (Looking North)

For each truck run, the truck was driven at a crawl speed, and then stopped with the center axle resting at a given cross-section. The resulting racking and induced vibrations were allowed to settle to obtain a "pseudo-static" reading from each gage. This is desirable both from a design standpoint (current design methods use static analyses to obtain live load envelopes) and from a modeling standpoint (the proposed modeling technique assumed static behavior). For each run, the truck was stopped at two locations:

- 19 feet from the southern abutment (to maximize bending moment at the gage locations).

- Midspan (to generate maximum bending moment in the girders) 
During data collection, initial readings were taken before truck placement was started and after each truck placement was completed. The difference between these readings indicate the change in stress/strain caused by the placement of the vehicular live load. Utilizing the data reduction methods discussed in Chapter 4, the reduced readings in Table 5.2 were obtained. Truck runs referred to in Table 5.2 are described in Figure 5.12. Note that, due to the loading plan selected, both moments with the truck at the gage location and at midspan were obtained.

Table 5.2: Experimental Bending Moments Obtained from Live Load Placement (ft-kip)

\begin{tabular}{ccccccc}
\hline Truck Run & Truck Location & $\mathrm{M}_{\mathrm{G} 1}$ & $\mathrm{M}_{\mathrm{G} 2}$ & $\mathrm{M}_{\mathrm{G} 3}$ & $\mathrm{M}_{\mathrm{G} 4}$ & $\mathrm{M}_{\mathrm{G} 5}$ \\
\hline \multirow{2}{*}{ Run 1 } & $\mathrm{L}=19 \mathrm{ft}$ & 129.4 & 88.3 & 30.5 & 12.4 & 8.5 \\
& Midspan & 71.7 & 50.2 & 24.1 & 9.7 & 13.3 \\
\hline \multirow{2}{*}{ Run 2 } & L=19 ft & 104.0 & 101.2 & 37.8 & 13.8 & 19.8 \\
& Midspan & 62.0 & 48.1 & 26.1 & 10.8 & 16.8 \\
\hline \multirow{2}{*}{ Run 3 } & L=19 ft & 77.2 & 105.1 & 47.7 & 16.1 & 20.2 \\
& Midspan & 50.8 & 48.5 & 26.8 & 11.6 & 67.0 \\
\hline \multirow{2}{*}{ Run 4 } & L=19ft & 35.6 & 85.2 & 79.7 & 31.7 & 36.6 \\
& Midspan & 29.2 & 47.0 & 32.0 & 20.7 & 37.8 \\
\hline \multirow{2}{*}{ Run 5 } & L=19ft & 18.0 & 58.7 & 84.5 & 50.6 & 49.7 \\
& Midspan & 15.4 & 40.5 & 32.0 & 23.9 & 48.5 \\
\hline
\end{tabular}

\subsubsection{Finite Element Modeling}

Using the finite element modeling techniques discussed in Chapter 4, a finite element model simulating the live loading of the V-65 Jesup South Bridge was created and analyzed. Figure 5.13 illustrates the model used to simulate live loading on the structure. 


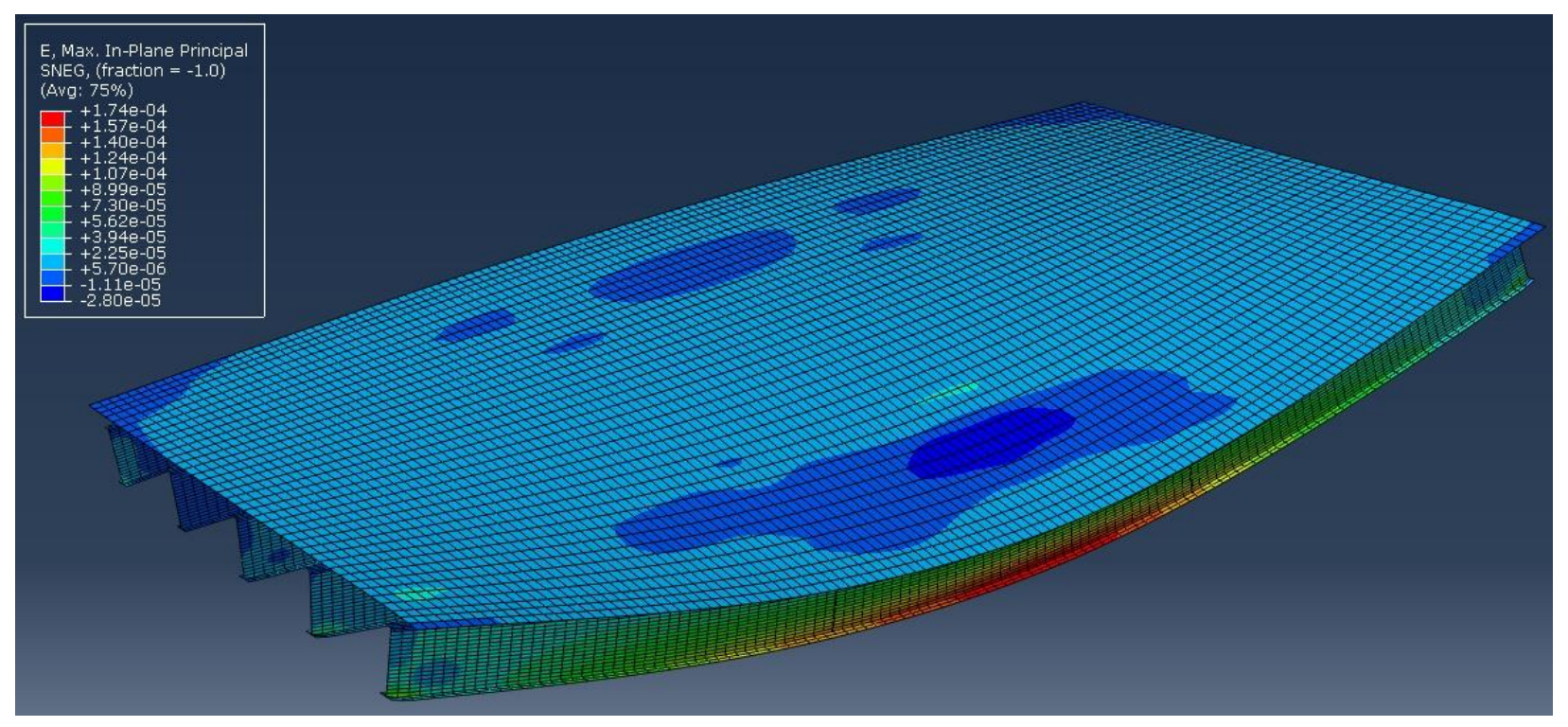

Figure 5.13: Finite Element Modeling Results of Live Loading

Utilizing the data reduction methods discussed in Chapter 4, a comparison of the experimentally-obtained data from the field test along with the results of the aforementioned finite element model are plotted in Figure 5.14. Specifically, a comparison of experimentallycomputed distribution factors and those reduced from finite element analyses are plotted. Each color represents a different girder, while each mark represents a different truck run $(\mathrm{L}=19 \mathrm{ft}$ and Midspan). As shown, there is good linear correlation between the experimental and analytical results. However, any variation in the experimentally-computed distribution factors and those reduced from finite element analyses are most likely a result of the boundary conditions of the models representing "hinge-roller" conditions and ignoring any fixity of the integral abutment. Further research into the fixity modeling effects of integral abutments, specifically in exterior girders is recommended. 


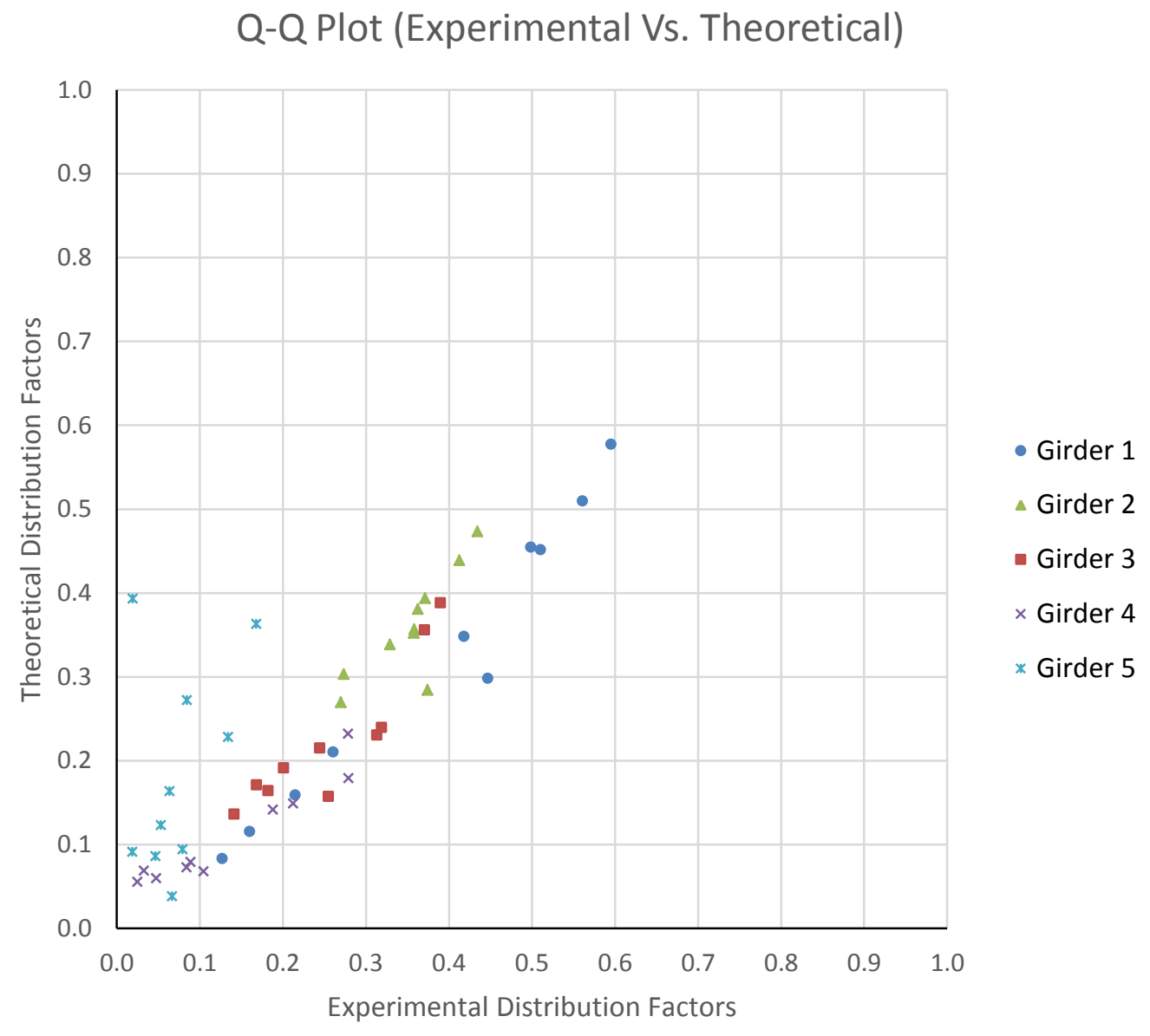

Figure 5.14: Results from Live Loading Assessment

\subsection{CONCLUSION}

The contents of this chapter have detailed two separate field tests conducted on the V-65 Jesup South Bridge. The accuracy of this data has been benchmarked against analytical investigations using methods discussed in Chapter 4. The results of these assessments show that the data generated from the field tests is quite accurate and will prove invaluable in future analytical studies on short-span steel bridge behavior. 


\section{Chapter 6: Summary \& CONCluding Remarks}

\subsection{Project Summary}

The scope of this thesis was to discuss the development of eSPAN140 and its associated design standards along with how eSPAN140 was utilized during its first documented application, the V-65 Jesup South Bridge. As discussed, it is clear that eSPAN140 is quite capable of producing efficient and economical solutions in the short-span range. This efficiency and economy stems largely from the use of commonly available plate and member sizes and the standardization of designs. For this project, eSPAN140 provided all the necessary parameters for county engineers to refine and synthesize an effective short-span steel bridge design.

\subsection{RECOMMENDATIONS FOR CONTINUED WORK}

The following tasks are recommended for future work:

- Deliver presentations summarizing this project at technical meetings and conferences, including SSSBA semiannual meetings, state/county engineering conferences, and other appropriate venues.

- Utilize experimental data obtained in this research to conduct future analytical studies in various aspects of short-span steel bridge behavior, such as:

- Lateral flange bending in steel I-girder bridges

○ Live load distribution in steel I-girder bridges

○ Etc. 


\section{REFERENCES}

AASHTO (2010). American Association of State Highway and Transportation Officials. AASHTO LRFD Bridge Design Specifications, Fifth Edition. AASHTO, Washington, DC, 2010.

Barker, M. G., Imhoff, C. M., McDaniel, W. T., and Frederick, T. L. (1999). "Field Testing and Load Rating Procedures for Steel Girder Bridges.” University of Missouri - Columbia: Missouri Department of Transportation.

Barth, K. E. (1996). Moment-Rotation Characteristics for Inelastic Design of Steel Bridge Beams and Girders. School of Civil Engineering. West Lafayette, IN, Purdue University. Doctor of Philosophy.

Barth, K. E. and H. Wu (2006). "Efficient Nonlinear Finite Element Modeling of Slab on Steel Stringer Bridges." Finite Elements in Analysis and Design 42(14): 10.

Beer, F., E. R. Johnston, et al. (2012). Mechanics of Materials. New York, NY, McGraw-Hill Higher Education.

Bentley Systems, Inc. (2008). LEAP CONSYS. Tampa, FL, Bentley Systems, Inc.

Boresi, A. P. and R. J. Schmidt (2003). Advanced Mechanics of Materials. Hoboken, NJ, John Wiley \& Sons, Inc.

Bridge Diagnostics, Inc. (n.d.). STS-WiFi Operations Manual. Boulder, CO.

Burgueño, R. and B. S. Pavlich (2008). Evaluation of Prefabricated Composite Steel Box Girder Systems for Rapid Bridge Construction. East Lansing, MI, Michigan State University.

Burner, K. A. (2010). Experimental Investigation of Folded Plate Girders and Slab Joints Used in Modular Construction. Department of Civil Engineering. Lincoln, NE, University of Nebraska-Lincoln. Master of Science.

Chandar, G., M. D. Hyzak, et al. (2010). Rapid Economical Bridge Replacement. Modern Steel Construction. Chicago, IL, National Steel Bridge Alliance. 2010.

Chen, W. F. and D. J. Han (1988). Plasticity for Structural Engineers. New York, NY, SpringerVerlag.

Dassault-Systèmes (2010). Abaqus/CAE. Providence, RI, Dassault Systèmes Simulia Corp.

Egilmez, O. O., T. A. Helwig, et al. (2007). "Stiffness and Strength of Metal Bridge Deck Forms." ASCE Journal of Bridge Engineering 12(4): 8. 
Eom, J., and Nowak, A. S. (2001). "Live Load Distribution for Steel Girder Bridges." ASCE Journal of Bridge Engineering 489-497.

Galambos, T. V. (1968). Structural Members and Frames. Englewood Cliffs, NJ, Prentice-Hall, Inc.

Galindez, N. Y. (2009). Levels of Lateral Flange Bending in Straight, Skewed and Curved Steel I-Girder Bridges During Deck Placement. Department of Civil \& Environmental Engineering. Morgantown, WV, West Virginia University. Doctor of Philosophy.

Garrell, C. (2011). Steel Plate Availability for Highway Bridges. Modern Steel Construction. Chicago, IL, National Steel Bridge Alliance. 2011.

Glaser, L. A. (2010). Constructability Testing of Folded Plate Girders. Department of Civil Engineering. Lincoln, NE, University of Nebraska-Lincoln. Master of Science.

Graybeal, B. A. (2010). Behavior of Field-Cast Ultra-High Performance Concrete Bridge Deck Connections Under Cyclic and Static Structural Loading. McLean, VA, Federal Highway Administration.

Helwig, T. A. and K. H. Frank (1999). "Bending Behavior of Composite Girders with Cold Formed Steel U Section." ASCE Journal of Structural Engineering 125(11):

ITD (2014). ITD Bridge Design LRFD Manual. Boise, ID, Idaho Transportation Department.

Jackson, J. J. (2013). Evaluation of Deck Casting on the Construction Performance of Straight and Skewed Steel I-Girder Bridges. Department of Civil \& Environmental Engineering. Morgantown, WV, West Virginia University. Master of Science.

Kala, Z. (2013). Elastic Lateral-Torsional Buckling of Simply Supported Hot-Rolled Steel IBeams with Random Imperfections. 11th International Conference on Modern Building Materials, Structures and Techniques. Vilnius, Lithuania.

Lay, M., Adams, P., and Galambos, T. "Experiments on High Strength Steel Members," Fritz Engineering Laboratory Report No. 297.8, Fritz Engineering Laboratory, Lehigh University, Bethlehem, PA. 1964.

MDX Software, Inc. (2009). MDX Version 6.5.910. MDX Software, Inc., Columbia, MO, 2009.

Michaelson, G. K. (2010). Live Load Distribution Factors for Exterior Girders in Steel I-Girder Bridges. Department of Civil \& Environmental Engineering. Morgantown, WV, West Virginia University. Master of Science.

Micro-Measurements, Inc. (2010). StrainSmart. Raliegh, NC, Micro-Measurements, Inc. 
Morgan, S. A. (2010). Towards the Development of Efficient and Economical Short Span Modular Bridges. Department of Civil \& Environmental Engineering. Morgantown, WV, West Virginia University. Master of Science.

Nagy, G. (2008). Development of an optimized Short-Span Steel Bridge Design Package. Department of Civil \& Environmental Engineering. Morgantown, WV, West Virginia University. Master of Science.

Nakamura, S. (2002). "Bending Behavior of Composite Girders with Cold Formed Steel U Section." ASCE Journal of Structural Engineering 128(9): 8.

NSAB (2012). Design Example 1: Three-Span Continuous Straight Composite Steel I-Girder Bridge. Steel Bridge Design Handbook. Washington, DC, National Steel Bridge Alliance.

NSBA (2012). Design Example 2A: Two-Span Continuous Straight Composite Steel I-Girder Bridge. Steel Bridge Design Handbook. Washington, DC, National Steel Bridge Alliance.

Nutt, R. V., Schamber, R. A., and Zokaie, T. (1988). NCHRP 12-26: Distribution of Wheel Loads on Highway Bridges. Final Report for National Cooperative Highway Research Program.

Righman, J. E. (2005). Rotation Compatibility Approach to Moment Redistribution for Design and Rating of Steel I-Girders. Department of Civil \& Environmental Engineering. Morgantown, WV, West Virginia University. Doctor of Philosophy.

Roberts, N. R. (2004). Evaluation of the Ductility of Composite Steel I-Girders in Positive Bending. Department of Civil \& Environmental Engineering. Morgantown, WV, West Virginia University. Master of Science.

Schafer, B. W. and S. Ádány (2006). Buckling analysis of cold-formed steel members using CUFSM: conventional and constrained finite strip methods 18 th International Specialty Conference on Cold-Formed Steel Structures. Orlando, FL.

Schilling, C. and S. Morcos. Moment-Rotation Tests of Steel Girders with Ultra-Compact Flanges. Project 188 Autostress Design of Highway Bridges. American Iron and Steel Institute, 1988.

Snyder, D. and Bennett, D. (2014). Case Study: Buchanan County's eSPAN140 Demonstration Project Sets Stage for New Era in Short Span Steel Bridge Design. Short Span Steel Bridge Alliance. 
Stallings, J. M., and Yoo, C. H. (1993). Tests and Ratings of Short-Span Steel Bridges. ASCE Journal of Structural Engineering 2150-2168.

Systemes, D. (2014). Abaqus/CAE Users Manual (Version 6.14). Providence, RI: Dassault Systemes Simulia Corp.

Taly, N. and H. Gangarao (1979). "Prefabricated Press-Formed Steel T-Box Girder Bridge System." AISC Engineering Journal 16(3): 9.

The Mathworks, Inc. (2010). MATLAB. Natick, MA, The Mathworks, Inc.

Tricon Precast, Con-Struct Prefabricated Bridge System. Standard plans. Tricon Engineering Group, Ltd. 2008.

Yang, L. (2004). Evaluation of Moment Redistribution for Hybrid HPS 70W Bridge Girders. Department of Civil \& Environmental Engineering. Morgantown, WV, West Virginia University. Master of Science.

Ziemian, R. D. (2010). Guide to Stability Design Criteria for Metal Structures, John Wiley \& Sons, Inc. 


\section{Appendix A: eSPAN140 Output}

The following appendix includes the eSPAN140 output for the V-65 Jesup South Bridge.

It should be noted that some of the final design parameters were altered from the eSPAN140 output and verified. 


\title{
eSPAN140"
}

\section{Steel Bridge Solutions}

\author{
Jesup Bridge \\ Brian Keierleber \\ Buchanan County lowa
}

5/31/2013 3:08 PM

www.ShortSpanSteelBridges.org I www.eSPAN140.com 


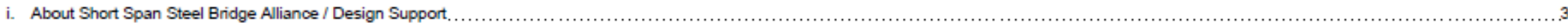

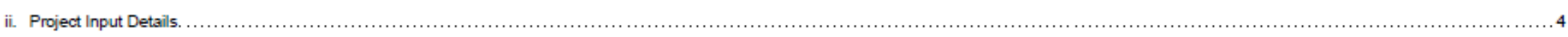

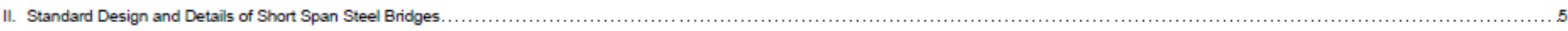

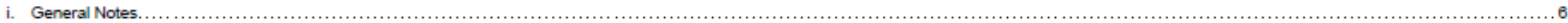

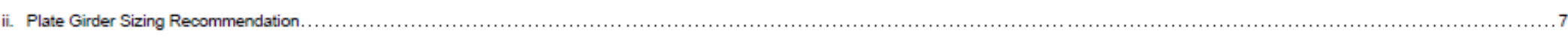

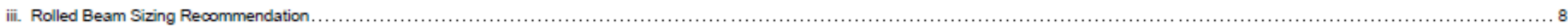

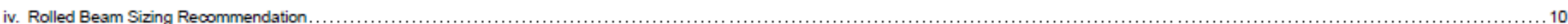

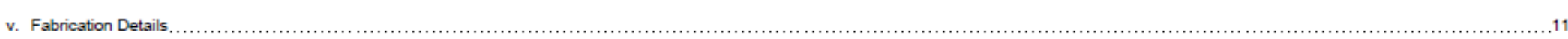

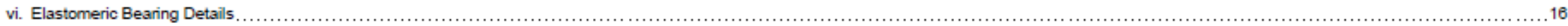

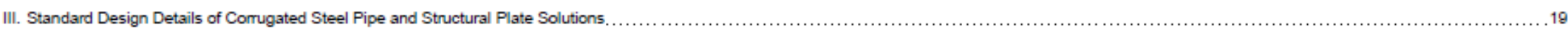

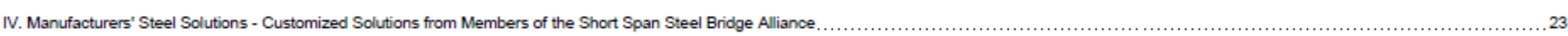

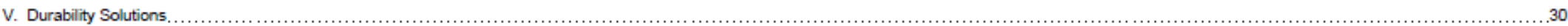

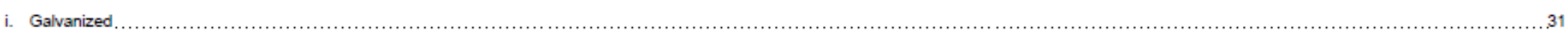

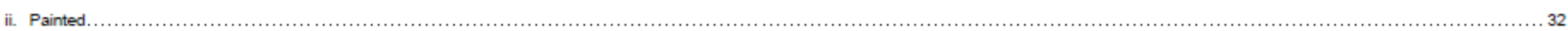

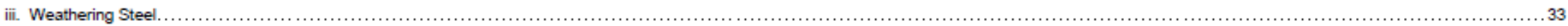

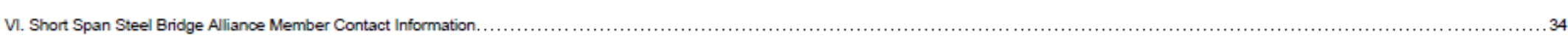

O2013 Short Span Steel Bridge Allanoe and ESPAN140 | www.ShortSpanSteeleridge6. org | www.eSPAN140.com 


\section{About Short Span Steel Bridge Alliance}

The Short Span Steel Bridge Alliance (SSSBA) is a group of bridge and culvert industry leaders including steel manufacturers, fabricators, service centers, coaters, researchers, and representatives who have joined together to provide

educational information on the design and construction of short span steel bridges in installations up to 140 feet in length.

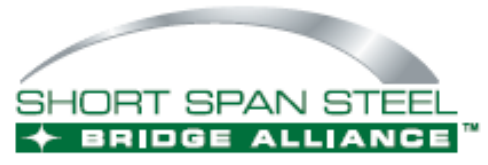

For more information about the SSSBA, please contact:

\section{Daniel R. Snyder}

Manager, Business Development

Steel Market Development Institute, a Business Unit of AIS

25 Massachusetts Ave, NW

Suite 800

Washington, DC 20001

Email: dsnyder(i)steel, 0 (n)

For media related information, please contact:

Dianne Newton-Shaw

The Placemaking Group

299 Third Street

Oakland, CA 94607

Work Phone: (510) 496-2352 ext 200

Fax: (510) 238-0589

Email: dnshawQiplacemakinggroup.con

\section{Design Support}

The Short Span Steel Bridge Alliance offers complimentary design support for questions relating to bnidge and culvert design. Design support is offered by the following organizations (to submit an

Standard Design and Details of Short Span Bridges (Plate Girder 8 Rolled Beam Bridges)

The Bridge Technology Center is a complimentary resource available for questions specific to standard design and detail solutions of short span steel bridges (refer to the section of this Solutions rce provided by West Virginia University and the University of Wyoming.

\section{W West VirginiaUniversity}

UNIVERSITY

OF WYOMING

$$
\text { New Thiveking }
$$

\section{Standard Design and Details of Corrugated Steel Pipe and Structural Plate}

The National Corrugated Steel Pipe Association provides complimentary design support for questions pertaining specifically to standard design and detail solutions of corngatied steel pipe and corrugated structural plate (refer to the section of this Solutions Book on corrugated steel pipe and corrugated structural plate standards,

Manufactured Steel Solutions

For questions pertaining to a specific manufacturer's solution (refer to section on Manufacturer's Steel Solutions of this Solutions Book), it is recommended that you directly contact the manufacturer by utilizing the contact information listed with the solution. 


\begin{tabular}{|l|r|}
\hline User Name: & Brian Keierleber \\
\hline User Company: & Buchanan County lowa \\
\hline User Input Date: & $05 / 31 / 2013$ \\
\hline Project Name: & Jesup Bridge \\
\hline City: & Buchanan County \\
\hline State/Province: & IA \\
\hline Roadway: & V-65 Benson Shady Grove \\
\hline Span Length: & $65^{\prime}$ \\
\hline Number of Striped Traffic Lanes: & 2 \\
\hline Roadway Width: & $40^{\prime}$ \\
\hline Total Parapet Width: & $3.5^{\prime \prime}$ \\
\hline Total Deck Overhang Width: & $2^{\prime} 7.2^{\prime \prime}$ \\
\hline Pedestrian Access: & No \\
\hline Number of Sidewalks: & Not provided \\
\hline Total Width of Each Sidewalk: & Not provided \\
\hline Skew Angle: & 0 degrees \\
\hline Average Daily Traffic (ADT): & Over 2,000 \\
\hline Design Speed: & $46+$ mph \\
\hline Waterway Area: & $500 \mathrm{ft}^{2}$ \\
\hline Height of Cover: & Not provided \\
\hline
\end{tabular}

\section{Disclaimer}

This document has been prepared in accordance with information made available to the Short Span Steel Bridge Alliance (SSSBA) at the time of its preparation. While it is believed to reasonably refiect an engineering or construction document and should not be used or relied upon for any specific application without competent professional examination and verification of its accuracy, suitability. and applicability by a licensed engineer, architect or other professional. SSSBA disclaims any liability arising from information provided by others or from the unauthorized use of the information contained in this document, and does not accept any obligation to issue supplements or corrections in the event of errors being discovered or advanoes being made in the techniques discussed in the document.

\section{Notes}

- Short span standards for rolled beam solutions are only available for input lengths between 40 and 100 feet and skew angles under 20 degrees.

- Short span standards for homogeneous plate girder solutions are only available for input lengths between 60 and 140 feet and skew angles under 20 degrees."

- Short span standards for hybrid plate girder solutions are only available for input lengths between 80 and 140 feet and skew angles under 20 degrees.

- Design standards for rolled beam and plate girder solutions are rounded in five (5) foot increments.

- Corrugated steel pipe and structural plate standards are only available for input lengths under 85 feet.

- Customized prefabricated manufacture solutions are available for all lengths and skew angles.

* Far bridges/culverts outside of this range, standard designs will not appear in your solutions book.

\section{Pricing Inquiries}

To obtain budget estimates or pricing information, contact a Short Span Steel Bridge Alliance Fabricator (see sections IV and VI in the Solutions Book for contact information). 


\section{Standard Design and Details of Short Span Steel Bridge Solutions}

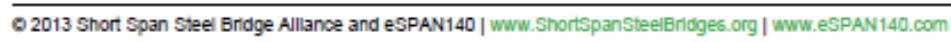




\section{General}

These plans are intended to serve as a guide to state, county. and local highway departments in the development of suitable and economical steel bridge superstructure designs. The plans should be

\section{Specifications}

Specifications for design, materials, and construction are included in the following:

- AASHTO LRFD bridge design specifications, fifth edition with 2010 interim revisions. 2010. 作 Officials. Washington, $D C$

- AASHTOINSBA Collaboration Standard S2.1. Steel Bridge Fabrication Guide Specifications, 2008. Developed by the AASHTO/NSBA Steel Bridge Collaboration. Washington, DC

- AASHTOINSBA Collaboration Standard G1.4. Guidelines for design details. 2006. Developed by the AASHTO/NSBA Steel Bridge Collaboration, Washington, DC

- ASTM Standards. Published by the American Society for Testing and Materials. ASTM International, 100 Barr Harbor Drive, P.O. Box C700, West Conshohocken, PA 19428-2959 USA.

\section{Design Loading}

AASHTO HL-93 Vehicular Live Loading was used throughout.

\section{Design Method}

Load and Resistance Factor Design (LRFD) method was employed throughout. Designs were originated using 5 girders with equal spacing. However, plate sizes and beam selections are perpendicular, and are intended to be paralle.

Three options are available for steel superstructure composite l-girders. These options are as follows

1. Homogenous plate girders comprised of ASTM A709-50W steel. These designs are available 列
2. Hybrid plate girders comprised of ASTM A709-50W and A709-70W steel. A709-50W steel is utilized for the top flange and web. A709-70W steel is utilized for the bottom flange. Thes designs are available for a span range of $80^{\prime}-140^{\prime}$

3. Rolled beams comprised of ASTM A709-50W steel. These designs are available for a span range of $40^{\prime}-100^{\prime}$.

\section{Structural Steel}

All structural steel shall œonform to AASHTO M270 (ASTM A709) grade 50, 50W, or 70W, as applicable. Refer to "Design Method."

Concrete

Concrete for deck and parapet shall have a minimum 28-day compressive strength ( $\mathrm{f}^{\prime} \mathrm{c}$ ) of $4,000 \mathrm{PSI}$.

\section{Concrete Deck}

The deck thickness employed for design was $8^{\prime \prime}$. This includes a 1/4" integral wearing surface which is not considered part of the structural depth. The owner shall specify the required deck cross slope and grade.

\section{Reinforcing Steel}

Reinforcing steel shall conform to ASTM AB15 grade 60

\section{Shear Connectors}

Welded stud shear connectors shall conform to the requirements of ASTM A108.

\section{Elastomeric Bearings}

See Elastomeric Bearing Details. 


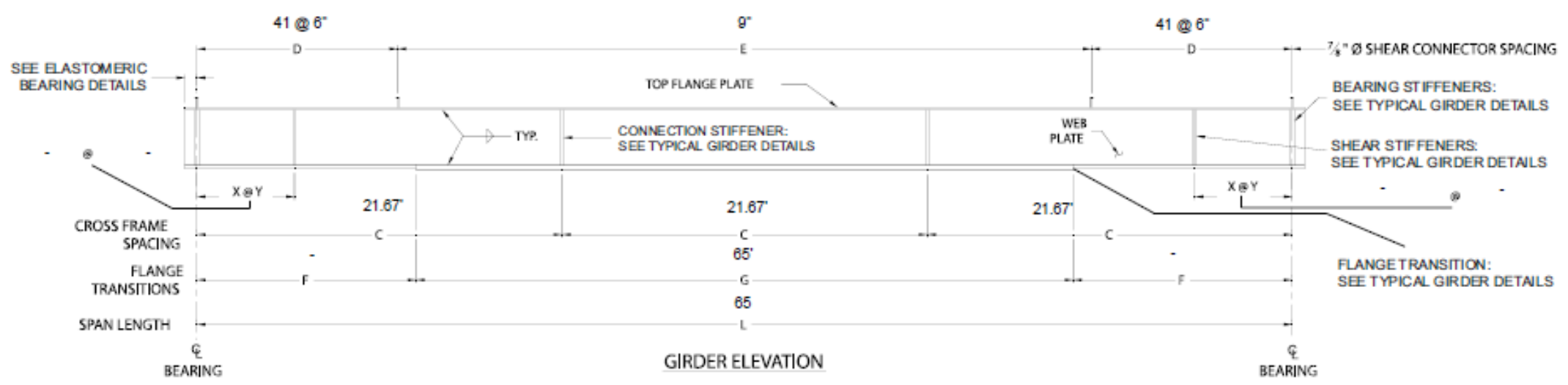

\begin{tabular}{|c|c|c|c|c|c|c|c|c|c|c|c|c|}
\hline \multirow{3}{*}{ SPAN (L) - $\mathrm{ft}$} & \multicolumn{6}{|c|}{ PLATE GIRDER SIZE } & \multirow{3}{*}{$\begin{array}{l}\text { DIAPHRAGM } \\
\text { sPACING (C) - tt }\end{array}$} & \multirow{2}{*}{\multicolumn{2}{|c|}{ SHEAR STIFFENERS }} & \multirow{2}{*}{\multicolumn{2}{|c|}{$\begin{array}{l}\text { SHEAR CONNECTOR MAX. SPAC- } \\
\text { ING }\end{array}$}} & \multirow{3}{*}{$\begin{array}{l}\text { INDINDUAL GIRDER } \\
\text { WEIGHT }\end{array}$} \\
\hline & \multirow{2}{*}{$\begin{array}{l}\text { TOP FLANGE } \\
-\ln \end{array}$} & \multicolumn{2}{|c|}{$\begin{array}{l}\text { BOTTOM FLANGE } \\
\text { (F) } \\
\end{array}$} & \multicolumn{2}{|c|}{ BOTTOM FLANGE (G) } & \multirow{2}{*}{ WEB PLATE-In } & & & & & & \\
\hline & & PLATE - in & LENGTH - In & PLATE - In & LENGTH - In & & & X (No. REQ Rd) & $\mid \mathrm{Y}$ - It. (SPACING) $\mid$ & D & $\mathbf{E}$ & \\
\hline 65 & $14 \times 3 / 4^{\prime \prime}$ & - & - & $14 \times 11 / 2$ & $65^{\circ}$ & $24 \times 1 / 2^{2}$ & 21.67 & - & - & 41 (6) 6" & $\theta^{*}$ & 9,621 lbs \\
\hline
\end{tabular}

\begin{tabular}{|c|c|c|c|c|c|c|c|c|c|}
\hline \multicolumn{4}{|c|}{ STEEL D.L CAMBER - In } & \multicolumn{5}{c|}{ TOTAL D.L CAMBER - In } \\
\hline $\mathbf{1}$ & $\mathbf{2}$ & $\mathbf{3}$ & $\mathbf{4}$ & $\mathbf{5}$ & $\mathbf{1}$ & $\mathbf{2}$ & $\mathbf{3}$ & $\mathbf{4}$ & $\mathbf{5}$ \\
\hline $0.147^{*}$ & $0.277^{*}$ & $0.379^{*}$ & $0.444^{*}$ & $0.467^{*}$ & $1.159^{*}$ & $2.190^{*}$ & $2.998^{*}$ & $3.511^{*}$ & $3.687^{*}$ \\
\hline
\end{tabular}

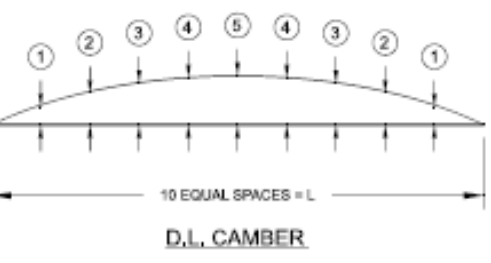

2013 Short Span Steel Bridge Allanoe and eSPAN140 | www. ShortSpan Steeleridge6. org | www.eSPAN140.com 
COMPOSITE ROLLED BEAM WITH PARTIALLY STIFFENED WEB - 5 GIRDERS AT 8' 10.15" GIRDER SPACING, LIGHTEST WEIGHT

The selected rolled beam section is based on the widest $\left(10^{\prime}-6^{\circ}\right)$ girder spacing used in the development of the standards. The steel industry generally recommends the use of the widest girder spacing possible to reduce the potential number of girder lines for optimum economy. If you use additional beam lines and/or desire a beam spacing less than 10'-6, a rolled beam with a lighter foot-weight or less depth may be appropriate. See tables in this section of the Solutions Book for additional size recommendations.

SEE ELASTOMERIC
BEARING DETALS
CROSS FRAME
SPACING
SPAN LENGTH

BEAM ELEVATION

\begin{tabular}{|c|c|c|c|c|c|}
\hline \multirow{2}{*}{ SPAN (L) $-\pi$} & \multirow{2}{*}{ SELECTED SECTIONS } & \multirow{2}{*}{$\begin{array}{l}\text { DIAPHRAGM SPACING (C) } \\
-\pi \mathrm{t} \\
\end{array}$} & \multicolumn{2}{|c|}{ SHEAR CONNECTOR MAX. SPACING } & \multirow{2}{*}{ WEGeht } \\
\hline & & & D & $\mathrm{E}$ & \\
\hline 65 & W40x149 & 21.67 & $16 @ 6^{-}$ & $\theta^{*}$ & $10,855 \mathrm{lbs}$ \\
\hline
\end{tabular}

\begin{tabular}{|c|c|c|c|c|c|c|c|c|c|}
\hline \multicolumn{5}{|c|}{ STEEL DL CAMBER - In } & \multicolumn{5}{|c|}{ TOTAL D.L CAMBER - In } \\
\hline 1 & 2 & 3 & 4 & 5 & 1 & 2 & 3 & 4 & 5 \\
\hline $0.081^{\prime \prime}$ & $0.154^{\prime \prime}$ & $0.210^{\prime \prime}$ & $0.246^{\prime \prime}$ & $0.258^{\prime \prime}$ & $0.623^{\prime \prime}$ & $1.178^{\circ}$ & $1.612^{*}$ & $1.889^{\circ}$ & $1.983^{\circ}$ \\
\hline
\end{tabular}

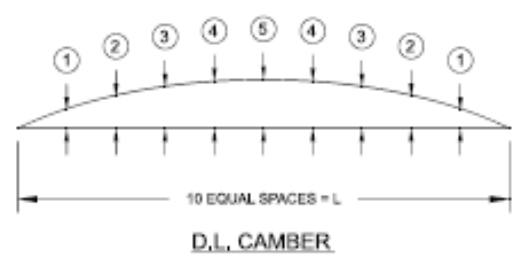

O 2013 Short Span Steel Brdge Allance and ESPAN140 | Www.ShortSpan Steeleridge6. org | www.eSPAN140.com 
COMPOSITE ROLLED BEAM WITH PARTIALLY STIFFENED WEB - 5 GIRDERS AT 8' 10.15" GIRDER SPACING, LIMITED DEPTH

The selected rolled beam section is based on the widest $\left(10^{\prime}-6^{\circ}\right)$ girder spacing used in the development of the standards. The steel industry generally recommends the use of the widest girder spacing possible to reduce the potential number of girder lines for optimum economy. If you use additional beam lines and/or desire a beam spacing less than 10'-6", a rolled beam with a lighter foot-weight or less depth may be appropriate. See tables in this section of the Solutions Book for additional size recommendations.

SEE ELASTOMERIC
BEARING DETALS

BEAM ELEVATION

\begin{tabular}{|c|c|c|c|c|c|}
\hline \multirow{2}{*}{ SPAN (L) - $\mathbf{t t}$} & \multirow{2}{*}{ SELECTED SECTIONS } & \multirow{2}{*}{$\begin{array}{l}\text { DIAPHRAGM SPACING (C) } \\
-\pi \mathrm{t} \\
\end{array}$} & \multicolumn{2}{|c|}{ SHEAR CONNECTOR MAX. SPACING } & \multirow{2}{*}{ WEGeht } \\
\hline & & & D & $\mathrm{E}$ & \\
\hline 65 & W24x182 & $21.67^{\prime}$ & $26 @ 6^{\circ}$ & $\theta^{*}$ & $12,610 \mathrm{lbs}$ \\
\hline
\end{tabular}

\begin{tabular}{|c|c|c|c|c|c|c|c|c|c|}
\hline \multicolumn{5}{|c|}{ STEEL D. CAMBER - In } & \multicolumn{5}{|c|}{ TOTAL D.L CAMBER - In } \\
\hline 1 & 2 & 3 & 4 & 5 & 1 & 2 & 3 & 4 & 5 \\
\hline $0.122^{\prime \prime}$ & $0.230^{\prime \prime}$ & $0.315^{\prime \prime}$ & $0.389^{\prime \prime}$ & $0.387^{\prime \prime}$ & $0.785^{\prime \prime}$ & $1.485^{\circ}$ & $2.034^{*}$ & $2.382^{*}$ & $2.501^{\circ}$ \\
\hline
\end{tabular}

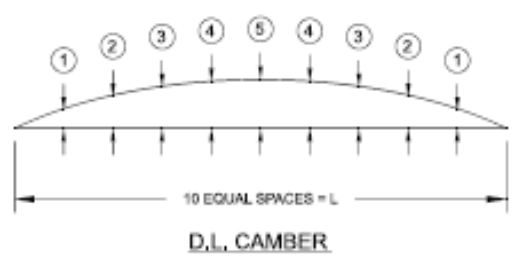

O 2013 Short Span Steel Brdge Allance and ESPAN140 | Www.ShortSpan Steeleridge6. org | www.eSPAN140.com 
As noted on the Rolled Beam Sizing Recommendation sheets the selected rolled beam section is based on the widest girder spacing used in these standards, $10^{-10}-6^{*}$. If you use additional beam lines and/or desire a beam spacing less than $10^{-}-6^{\circ}$ the following tables may be used to select an appropriate section. To use these tables given a desired span length and girder spacing select the section by rounding your span length up to the nearest $5 \mathrm{ft}$ increment equal to or greater than your span length and round your girder spacing up to the nearest column equal to or greater than your girder spacing. For example, using the table for the Limited Depth Designs, if you have a span length of $62 \mathrm{rt}$. and a girder spacing of $8-6$ you would select the table entry for a $65 \mathrm{ft}$. span length and $9 \mathrm{ft}$. girder spacing which yields a W24 $\mathrm{x} 176$. (Note: recalculate cambers, shown on previous Rolled Beam Sizing Recommendation sheets, to suit revised beam size / spacing)

\begin{tabular}{|c|c|c|c|c|c|c|}
\hline \multicolumn{7}{|c|}{ COMPOSITE ROLLED BEAM WITH PARTIALLY STIFFENED WEB - LMMTED DEPTH DESIGNS } \\
\hline \multirow{2}{*}{$\begin{array}{l}\text { SPAM } \\
\text { (L) - It: }\end{array}$} & \multicolumn{4}{|c|}{ GIRDER SPACING } & \multirow{2}{*}{$\begin{array}{l}\text { SELECTED } \\
\text { SECDIONS } \\
\text { RECOMMENDED }\end{array}$} & \multirow{2}{*}{$\begin{array}{l}\text { DLAPHRAGM } \\
\text { SPACING } \\
\text { (C) }-\mathrm{ft} \text {. }\end{array}$} \\
\hline & $600^{\circ}$ & $T \cdot 6^{n}$ & $9^{2}-0^{\circ}$ & $10^{\circ}-6^{\prime \prime}$ & & \\
\hline 40 & W21 $\times 62$ & W21x73 & W21 $1 \times 83$ & W21 $\times 93$ & W21 $1 \times 93$ & 20 \\
\hline 45 & W21 $\times 63$ & w21 2101 & W21 10101 & W21x111 & W21x111 & 22.5 \\
\hline 50 & W21x111 & W21 x111 & W21 122 & W21 $\times 132$ & W21x132 & 25 \\
\hline 55 & W24x117 & W24x117 & W24x131 & W24x146 & W24x146 & 27.5 \\
\hline 60 & W24x162 & W27x $\times 129$ & W24x146 & W24x162 & W24x162 & 20 \\
\hline 65 & W24x192 & w30x132 & W24x176 & W24x192 & W24x192 & 21.67 \\
\hline 70 & W27 $\times 194$ & W30x148 & W27x178 & W27 $\times 194$ & W27x194 & 23.33 \\
\hline 75 & W27 $\times 217$ & W36x 150 & W27 $\times 194$ & W27 2217 & 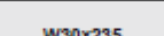 & 25 \\
\hline 80 & W30x211 & W36x160 & W30x211 & W30x235 & Wisuess & 20 \\
\hline 85 & w33×221 & w36x182 & w33x221 & W33*241 & & 21.25 \\
\hline 90 & w33×241 & W40x183 & w33×241 & W33×291 & W33x291 & 22.5 \\
\hline 95 & W36x247 & W40x 199 & W36×247 & W36x282 & waccren & 23.75 \\
\hline 100 & W36x282 & W40x211 & W36×262 & W36x302 & & 25 \\
\hline
\end{tabular}

\begin{tabular}{|c|c|c|c|c|c|c|}
\hline \multicolumn{7}{|c|}{ COMPOSITE ROLLE BEAM WTH PARTLALY STIFFENED WEB - LGHTEST WEIGHT DESIGNS } \\
\hline \multirow{2}{*}{$\begin{array}{l}\text { SPAM } \\
\text { (LL) }-\mathrm{tt}\end{array}$} & \multicolumn{4}{|c|}{ GIRDER SPACING } & \multirow{2}{*}{$\begin{array}{l}\text { SELECTED } \\
\text { SECIONS } \\
\text { RECCMMENDED }\end{array}$} & \multirow{2}{*}{$\begin{array}{l}\text { DIAPHRAGM } \\
\text { SPACING } \\
\text { (C) }-\mathrm{ft} .\end{array}$} \\
\hline & $60^{\prime \prime}$ & $T \cdot 6^{\prime \prime}$ & $9 \cdot 0 "$ & $10^{\prime}-6^{n}$ & & \\
\hline 40 & W21 $1 \times 52$ & W21 $\times 73$ & W24x76 & W2 $4 \times 84$ & W24x84 & 20 \\
\hline 45 & W24x68 & W21x101 & W27 $\times 84$ & W30x90 & W30x90 & 22.5 \\
\hline 50 & W27 278 & W21x111 & W30x99 & W30×108 & W30x108 & 25 \\
\hline 55 & W30x90 & W24x117 & W30x116 & W33x118 & W33x118 & 27.5 \\
\hline 60 & w30x108 & W27x129 & w33x118 & W36x135 & w36x135 & 20 \\
\hline 65 & W33x118 & W30x132 & W36x135 & W40x149 & W40x149 & 21.67 \\
\hline 70 & W33x130 & W30×148 & W40x149 & W40x167 & W40x167 & 23.33 \\
\hline 75 & W36x 135 & W $36 \times 150$ & W40x167 & W36x182 & 1 & 25 \\
\hline 80 & W40 149 & W $36 \times 160$ & W36x182 & W36x210 & W $36 \times 2 \times 210$ & 20 \\
\hline 85 & W40x167 & W36x182 & W36 6210 & W36x231 & & 21.25 \\
\hline 90 & W40x183 & W40x183 & W40 $\times 211$ & W36 247 & W $36 \times 247$ & 22.5 \\
\hline 95 & W40 $\times 211$ & W40x199 & W40x235 & W40 249 & nut & 23.75 \\
\hline 100 & W $44 \times 230$ & $w 40 \times 211$ & W40 249 & W44x262 & W $44 \times 262$ & 25 \\
\hline
\end{tabular}


Typical Girder Details
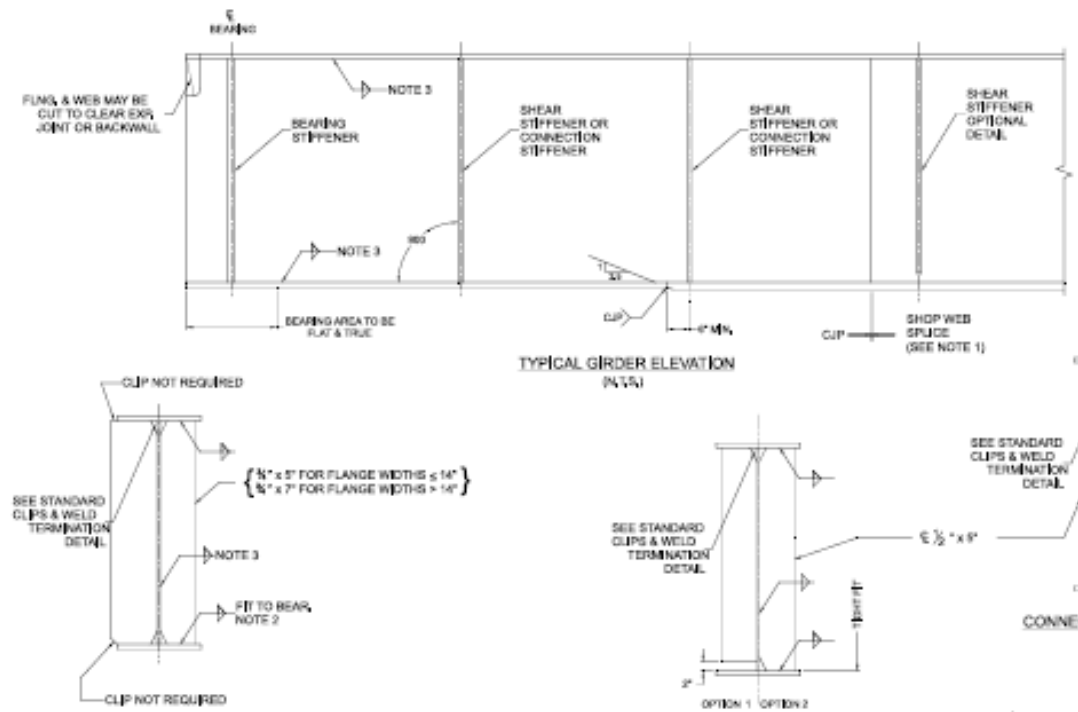

TWFICAL GIRDER ELENATION

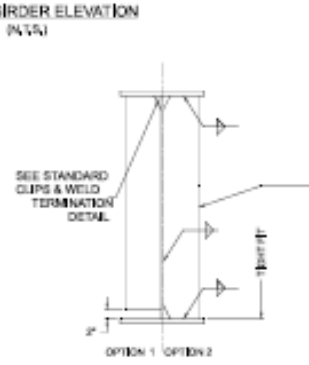

$\underset{\text { BEARING STIFFENE: }}{\text { DN.T.S. }}$

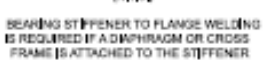

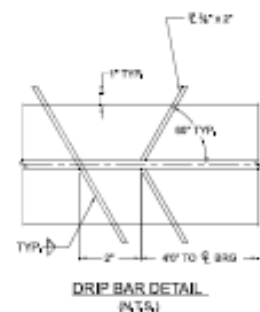

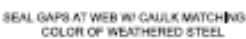

\section{NOTES:}

1. All C.PP welds to be ground and tested per state specifications.

2. Fit to bearing is to be $50 \%$ in contact with flange and within $1 / 16^{*}$ for remainder.

3. MT 1 ' of every $10^{\prime}$ (extents of mag particle inspection for fillet welds) -OR- see state specs.

O 2013 Short Span Steel Bridge Allanoe and ESPAN140 | www.ShortSpanSteeleridge6. org | uww.eSPAN140.com 
Rolled Shape and Bent Plate Diaphragm Details

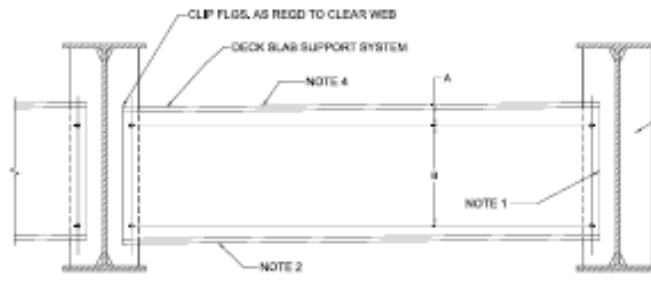

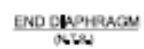

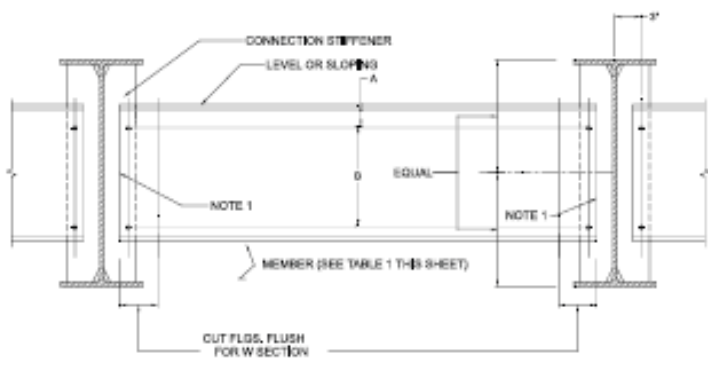

NTERUECWTE DLPHRAGM

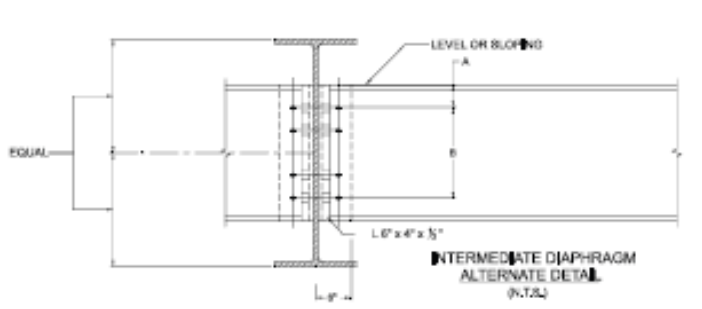

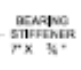
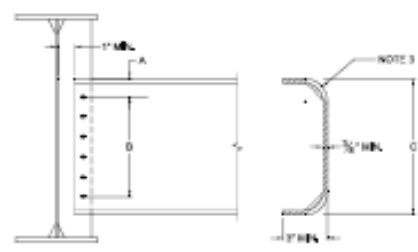

BENT PUTE ONPHAMON

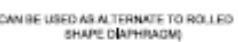

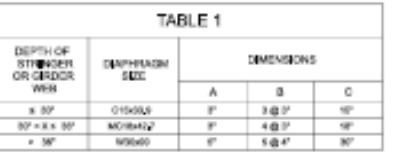

\section{NOTES:}

1. Slope diaphragm and keep holes vertical in stiffener at constant dimensions (to keep all stiffeners the same) and cut ends of diaphragm square.

2. At expansion joint, orient channel flanges away from joint opening.

3. Minimum radius as per AASHTO/NSBA fabrication S2.1 table 4.3.2-1. Per section 4.3.2, if the bend is parallel to direction of rolling, multiply the minimum

4. All holes to be $15 / 16^{\circ}$ ø for $7 / 8^{\circ}$ ๑ HS bolts, ASTM A325 type 3 w/ F438-3 washers (RCT)

5. Threads excluded from shear plane.

6. Application of the Intermediate Diaphragm Alternate Detail is limited to rolled beams in straight bridges with composite reinforced decks whose supports are nomal or skewed not more than 10 degrees from nomal and when the intermediate diaphragms are placed in contiguous lines parallel to the supports. 
Framing Plan

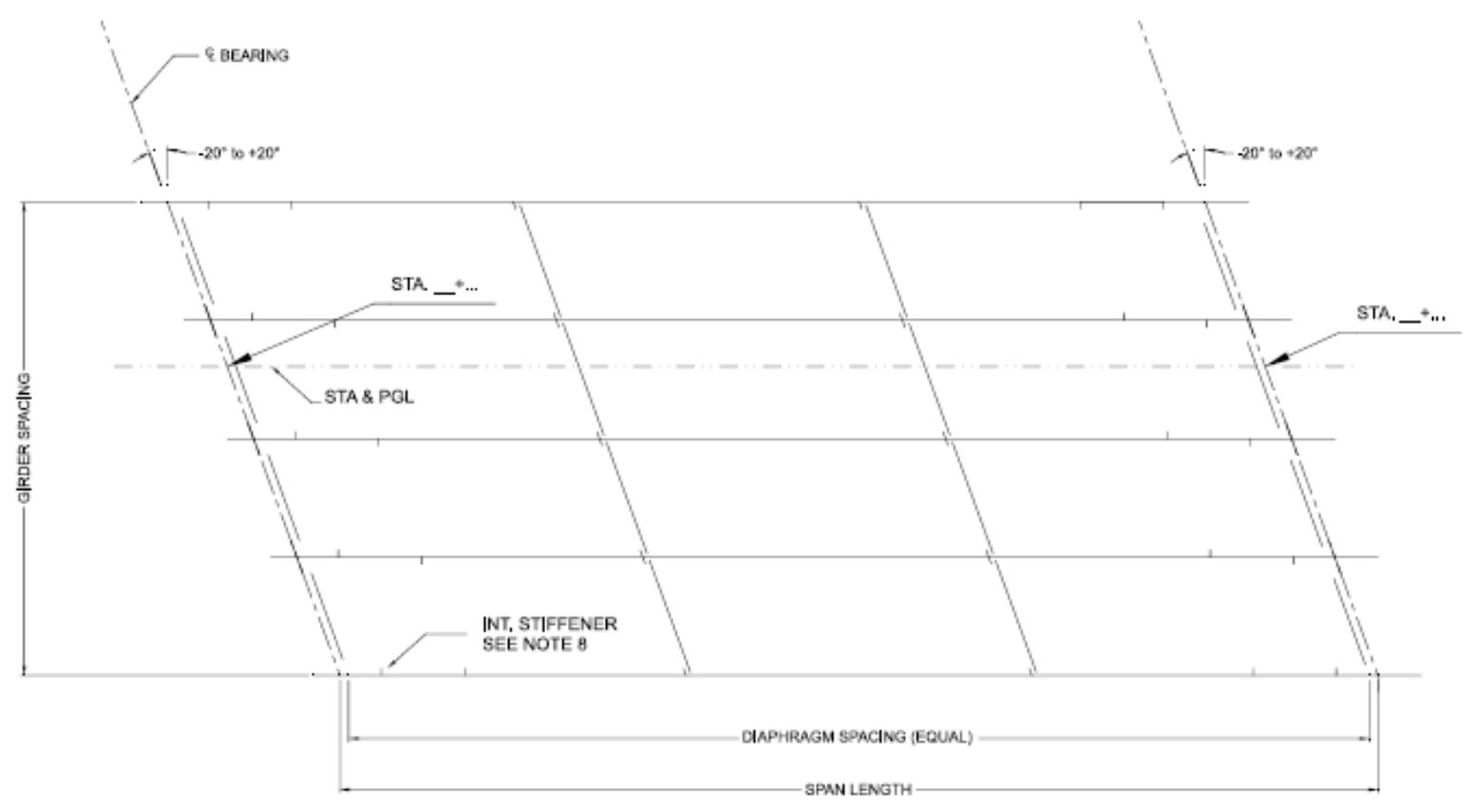

NOTES:

1. Superstructure may sit on existing bridge seats. Contractor to verify spacing in field.

2. Design will accommodate skews up to $20^{\circ}$ from $\perp$ but are intended to be paralle.

3. Station line is intended to be on a tangent alignment.

\section{Max grade at bearing is $\pm 5 \%$.}

5. Orient toes of channel diaphragm down grade.

6. Diaphragms may be placed on either side of connection plate at the contractor's discretion.

7. Keep diaphragm lines parallel to bearing lines.

8. Int. stiffeners are required on one side of web only. On fascia girders, orient stiffeners to the inside of
the girder. On interior girders, stiffeners should alternate sides. See Girder Elevations for spacing. 
Typical Section

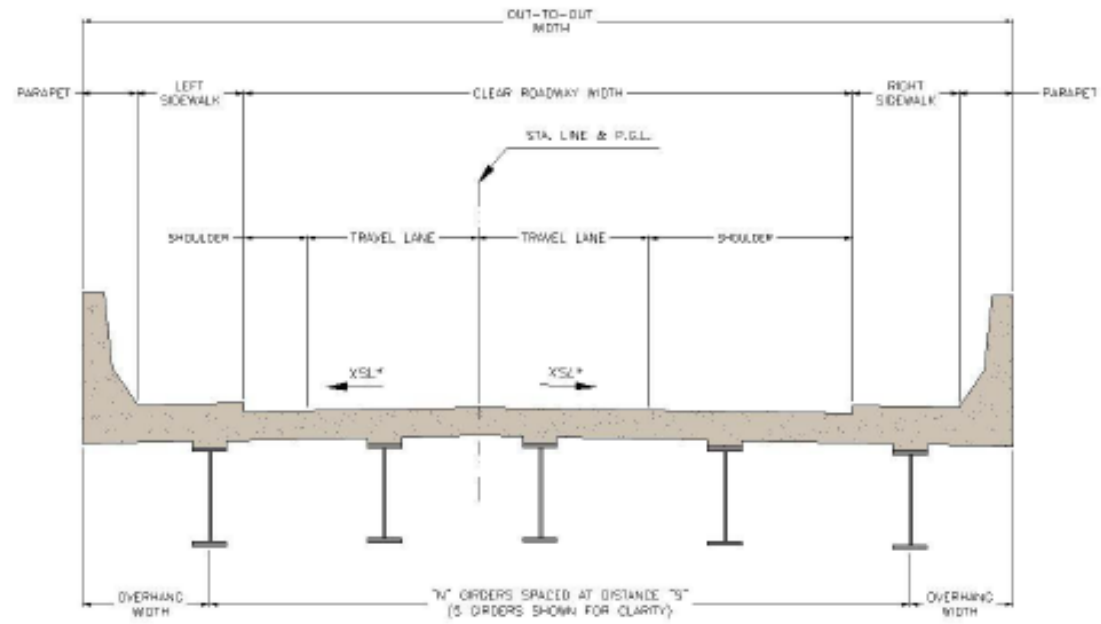

NOTES:

1. For shear stud spacing, see Girder Elevations.

2. Parapets per state DOT requirements, if cast in place, provide $2^{2}-0^{-}$lap with transverse bars.

NOTE: XSL - Cross slope can vary from $-06 \%$ to $+.06 \%$

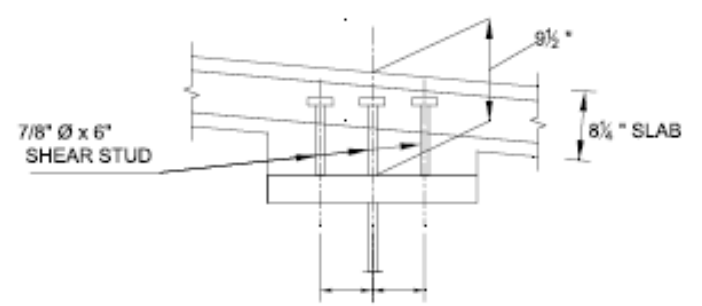

DETAILA

O 2013 Short Span Steel Bridge Allanoe and eSPAN140 | www. ShortSpansteeleridge6. org | www.eSPAN140.com 
Deck Design

ตรeñ

1

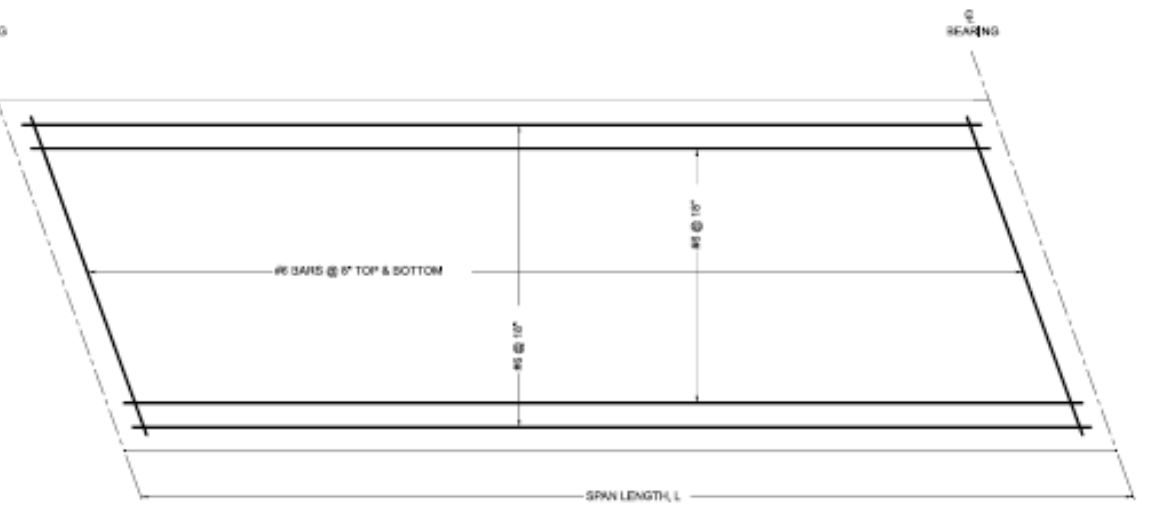

REINFORCING PLAN

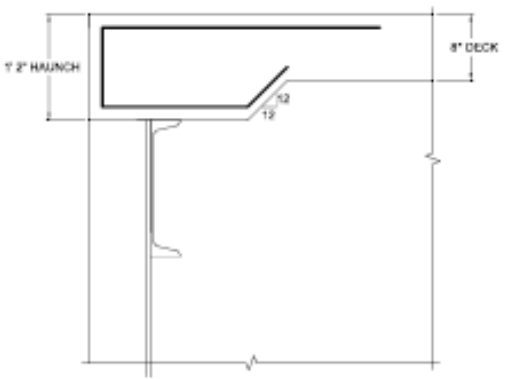

HAUNCH DETALL
NOTES:

1. Forming brackets must extend to bottom flange. 
COMPOSITE PLATE GIRDERS - 8' 10.15" GIRDER SPACING, HOMOGENEOUS

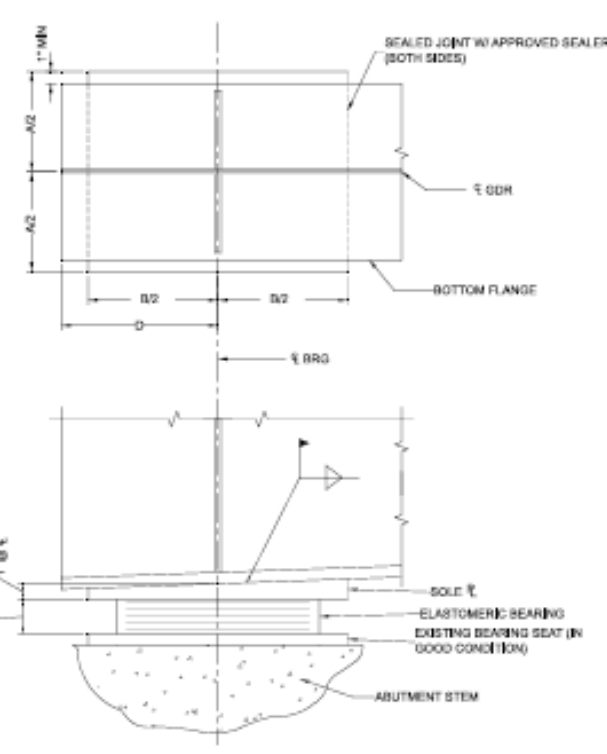

BEARING ELEVATION OPTION *A*
(N.T.S.)
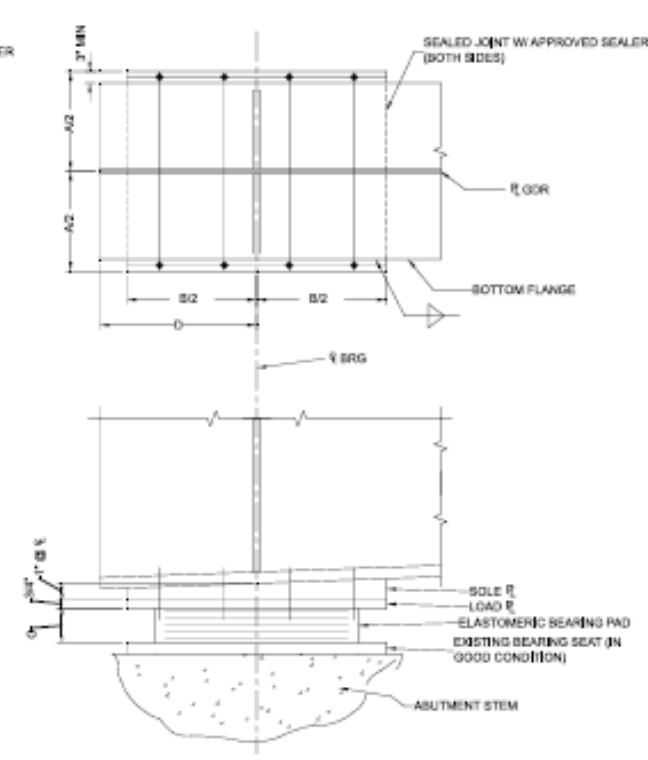

BEARING ELEVATION
OPTION E:

\section{NOTES:}

1. Bevel sole $\mathcal{R}$ if grade exceeds $\pm 1 \%$.

2. Max Grade is $\pm 5 \%$.

Sole $\mathrm{R}$ to be factory vulcanized to elastomeric

4. Holes to be $11 / 16^{*} \varnothing$ in sole $\left\{\right.$ for $7 / 8^{*} \varnothing$ bolt.

5. All elastomeric cover layers are 1/4" thick.

\section{COMMENTARY:}

1. Care must be exercised with the field welding. The temperature of the steel adjacent to the bearing
must be kept below $250^{\circ} \mathrm{F}\left(120^{\circ} \mathrm{C}\right)$. Temperature crayons should be used to monitor the steel temperature during welding.

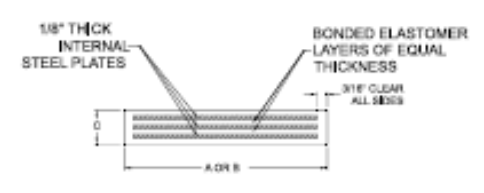

SECTION VIEW OF ELASTOMERIC BEARING

\begin{tabular}{|c|c|c|c|c|c|}
\hline \multicolumn{6}{|c|}{ ELASTOMETRAC BEARING DETALS - In } \\
\hline \multirow{2}{*}{ A } & \multirow{2}{*}{ B } & \multirow{2}{*}{ c } & \multirow{2}{*}{ D } & \multicolumn{2}{|c|}{ WIERWAL ELASTOMER LAYERS } \\
\hline & & & & MO. OF LAYERS & THICKNESS - In \\
\hline $14^{-}$ & $16^{\circ}$ & $3.125^{\circ}$ & $12^{\prime}$ & 4 & $0.5^{\prime \prime}$ \\
\hline
\end{tabular}


COMPOSITE ROLLED BEAM - 8' 10.15" GIRDER SPACING, LIGHTEST WEIGHT
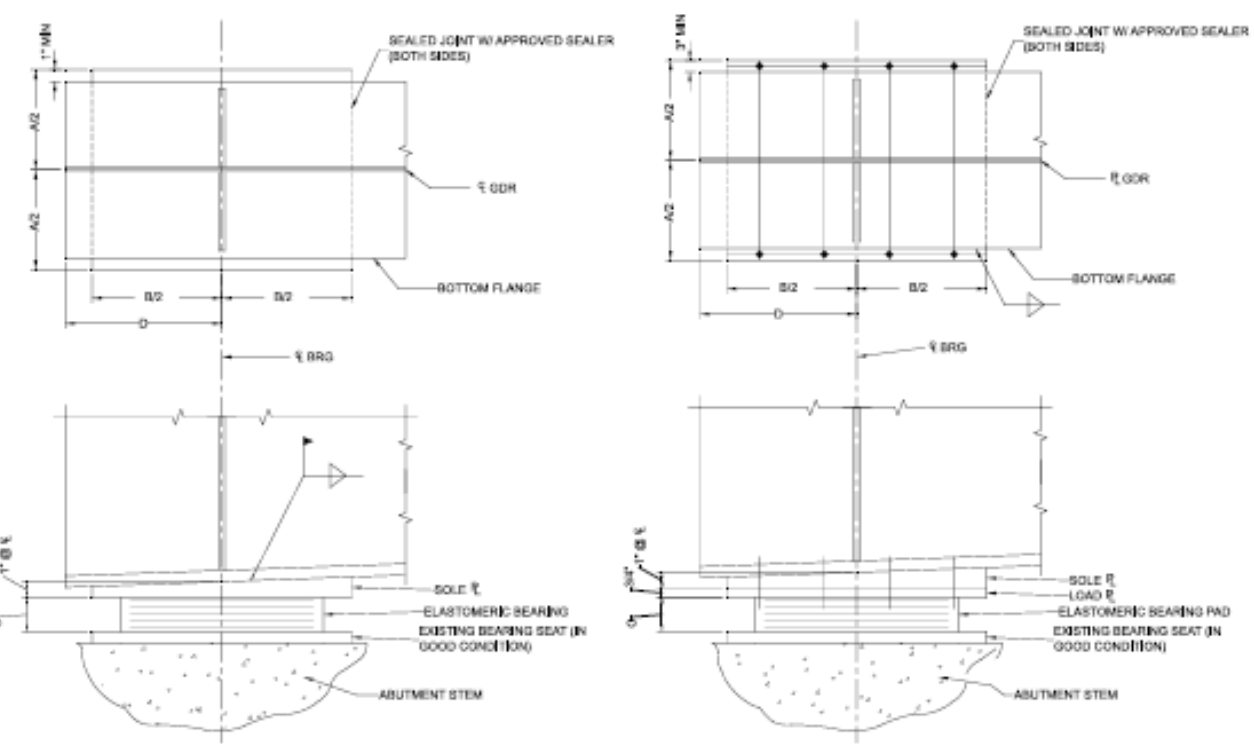

\section{NOTES:}

1. Bevel sole $\mathrm{R}$ if grade exceeds $\pm 1 \%$

. Max Grade is $\pm 5 \%$.

Sole $\mathrm{P}$ to be factory vulcanized to elastomeric

. Holes to be $11 / 16^{-} \varnothing$ in sole $₹$ for $7 / 8^{*} \varnothing$ bolt

5. All elastomeric cover layers are $1 / 4 "$ thick.

\section{COMMENTARY:}

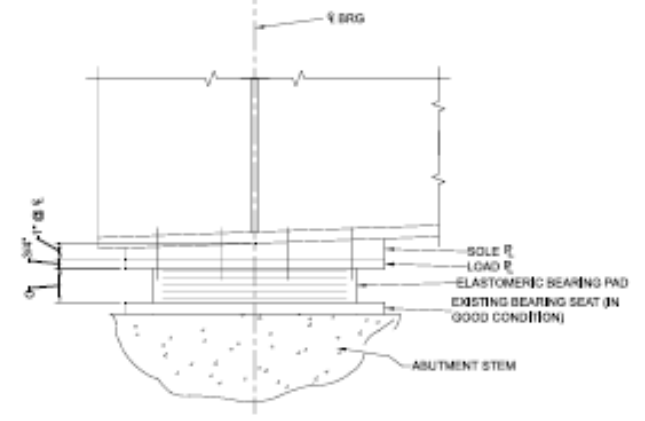

1. Care must be exercised with the field welding. The temperature of the steel adjacent to the bearing must be kept below $250^{\circ} \mathrm{F}\left(120^{\circ} \mathrm{C}\right)$. Temperature crayons should be used to monitor the steel temperature during welding.

BEARING ELEVATION

BEARING ELEVATION

(N.T.T.S)

कPTT.S.)

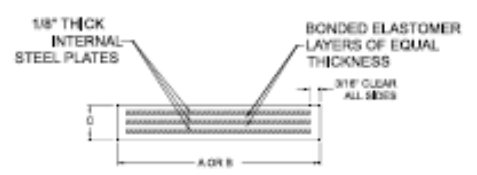

SECTION VIEW OF ELASTONERIC BEARING

\begin{tabular}{|c|c|c|c|c|c|}
\hline \multicolumn{6}{|c|}{ ELASTOMETRIC BEARING DETAILS - In } \\
\hline \multirow{2}{*}{ A } & \multirow{2}{*}{ B } & \multirow{2}{*}{ c } & \multirow{2}{*}{ D } & \multicolumn{2}{|c|}{ WTERNAL ELASTOMER LAYERS } \\
\hline & & & & MO. OF LAYERS & THICKNESS - In \\
\hline $14^{-}$ & $16^{*}$ & $3.125^{\circ}$ & $12^{\prime \prime}$ & 4 & $0.5^{\prime \prime}$ \\
\hline
\end{tabular}

O 2013 Short Span Steel Brdge Allance and ESPAN140 | www.ShortSpanSteel|rridge6. org | www.eSPAN140.com 
COMPOSITE ROLLED BEAM - 8' 10.15" GIRDER SPACING, LIMITED DEPTH

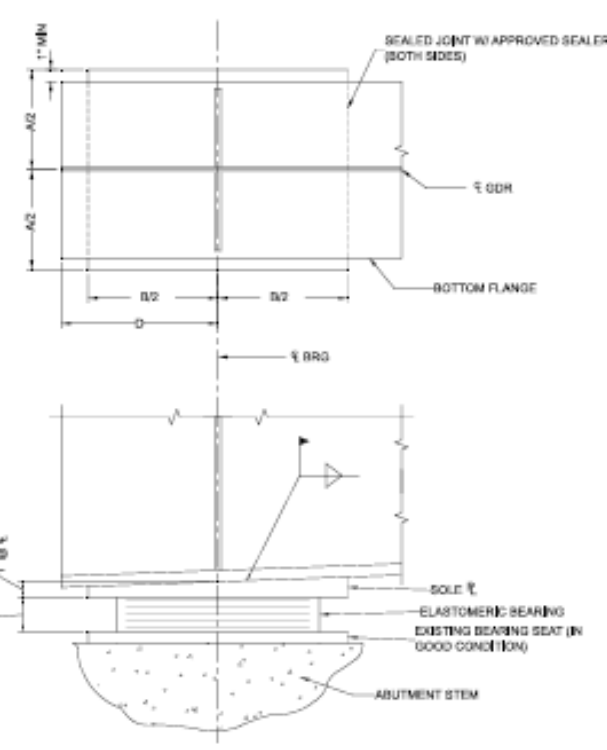

BEARING ELEVATION

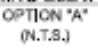
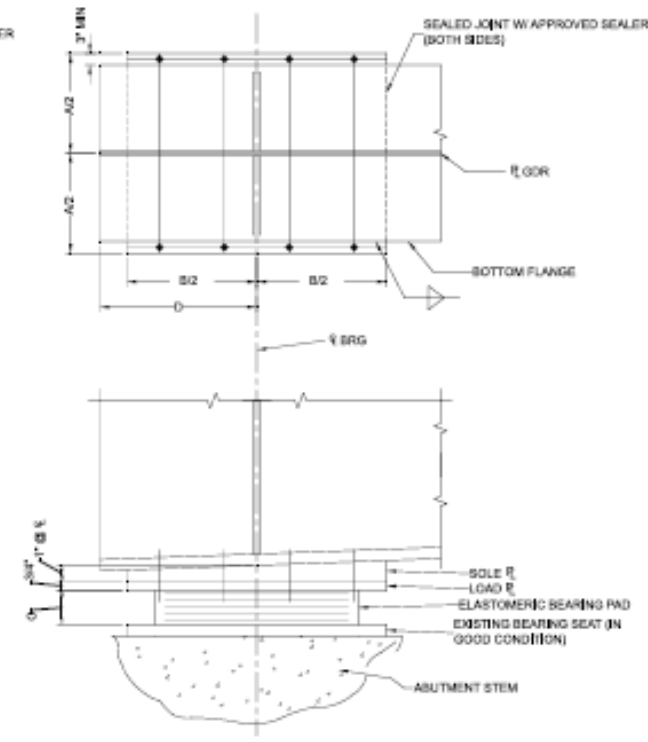

BEARING ELEVATION

\section{NOTES:}

1. Bevel sole $\mathbb{R}$ if grade exceeds $\pm 1 \%$.

2. Max Grade is $\pm 5 \%$.

Sole $\mathrm{R}$ to be factory vulcanized to elastomeric

4. Holes to be $11 / 16^{-} \varnothing$ in sole $\left\{\right.$ for $7 / 8^{*} \varnothing$ bolt

5. All elastomeric cover layers are $1 / 4 "$ thick.

\section{COMMENTARY:}

1. Care must be exercised with the field welding. The temperature of the steel adjacent to the bearing crayons should be used to monitor the steel temperature during welding.

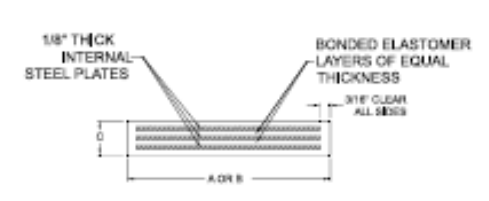

SECTION VIEW OF ELASTOMERIC BEARING

\begin{tabular}{|c|c|c|c|c|c|}
\hline \multicolumn{6}{|c|}{ ELASTOMETRIC BEARING DETAILs - In } \\
\hline \multirow{2}{*}{ A } & \multirow{2}{*}{ B } & \multirow{2}{*}{ c } & \multirow{2}{*}{ D } & \multicolumn{2}{|c|}{ WTERNAL ELASTOMER LAYERS } \\
\hline & & & & MO. OF LAYERS & THICKNESS - In \\
\hline $14^{-}$ & $16^{*}$ & $3.125^{*}$ & $12^{\prime}$ & 4 & $0.5^{n}$ \\
\hline
\end{tabular}




\section{Standard Design and Details of Corrugated Steel Pipe and Structural Plate Solutions}


Single-Radius Arch $15 \times 5.5$
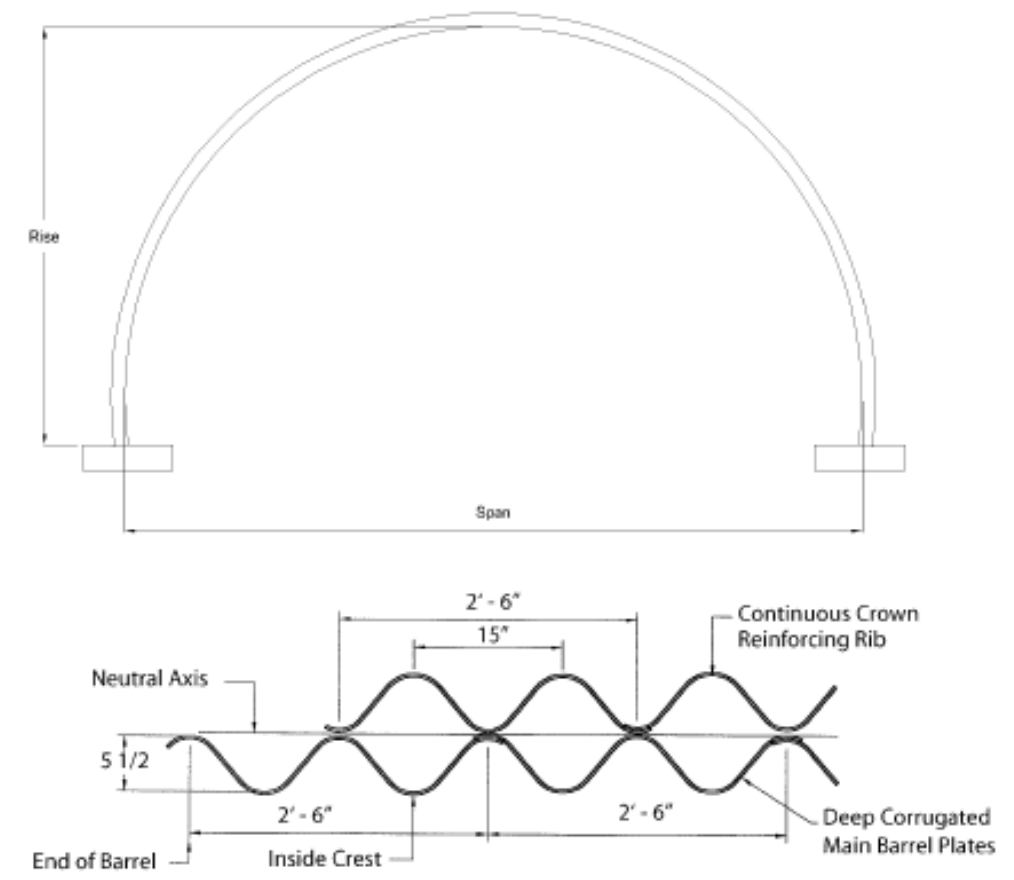

\section{MINIMUM COVER}

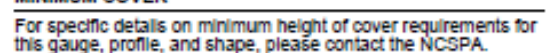

MAXIMUM COVER

For specinc detals on maximum height of cover reguirements for

\begin{tabular}{|c|c|c|c|c|}
\hline \multirow{2}{*}{ SPAN $-\mathrm{tt}-\mathrm{In}$} & \multirow{2}{*}{ RISE - $\mathrm{ft}$ - In } & \multirow{2}{*}{$\begin{array}{l}\text { WATERWAY } \\
\text { AREA }-n^{2}\end{array}$} & \multicolumn{2}{|c|}{ RADIUS - In } \\
\hline & & & Rt & Rs \\
\hline $66^{\prime \prime} 3^{\prime \prime}$ & $33^{\prime} 1^{\prime \prime}$ & $1722^{\prime}$ & $33^{\prime} 2^{\prime}$ & 78 \\
\hline
\end{tabular}

O 2013 Short Span Steel Bridge Allance and ESPAN140 | www.ShortSpan Steelerridge6. org | www.eSPAN140.com 

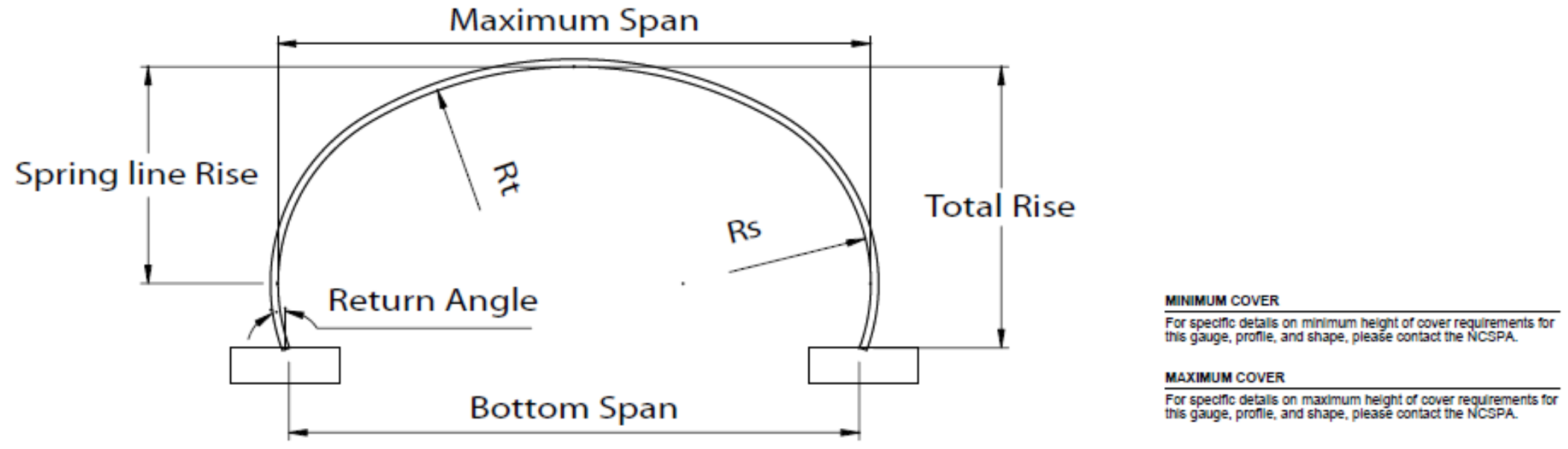

\begin{tabular}{|c|c|c|c|c|c|c|}
\hline \multirow{2}{*}{ SPAN - It - In } & \multirow{2}{*}{ RUSE $-\boldsymbol{t}$ - In } & \multirow{2}{*}{$\begin{array}{l}\text { BOTTOM SPAN - } \\
\pi-\ln \end{array}$} & \multirow{2}{*}{$\begin{array}{l}\text { WATERWAY } \\
\text { AREA }-\pi^{2}\end{array}$} & \multicolumn{2}{|c|}{ RADIUS - In } & \multirow{2}{*}{ RETURN ANGLE } \\
\hline & & & & Rt & $R c$ & \\
\hline $65^{\prime} 7^{\prime \prime}$ & $20^{\prime} 6^{\circ}$ & $65^{\prime} 4^{\prime \prime}$ & 1055..$^{\prime}$ & $548^{\circ}$ & $135^{\circ}$ & 8.6 \\
\hline
\end{tabular}

O 2013 Short Span Steel Bridge Allanoe and ESPAN140 | www.ShortSpanSteeleridge6. org | www.eSPAN140.com 

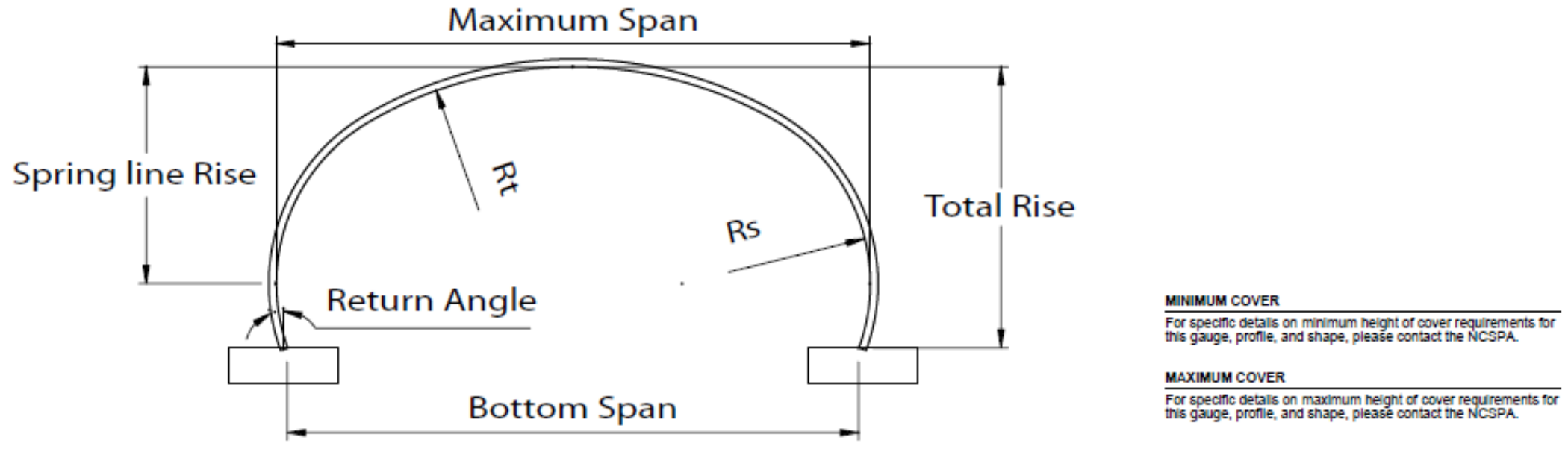

\begin{tabular}{|c|c|c|c|c|c|c|}
\hline \multirow{2}{*}{ SPAN - it - In } & \multirow{2}{*}{ RISE $-\boldsymbol{n t}$ - In } & \multirow{2}{*}{$\begin{array}{c}\text { BOTrOM SPAN - } \\
\pi-\ln \end{array}$} & \multirow{2}{*}{$\begin{array}{l}\text { WATERWAY } \\
\text { AREA }-\pi^{z}\end{array}$} & \multicolumn{2}{|c|}{ RADIUS - In } & \multirow{2}{*}{ RETURN ANGLE } \\
\hline & & & & Rt & $\mathrm{Re}$ & \\
\hline $65^{\prime} 7^{\prime \prime}$ & $24^{\prime} 4^{*}$ & $65^{\prime} 4^{\prime \prime}$ & $1293.5^{\prime}$ & $548^{\circ}$ & $214^{-}$ & 7 \\
\hline
\end{tabular}

O 2013 Short Span Steel Bridge Allanoe and ESPAN140 | www.ShortSpanSteeleridge6. org | www.eSPAN140.com 


\section{Manufacturer's Steel Solutions - Customized Solutions from Members of the Short Span Steel Bridge Alliance}

To obtain budget estimates or pricing information, contact a Short Span Steel Bridge Alliance Fabricator (see sections IV and VI in the Solutions Book for contact information). 


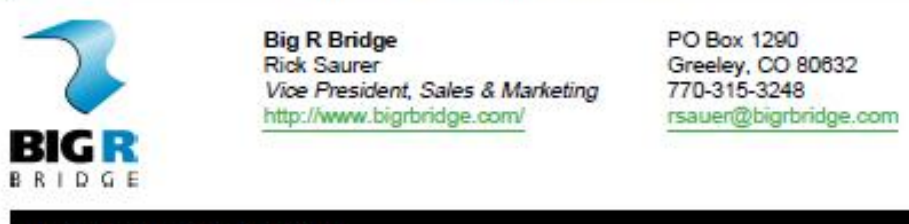

Big R Bridge is a world leader in developing innovative engineered solutions in Prefabricated Bridges, Structural Plate, MSE Wall Systems and Corrugated Pipe for the transportation, public works, raikway. mining, forestry and development sectors. By design, our custom infrastructure solutions are easy to ship and install with minimal equipment and labor requirements, making them ideal even in remote locations. Big R's Technical Sales Representatives and Engineers are well-positioned to ensure your project's success through every phase. With product innovation, in-house engineering strength

Vehicular Modular Bridges

Vehicular Modular Bridges

As the name suggests, these bridges are manufactured and shipped in modular sections that allow As the name suggests, these bridges are manufactured and shipped in modular sections that allow
for rapid instaliation. Using equipment on hand, local crews can typically place the superstructure in
one day-reducing costs and road closure time. Superstructures can be fabricated with both square and skewed ends to suit any site conditions. We also offer Portable Detour Bridges.

- Strong: able to withstand heavy-duty loading

-8 ' wide modules are typical
$-4.25^{\prime \prime}$ corrugated steel deck (galvanized) is standarc

- Decking options - poured or precast concrete, asphalt, grating, wood or grave

- Weathering. galvanized or painted structural stee

- Curb or rail system

on be added to enhance use

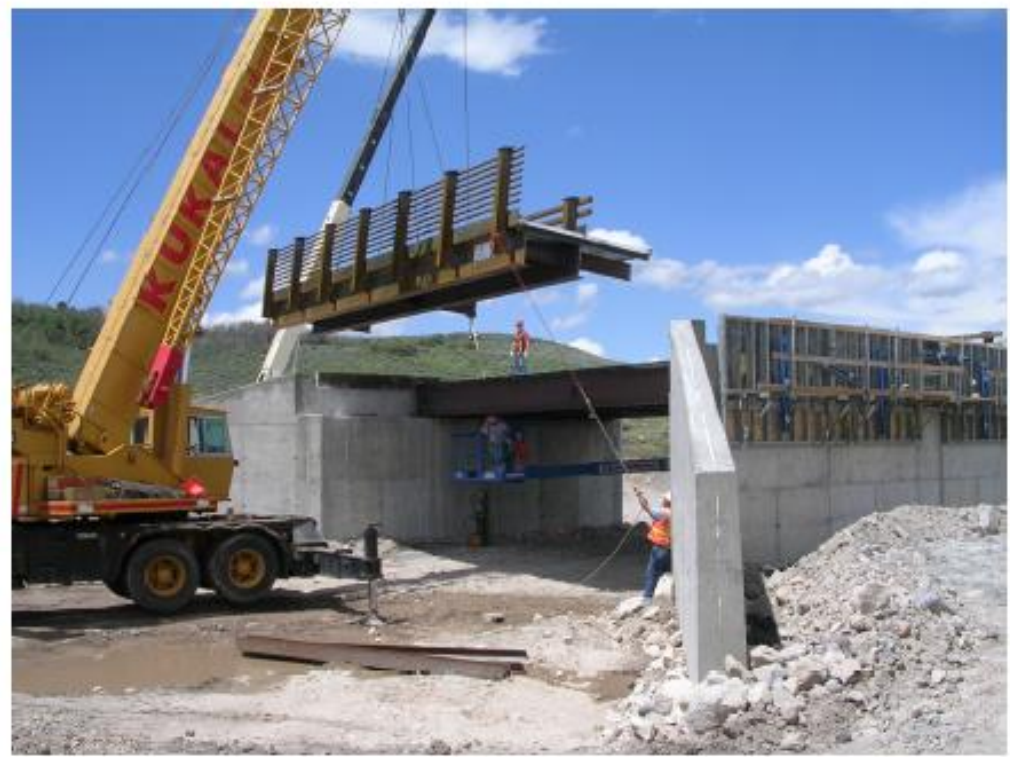


BIG

Big R Bridge

Vice President, Sales \& Marketing

hitip://Www. bigitbridge.com/

Greeley. CO 8063

rsauer(abigrbridge.com

Big R Bridge is a world leader in developing innovative engineered solutions in Prefabricated Bridges, Structural Plate, MSE Wall Systems and Cornugated Pipe for the transportation, public works, raikway. mining, forestry and development sectors. By design, our custom infrastructure solutions are easy to ship and install with minimal equipment and labor requirements, making them ideal even in remote locations. Big R's Technical Sales Representatives and Engineers are well-positioned to ensure your project's success through every phase. With product innovation, in-house engineering strength

Vehicular Modular Bridges

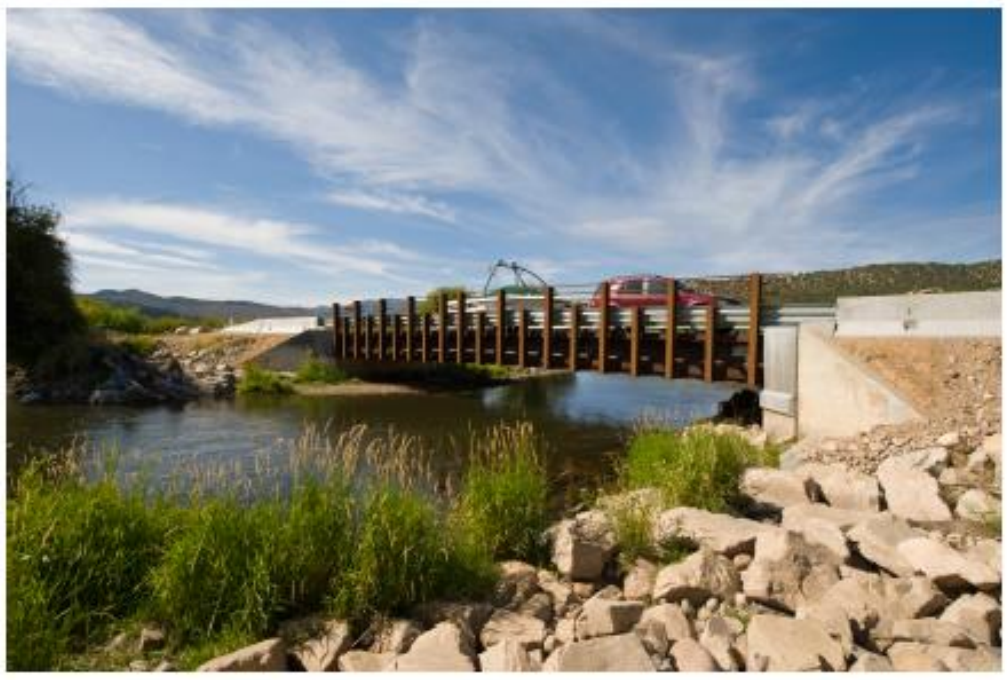

O 2013 Short Span Steel Brdge Allanoe and ESPAN140 | www. ShortSpan Steeleridge6. org | www. ESPAN140.com 


\begin{tabular}{|c|c|c|}
\hline Â Truenocthsecel & $\begin{array}{l}\text { TrueNorth Steel } \\
\text { Jamie Holzberger } \\
\text { Area Manager, Bridge } \\
\text { hitp://www. truenorthsteel.com/ }\end{array}$ & $\begin{array}{l}5405 \text { Momont Road } \\
\text { Missoula, MT } 59808 \\
\text { 406-532-7126 } \\
\text { Jamie.Holzberger(a) TrueNorth Steelicom }\end{array}$ \\
\hline
\end{tabular}

TrueNorth Steel designs reliable steel Structures, Tanks, Corrugated Pipe and Bridges you can count on to always be on time and delivered to the highest quality standards.

\section{TrueNorth Steel Bridges \& Corrugated Steel Pipe}

Built to AASHTO specifications TrueNorth Steel Bridge provides safe passage for pedestrians and all types of venicles. Wh decaderibitide buing experience, we ve developed a design-buld, botunique application, while delivering safety, durabilty and asy intion. In addition to the bridges me offer preengineered and prefabricated Supersil's and Bact-Walls to simplify and reduce bridges abutment construction and design costs.

TrueNorth Steel Corrugated Pipe has been a critical part of north America's evolving infrastructure for more than six decades. Our corrugated steel pipe offers tremendous durability and stability for casing, architecture and nearly and drainage and water flow application.

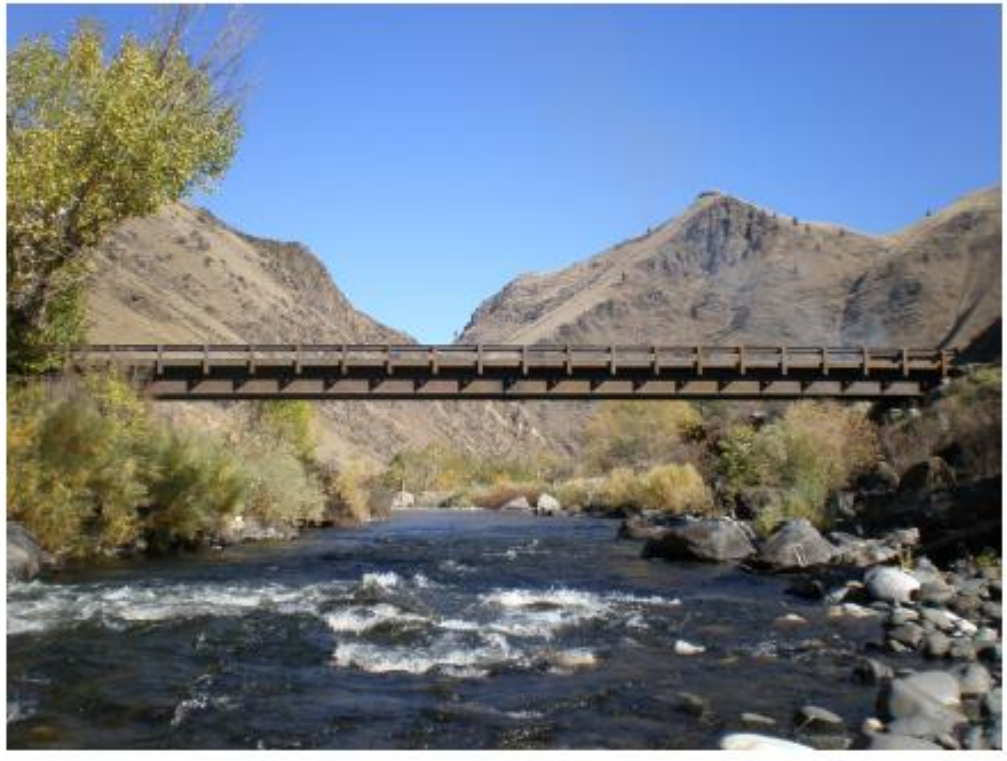




\begin{tabular}{|c|c|c|}
\hline Â Truenoethstesel & $\begin{array}{l}\text { TrueNorth Steel } \\
\text { Jamie Holzberger } \\
\text { Area Manager, Bridge } \\
\text { hittp://wwww.truenorthsteel.com/ }\end{array}$ & $\begin{array}{l}5405 \text { Momont Road } \\
\text { Missoula, MT } 59808 \\
\text { 406-532-7126 } \\
\text { Jamie.Holzberger@T TrueNorthSteel.com }\end{array}$ \\
\hline
\end{tabular}

TrueNorth Steel designs reliable steel Structures, Tanks, Corrugated Pipe and Bridges you can count on to always be on time and delivered to the highest quality standards.

TrueNorth Steel Bridges \& Corrugated Steel Pipe
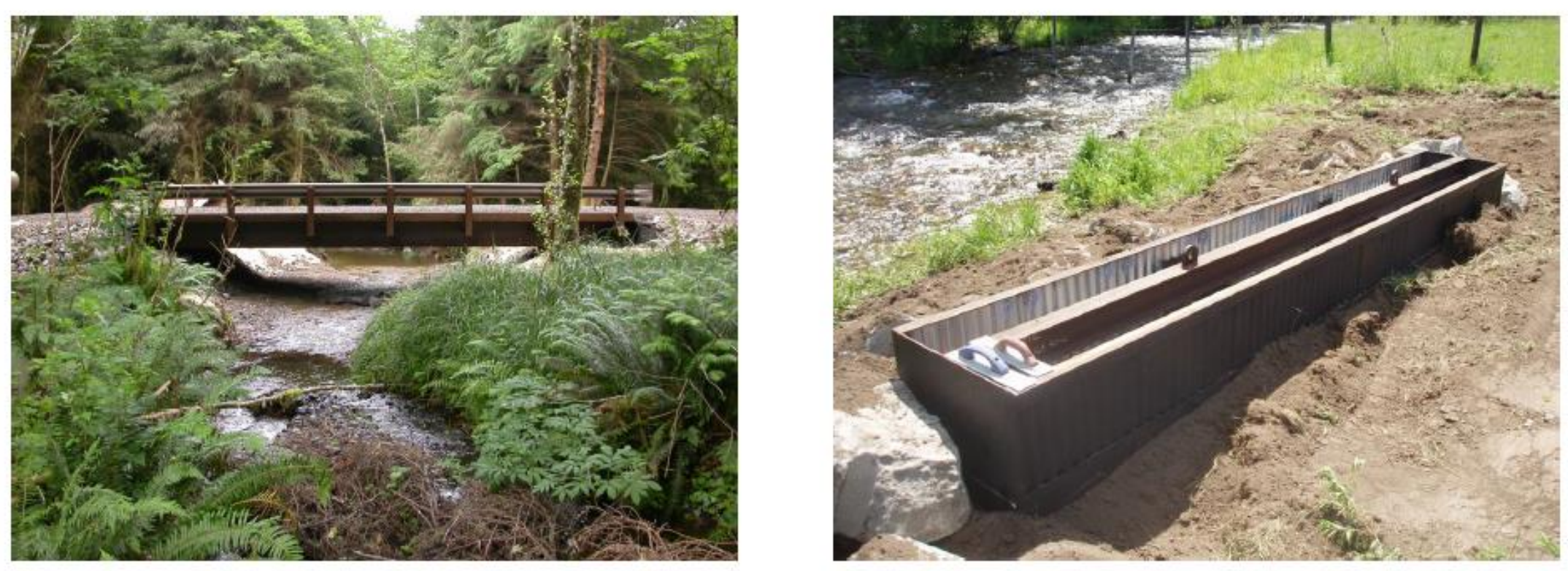

O2013 Short Span Steel Bndoge Alllance and eSPAN140 | www. ShortSpanSteelEridge6.org | www.eSPAN140.00m 27 


\begin{tabular}{lll} 
Wheeler & $\begin{array}{l}\text { Wheeler } \\
\text { David Clemens } \\
\text { Sales Manager, Highway }\end{array}$ & 9330 James Avenue South \\
& Bloomington, MN 55431 \\
& www.wheeler-con.com & $952-929-7854$ \\
\hline
\end{tabular}

Wheeler's Steel Fabrication Division is an extension of the experience gained by $100+$ years of designing \& supplying bridge materials. We have a staff of Professional Engineers \& draters who provide detailed plans specific to each project. Wheeler maintains AlsC certification for simple and applications. The bridges are shop manufactured, detailed \& shipped to site ready for installation.

\section{Steel Stringer Vehicle Bridges Utilizing Transverse Treated Timber Deck Panels}

Treated timber deck panels provide a versatile option as prefabricated bridge components. The deck panels are a good compliment to steel stinger superstructures. The combination res

The deck panels can be designed for all loading conditions (ie. HS20, HS25, HL93, U80, U102). The panel thickness is based on loading condition and stringer spacing.

The deck panels are custom detailed to the specific application. Individual deck laminae are fabricated and pressure treated before being assembled into the panels. This enhances the long
term durability of the deck system. Multiple attachment systems can be used to connect the panels to the steel stringers. As they are installed the panels are interconnected to provide load transfer improving the pertormance of an asphalt overlay wear surface.

Crash-tested timber railing kits attach directly to the deck panels. Pedestrian railings are available.

Advantages:

Components are largely preassembled and sized for easy handling

Shop fabricted to contol quality

Speeds installation at the site

Aocepts traffic immediately after installation

Not temperature sensitive, no curing time

Ideal for remote sites

Treatment is water resistant, not susceptible to damage from road salt

Multiple wear surface options including asphalt

Compatible with crash-tested railing system

Wheeler provides complete superstructure plans for all projects supplied. All hardware is included. Foundation designs are available depending on site conditions.

Contact us for project specific pricing and application advice.

Set your project apart with a bridge from Wheeler.

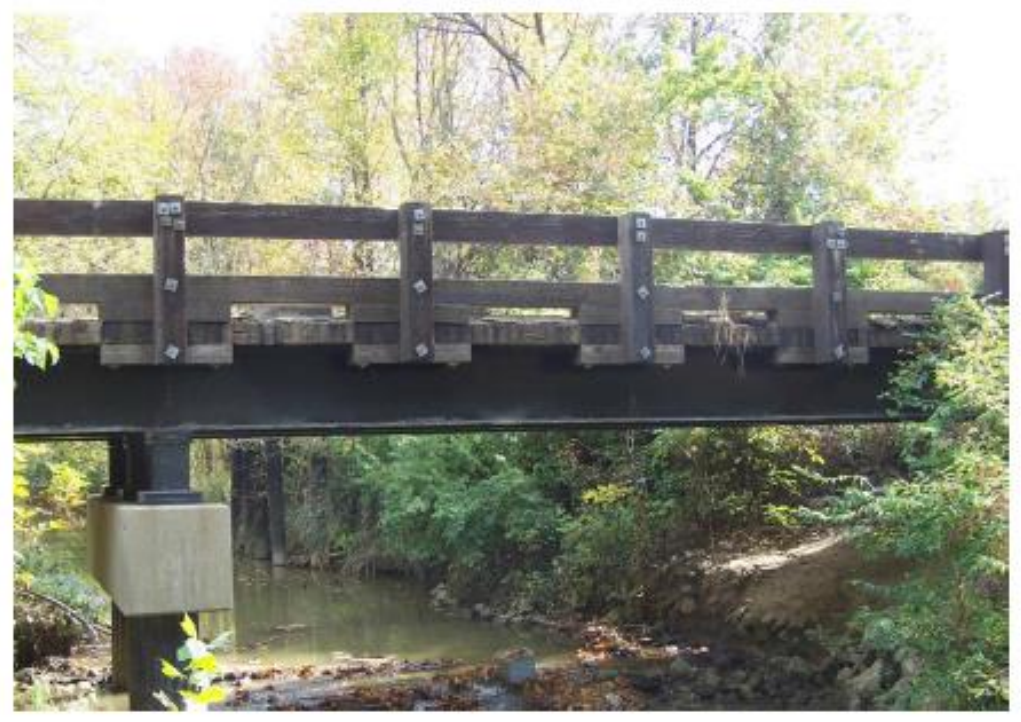




\begin{tabular}{lll} 
& Wheeler & 9330 James Avenue South \\
Wheeler & $\begin{array}{l}\text { David Clemens } \\
\text { Sales Manager, Highway }\end{array}$ & Bloomington, MN 55431 \\
& www.wheler-con.com & $952-929-7854$ \\
\hline
\end{tabular}

Wheeler's Steel Fabrication Division is an extension of the experience gained by $100+$ years of designing \& supplying bridge materials. We have a staff of Professional Engineers \& drafters who provide detailed plans specific to each project. Wheeler maintains AISC certification for Simple and Major Steel Bridges. Prefabricated bridge kits provide rapid construction for recreation \& vehicular
applications. The bridges are shop manufactured, detailed \& shipped to site ready for installistion.

Steel Stringer Vehicle Bridges Utilizing Transverse Treated Timber Deck Panels
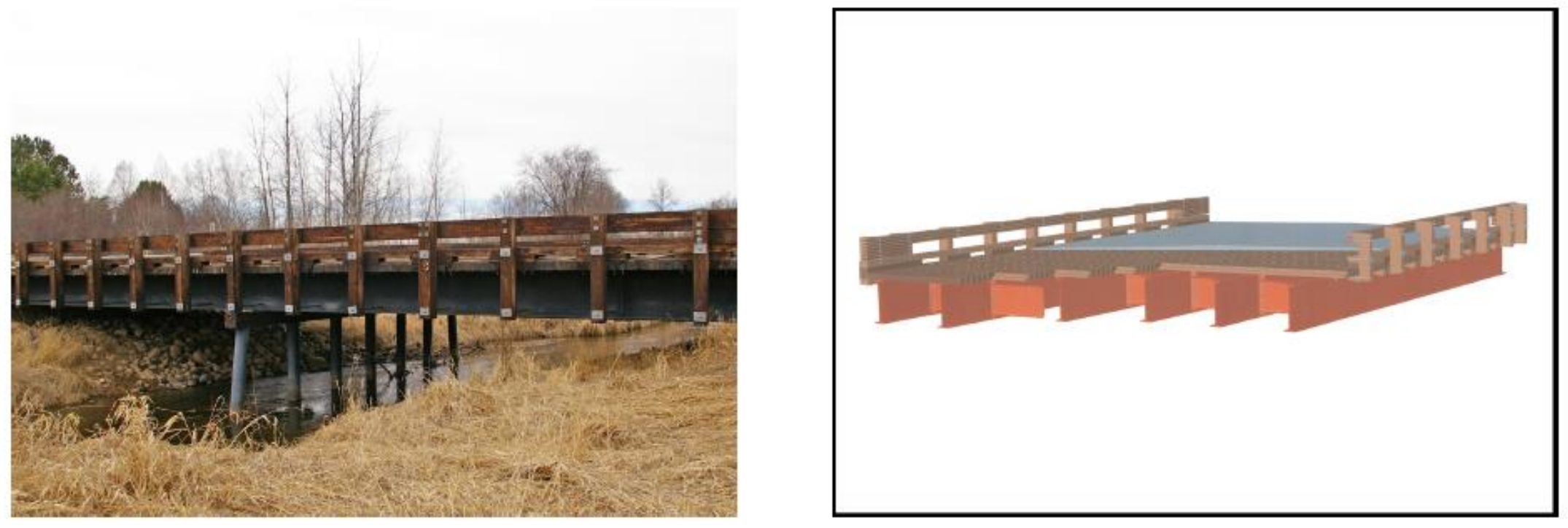

O 2013 Short Span Steel Bridge Allance and ESPAN140 | www. ShortSpan Steelerildge6. org | www.eSPAN140.com 


\section{Durability Solutions}




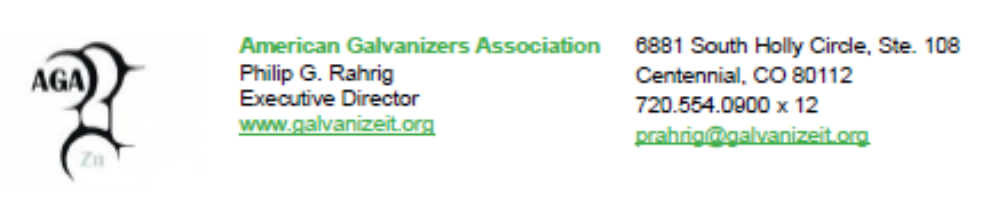

Hot-Dip Galvanizing

\section{The Process}

Hot-dip galvanizing (HDG) is the process whereby fabricated steel, structural steel, or small parts, including fasteners, are immersed in a kettle or vat of molten zinc, resulting in a metallurgically bonded alloy coating that protects the steel from corrosion. Galvanizing forms a metallurgical bond between the zinc and the underlying steel or iron, creating a barrier that is part of the metal itseff. During galvanizing, the molten zinc reacts with the surface of the steel or iron article to form a series process naturally produces costings that are at least as thick at the corners and edges as the on the rest of the article. Because the galvanizing process involves total immersion of the material, al surfaces are coated.

\section{How Hot-Dip Galvanizing Works}

Galvanizing takes place in a factory regardless of weather or humidity conditions and is available $24 / 7 / 385$ in close proximity to most new bridge locations. Freshly galvanized steel progresses through a natural weathering process to develop a corrosion resistant patina made up of zinc-oxide, zinc-hydroxide, and zinc carbonate. Typically, it takes approximately $6-12$ months to fully develop. Because the comsion rate of zinc is approximattely 20 ippes less than that for black steel, the HDG

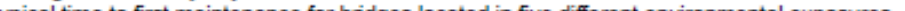

Economics and Life-cycle Cost

HDG is typically very similar and often lower in initial cost than most other corrosion protection systems considered for steel bridges and because it requires zero maintenance for 75 years or more. the life-cycle cost is typically 4 to 8 times less.

\section{Natural and Sustainable Zinc}

Zinc is found everywhere in daily life: in every cell of the human body, in the earth, in food and in products consumer products (sunblock, automobiles, cosmetics, airplanes, applianoes, surgical tools.
Founded in 1935, the American Galvanizers Association (AGA) is a non-profit trade association dedicated to serving the needs of fabricators, architects, specifiers, and engineers, providing technica support on today's innovative applications and state-of-the-art technological developments in hot-dip. galvanizing for corrosion control. The AGA maintains a large technical library, provides multimedia
seminars, and offers a toll-free technical support hotline to assist specifiers in North America.

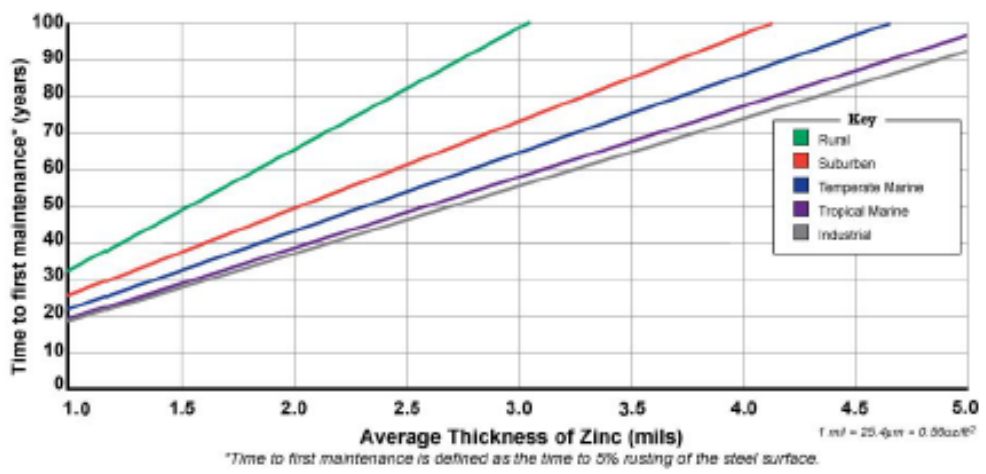

The U.S. Recommended Daily Allowance is 15 milligrams of zinc.Zinc is $100 \%$ recyclable and over $80 \%$ of the zinc available for recycling is currently recycled. For more information, click on httro-//hwww. galvanizeit.orglabout-hot-dip-galvanizinglis-hdo-sustainable

\section{Bridge Projects}

HDG is commonly used on short-span bridges, especially when the bridge will be located in relatively corrosive environments such as above rivers and streams and in humid climates. To view examples of bridges utilizing HDG steel, click on hittp://galvanizeitorg/project-gallery/gallery (and select "sector" and then 'Bridge \&Highway) 


\begin{tabular}{|lll} 
& KTA-Tator, Inc. & 115 Technology Drive \\
Eric S. Kline & Pittsburgh, Pa. 15275 \\
Executive Vice President & $412.788 .1300, \times 206$ \\
whww kta.com & ekline. 1 hta.com
\end{tabular}

\section{Paint}

\section{Overview}

Constructing bridges extends back thousands of years. In a relative sense steel bridge construction is in its infancy. The first iron bridge was built in 1779 , while the first steel was used in a bridge in 1828 . Coated bridges from the 19th century survive today.

Conrosion protection via coatings is also an interrelated subject, i.e., in order to lower longer term Costs, coatings can be efficiently applied when new steel is in tie fatrication shop.

\section{Design Phase}

A comprehensive plan for successful corrosion protection and mitigation is needed from the inception of the project and consists of actions which continue throughout the life of the bridge. A plan is needed which includes decisions made duning the bridge design process. During this time, the site for the structure is identified. The extent of exposure to any detrimental environmental conditions should drive certain corrosion prevention design choices, such as: type of bridge, type of steel used; the details utilzed in developing the shape of members, types of secondary members, and their connections are but a few. The clearance and exposure beneath the structures must be carefully planned. In this process, a corrosion protection plan which provides long-term protection is devised.

Corrosion mitigation choices may vary somewhat; however, for exposure in corrosion prone areas of the country, the use of zinc on bare steel should be considered. American Galvanizers Association Coatings (www sspcovere environment with no paintards for surface preparation of steel and for the various zinc rich coatings. The American Galvanizers Association (AGA.galvaniteitorg) has information about the uses of galvanizing.

Appropriately selected and applied layers or coats of paint over the hot dip galvanize or thermal spray applied zinc or zinc-rich paint will extend the servioe life of the corrosion protection. The AGA refers to
these as duplex systems.

Since the first use of zinc rich primer coated steel in the late 1980 's thousands of zinc-rich primer coated steel bridges have survived for almost 50 years. These bridges are distributed across the country and are examples of permanently installed corrosion protection.
Installation

Even with a properly selected system to address the most challenging exposure, a system must stil be correctly installed, and the bridge must be buil and maintained! SSPC has detailed information about installation practices, specification and conducts training classes.

\section{Maintenance Completes the Process}

The comosion control effort begins with a comprehensive "corrosion review and

planning" prior to and during the bridge design process. Implementation of the plan during detailing painting, touch-up, and performing critical steps identified in a proper maintengnoe plan are the necessary items in the corrosion protection and mitigation plan. If the planning or maintenance are skipped, we are choosing to save resources in the short tem, but in doing $50 \mathrm{we}$ are consigning ourselves to pay more later on in earlier repairs.

As a reference, please see the included photo of untopcoated Zinc rich paint on the Golden Gate Bridge after $45+$ years. (Photo used with permission from Golden Gate Bridge, www goldengate org)

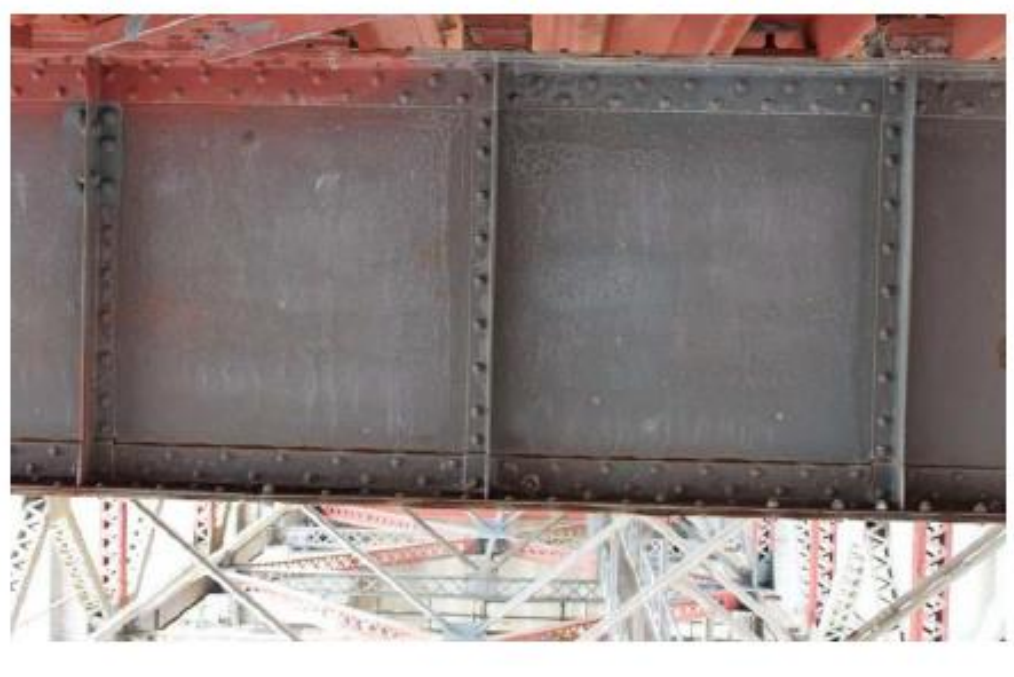




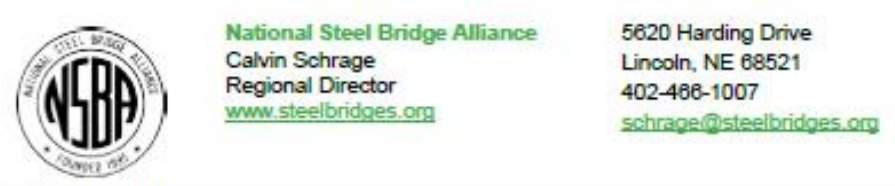

\section{Weathering Steel}

The following information is an excerpt from the National Steel Bridge Alliance's Steel Bridge Design Book. Please visit hitp: $/ /$ wwww. aisc.orglcontentNSBA aspx?id=20244 for the complete book.

Weathering steel is an important option for the bridge designer. The FHWA Technical Advisory

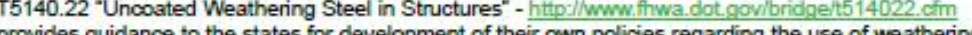
provides guidance to the states for development of their own policies regarding the use of weatherin steel. This document contains a digest of the primary benefits and concems regarding weatherin undergoing a review and rewrite; however, the majority of its content remains useful as a sarting

Weathering grade steels have been available for several decades. They have been produced in various proprietary chemistries; but essentially small amounts of copper, chromium, nickel and silicon are added to carbon steel to achieve an alloy with enhanced weathering properties. These steels wil form a rust patina when exposed to the environment providing a barner between the bare steel and the corrosive elements of the environment. When propenty detailed and exposed to enviranments that include cyclic weVdry exposures and do not introduce significant amounts of corrosive contaminants to the steel surface, this tightly adherent patina provides a weathering steel structure with its own

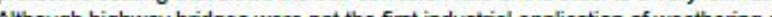
mid 1960's.

The primary benefit of weathering steel is the promise of long-term corrosion protection without the need for either initial or maintenance painting. The steel industry has made the point that weathering steel, when properly applied, results in a structure that provides first cost and life cycle cost savings. However, due to the assumption that all bridge expansion joints will eventually leak, current

guidelines require weashering steel bridge elements to be painted at non-integral beam ends to a

length of 1.5 times the girder depth. In addition, weathering steel girders are shop blasted to remove miliscale so that the initial protective
Extensive data exists regarding the corrosion performance of weathering steels. The following highlights conclusions taken from the pertinent data:

Weathering steel requires some amount of moisture and a wetdry weathering cycle over a period of time to develop a tighty adherent, protective oxide layer. However, excessive moisture or the presence of salt will disrupt this process and result in a structure that corrodes at an unacceptable (much higher) rate.

Nearly all of the reported failures of weathering steel on bridges have occurred in applications where the steel is wet for a significant portion of time or the steel is exposed to salt from the ocean or deicing operations.

Properly functioning weathering steel will corrode at a steady-state rate less than 0.3 mils per year ( 7.5 microns per year) Corrosion in excess of this rate indicates that weathering steel should not be used bare at that location.

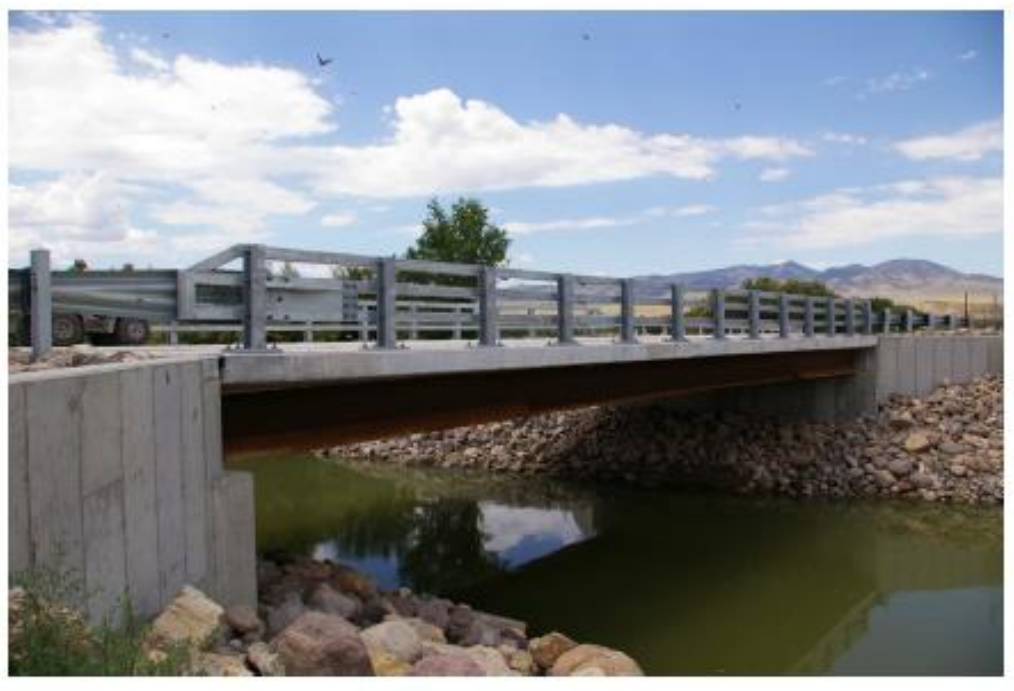




\section{Appendix B: V-65 Jesup South Bridge Plans}

The following appendix includes the plans for the V-65 Jesup South Bridge. It should be noted that the plans have been scaled down from their original $11 \times 17$ format to $81 / 2 \times 11$. 


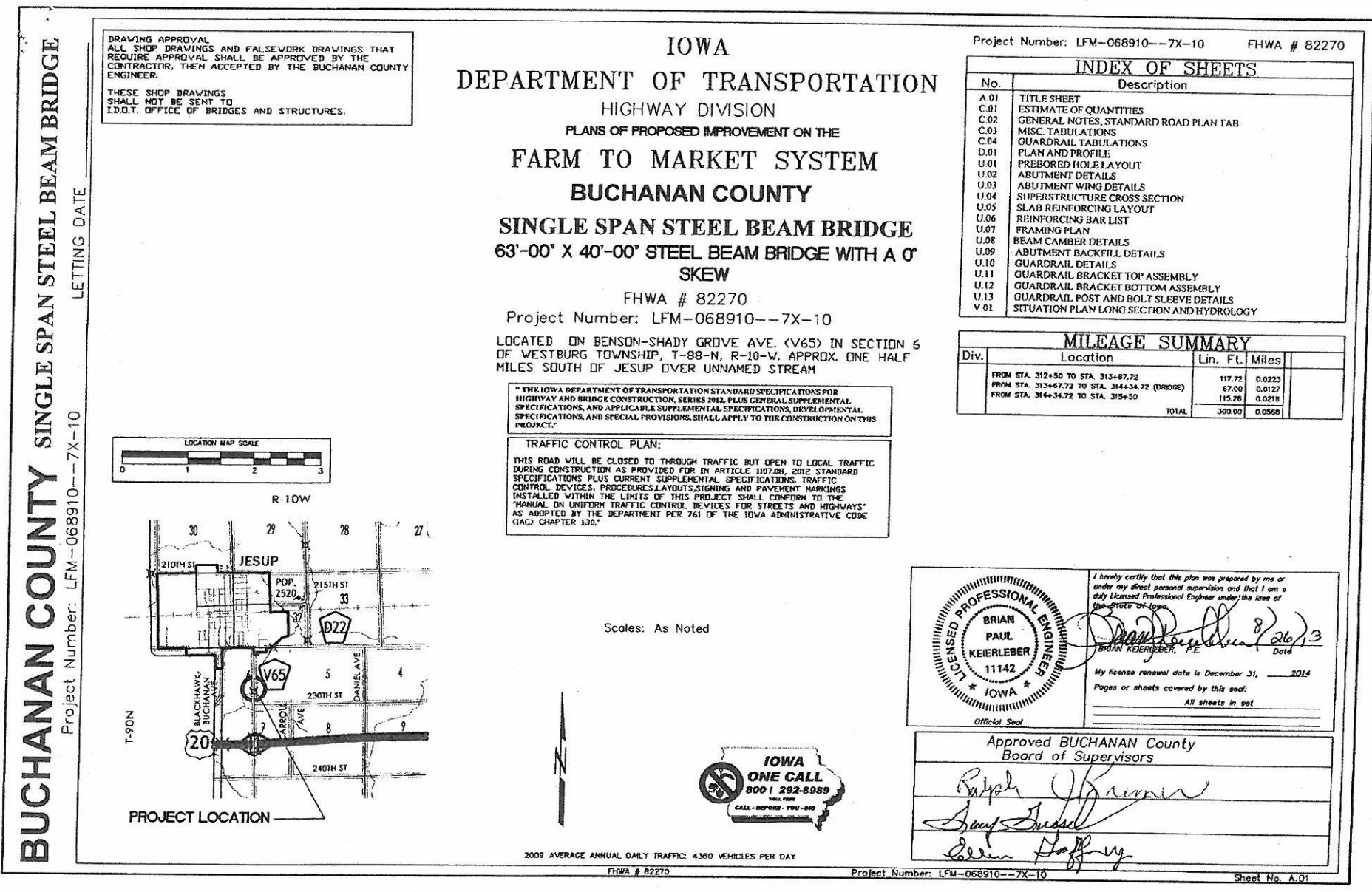




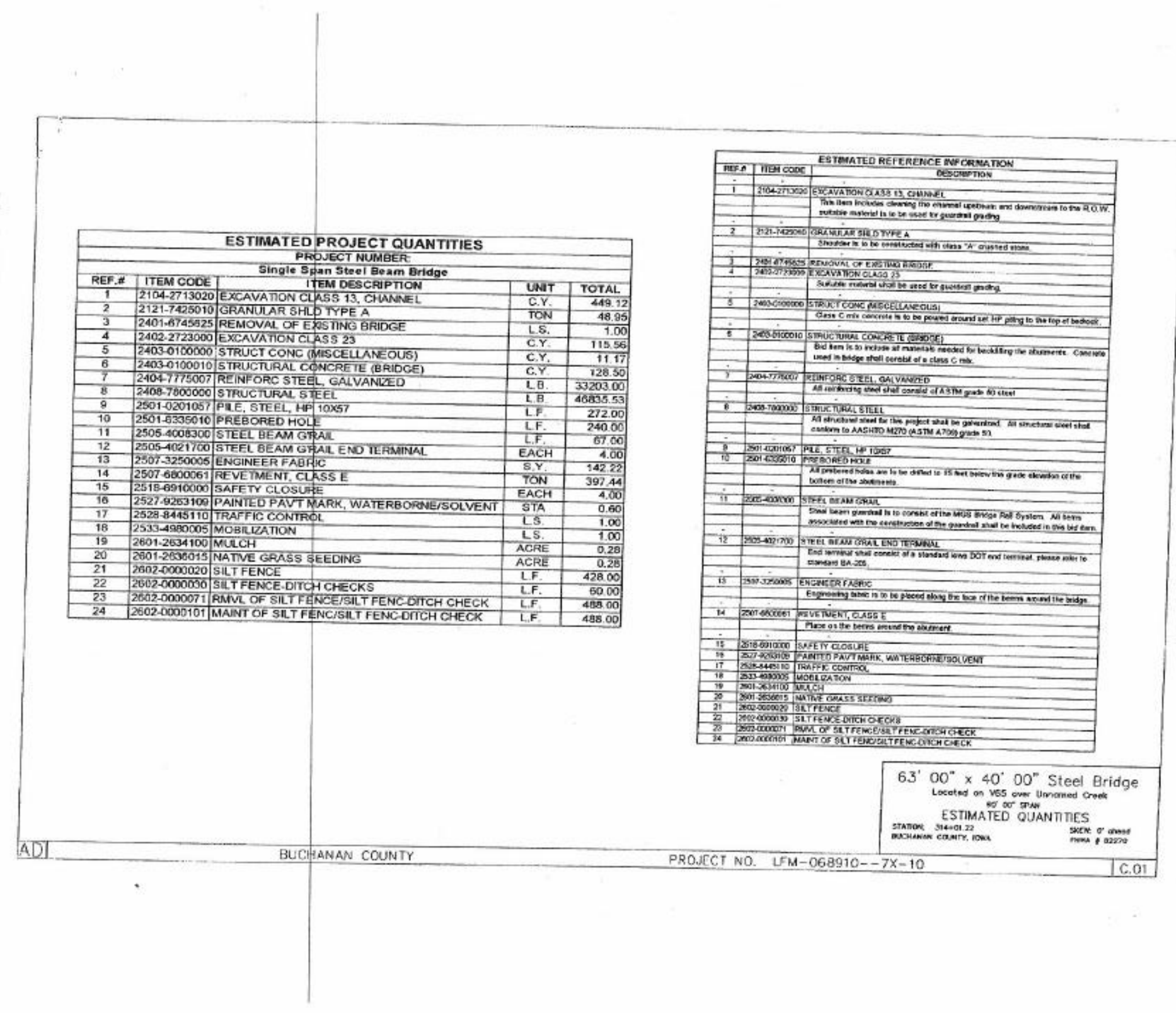




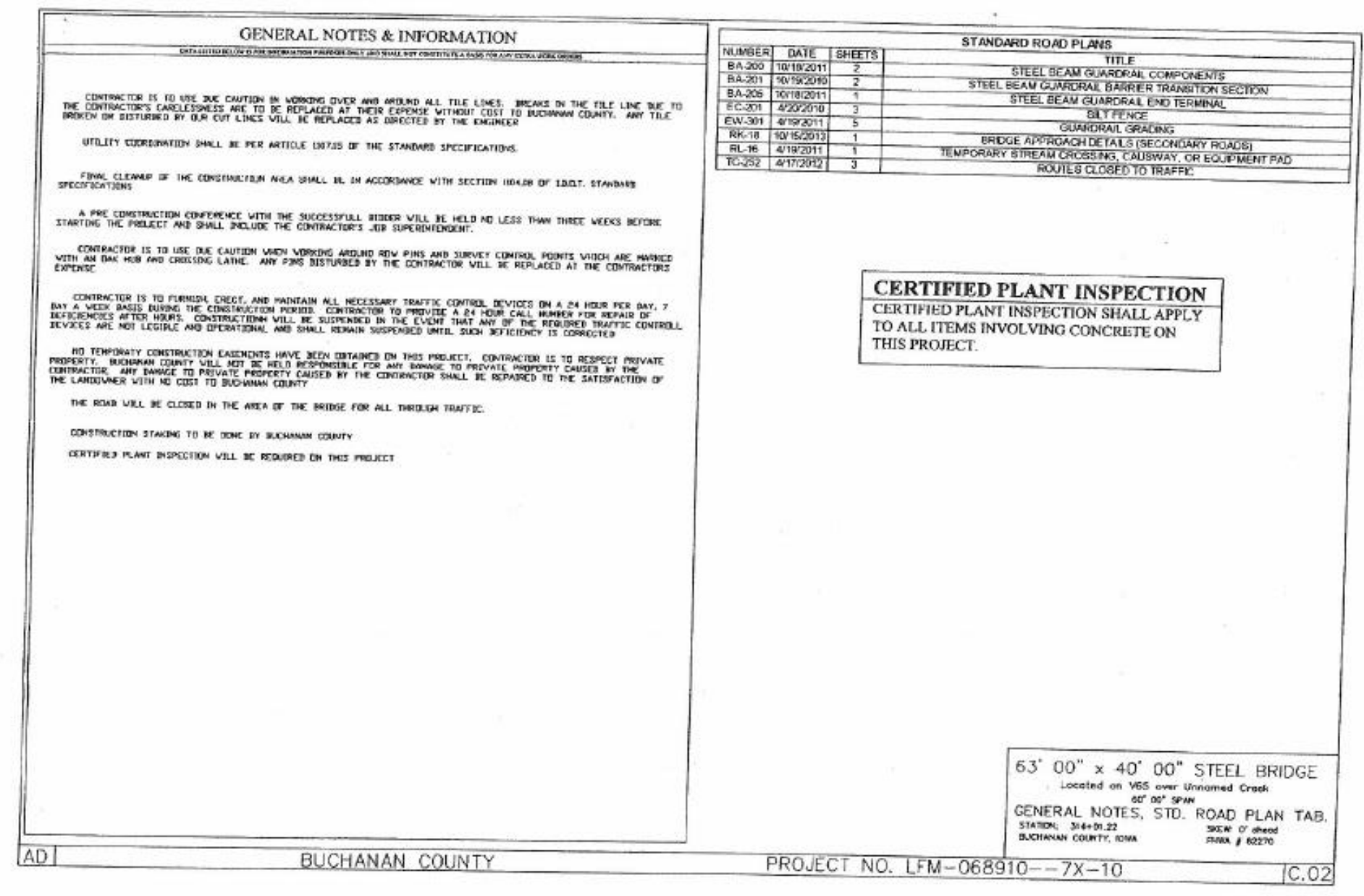




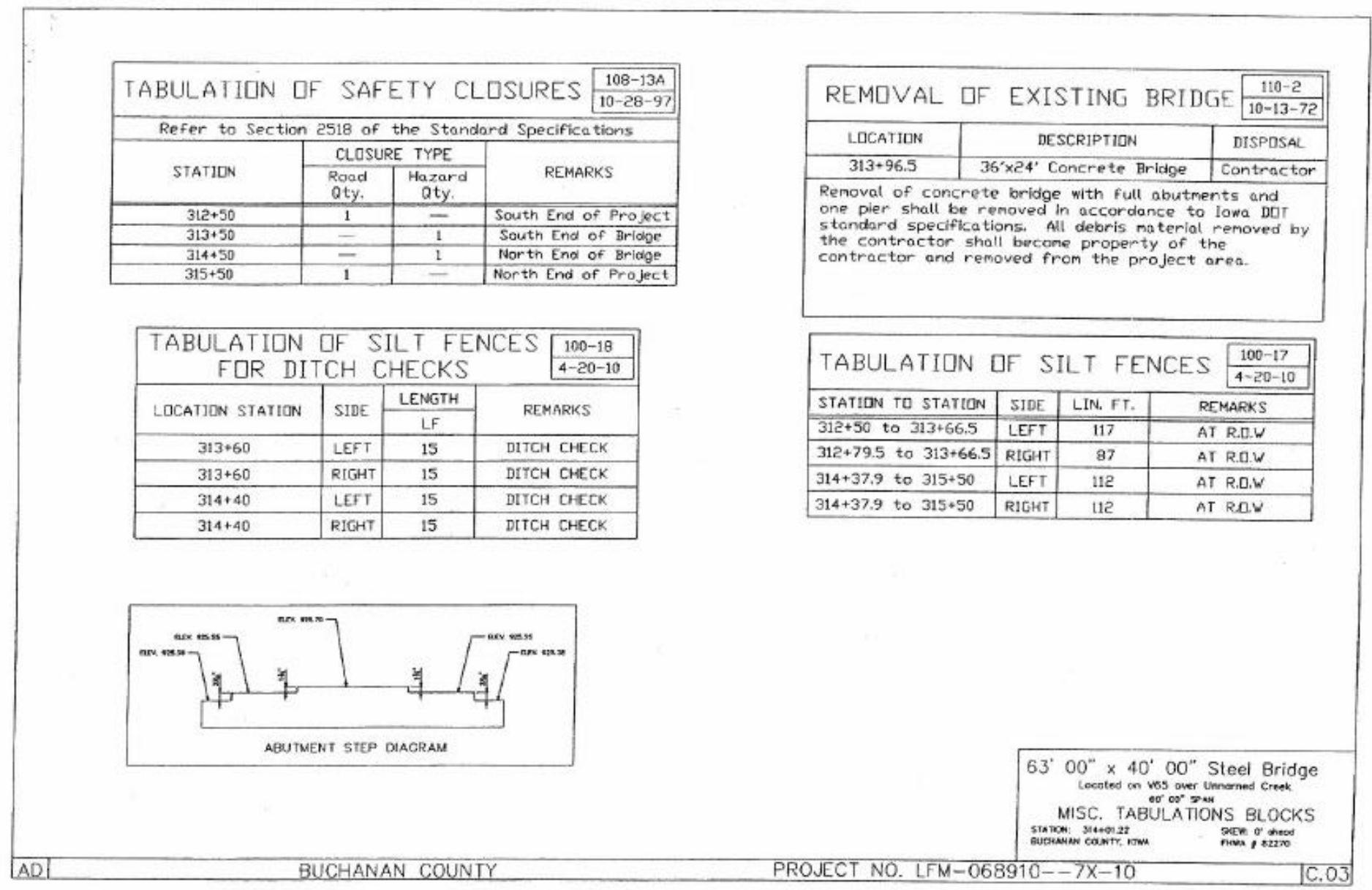




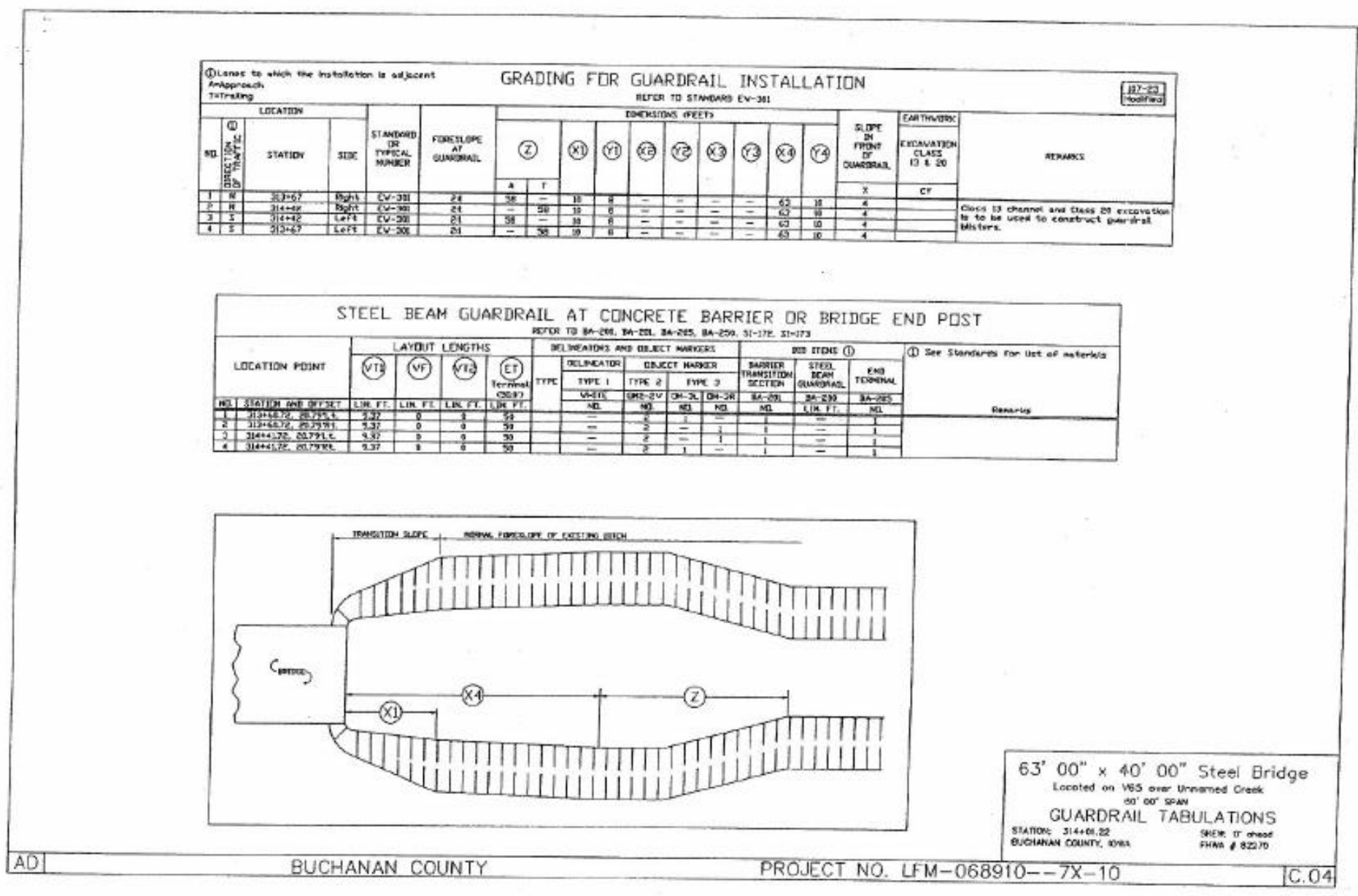




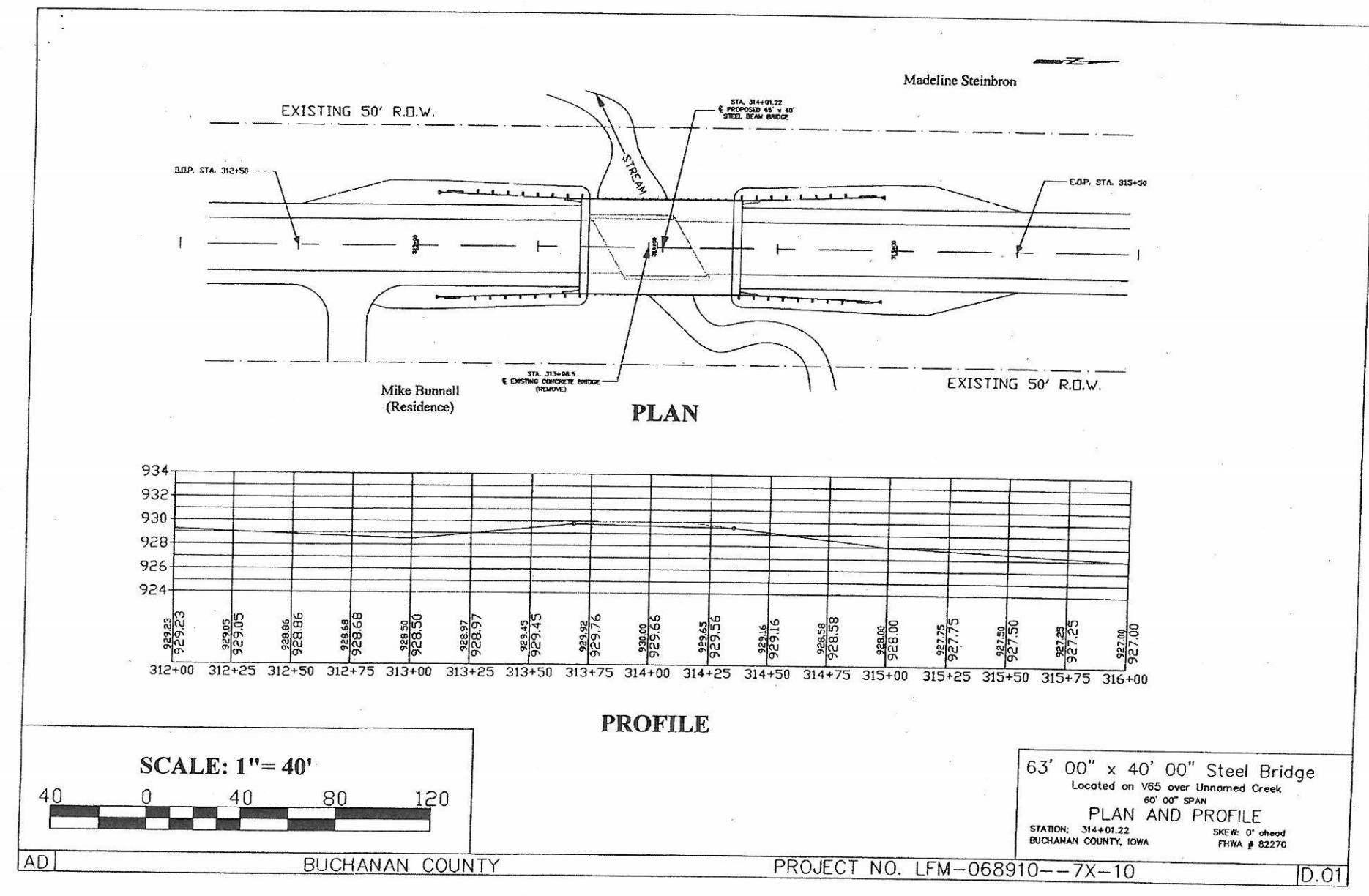




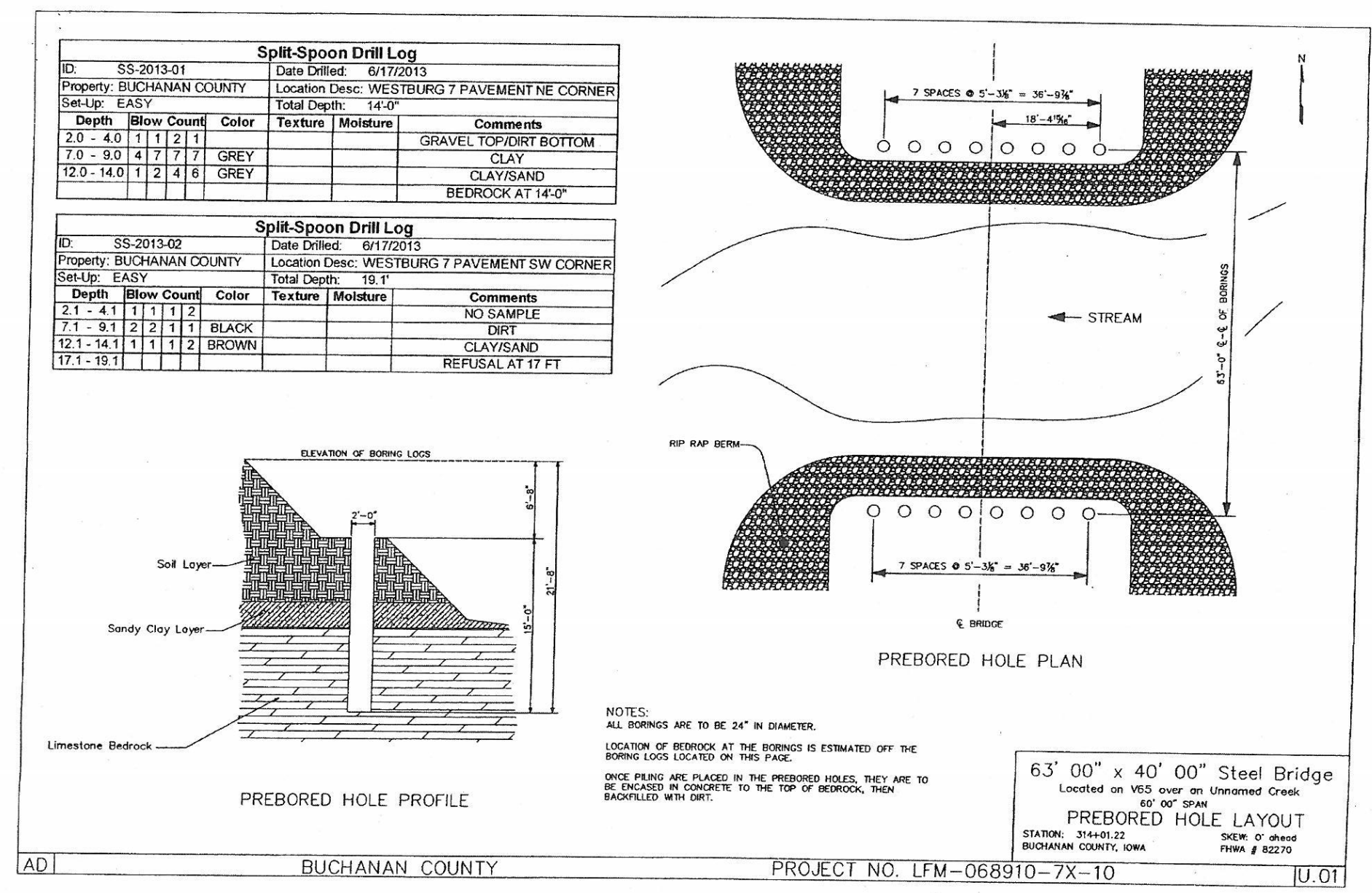




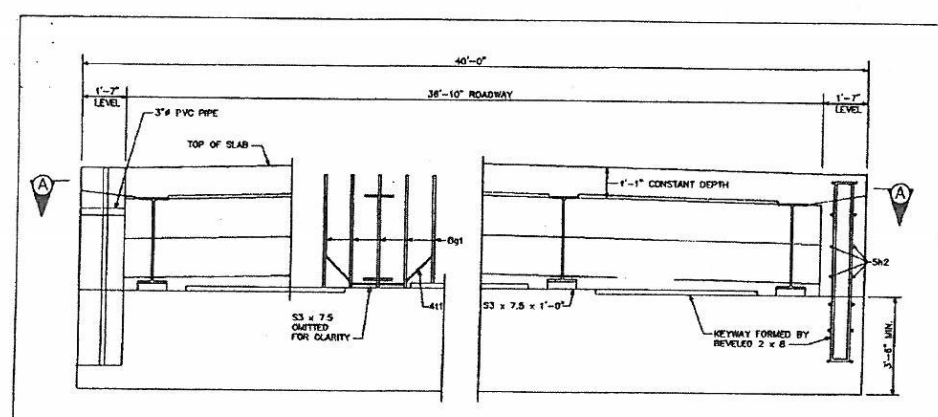

PART REAR ELEVATION AT ABUTMENT

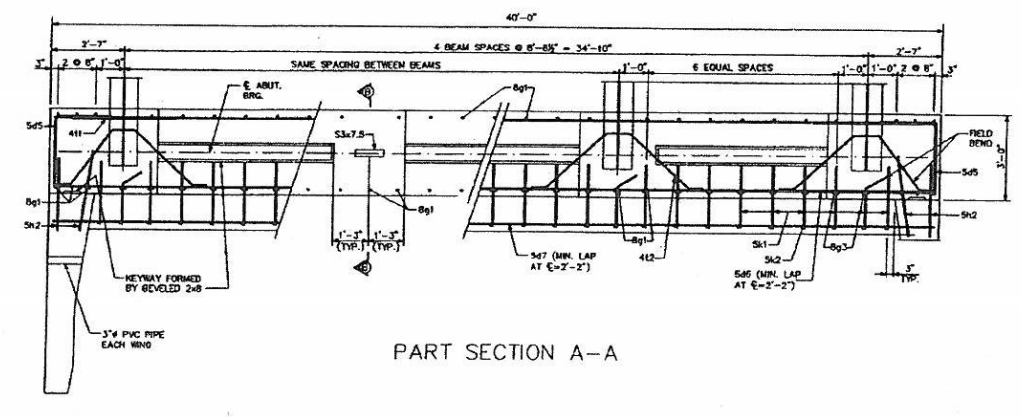

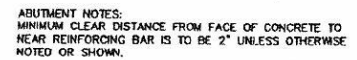

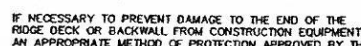

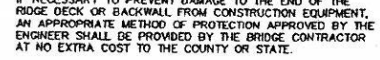

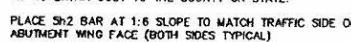

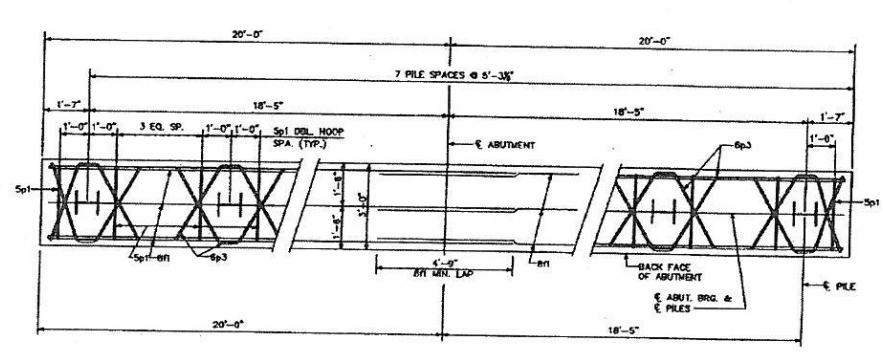

ABUTMENT PILE PLAN

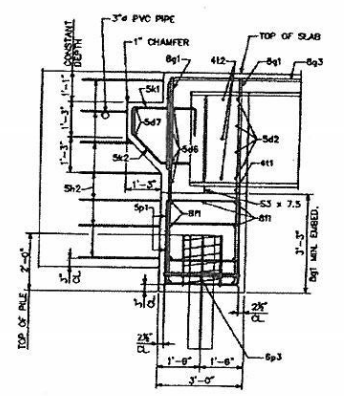

PART SECTION B-B

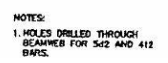

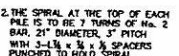

$63^{\prime} 00^{\prime \prime} \times 40^{\prime} 00^{\prime \prime}$ Steel Bridge ABUTMENT DETAILS

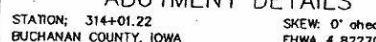




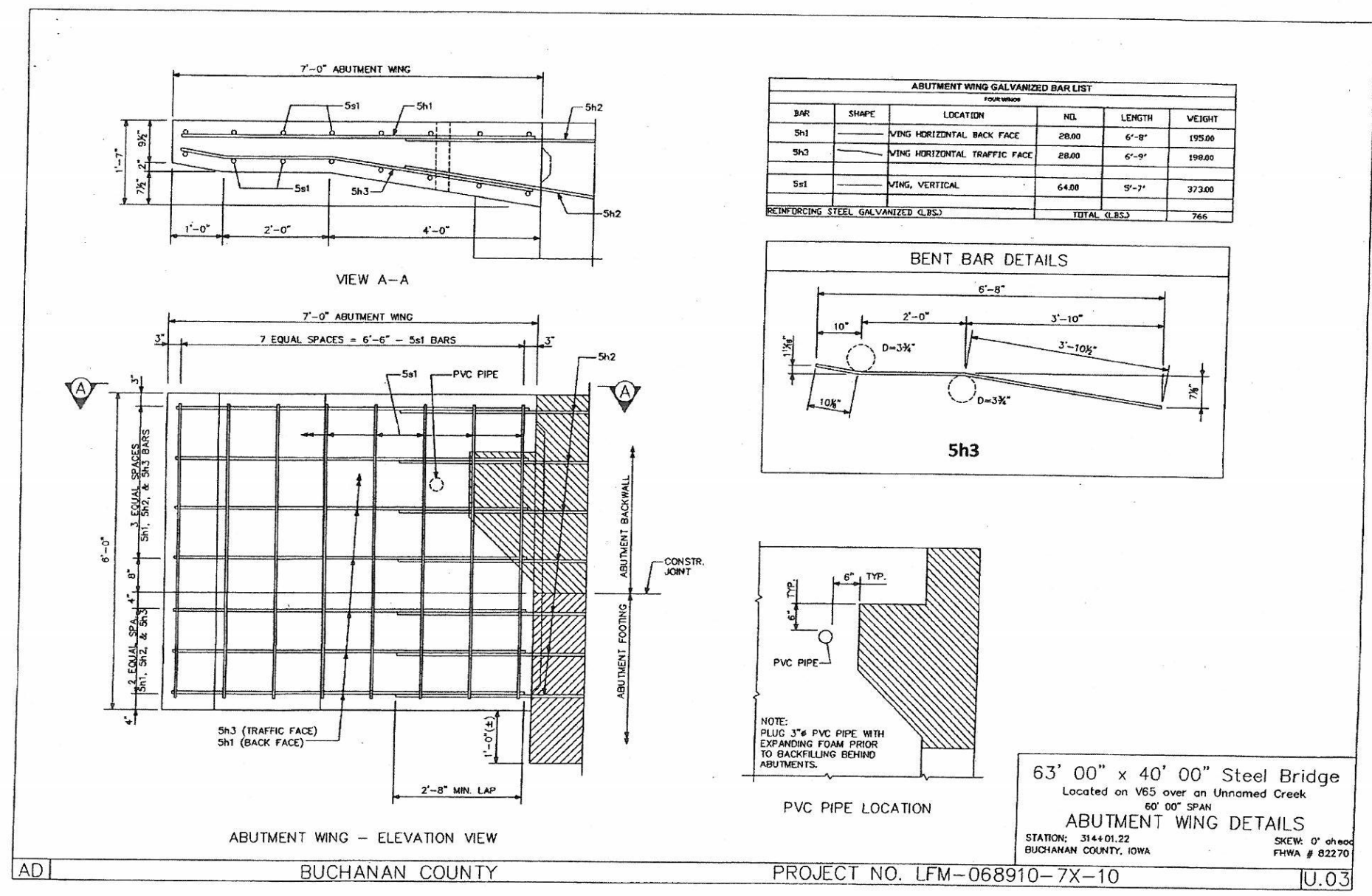




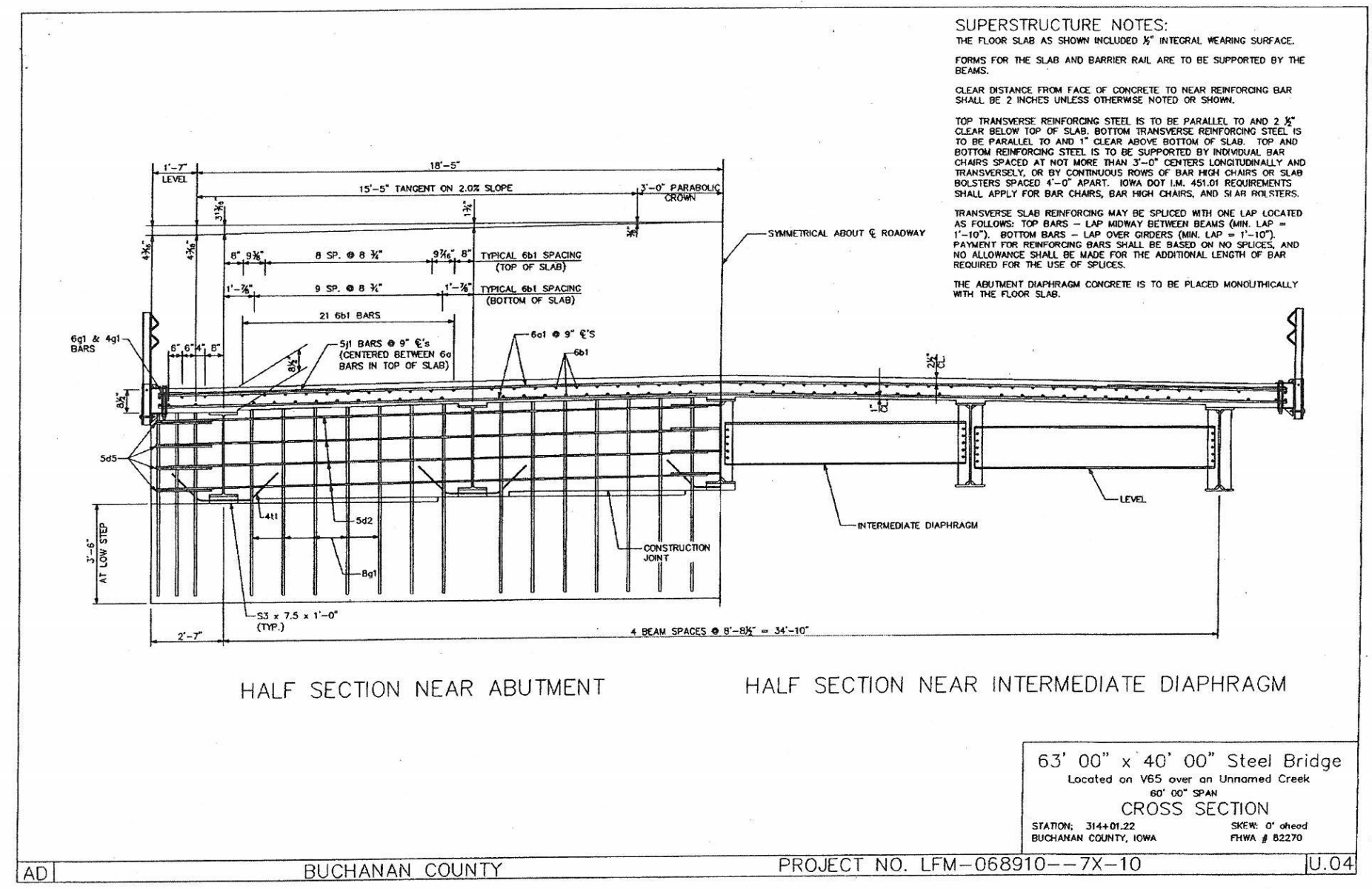




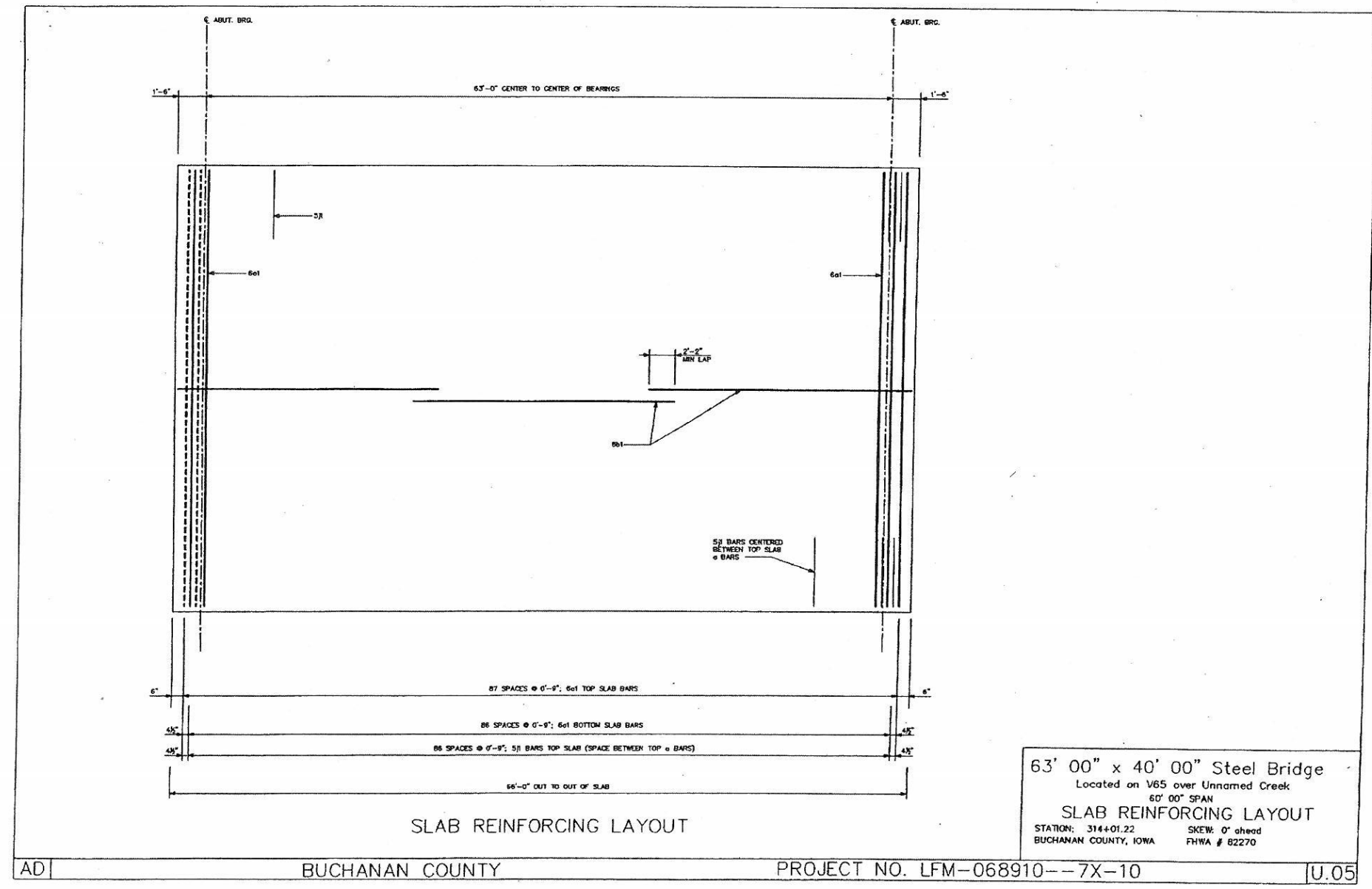




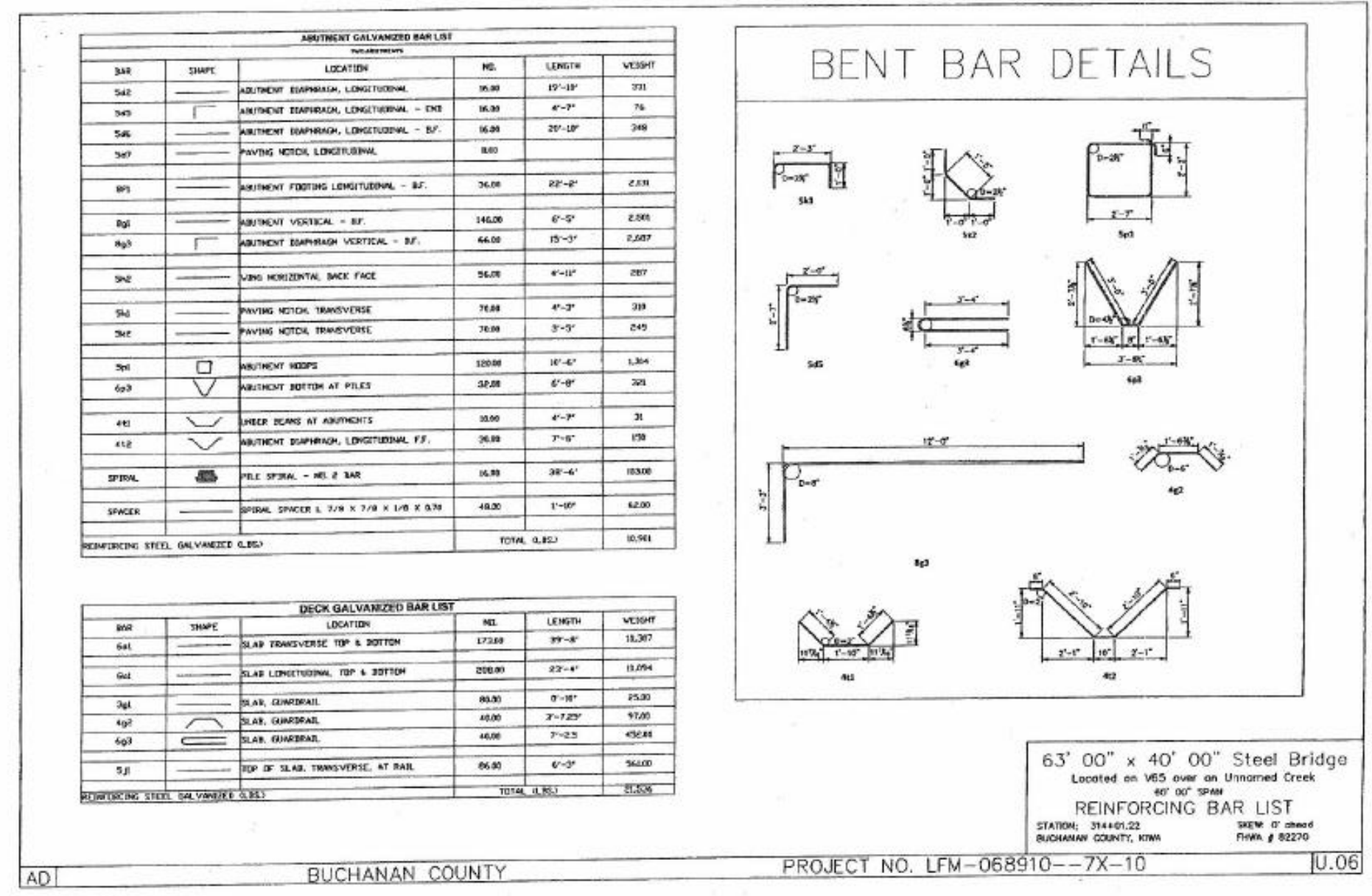




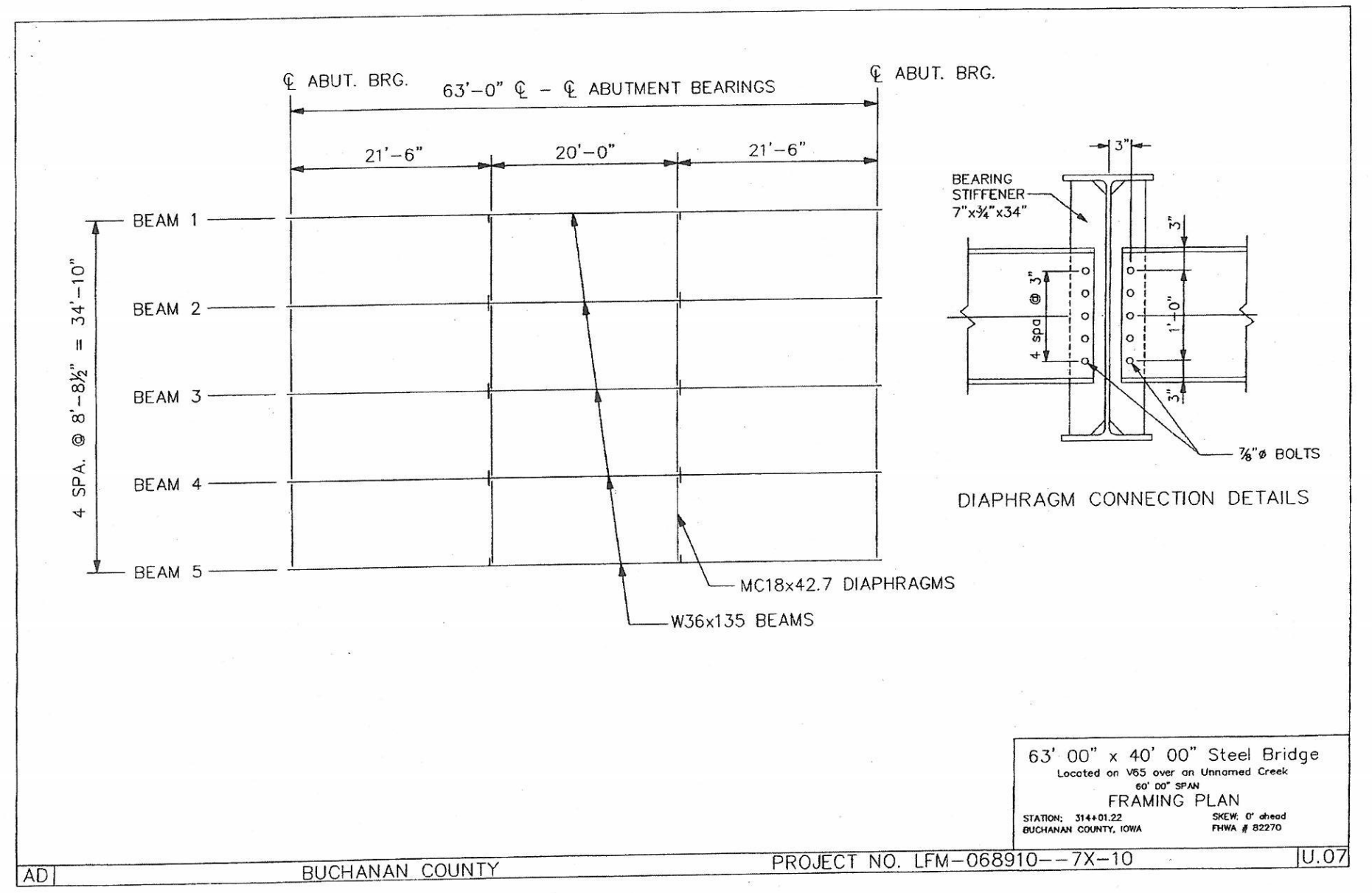




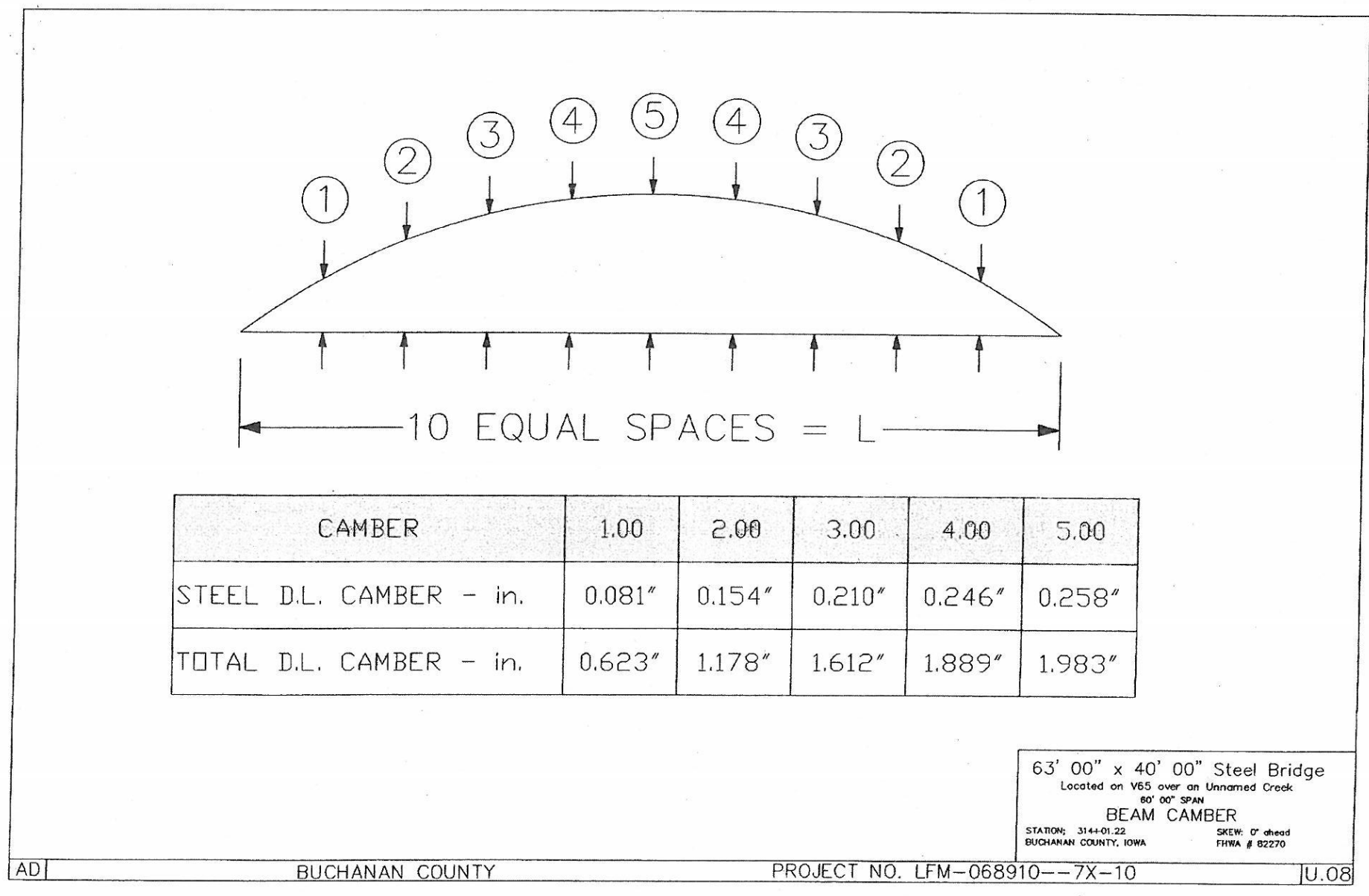




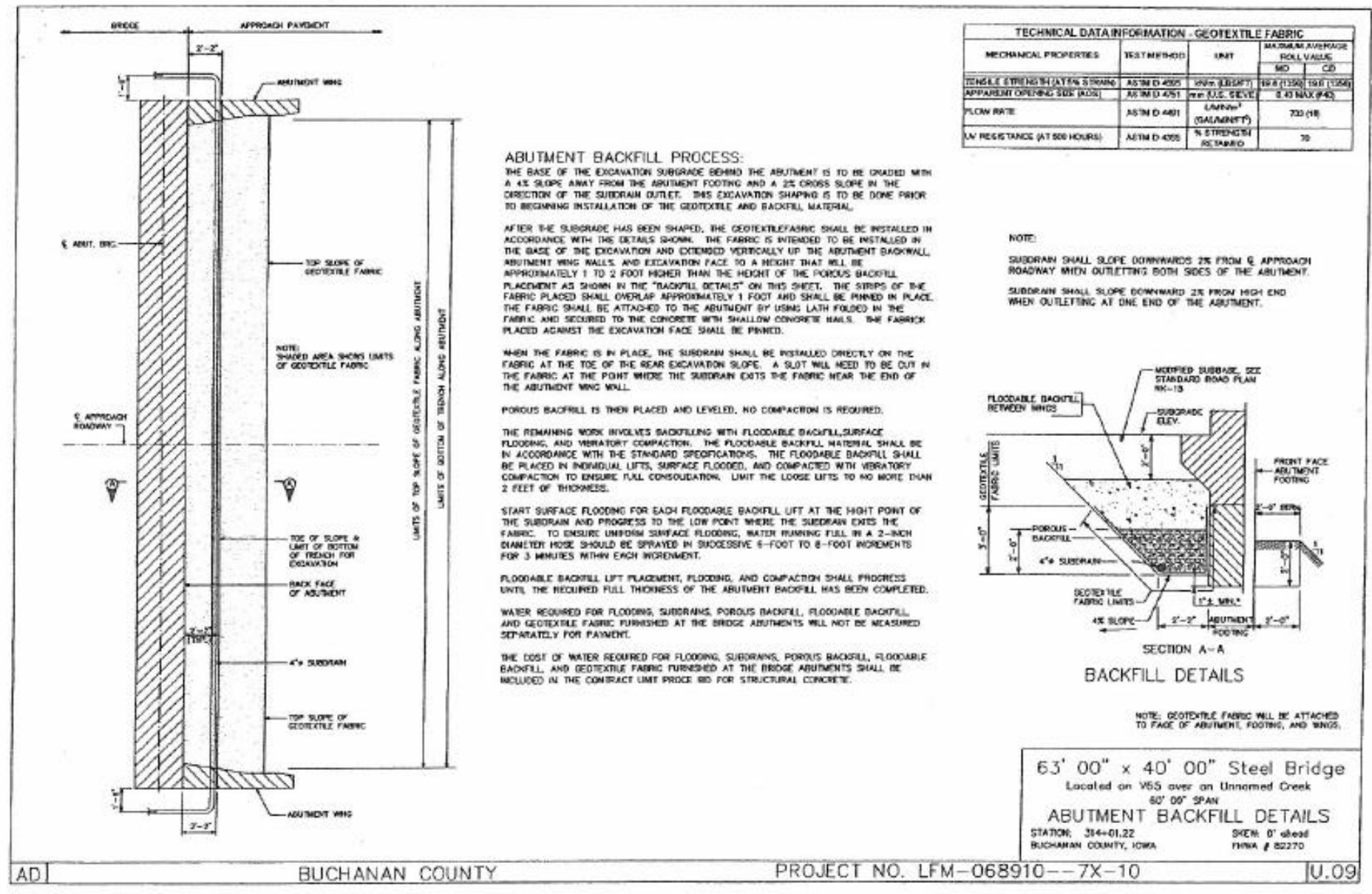




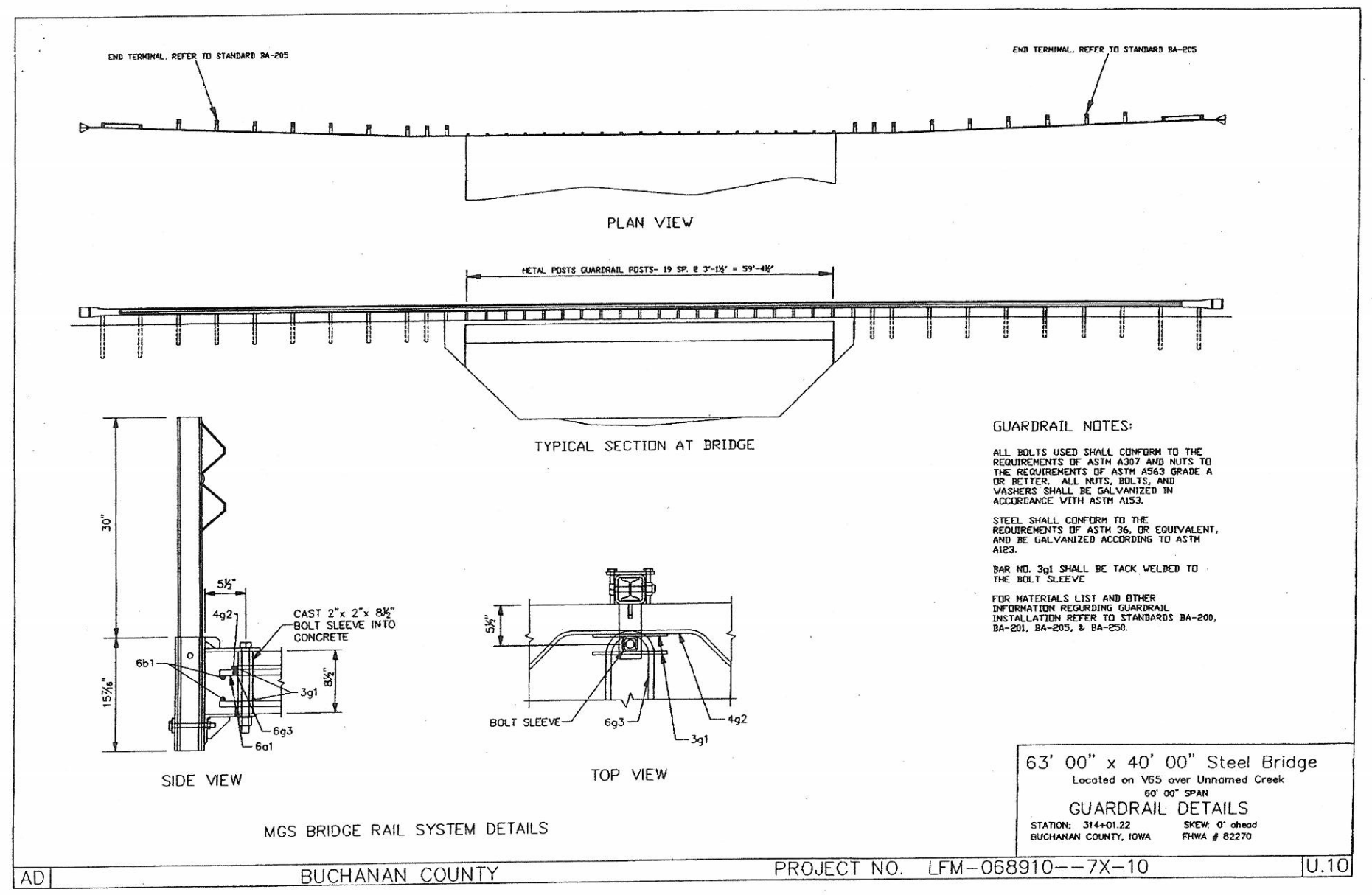




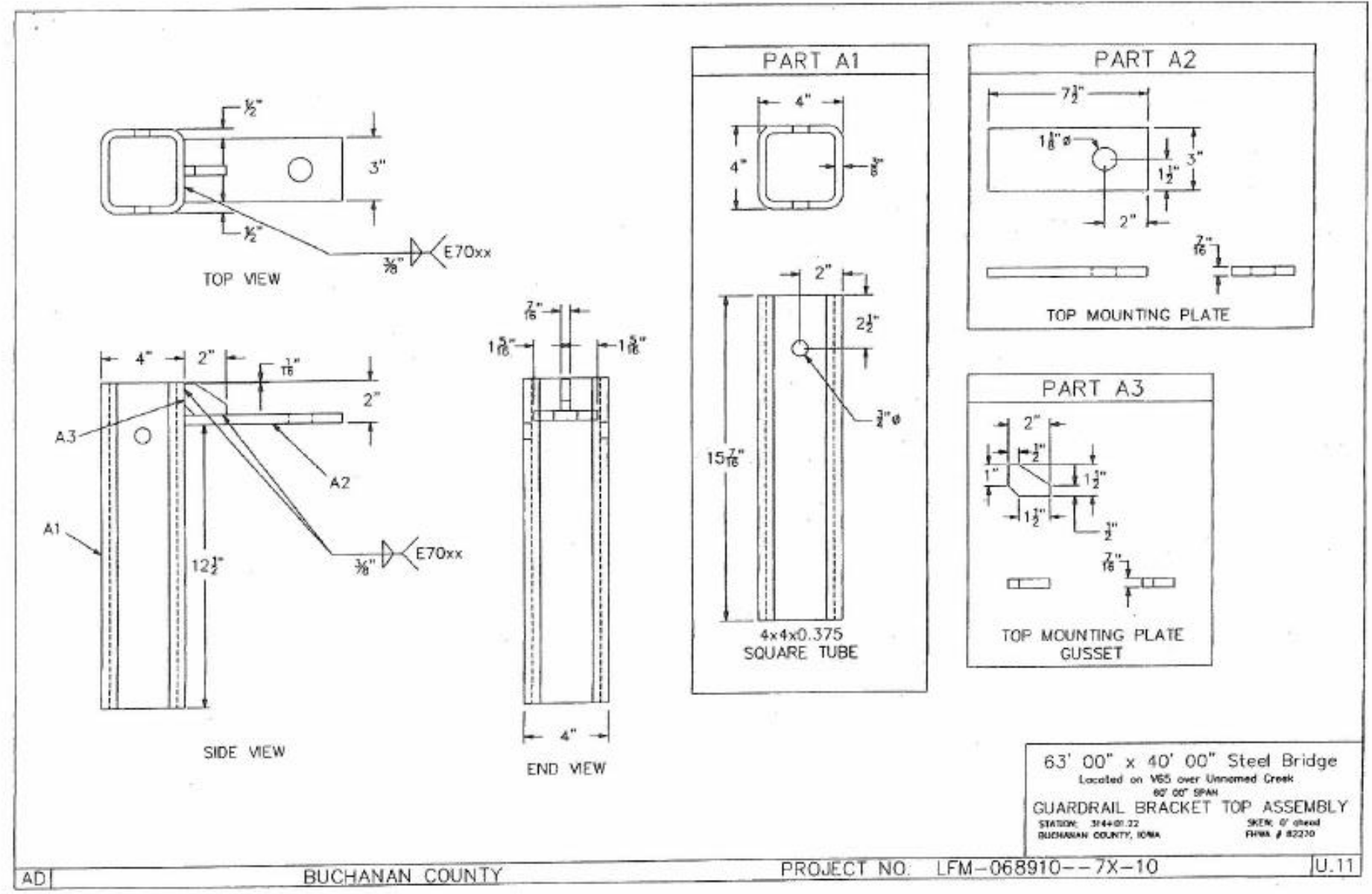




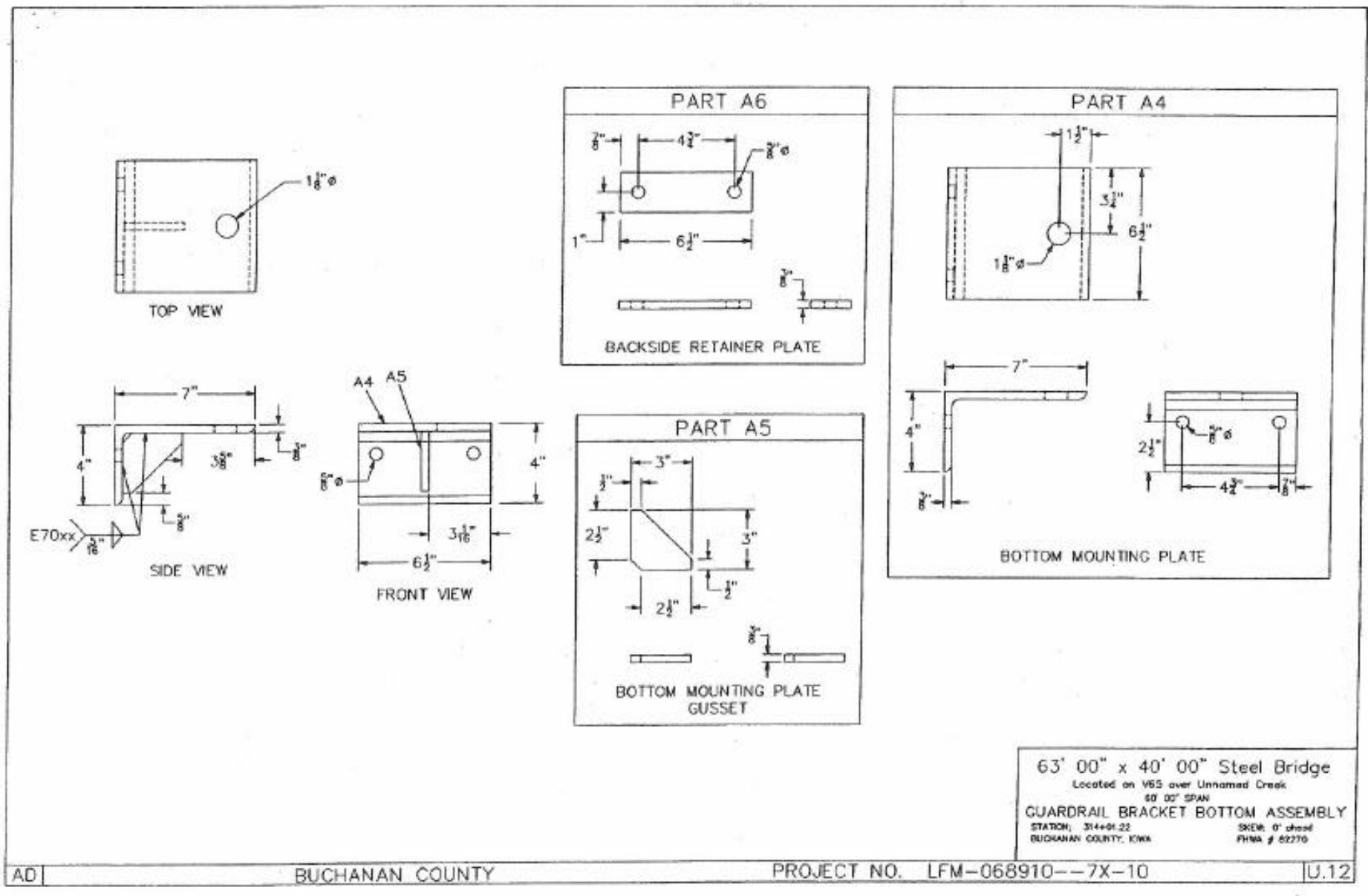




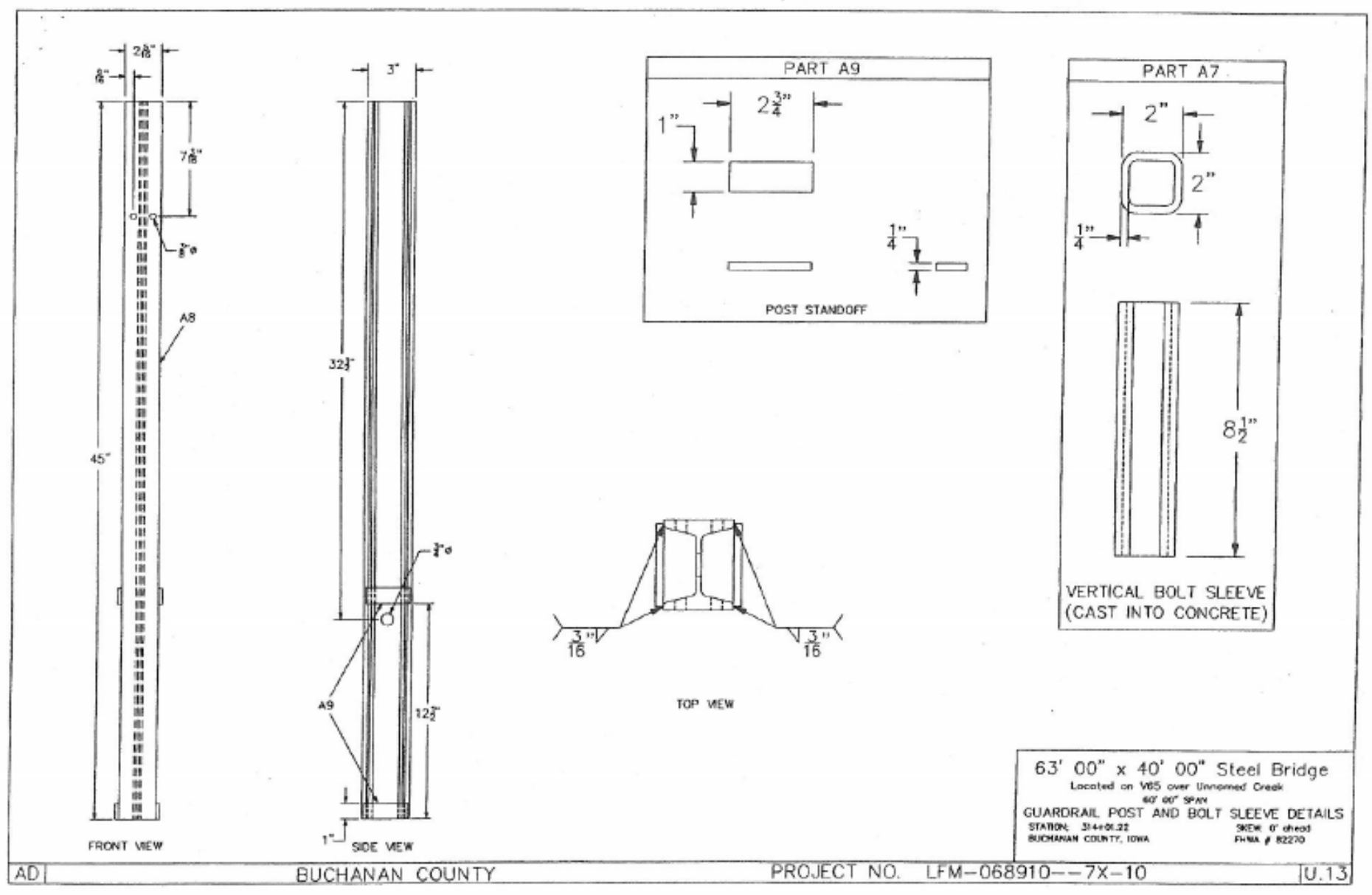




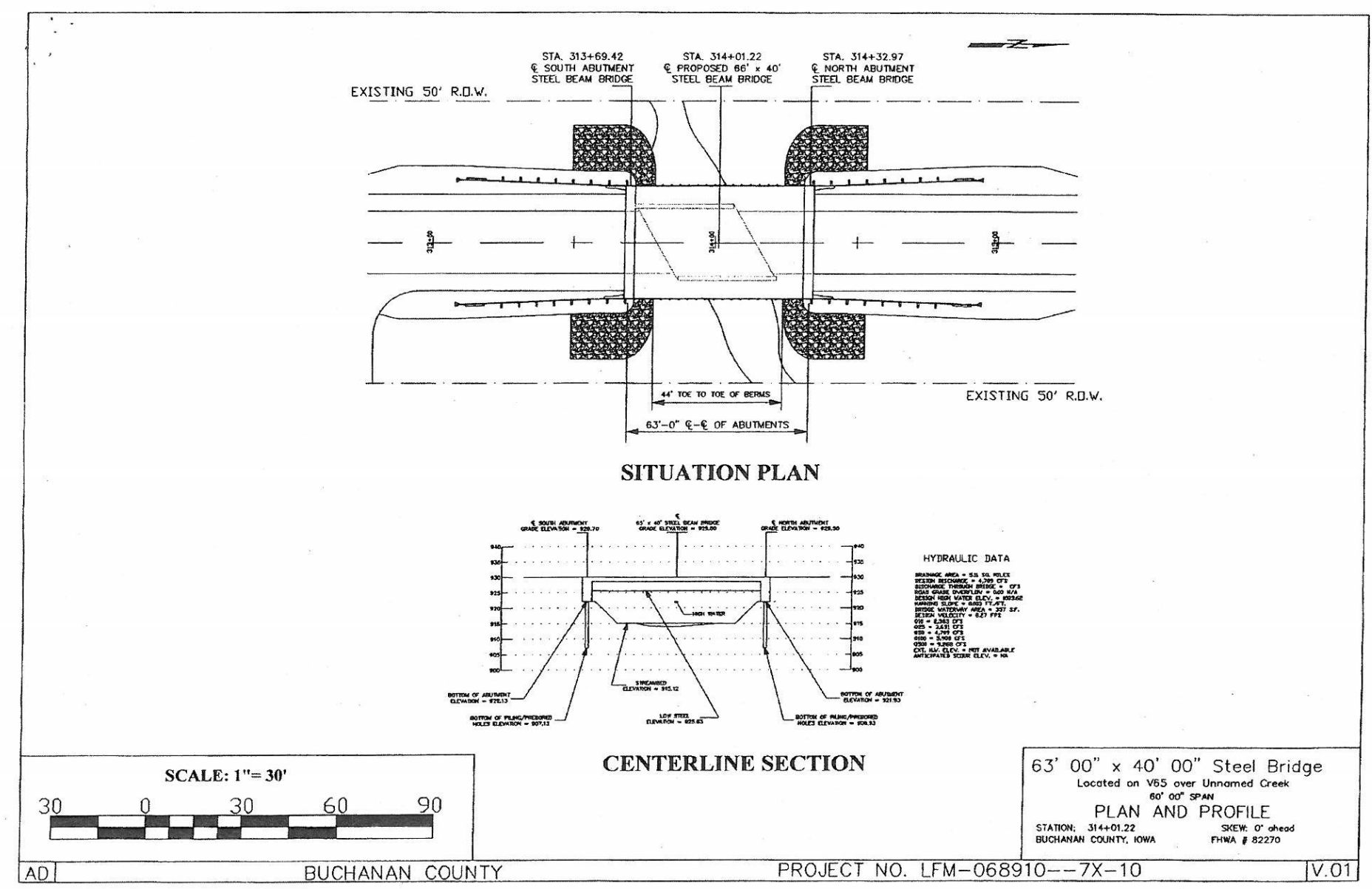




\section{Appendix C: AASHTO Design Calculations}

The following appendix includes the AASHTO Design Calculations for the V-65 Jesup South Bridge. 


\section{Section C1: Design Parameters}

\section{C1.1 InTRODUCTION}

Contained in this chapter is an overview of the layout of the V-65 Jesup South Bridge assessed in this design evaluation. In addition, a comprehensive overview of loads, load combinations, and limit states employed are included. Finally, a discussion of parameters and calculations are presented.

\section{C1.2 BRIDGE LAYOUT}

As shown in the figure below, the bridge in this design evaluation is designed for two 12 foot travel lanes and two 7.5 foot shoulders. The bridge has two guardrails that are mounted to the edges of the deck. To accommodate the lanes and shoulders, the bridge consists of 5 girders spaced at 8.71 feet with 2.58-foot-wide overhangs. An 8.5-inch-thick concrete deck is employed, which includes a $1 / 2$ inch sacrificial wearing surface (also referred to as an integral wearing surface, or IWS) and 2-inch haunch (measured from the bottom of the top flange to the bottom of the deck). In addition, this bridge is designed for a simple span of 63 feet with diaphragms spaced at 21.5 feet from each end. No skew is present in this girder layout.

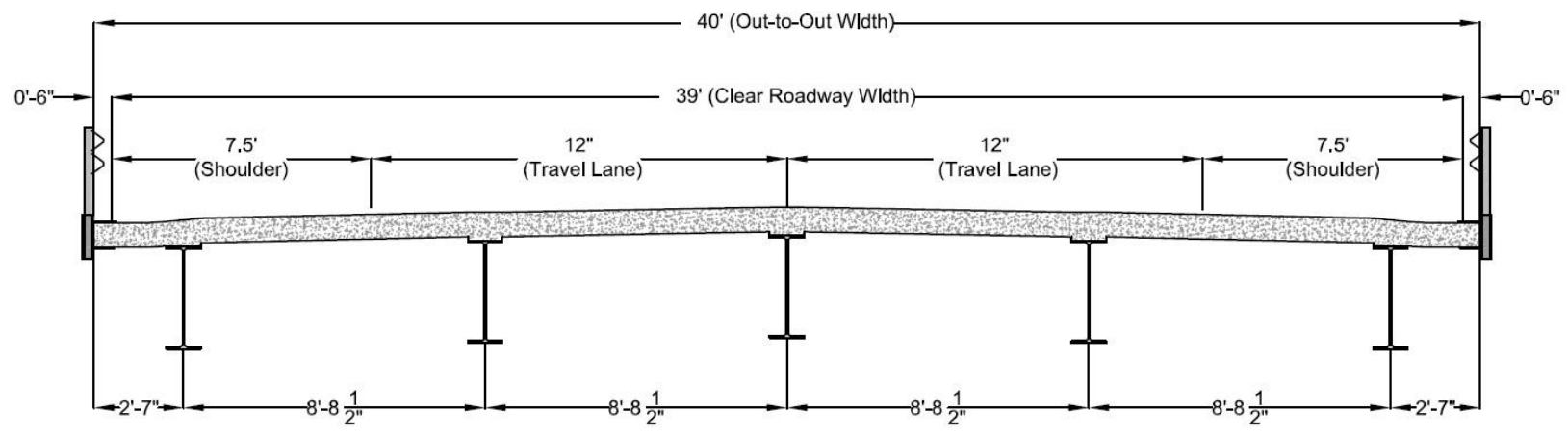

Figure C1.1: V-65 Jesup South Bridge Cross Section 


\section{C1.3 Design Parameters}

The V-65 Jesup South Bridge has been designed according to the fifth edition of the AASHTO LRFD Bridge Design Specifications (2010). All Articles referred to hereafter will refer directly to the AASHTO Specifications. Contained in this section is a description of the loads and load combinations employed, the limits states assessed in this design evaluation, and the loads used throughout this design process.

\section{C1.3.1 Loads \& Load Combinations}

For this set of design evaluations, the following permanent and transient loads are evaluated:

- $\quad \mathrm{DC}=$ dead load of structural components and nonstructural attachments

○ Divided into two components: $\mathrm{DC}_{1}$ (applied to the noncomposite section) and $\mathrm{DC}_{2}$ (applied to the composite section)

- $\quad$ DW = dead load of wearing surface and utilities

- $\quad \mathrm{IM}=$ vehicular dynamic load allowance

- Serves to amplify the vehicular components of the HL-93 live load (i.e. the truck and tandem)

For the fatigue limit state, $\mathrm{IM}=15 \%$ (Article 3.6.2)

○ For all other limit states, $\mathrm{IM}=33 \%$ (Article 3.6.2)

- $\quad \mathrm{LL}=$ vehicular live load

o The HL-93 vehicular live load as defined in Article 3.6.1.2.

- Combination of either design truck + design lane or the design tandem + design lane (whichever yields the largest force effect).

$\circ$ Note that for the fatigue limit state, the fatigue load consists of only one design truck with a fixed rear axle spacing of 30 feet (Article 3.6.1.4.1) 
Using these specified loads, the following load combinations are assessed (values for load factors were derived from Tables 3.4.1-1 and 3.4.1-2 unless otherwise specified). For this set of design calculations, $\eta_{D}$ (ductility factor), $\eta_{R}$ (redundancy factor), and $\eta_{I}$ (operational importance factor) are all taken to be 1.00 .

- Strength I: basic load combination relating to the normal vehicular use of the bridge without wind

○ $1.25 \mathrm{DC}+1.50 \mathrm{DW}+1.75(\mathrm{LL}+\mathrm{IM})$

- In addition, for evaluating the constructability requirements of Article 6.10.3, according to Article 3.4.2, all load factors associated with construction loads were taken to be 1.50 .

- Strength IV: load combination relating to very high dead to live load force effect ratios

○ $1.50 \mathrm{DC}+1.50 \mathrm{DW}$

- Service I: load combination associated with evaluation of live load deflections (Article 3.4.2.2)

$\circ 1.00(\mathrm{LL}+\mathrm{IM})$

- Service II: load combination intended to control yielding of steel structures

$\circ 1.00 \mathrm{DC}+1.00 \mathrm{DW}+1.30(\mathrm{LL}+\mathrm{IM})$

- Fatigue I: fatigue load combination related to infinite load-induced fatigue life (see 2.4.3 for evaluation)

$\circ 1.50(\mathrm{LL}+\mathrm{IM})$

The following loads were taken for all of the calculations in this design evaluation:

- Unit weight of concrete $=150 \mathrm{pcf}$

- Compressive strength of concrete $=4000 \mathrm{psi}$

- These values correspond to normal weight concrete. For normal weight concrete, according to the provisions of Article C6.10.1.1.1b, this yields a modular ratio, $n$, of 8 .

- Unit weight of steel $=490 \mathrm{pcf}$

- Steel stay-in-place formwork (SIP) unit weight $=15 \mathrm{psf}$

- Future wearing surface $=25 \mathrm{psf}$ 
- To account for miscellaneous steel details, such as diaphragms and connection stiffeners, the weight of the steel girders was increased by $5 \%$.

- Construction loads:

$\circ$ Overhang deck forms $=40 \mathrm{lb} / \mathrm{ft}$

- Screed rail $=85 \mathrm{lb} / \mathrm{ft}$

○ Railing $=25 \mathrm{lb} / \mathrm{ft}$

○ Walkway $=125 \mathrm{lb} / \mathrm{ft}$

○ Finishing machine $=3000 \mathrm{lb}$

\section{C1.3.2 Limit States Evaluated}

The limit states that pertain to the performance of the girders are discussed in this section. It should be noted that, for all limit states, according to Article 6.5.4.2, the resistance factor for flexure, $\phi_{f}$, and for shear, $\phi_{v}$, are both taken to be 1.00. In addition, since both girders are fully comprised of 50-ksi steel, the hybrid factor, $R_{h}$, is taken as 1.0.

\section{C1.3.2.1 Cross-Section Proportion Limits (Article 6.10.2)}

The girders in this design evaluation were evaluated to meet the cross-section proportion limits of Article 6.10.2. These limits are divided into two main categories: flange proportions and web proportions.

For webs without longitudinal stiffeners, the following limit is employed from Article 6.10.2.1.1.

$$
\frac{D}{t_{w}} \leq 150
$$


The following limits are employed for flange proportions. In addition to the limits set forth in Article 6.10.2.2, Article C6.10.3.4 specifies an additional limit to prevent out-of-plane distortions of the girder compression flanges and web during construction, which is also employed throughout this design evaluation.

$$
\begin{aligned}
& \frac{b_{f}}{2 t_{f}} \leq 12.0 \\
& b_{f} \geq \frac{D}{6} \\
& t_{f} \geq 1.1 t_{w} \\
& 0.1 \leq \frac{I_{y c}}{I_{y t}} \leq 10 \\
& b_{f c} \geq \frac{L}{85}
\end{aligned}
$$

\section{C1.3.2.2 Constructibility (Article 6.10.3)}

Article 2.5.3 requires that bridges should be designed in a manner such that fabrication/erection can be performed without undue difficulty or distress and that locked-in construction force effects are within tolerable limits. To meet this requirement, the provisions of Article 6.10.3 are employed. Article 6.10.3 outlines several provisions for limiting stress in discretely-braced compression and tension flanges related to yielding of the flanges, flexural resistance of the compression flange, and web bend-buckling resistance, and are as follows. Details regarding the computation of the flexural resistance of the compression flange, $F_{n c}$, and the web bend-buckling resistance, $F_{c r w}$, are reserved for Section C2. 
$f_{b u}+f_{l} \leq \phi_{f} R_{h} F_{y c}$

Eq. 6.10.3.2.1-1

$f_{b u}+\frac{1}{3} f_{l} \leq \phi_{f} F_{n c}$

Eq. 6.10.3.2.1-2

$f_{b u} \leq \phi_{f} F_{c r w}$

Eq. 6.10.3.2.1-3

$f_{b u}+f_{l} \leq \phi_{f} R_{h} F_{y t}$

To determine the stresses resulting from lateral loads during construction, an approximation for lateral moments is specified Article C6.10.3.4, which idealizes the girder as a fixed beam between lateral bracing elements. Lateral bending moments are approximated as shown for statically equivalent uniform loads, $F_{l}$, and concentrated loads, $P_{l}$. For this bridge, constructibility requirements are evaluated at the middle unbraced segment, which has an unbraced length, $L_{b}$, of 20 feet.

$$
\begin{aligned}
& M_{l}=\frac{F_{l} L_{b}{ }^{2}}{12} \\
& M_{l}=\frac{P_{l} L_{b}}{8}
\end{aligned}
$$

In addition to this approximation, Article 6.10.1.6 specifies that a second-order analysis must be performed for lateral flange bending stresses in the compression flange if the unbraced length violates the limit set forth in Eq. 6.10.1.6-3. If this limit is not satisfied, an approximation is provided which amplifies first-order lateral flange bending stresses, $f_{l l}$, as a function of the major-axis bending stress and the elastic lateral torsional buckling stress, $F_{c r}$.

$$
\begin{gathered}
L_{b} \leq 1.2 L_{p} \sqrt{\frac{C_{b} R_{b}}{M_{u} / M_{y c}}} \\
f_{l} \leq\left(\frac{0.85}{1-\frac{M_{u}}{F_{c r} S_{x c}}}\right) f_{l 1} \geq f_{l 1}
\end{gathered}
$$


In lieu of performing a deck casting sequence analysis, since this bridge layout is a simple span, the deck is conservatively assumed to be cast in one pour. Therefore, the majoraxis bending stress, $f_{b u}$, is that from the total noncomposite dead load, or $\mathrm{DC}_{1}$. Also, when checking constructibility, the web load-shedding factor, $R_{b}$, is taken as 1.0 , according to Article 6.10.1.10.2.

It should be noted that Article 6.10 .3 also specifies that the webs shall satisfy a capacity requirement during construction. However, as the construction shear loads in this design evaluation are lower than the shear loads the girder must withstand at the strength limit state, this requirement is not explicitly evaluated here; instead, this is evaluated at the strength limit state (see C1.3.2.5).

\section{C1.3.2.3 Service Limit State (Article 6.10.4)}

The intent of the service limit state is to limit stresses and deformations under regular operating conditions. This is accomplished by limiting the levels of stress that the member experiences in order to prevent localized yielding. This is shown in the equations below. Note that for the girders in the design evaluation, no lateral stresses are considered at service conditions.

FOR THE TOP STEEL FLANGE OF COMPOSITE SECTIONS

$$
f_{f} \leq 0.95 R_{h} F_{y f}
$$

FOR THE BOTTOM STEEL FLANGE OF COMPOSITE SECTIONS

$$
f_{f}+\frac{f_{l}}{2} \leq 0.95 R_{h} F_{y f}
$$

In addition to the limit set forth for permanent deformations, many state DOTs and owner agencies choose to invoke optional live load deflection criteria which are meant to ensure user comfort. This optional limit is also evaluated. Article 2.5.2.6.2 specifies deflection criteria that may be used; for bridges subjected to vehicular loads only, a limit of $L / 800$ is specified. Therefore, for a span length of $63 \mathrm{ft}$, this equates to a live load deflection limit of 0.945 inches. 


\section{C1.3.2.4 Fatigue Limit State (Article 6.10.5)}

The intent of the fatigue limit state is to control crack growth under cyclic loading conditions by limiting the range of live load stress, $\Delta f$, that steel members are subjected to. Specifically, load induced fatigue categories must satisfy the limit below. For the limit state, the load factor, $\gamma$, and the nominal fatigue resistance, $(\Delta F)_{n}$, associated with the fatigue limit state are a function of the number of stress cycles the girder is subjected to. This is discussed explicitly in C1.4.3.

$\gamma(\Delta f) \leq(\Delta F)_{N}$

Article 6.10.5 also specifies a special fatigue requirement for webs with interior transverse shear stiffeners. For this bridge, the webs are unstiffened by transverse shear stiffeners. Therefore, the special web fatigue requirement specified in Article 6.10.5.3 does not need to be evaluated for this design.

\section{C1.3.2.5 Strength Limit State (Article 6.10.6)}

The intent of the strength limit state is to ensure that the structure has adequate strength and stability when subjected to maximum factored loads. For composite sections in positive flexure, sections must meet flexural resistance requirements as well as a ductility requirement as

specified in Article 6.10.7.3. In addition, the section must also have adequate shear capacity under maximum factored loads. The computation of the girders' flexural resistance, shear resistance, and ductility are discussed in the next section, along with the factored loads and force effects that the girder must withstand.

\section{C1.4 Common Parameters \& Calculations}

Contained herein is a brief description of parameters and values that are used for the rolled beam solution used for this design evaluation. 


\section{C1.4.1 Section Properties}

As stated in Article 6.10.1.1.1, stresses in a composite section due to applied loads shall be the sum of stresses applied separately to the noncomposite (or steel) section, the short-term composite section, and the long-term composite section. For calculating flexural stresses, the concrete deck is transformed to an equivalent area of steel through the use of the modular ratio, $n$. As stated in C1.3.1, for these bridges, $n=8$. For loads applied to the short-term composite section (i.e. LL + IM), the concrete is transformed by dividing the concrete's effective flange width by $n$; for loads applied to the long-term composite section (i.e. $\mathrm{DC}_{2}$ and $\mathrm{DW}$ ), the concrete is transformed by dividing the concrete's effective flange width by $3 n$.

To compute the effective flange width, Article 4.6.2.6 states that the effective flange width of a concrete deck shall be taken as the tributary width. Therefore, for the bridge layout in this evaluation, for interior and exterior girders, the effective flange width is 104.5 inches and 83.25 inches, respectively.

\section{C1.4.2 Multiple Presence Factors \& Live Load Distribution Factors}

Multiple presence factors account for the probability of coincident live loadings, and are listed in Article 3.6.1.1.2. These factors have already been included in the empirical equations listed in Article 4.6.2.2. However, when employing the lever rule or special analysis, the engineer must apply these factors. For the reader's convenience, these factors are listed in Table C1.1. It should be noted that multiple presence factors are not applied when evaluating the fatigue limit state.

Table C1.1: Multiple Presence Factors

\begin{tabular}{cc}
\hline Number of Lanes Loaded & $\mathrm{m}$ \\
\hline One Lane Loaded & 1.20 \\
Two Lanes Loaded & 1.00 \\
Three Lanes Loaded & 0.85 \\
More Than Three Lanes Loaded & 0.65 \\
\hline
\end{tabular}


In lieu of a complex three-dimensional analysis, live load distribution factors were employed to determine live loads on individual girders. As stated in Article 4.6.2.2, these factors are only applicable if the bridge falls within a certain range of parameters.

Parameters for this set of bridges as well as their specified limits in Article 4.6.2.2 are listed. As shown, all parameters are within the specified limits. Note that the limit for $K_{g}$ is not explicitly evaluated here and will be discussed later.

- $3.5 \leq S \leq 16.0$

○ $S=$ girder spacing $(\mathrm{ft})=8.67$

- $4.5 \leq t_{s} \leq 16$

$\circ \quad t_{s}=$ structural slab thickness $($ in $)=8.00$

- $20 \leq L \leq 240$

○ $L=$ span length $(\mathrm{ft})=63$

- $N_{b} \geq 4$

○ $N_{b}=$ number of bridge girders $=5$

- $-1.0 \leq d_{e} \leq 5.5$

○ $d_{e}=$ distance from the centerline of the exterior girder's web to the edge of the deck $(\mathrm{ft})=2.58$

- $10,000 \leq K_{g} \leq 7,000,000$

As previously stated, any of the distribution factors in Article 4.6.2.2 are a function of a longitudinal stiffness parameter, $K_{g}$, which is found as follows.

$K_{g}=n\left(I+A e_{g}^{2}\right)$

Once the longitudinal stiffness parameter is found, the distribution factors used in these analyses are found as follows:

BENDING MOMENT FOR AN INTERIOR GIRDER, ONE LANE LOADED

$$
g=0.06+\left(\frac{S}{14}\right)^{0.4}\left(\frac{S}{L}\right)^{0.3}\left(\frac{K_{g}}{12.0 L t_{s}^{3}}\right)^{0.1}
$$


BENDing MOMENT FOR AN INTERIOR GIRDER, MUlTIPLE LANES LOADED

$$
g=0.075+\left(\frac{S}{9.5}\right)^{0.6}\left(\frac{S}{L}\right)^{0.2}\left(\frac{K_{g}}{12.0 L t_{s}^{3}}\right)^{0.1}
$$

SHEAR FOR AN INTERIOR GIRDER, ONE LANE LOADED

$$
g=0.36+\frac{S}{25.0}
$$

SHEAR FOR AN INTERIOR GIRDER, MULTIPLE LANES LOADED

$$
g=0.2+\frac{S}{12}-\left(\frac{S}{35}\right)^{2.0}
$$

BENDING MOMENT FOR AN EXTERIOR GIRDER, ONE LANE LOADED

Use of the Lever Rule is employed (Tab. 4.6.2.2.2d-1)

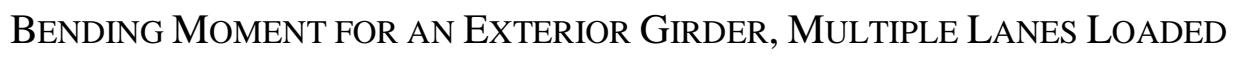

$$
g=\left(0.77+\frac{d_{e}}{9.1}\right) g_{\text {interior }}
$$

SHEAR FOR AN EXTERIOR GIRDER, ONE LANE LOADED

Use of the Lever Rule is employed (Tab. 4.6.2.2.3b-1)

SHEAR FOR AN EXTERIOR GIRDER, MULTIPLE LANES LOADED

$$
g=\left(0.6+\frac{d_{e}}{10}\right) g_{\text {interior }}
$$

According to Article C4.6.2.2.2d, an additional investigation is required for steel slab-onbeam bridges, which assumes the entire cross-section rotates as a rigid body about the longitudinal centerline of the bridge. Additional distribution factors for bending moment and shear for exterior girders are computed according to the following formula. 
$R=\frac{N_{L}}{N_{b}}+\frac{X_{e x t} \sum_{N_{L}} e}{\sum_{N_{b}} x^{2}}$

Eq. C4.6.2.2.2d-1

To determine the distribution of live load deflections, according to Article 2.5.5.6.2, all design lanes should be loaded, and all supporting components should be assumed to deflect equally. In addition, it is stated that the appropriate multiple presence factor shall be applied. This is described mathematically in the formula below.

$$
g=m \frac{N_{L}}{N_{b}}
$$

\section{C1.4.2.1 Lever Rule Analysis}

To determine the live load distribution of moment and shear in exterior beams for one lane loaded scenarios, the Specifications state that the lever rule shall be employed. A diagram showing the placement of the truck for the Lever Rule is shown in the Figure C1.2. According to Article 3.6.1.3.1, for the design of all bridge components other than the deck overhang, the design vehicle is to be positioned transversely such that the center of any wheel load is not closer than 2.0 feet from the edge of the design lane. Therefore, to produce the extreme force effect in the exterior girder, the truck is placed as close to the edge of the bridge as possible, i.e. 2 feet from the barrier or curb. To determine the distribution factor, moments are summed at the assumed hinge at the adjacent interior girder to determine the percentage of load resisted by the exterior girder. 


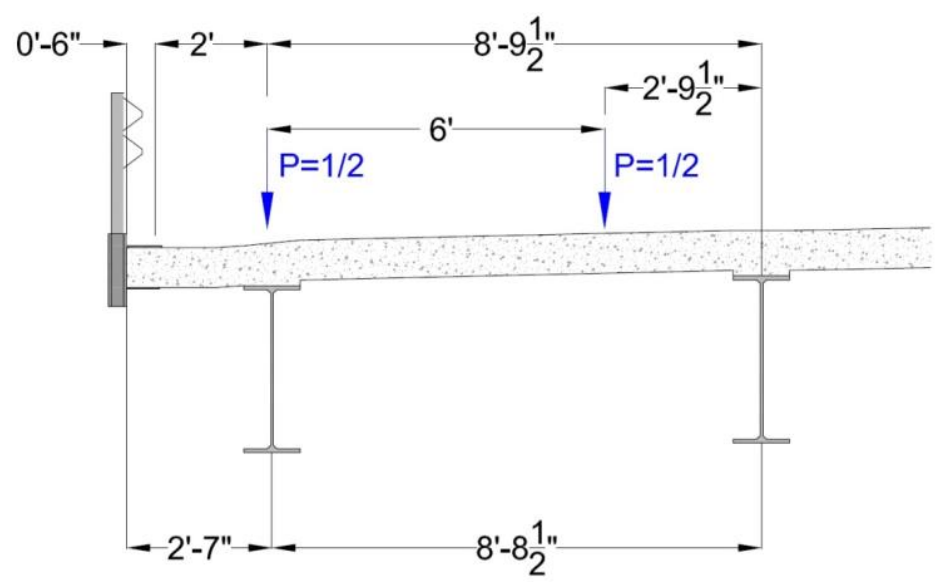

Figure C1.2: Lever Rule Truck Placement

Therefore, the lever rule analysis is as follows:

Lever Rule Analysis $=\frac{0.5(8.79)+0.5(2.79)}{8.71}=0.665$

To obtain the resulting distribution factor, this value is simply multiplied by the appropriate multiple presence factor for one-lane-loaded scenarios, or 1.20.

$g=1.20(0.665)=0.798$

\section{C1.4.2.2 Special Analysis (Article C4.6.2.2.2d)}

As stated, an additional investigation is required which assumes the entire cross-section rotates as a rigid body about the longitudinal centerline of the bridge. When applying Special Analysis, the process is iterated for as many design vehicles that can fit onto the bridge crosssection. Also, it is the responsibility of the designer or analyst to apply the appropriate multiple presence factors to the derived reactions. 
The first step is determining the eccentricities of the girders from the center-of-gravity of the girder group ( $x$ values) and the squares of those values. These values are listed in the table below.

Table C1.2: Girder Eccentricities

\begin{tabular}{ccc}
\hline Girder & $\mathrm{x}(\mathrm{ft})$ & $\mathrm{x}^{2}\left(\mathrm{ft}^{2}\right)$ \\
\hline 1 & -17.42 & 303.34 \\
2 & -8.71 & 75.84 \\
3 & 0 & 0 \\
4 & 8.71 & 75.84 \\
5 & 17.42 & 303.34 \\
\hline & $\Sigma=$ & 758.64
\end{tabular}

Therefore, $\sum_{N_{b}} x^{2}=758.64 \mathrm{ft}^{2}$.

The next step is to determine the placement of trucks and the eccentricity of these trucks from the center-of-gravity of the girder group ( $e$ values). This step is shown graphically in the figure below.

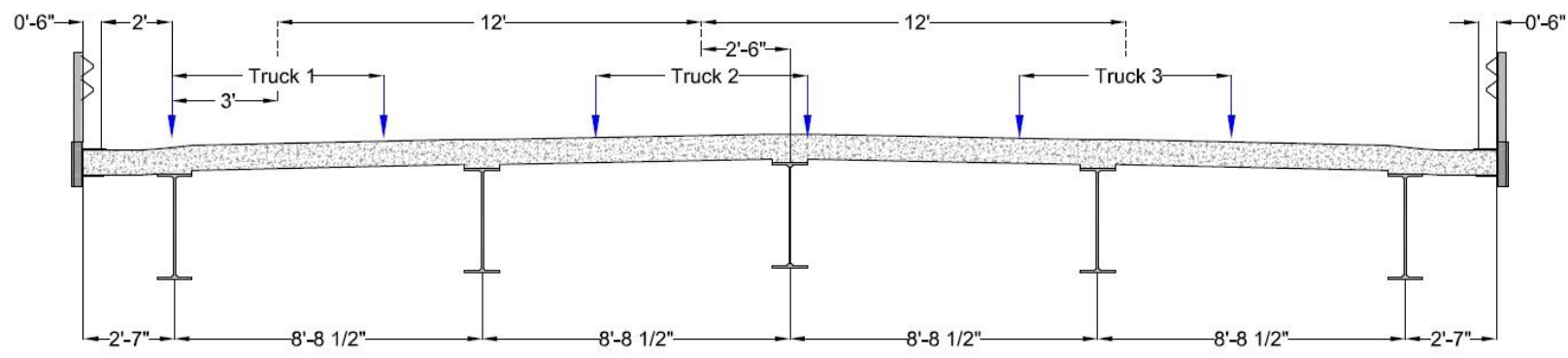

Figure C1.3: Special Analysis Truck Placement 
Therefore, for this truck placement scheme, the eccentricities, and their sums are as follows:

$$
\begin{array}{ll}
e_{1}=14.5 \mathrm{ft}, & \sum_{N_{L}} e=14.5 \mathrm{ft} \\
e_{2}=2.5 \mathrm{ft}, \quad & \sum_{N_{L}} e=14.5 \mathrm{ft}+2.5 \mathrm{ft}=17 \mathrm{ft} \\
e_{2}=-9.5 \mathrm{ft}, \quad & \sum_{N_{L}} e=14.5 \mathrm{ft}+2.5 \mathrm{ft}+(-9.5 \mathrm{ft})=7.5 \mathrm{ft}
\end{array}
$$

Employing these values and the appropriate multiple presence factors (Article 3.6.1.1.2), special analysis distribution factors can then be calculated. For these calculations, $X_{\text {ext }}$ is simply the distance from the center-of-gravity of the girder group to the exterior girder, or 17.42 feet.

$$
\begin{aligned}
& R_{1}=1.20\left[\frac{1}{5}+\frac{(17.42 \mathrm{ft})(14.5 \mathrm{ft})}{758.64 \mathrm{ft}^{2}}\right]=0.640 \\
& R_{2}=1.00\left[\frac{2}{5}+\frac{(17.42 \mathrm{ft})(17 \mathrm{ft})}{758.64 \mathrm{ft}^{2}}\right]=0.790 \\
& R_{3}=0.85\left[\frac{3}{5}+\frac{(17.42 \mathrm{ft})(7.5 \mathrm{ft})}{758.64 \mathrm{ft}^{2}}\right]=0.656
\end{aligned}
$$

\section{C1.4.2.3 Distribution Factor for Live Load Deflection (Article 2.5.2.6.2)}

To determine the distribution factor for live load deflections, all girders are assumed to deflect equally as previously stated, and the appropriate multiple presence factor shall be applied. For this bridge, with a clear roadway width of 39 feet, this equates to three design lanes (Article 3.6.1.1.1). Therefore, with a multiple presence factor of 0.85 for three loaded lanes (Article 3.6.1.1.2), the distribution factor is as follows:

$$
g=0.85\left(\frac{3}{5}\right)=0.51
$$




\section{C1.4.3 Nominal Fatigue Resistance}

Article 6.10.5.1 requires that fatigue be investigated in accordance with Article 6.6.1, which states that the live load stress range be less than the fatigue resistance. The fatigue resistance $(\Delta F)_{n}$ varies based on the fatigue category to which a particular member or detail belongs. The nominal fatigue resistance is taken as follows:

For the Fatigue I load combination (infinite life):

$$
(\Delta F)_{n}=(\Delta F)_{T H}
$$

For the Fatigue II load combination (finite life):

$$
\begin{aligned}
& (\Delta F)_{n}=\left(\frac{A}{N}\right)^{\frac{1}{3}} \\
& N=(365)(75) n(A D T T)_{S L}
\end{aligned}
$$

For this design evaluation, the detail chosen for evaluation is the base metal at the weld joining the lateral bracing connection plates at interior diaphragms. According to Table 6.6.1.2.3-1, this detail is listed with a fatigue category C'. For a C' fatigue category, a constant amplitude fatigue threshold, $(\Delta F)_{T H}=12 \mathrm{ksi}$ (Table 6.6.1.2.5-3) is obtained.

Values for $n$, or the cycles per truck passage, are listed in Table 6.6.1.2.5-2. For a simple-span girder with a span length larger than 40 feet, $n$ is taken as 1.0.

To determine the single-lane average daily truck traffic, $(A D T T)_{S L}$, a value of the average daily truck traffic , $A D T T$, must be assumed. For this example, an ADTT of 4000 trucks per day was assumed. Table 3.6.1.4.2-1 list $p$ values, which are fractions of $A D T T$ that can be expected in a single lane. For a two-lane bridge, $p=0.85$. Therefore, according to Equation 3.6.1.4.2-1, $(A D T T)_{S L}$ can be easily evaluated.

$$
(A D T T)_{S L}=p(A D T T)=0.85(4000 \text { trucks } / \text { day })=3400 \text { trucks } / \text { day }
$$


Table 6.6.1.2.3-2 lists average daily truck traffic values which are equivalent to infinite life. Specifically, Article 6.6.1.2.3 states that when the actual $(A D T T)_{S L}$ value is larger than that listed in the Table, the detail in question shall be designed for the Fatigue I load combination for infinite life. For a fatigue category C', a value of 745 trucks/day is listed. Therefore, the detail chosen for this design evaluation is evaluated for the Fatigue I load combination for infinite life.

\section{C1.5 SUMMARY}

This section contained an overview of the layout of the V-65 Jesup South Bridge assessed in this design evaluation. In addition, a comprehensive overview of loads, load combinations, and limit states employed were included. Finally, a discussion of parameters and calculations was presented. These parameters will be used to evaluate the girder solution in the following section. 


\section{Section C2: Design Assessment}

\section{C2.1 INTRODUCTION}

Contained in this section is a design assessment according to current AASHTO LRFD Specifications of a rolled beam selected from the V-65 Jesup South Bridge. In this design assessment, an evaluation of the girder at the strength, service, and fatigue limit states is conducted. Additionally, an analysis is conducted to determine whether the girder meets constructibility requirements under typical construction loads as specified in Article 6.10.3.

\section{C2.2 Girder GeOMETRY}

The rolled beams used in the V-65 Jesup South Bridge were comprised of ASTM A709 Grade 50 steel $\left(F_{y}=50 \mathrm{ksi}\right)$. The properties of this selection, a $\mathrm{W} 36 \times 135$, were obtained from the current edition of the AISC Steel Construction Manual, and are listed below:

$$
\begin{aligned}
& A_{g}=39.9 \mathrm{in}^{2} \quad d=35.6 \mathrm{in} \\
& t_{w}=0.600 \text { in } \quad b_{f}=12.0 \mathrm{in} \\
& t_{f}=0.790 \text { in } \quad \frac{b_{f}}{2 t_{f}}=7.56 \\
& I_{x}=7800 \mathrm{in}^{4} \quad S_{x}=439 \mathrm{in}^{3} \\
& Z_{x}=509 \mathrm{in}^{3} \quad r_{t s}=2.99 \text { in } \\
& h_{o}=34.8 \text { in } \quad J=7.00 \mathrm{in}^{4}
\end{aligned}
$$




\section{C2.2.1 Section Properties}

Section properties for the girder are listed on the following pages. For these calculations, all " $y$ " distances are taken from the bottom of the bottom flange. Section properties are calculated for short-term composite sections (dividing the effective flange width by $n$ ) and longterm composite sections (dividing the effective flange width by $3 n$ ). As stated in Section $\mathrm{C} 1$, the modular ratio, $n$, for this bridge is taken as 8 , and the effective flange widths are as follows.

- For interior girders, 104.5 inches

- For exterior girders, 83.25 inches

\begin{tabular}{ccccccc}
\hline \multicolumn{7}{c}{ Long Term Composite Section (Exterior Girder) } \\
Shape & $\mathrm{A}\left(\mathrm{in}^{2}\right)$ & $\mathrm{y}(\mathrm{in})$ & $\mathrm{Ay}\left(\mathrm{in}^{3}\right)$ & $\mathrm{I}_{0}\left(\mathrm{in}^{4}\right)$ & $\mathrm{d}(\mathrm{in})$ & $\mathrm{I}\left(\mathrm{in}^{4}\right)$ \\
\hline Girder & 39.9 & 17.80 & 710.2 & 7800.0 & 9.44 & 11354.6 \\
Slab & 27.8 & 40.81 & 1132.5 & 148.0 & -13.57 & 5259.0 \\
\hline$\Sigma$ & 67.7 & & 1842.7 & & & 16613.7 \\
& & & & & \\
\hline
\end{tabular}

Short Term Composite Section (Exterior Girder)

\begin{tabular}{ccccccc} 
Shape & $\mathrm{A}\left(\mathrm{in}^{2}\right)$ & $\mathrm{y}(\mathrm{in})$ & $\mathrm{Ay}\left(\mathrm{in}^{3}\right)$ & $\mathrm{I}_{0}\left(\mathrm{in}^{4}\right)$ & $\mathrm{d}(\mathrm{in})$ & $\mathrm{I}\left(\mathrm{in}^{4}\right)$ \\
\hline Girder & 39.9 & 17.80 & 710.2 & 7800.0 & 15.55 & 17454.0 \\
Slab & 83.3 & 40.81 & 3397.4 & 444.0 & -7.46 & 5070.9 \\
\hline$\Sigma$ & 123.2 & & 4107.7 & & & 22524.9
\end{tabular}

\begin{tabular}{ccccccc}
\hline & \multicolumn{6}{c}{ Long Term Composite Section (Interior Girder) } \\
Shape & $\mathrm{A}\left(\mathrm{in}^{2}\right)$ & $\mathrm{y}(\mathrm{in})$ & $\mathrm{Ay}\left(\mathrm{in}^{3}\right)$ & $\mathrm{I}_{0}\left(\mathrm{in}^{4}\right)$ & $\mathrm{d}(\mathrm{in})$ & $\mathrm{I}\left(\mathrm{in}^{4}\right)$ \\
\hline Girder & 39.9 & 17.80 & 710.2 & 7800.0 & 10.73 & 12389.5 \\
Slab & 34.8 & 40.81 & 1421.5 & 185.8 & -12.29 & 5442.9 \\
\hline$\Sigma$ & 74.7 & & 2131.8 & & & 17832.4
\end{tabular}

\begin{tabular}{ccccccc}
\hline \multicolumn{7}{c}{ Short Term Composite Section (Interior Girder) } \\
Shape & $\mathrm{A}\left(\mathrm{in}^{2}\right)$ & $\mathrm{y}(\mathrm{in})$ & $\mathrm{Ay}\left(\mathrm{in}^{3}\right)$ & $\mathrm{I}_{0}\left(\mathrm{in}^{4}\right)$ & $\mathrm{d}(\mathrm{in})$ & $\mathrm{I}\left(\mathrm{in}^{4}\right)$ \\
\hline Girder & 39.9 & 17.80 & 710.2 & 7800.0 & 16.65 & 18863.8 \\
Slab & 104.5 & 40.81 & 4264.6 & 557.3 & -6.36 & 4781.7 \\
\hline$\Sigma$ & 144.4 & & 4974.9 & & & 23645.5
\end{tabular}




\section{C2.2.2 Cross-Section Proportion Limits}

The girder in this design evaluation was evaluated to meet the cross-section proportion limits of Article 6.10.2. For webs without longitudinal stiffeners, the following limit is employed from Article 6.10.2.1.1.

$$
\begin{aligned}
& \frac{D}{t_{w}} \leq 150 \\
& \frac{35.6-2(0.79)}{0.600} \leq 150
\end{aligned}
$$

$56.7 \leq 150 \therefore O K$

As previously stated, the following limits are employed for flange proportions. In addition to the limits set forth in Article 6.10.2.2, Article C6.10.3.4 specifies an additional limit for the compression flange, and is presented below. For this evaluation, the results show that the girder meets all applicable cross-section proportion limits.

$$
\frac{b_{f}}{2 t_{f}} \leq 12.0
$$

$7.56 \leq 12.0 \therefore O K$

$b_{f} \geq \frac{D}{6}$

Eq. 6.10.2.2-2

$12.0 \geq \frac{35.6-2(0.79)}{6}$

$12.0 \geq 5.67 \therefore O K$

$t_{f} \geq 1.1 t_{w}$

Eq. 6.10.2.2-3

$0.79 \geq 1.1(0.600)$

$0.79 \geq 0.66 \therefore O K$ 
$0.1 \leq \frac{I_{y c}}{I_{y t}} \leq 10$

Eq. 6.10.2.2-3

$0.1 \leq \frac{(0.79)\left(12.0^{3}\right) / 12}{(0.79)\left(12.0^{3}\right) / 12} \leq 10$

$0.1 \leq 1.0 \leq 10 \therefore O K$

$b_{f c} \geq \frac{L}{85}$

Eq. C6.10.3.4-1

$12.0 \geq \frac{63(12)}{85}$

$12.0 \geq 8.89 \therefore O K$

\section{C2.3 DEAD LOADS}

The dead loads computed for this girder consist of the component and attachment dead load (DC) and the wearing surface dead load (DW) and are described herein.

\section{C2.3.1 Component and Attachment Dead Load (DC)}

The dead load of structural components and nonstructural attachments are computed as follows. As previously stated, the DC load is divided into two components, the load applied to the noncomposite section $\left(\mathrm{DC}_{1}\right)$ and the load applied to the long-term composite section $\left(\mathrm{DC}_{2}\right)$. Loads such as the slab, overhang tapers, the guardrail, and the SIP formwork are assumed to be equally distributed to all of the girders. 
NONCOMPOSITE DEAD LOAD ( $\left(\mathrm{DC}_{1}\right)$ :

$\mathrm{Slab}=\frac{0.150}{5}\left[\left(\frac{8.5}{12}\right)(40)\right]$

$0.850 \mathrm{kip} / \mathrm{ft}$

Haunch $=0.150\left[\left(\frac{12}{12}\right)\left(\frac{2.0-0.79}{12}\right)\right]$

$0.015 \mathrm{kip} / \mathrm{ft}$

Taper $=0.150\left(\frac{2}{5}\right)\left[\left(\frac{2.0-0.79}{12}\right)\left(\frac{31-12 / 2}{12}\right)\right]$

$0.013 \mathrm{kip} / \mathrm{ft}$

$\mathrm{SIP}=\frac{0.015}{5} 4\left[8.71-\frac{12}{12}\right]$

$0.093 \mathrm{kip} / \mathrm{ft}$

Girder $=$ W36 $\times 135$

$0.135 \mathrm{kip} / \mathrm{ft}$

Misc. Details $=5 \%$

$0.007 \mathrm{kip} / \mathrm{ft}$

$1.113 \mathrm{kip} / \mathrm{ft}$

Composite DeAd LoAD $\left(\mathrm{DC}_{2}\right)$ :

Guardrail $=\frac{2}{5}(0.100)$

$0.040 \mathrm{kip} / \mathrm{ft}$

0.040 kip/ft

\section{C2.3.2 Wearing Surface Dead Load (DW)}

The dead load of the future wearing surface is applied across the clear roadway width of 39 feet. Like $\mathrm{DC}_{1}$ and $\mathrm{DC}_{2}$, loads are assumed to be equally distributed to all of the girders.

WEARING SURFACE DEAD LOAD (DW):

Wearing Surface $=\frac{0.025}{5}(39)$

$0.195 \mathrm{kip} / \mathrm{ft}$

0.195 kip/ft 


\section{C2.4 Structural Analysis}

For this design evaluation, an approximate analysis is conducted which employs a linegirder analysis model. Dead loads, as stated earlier, are assumed to be evenly distributed to all girders. For live loads, live load distribution factors are used to distribute the vehicular live load to the line-girder model.

\section{C2.4.1 Live Load Distribution Factors (Article 4.6.2.2)}

As previously stated, many of the bending moment distribution factors specified in Article 4.6.2.2 are a function of $K_{g}$, a longitudinal stiffness parameter. $K_{g}$ is computed according to Eq. 4.6.2.2.1-1, and is shown below for an interior girder. Note that $K_{g}$ does not need to be calculated for exterior girders since the lever rule, special analysis, and modified interior distribution factors serve as the exterior girder moment distribution factors. In addition, as previously stated, $K_{g}$ must lie between 10,000 in ${ }^{4}$ and 7,000,000 in ${ }^{4}$ for the application of these distribution factors to be valid; as shown, this limit is clearly met.

$$
\begin{aligned}
& K_{g}=n\left(I+A e_{g}{ }^{2}\right) \\
& K_{g}=8\left[7800+(39.9)\left(\frac{35.6}{2}+(2.0-0.79)+\frac{8.0}{2}\right)^{2}\right] \\
& K_{g}=231,404 \mathrm{in}^{4}
\end{aligned}
$$

\section{C2.4.1.1 General Live Load Distribution Factors}

Using the formulas and methods discussed in C1.4.2, moment and shear distribution factors for the strength and service limit states are calculated and listed as follows. Note that many of the values are repeated as the lever rule and special analysis apply to both moment and shear distribution. 


\begin{tabular}{lc}
\multicolumn{2}{l}{ StREnGTH AND SERVICE LiMit STATE } \\
Bending Moment - Interior Girder \\
$\quad$ One Lane Loaded & 0.494 \\
Multiple Lanes Loaded & 0.682 \\
Shear - Interior Girder & \\
One Lane Loaded & 0.708 \\
Multiple Lanes Loaded & 0.864 \\
Bending Moment - Exterior Girder & \\
One Lane Loaded & 0.798 \\
Multiple Lanes Loaded & 0.716 \\
Special Analysis (1 Lane) & 0.64 \\
Special Analysis (2 Lanes) & 0.79 \\
Special Analysis (3 Lanes) & 0.659 \\
Shear - Exterior Girder & \\
One Lane Loaded & 0.798 \\
Multiple Lanes Loaded & 0.682 \\
Special Analysis (1 Lane) & 0.64 \\
Special Analysis (2 Lanes) & 0.79 \\
Special Analysis (3 Lanes) & 0.659
\end{tabular}

\section{C2.4.1.2 Fatigue Live Load Distribution Factors}

Using the formulas and methods discussed in C1.4.2, live load distribution factors for the fatigue limit state are calculated and listed below. To obtain these values, the previously computed distribution factors for one-lane-loaded scenarios (chosen since the fatigue loading consists of only one design truck) are divided by 1.20, the multiple presence factor for one lane loaded (as previously stated, multiple presence factors are not applied at the fatigue limit state). 


\author{
FATIGUE LiMit STATE \\ Bending Moment - Interior Girder \\ One Lane Loaded \\ 0.412 \\ Bending Moment - Exterior Girder \\ One Lane Loaded $\quad 0.665$ \\ Special Analysis (1 Lane) $\quad 0.533$
}

\title{
C2.4.1.3 Live Load Distribution Factor Summary
}

Governing distribution factors are listed below for interior and exterior girders. As shown, distribution factors for exterior girders, on average, exceed those for interior girders. Also, the distribution factor for deflection (computed earlier) is also presented.

$\begin{array}{lcc}\text { SUMMARY } & \underline{\text { Interior }} & \text { Exterior } \\ \text { Moment } & 0.682 & 0.798 \\ \text { Shear } & 0.864 & 0.798 \\ \text { Fatigue Moment } & 0.412 & 0.665 \\ \text { Deflection } & 0.510 & 0.510\end{array}$

\section{C2.5 ANALysis Results}

The tables in this section contain the moments, shears, and deflections resulting from structural analysis of the girder. Analyses were generated using the commercial software package LEAP CONSYS (2008), which idealizes the structure as a continuous line-girder. For these analyses, properties from the exterior girder were utilized for the stiffness of the line-girder model. This was due to the reduced section properties (due to a smaller effective flange width) and the increased live load distribution factors. An exception to this, however, is the set of distributed shears, which are distributed according to the interior girder (chosen for its high live load distribution factor). 


\begin{tabular}{|c|c|c|c|c|c|c|c|c|c|c|c|}
\hline \multirow{3}{*}{$x / L$} & \multicolumn{11}{|c|}{ Unfactored/Undistributed Moments (ft-kip) } \\
\hline & \multirow{2}{*}{$D C_{1}$} & \multirow{2}{*}{$D C_{2}$} & \multirow{2}{*}{$D W$} & \multicolumn{2}{|c|}{ Truck } & \multicolumn{2}{|c|}{ Lane } & \multicolumn{2}{|c|}{ Tandem } & \multicolumn{2}{|c|}{ Fatigue Truck } \\
\hline & & & & $(+)$ & $(-)$ & $(+)$ & $(-)$ & $(+)$ & $(-)$ & $(+)$ & $(-)$ \\
\hline 0 & 0.0 & 0.0 & 0.0 & 0 & 0 & 0 & 0 & 0 & 0 & 0 & 0 \\
\hline 0.1 & 199.7 & 7.1 & 34.8 & 341.0 & 0 & 114.3 & 0 & 273.5 & 0 & 277.0 & 0 \\
\hline 0.2 & 355.0 & 12.7 & 61.9 & 591.4 & 0 & 203.2 & 0 & 484 & 0 & 463.4 & 0 \\
\hline 0.3 & 465.9 & 16.7 & 81.3 & 751.0 & 0 & 266.7 & 0 & 631.5 & 0 & 586.2 & 0 \\
\hline 0.4 & 532.5 & 19.1 & 92.9 & 842.2 & 0 & 304.8 & 0 & 716 & 0 & 637.4 & 0 \\
\hline 0.5 & 554.7 & 19.8 & 96.7 & 854.0 & 0 & 317.5 & 0 & 737.5 & 0 & 598.0 & 0 \\
\hline 0.6 & 532.5 & 19.1 & 92.9 & 842.2 & 0 & 304.8 & 0 & 716 & 0 & 637.4 & 0 \\
\hline 0.7 & 465.9 & 16.7 & 81.3 & 751.0 & 0 & 266.7 & 0 & 631.5 & 0 & 586.2 & 0 \\
\hline 0.8 & 355.0 & 12.7 & 61.9 & 591.4 & 0 & 203.2 & 0 & 484 & 0 & 463.4 & 0 \\
\hline 0.9 & 199.7 & 7.1 & 34.8 & 341.0 & 0 & 114.3 & 0 & 273.5 & 0 & 277.0 & 0 \\
\hline 1 & 0.0 & 0.0 & 0.0 & 0 & 0 & 0 & 0 & 0 & 0 & 0 & 0 \\
\hline
\end{tabular}

\begin{tabular}{|c|c|c|c|c|c|c|c|c|c|}
\hline \multirow{3}{*}{$x / L$} & \multirow{3}{*}{$D C_{1}$} & \multirow{3}{*}{$D C_{2}$} & \multicolumn{5}{|c|}{ Unfactored/Undistributed Shears (kip) } & \multirow{2}{*}{\multicolumn{2}{|c|}{ Tandem }} \\
\hline & & & \multirow{2}{*}{$D W$} & \multicolumn{2}{|c|}{ Truck } & \multicolumn{2}{|c|}{ Lane } & & \\
\hline & & & & $(+)$ & $(-)$ & $(+)$ & $(-)$ & $(+)$ & $(-)$ \\
\hline 0 & 35.2 & 1.3 & 6.1 & 61.3 & 0.0 & 20.2 & 0 & 48.4 & 0 \\
\hline 0.1 & 28.2 & 1.0 & 4.9 & 54.1 & -3.2 & 16.3 & -0.2 & 43.4 & -3.4 \\
\hline 0.2 & 21.1 & 0.8 & 3.7 & 46.9 & -6.4 & 12.9 & -0.8 & 38.4 & -8.4 \\
\hline 0.3 & 14.1 & 0.5 & 2.5 & 39.7 & -12.1 & 9.9 & -1.8 & 33.4 & -13.4 \\
\hline 0.4 & 7.0 & 0.3 & 1.2 & 32.5 & -18.5 & 7.3 & -3.2 & 28.4 & -18.4 \\
\hline 0.5 & 0.0 & 0.0 & 0.0 & 25.3 & -25.3 & 5.0 & -5.0 & 23.4 & -23.4 \\
\hline 0.6 & -7.0 & -0.3 & -1.2 & 18.5 & -32.5 & 3.2 & -7.3 & 18.4 & -28.4 \\
\hline 0.7 & -14.1 & -0.5 & -2.5 & 12.1 & -39.7 & 1.8 & -9.9 & 13.4 & -33.4 \\
\hline 0.8 & -21.1 & -0.8 & -3.7 & 6.4 & -46.9 & 0.8 & -12.9 & 8.4 & -38.4 \\
\hline 0.9 & -28.2 & -1.0 & -4.9 & 3.2 & -54.1 & 0.2 & -16.3 & 3.4 & -43.4 \\
\hline 1 & -35.2 & -1.3 & -6.1 & 0 & -61.3 & 0.0 & -20.2 & 0 & -48.4 \\
\hline
\end{tabular}




\begin{tabular}{ccccc}
\hline \multicolumn{3}{c}{ Unfactored/Undistributed Deflections (in) } \\
$x / L$ & \multicolumn{2}{c}{ Truck } & \multicolumn{2}{c}{ Lane } \\
& $(+)$ & $(-)$ & $(+)$ & $(-)$ \\
\hline 0 & 0 & 0 & 0 & 0 \\
0.1 & 0.21 & 0 & 0.11 & 0 \\
0.2 & 0.4 & 0 & 0.21 & 0 \\
0.3 & 0.55 & 0 & 0.28 & 0 \\
0.4 & 0.65 & 0 & 0.33 & 0 \\
0.5 & 0.68 & 0 & 0.35 & 0 \\
0.6 & 0.65 & 0 & 0.33 & 0 \\
0.7 & 0.55 & 0 & 0.28 & 0 \\
0.8 & 0.4 & 0 & 0.21 & 0 \\
0.9 & 0.21 & 0 & 0.11 & 0 \\
1 & 0 & 0 & 0 & 0 \\
\hline
\end{tabular}

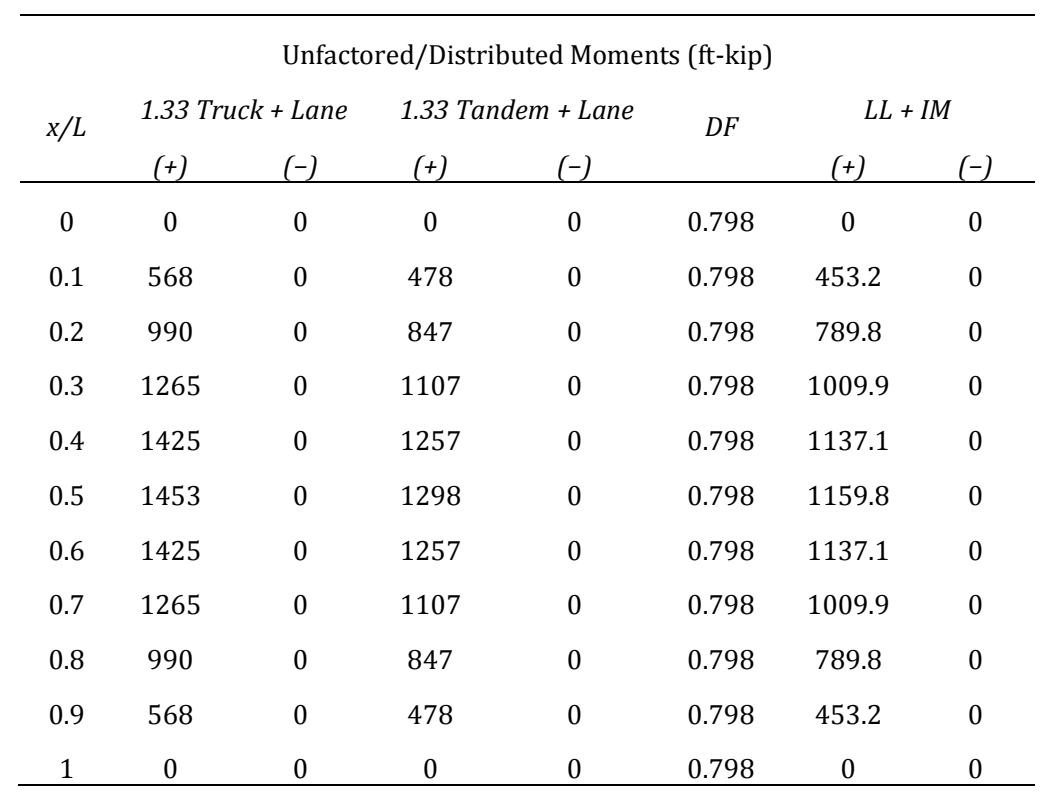




\begin{tabular}{|c|c|c|c|c|c|c|c|}
\hline \multicolumn{8}{|c|}{ Unfactored/Distributed Shears (kip) } \\
\hline \multirow{2}{*}{$x / L$} & \multicolumn{2}{|c|}{1.33 Truck + Lane } & \multicolumn{2}{|c|}{ 1.33 Tandem + Lane } & \multirow{2}{*}{$D F$} & \multicolumn{2}{|c|}{$L L+I M$} \\
\hline & $(+)$ & $(-)$ & $(+)$ & $(-)$ & & $(+)$ & $(-)$ \\
\hline 0 & 101.6 & 0.0 & 84.5 & 0.0 & 0.864 & 87.8 & 0 \\
\hline 0.1 & 88.3 & -4.5 & 74.1 & -4.7 & 0.864 & 76.3 & -4.1 \\
\hline 0.2 & 75.3 & -9.3 & 64.0 & -12.0 & 0.864 & 65.1 & -10.4 \\
\hline 0.3 & 62.7 & -17.9 & 54.3 & -19.7 & 0.864 & 54.2 & -17.0 \\
\hline 0.4 & 50.5 & -27.8 & 45.0 & -27.7 & 0.864 & 43.7 & -24.0 \\
\hline 0.5 & 38.7 & -38.7 & 36.2 & -36.2 & 0.864 & 33.5 & -33.5 \\
\hline 0.6 & 27.8 & -50.5 & 27.7 & -45.0 & 0.864 & 24.0 & -43.7 \\
\hline 0.7 & 17.9 & -62.7 & 19.7 & -54.3 & 0.864 & 17.0 & -54.2 \\
\hline 0.8 & 9.3 & -75.3 & 12.0 & -64.0 & 0.864 & 10.4 & -65.1 \\
\hline 0.9 & 4.5 & -88.3 & 4.7 & -74.1 & 0.864 & 4.1 & -76.3 \\
\hline 1 & 0.0 & -101.6 & 0.0 & -84.5 & 0.864 & 0 & -87.8 \\
\hline \multicolumn{8}{|c|}{ Strength I Moments (ft-kip) } \\
\hline \multirow[t]{2}{*}{$x / L$} & \multirow[t]{2}{*}{$1.25 D C_{1}$} & \multirow[t]{2}{*}{$1.25 D C_{2}$} & \multirow[t]{2}{*}{$1.50 \mathrm{DW}$} & \multicolumn{2}{|c|}{$1.75 L L+I M$} & \multicolumn{2}{|c|}{ Strength I } \\
\hline & & & & $(+)$ & $(-)$ & $(+)$ & $(-)$ \\
\hline 0 & 0 & 0 & 0 & 0 & 0 & 0 & 0 \\
\hline 0.1 & 249.6 & 8.9 & 52.2 & 793.1 & 0 & 1103.8 & 310.8 \\
\hline 0.2 & 443.7 & 15.9 & 92.9 & 1382.1 & 0 & 1934.6 & 552.5 \\
\hline 0.3 & 582.4 & 20.8 & 121.9 & 1767.3 & 0 & 2492.4 & 725.1 \\
\hline 0.4 & 665.6 & 23.8 & 139.3 & 1990.0 & 0 & 2818.7 & 828.7 \\
\hline 0.5 & 693.3 & 24.8 & 145.1 & 2029.6 & 0 & 2892.8 & 863.3 \\
\hline 0.6 & 665.6 & 23.8 & 139.3 & 1990.0 & 0 & 2818.7 & 828.7 \\
\hline 0.7 & 582.4 & 20.8 & 121.9 & 1767.3 & 0 & 2492.4 & 725.1 \\
\hline 0.8 & 443.7 & 15.9 & 92.9 & 1382.1 & 0 & 1934.6 & 552.5 \\
\hline 0.9 & 249.6 & 8.9 & 52.2 & 793.1 & 0 & 1103.8 & 310.8 \\
\hline 1 & 0 & 0 & 0 & 0 & 0 & 0 & 0 \\
\hline
\end{tabular}




\begin{tabular}{cccccccc}
\hline \multicolumn{7}{c}{ Strength I Shears (kip) } \\
$x / L$ & $1.25 D C_{1}$ & $1.25 D C_{2}$ & $1.50 D W$ & \multicolumn{2}{c}{$1.75 L L+I M$} & \multicolumn{2}{c}{ Strength I } \\
& & & & $(+)$ & $(-)$ & $(+)$ & $(-)$ \\
\hline 0 & 44.0 & 1.6 & 9.2 & 153.7 & 0 & 208.5 & 54.8 \\
0.1 & 35.2 & 1.3 & 7.4 & 133.6 & -7.2 & 177.4 & 36.7 \\
0.2 & 26.4 & 0.9 & 5.5 & 113.9 & -18.1 & 146.8 & 14.7 \\
0.3 & 17.6 & 0.6 & 3.7 & 94.8 & -29.7 & 116.8 & -7.8 \\
0.4 & 8.8 & 0.3 & 1.8 & 76.4 & -42.1 & 87.4 & -31.1 \\
0.5 & 0 & 0 & 0 & 58.6 & -58.6 & 58.6 & -58.6 \\
0.6 & -8.8 & -0.3 & -1.8 & 42.1 & -76.4 & 31.1 & -87.4 \\
0.7 & -17.6 & -0.6 & -3.7 & 29.7 & -94.8 & 7.8 & -116.8 \\
0.8 & -26.4 & -0.9 & -5.5 & 18.1 & -113.9 & -14.7 & -146.8 \\
0.9 & -35.2 & -1.3 & -7.4 & 7.2 & -133.6 & -36.7 & -177.4 \\
1 & -44.0 & -1.6 & -9.2 & 0 & -153.7 & -54.8 & -208.5 \\
\hline
\end{tabular}

Service II Moments (ft-kip)

\begin{tabular}{cccccccc}
$x / L$ & $1.00 D C_{1}$ & $1.00 D C_{2}$ & $1.00 D W$ & $1.30 L L+I M$ & \multicolumn{2}{c}{ Service II } \\
& & & & $(+)$ & $(-)$ & $(+)$ & $(-)$ \\
\hline 0 & 0 & 0 & 0 & 0 & 0 & 0 & 0 \\
0.1 & 199.7 & 7.1 & 34.8 & 589.1 & 0 & 830.8 & 241.7 \\
0.2 & 355.0 & 12.7 & 61.9 & 1026.7 & 0 & 1456.3 & 429.6 \\
0.3 & 465.9 & 16.7 & 81.3 & 1312.8 & 0 & 1876.7 & 563.9 \\
0.4 & 532.5 & 19.1 & 92.9 & 1478.3 & 0 & 2122.7 & 644.4 \\
0.5 & 554.7 & 19.8 & 96.7 & 1507.7 & 0 & 2179.0 & 671.3 \\
0.6 & 532.5 & 19.1 & 92.9 & 1478.3 & 0 & 2122.7 & 644.4 \\
0.7 & 465.9 & 16.7 & 81.3 & 1312.8 & 0 & 1876.7 & 563.9 \\
0.8 & 355.0 & 12.7 & 61.9 & 1026.7 & 0 & 1456.3 & 429.6 \\
0.9 & 199.7 & 7.1 & 34.8 & 589.1 & 0 & 830.8 & 241.7 \\
1 & 0 & 0 & 0 & 0 & 0 & 0 & 0 \\
\hline
\end{tabular}




\begin{tabular}{|c|c|c|c|c|c|c|c|}
\hline \multirow{3}{*}{$x / L$} & \multicolumn{7}{|c|}{ Service I Deflections (in) } \\
\hline & \multicolumn{2}{|c|}{ Truck } & \multicolumn{2}{|c|}{0.25 Truck + Lane } & \multirow{2}{*}{$D F$} & \multicolumn{2}{|c|}{ Service I } \\
\hline & $(+)$ & $(-)$ & $(+)$ & $(-)$ & & $(+)$ & $(-)$ \\
\hline 0 & 0 & 0 & 0 & 0 & 0.510 & 0 & 0 \\
\hline 0.1 & 0.28 & 0 & 0.18 & 0 & 0.510 & 0.14 & 0 \\
\hline 0.2 & 0.53 & 0 & 0.34 & 0 & 0.510 & 0.27 & 0 \\
\hline 0.3 & 0.73 & 0 & 0.46 & 0 & 0.510 & 0.37 & 0 \\
\hline 0.4 & 0.86 & 0 & 0.55 & 0 & 0.510 & 0.44 & 0 \\
\hline 0.5 & 0.90 & 0 & 0.58 & 0 & 0.510 & 0.461 & 0 \\
\hline 0.6 & 0.86 & 0 & 0.55 & 0 & 0.510 & 0.44 & 0 \\
\hline 0.7 & 0.73 & 0 & 0.46 & 0 & 0.510 & 0.37 & 0 \\
\hline 0.8 & 0.53 & 0 & 0.34 & 0 & 0.510 & 0.27 & 0 \\
\hline 0.9 & 0.28 & 0 & 0.18 & 0 & 0.510 & 0.14 & 0 \\
\hline 1 & 0 & 0 & 0 & 0 & 0.510 & 0 & 0 \\
\hline
\end{tabular}

Fatigue Moments (ft-kip)

\begin{tabular}{cccccc}
$x / L$ & \multicolumn{2}{c}{$L L+I M$} & $D F$ & \multicolumn{2}{c}{$1.50(L L+I M)$} \\
& $(+)$ & $(-)$ & & $(+)$ & $(-)$ \\
\hline 0 & 0 & 0 & 0.665 & 0 & 0 \\
0.1 & 318.6 & 0 & 0.665 & 317.8 & 0 \\
0.2 & 532.9 & 0 & 0.665 & 531.5 & 0 \\
0.3 & 674.1 & 0 & 0.665 & 672.4 & 0 \\
0.4 & 733.1 & 0 & 0.665 & 731.2 & 0 \\
0.5 & 687.7 & 0 & 0.665 & 686.0 & 0 \\
0.6 & 733.1 & 0 & 0.665 & 731.2 & 0 \\
0.7 & 674.1 & 0 & 0.665 & 672.4 & 0 \\
0.8 & 532.9 & 0 & 0.665 & 531.5 & 0 \\
0.9 & 318.6 & 0 & 0.665 & 317.8 & 0 \\
1 & 0 & 0 & 0.665 & 0 & 0 \\
\hline
\end{tabular}




\section{C2.6 Limit State Evaluations}

Presented in this section is an evaluation of an exterior girder for the V-65 Jesup South Bridge. The exterior girder was chosen due to the reduced section properties (due to a smaller effective flange width) and the increased live load distribution factors. In this evaluation, all of the aforementioned limit states, including strength, service, and fatigue are assessed. In addition, a constructibility evaluation is also performed.

\section{C2.6.1 Constructibility}

The provisions of Article 6.10.3 are employed to ensure adequate performance related to yielding of the flanges, flexural resistance of the compression flange, and web bend-buckling resistance during stages of construction. During construction, the noncomposite girder must have sufficient capacity to resist construction force effects. Therefore, the capacity of the noncomposite girder must be evaluated.

\section{C2.6.1.1 Compression Flange Resistance}

The first step is determining which Article is applicable in determining the flexural capacity of the noncomposite girder. Article 6.10.6.2.3 states that Appendix A6 may be employed if the girder meets certain limits. This is preferable, as Appendix A6 allows the girder's noncomposite capacity to exceed the yield moment. For Appendix A6 to be applicable, the flanges' yield strengths must not exceed $70.0 \mathrm{ksi}$ (this limit is met since $F_{y}=50 \mathrm{ksi}$ ), the skew must not exceed $20^{\circ}$ (no skew is present) and two additional limits must be met.

$$
\begin{aligned}
& \frac{2 D_{c}}{t_{w}}<5.7 \sqrt{\frac{E}{F_{y c}}} \\
& \frac{I_{y c}}{I_{y t}} \geq 0.3
\end{aligned}
$$


The depth of the web in compression of the noncomposite girder in the elastic range, $D_{c}$, is the distance from the top of the web to the neutral axis of the girder. In addition, $I_{y c}$ and $I_{y t}$ have already been determined for this girder (see C2.2.2). Therefore, the evaluation of these limits is as follows.

$$
\begin{aligned}
& D_{c}=\frac{35.6-2(0.79)}{2}=17.01 \mathrm{in} \\
& \frac{2 D_{c}}{t_{w}}<5.7 \sqrt{\frac{E}{F_{y c}}} \\
& \frac{2(17.01)}{0.600}<5.7 \sqrt{\frac{29000}{50}}
\end{aligned}
$$

$56.7<137.27 \therefore O K$

$$
\frac{I_{y c}}{I_{y t}} \geq 0.3
$$

$1.0>0.3 \therefore O K$

Therefore, Appendix A6 may be employed. To employ Appendix A6, the yield moment, $M_{y}$, and the plastic moment, $M_{p}$, of the noncomposite girder must be computed. The yield moment of the girder is simply the yield stress, $F_{y}$, multiplied by the section modulus, $S_{x}$. The plastic moment of the girder is simply the yield stress, $F_{y}$, multiplied by the plastic section modulus, $Z_{x}$.

$$
\begin{aligned}
& M_{y}=F_{y} S_{x} \\
& M_{y}=\frac{(50)(439)}{12} \\
& M_{y}=1829.2 \mathrm{ft}-\mathrm{kip}
\end{aligned}
$$




$$
\begin{aligned}
& M_{p}=F_{y} Z_{x} \\
& M_{p}=\frac{(50)(509)}{12} \\
& M_{p}=2120.8 \mathrm{ft}-\mathrm{kip}
\end{aligned}
$$

The first step in employing Appendix A6 is to determine whether the section is a compact web section or a noncompact web section. Compact web sections are those that meet the following requirements.

$$
\frac{2 D_{c p}}{t_{w}} \leq \lambda_{p w\left(D_{c p}\right)}
$$

$D_{c p}$ is the depth of the web in compression at the plastic moment. Since the plastic neutral axis of a rolled beam is at the same location as the elastic neutral axis, this value is the same as $D_{c}$, or 17.01 inches. $\lambda_{p w\left(D_{e q}\right)}$ is then computed as follows.

$$
\begin{aligned}
& \lambda_{r w}=5.7 \sqrt{\frac{E}{F_{y c}}} \\
& \lambda_{r w}=5.7 \sqrt{\frac{29000}{50}} \\
& \lambda_{r w}=137.27
\end{aligned}
$$

$$
\begin{aligned}
& \lambda_{p w\left(D_{p p}\right)}=\frac{\sqrt{\frac{E}{F_{y c}}}}{\left(0.54 \frac{M_{p}}{R_{h} M_{y}}-0.09\right)^{2}} \leq \lambda_{r w}\left(\frac{D_{c p}}{D_{c}}\right) \\
& \lambda_{p w\left(D_{c p}\right)}=\frac{\sqrt{\frac{29000}{50}}}{\left[0.54 \frac{2120.8}{(1.0)(1829.2)}-0.09\right]^{2}} \leq 137.27\left(\frac{17.01}{17.01}\right)
\end{aligned}
$$




$$
\begin{aligned}
& \lambda_{p w\left(D_{c p}\right)}=83.8<137.24 \\
& \lambda_{p w\left(D_{c p}\right)}=83.8
\end{aligned}
$$

Therefore, as shown below, the girder qualifies as a compact web section.

$$
\begin{aligned}
& \frac{2 D_{c p}}{t_{w}} \leq \lambda_{p w}\left(D_{c p}\right) \\
& \frac{2(17.01)}{0.600} \leq 83.8
\end{aligned}
$$

$56.7<83.8 \therefore$ Web is compact

To determine the flexural capacity of the compression flange for a compact web section, a web plastification factor for the compression flange, $R_{p c}$, must be determined. This essentially determines how much the girder's flexural capacity can exceed $M_{y}$. In addition, they can account for the influence of web slenderness on the maximum potential flexural resistance. The web plastification factor is computed as follows.

$$
\begin{aligned}
R_{p c} & =\frac{M_{p}}{M_{y c}} \\
R_{p c} & =\frac{2120.8}{1829.2} \\
R_{p c} & =1.159
\end{aligned}
$$

The flexural capacity of the compression flange is a function of the slenderness ratio of the flange and whether or not the flange is classified as compact. The web plastification factor computed earlier is then used to compute the section's flexural capacity. For flanges to be classified as compact, the slenderness ratio for the flange, $\lambda_{f}$, must be less than a limiting value, $\lambda_{p f}$. As shown, the flange meets the requirements for compactness. 


$$
\begin{aligned}
& \lambda_{f}=\frac{b_{f c}}{2 t_{f c}} \\
& \lambda_{f}=7.56
\end{aligned}
$$

$\lambda_{p f}=0.38 \sqrt{\frac{E}{F_{y}}}$

Eq. A6.3.2-4

$\lambda_{p f}=0.38 \sqrt{\frac{29000}{50}}$

$\lambda_{p f}=9.15$

$\lambda_{f}<\lambda_{p f} \therefore$ Flange is compact

Therefore, the flexural capacity of the compression flange is computed as follows. Equation A6.3.2-1 yields the flexural capacity in terms of the girder's overall capacity, not the flange's capacity. To obtain the capacity of the flange, in accordance with Article 6.10.3.2.1, the flange's capacity can be computed by dividing the girder's capacity by $S_{x c}$.

$M_{n c}=R_{p c} M_{y c}$

$M_{n c}=(1.159)(1829.2)$

$M_{n c}=2120 \mathrm{ft}-\mathrm{kip}$

$F_{n c}=\frac{M_{n c}}{S_{x c}}$

$F_{n c}=\frac{2120(12)}{439}$

$F_{n c}=57.95 \mathrm{ksi}$ 


\section{C2.6.1.2 Major Axis and Lateral Flange Bending Stresses}

The next step in performing this constructability analysis is to determine the major axis and lateral flange bending stresses that the girder will be subjected to during construction. First, major-axis bending stresses will be computed. As previously stated, the deck is assumed to be cast in one pour; therefore, major axis bending stresses will be computed according to $\mathrm{DC}_{1}$. From analysis results, the unfactored $\mathrm{DC}_{1}$ moment was found to be $554.7 \mathrm{ft}$-kip. Therefore, major axis bending stresses are as follows. For this computation, the Strength IV load combination is employed in addition to Strength I. This is because, during construction, the bridge is subjected to very high dead to live load force effect ratios. In addition, since this section is a symmetric rolled beam, the top flange stresses during construction will be equal (in magnitude) to the bottom flange stresses.

\section{STRENGTH I:}

$f_{b u}=\frac{1.25(554.7)(12)}{439}=18.95 \mathrm{ksi}$

STRENGTH IV:

$$
f_{b u}=\frac{1.50(554.7)(12)}{439}=22.74 \mathrm{ksi}
$$

Next, stresses due to lateral flange bending forces from construction loads must be computed. Before calculating lateral flange bending stresses, a determination must be made regarding whether or not a second-order analysis must be carried out for compressive stresses. To make this determination, a number of variables must be computed, including the effective radius of gyration for lateral torsional buckling, $r_{t}$, and the limiting unbraced length to achieve the maximum flexural resistance, $L_{p}$. For rolled beams, the AISC Steel Construction Manual provides a value for $r_{t}$ (or $r_{t s}$ as it is listed); for a $\mathrm{W} 36 \times 135$, the value is 2.99 inches. 


$$
\begin{aligned}
& L_{p}=1.0 r_{t} \sqrt{\frac{E}{F_{y c}}} \\
& L_{p}=1.0(2.99) \sqrt{\frac{29000}{50}} \\
& L_{p}=72.0 \mathrm{in}
\end{aligned}
$$

A moment gradient modifier, $C_{b}$, must then be computed in order to determine whether or not a second-order analysis must be carried out. $C_{b}$ is a coefficient which accounts for different moment gradients on lateral torsional buckling.

It was previously determined that Appendix A6 was applicable for this noncomposite girder. Therefore, to compute $C_{b}$, moments must be found at various lengths along the unbraced segment of interest. For this structure, the unbraced length, $L_{b}$, is simply the spacing of diaphragms, or 20 feet.

From analysis results (interpolating between tenth points), the following unfactored moments were obtained for the unbraced segment at midspan. It should be noted that since deck casting moments will result solely from $\mathrm{DC}_{1}$, this calculation for $C_{b}$ will be valid for both Strength I and Strength IV load combinations.

$M_{\text {mid }}=$ major-axis bending moment at the middle of the unbraced length $=554.7 \mathrm{ft}$-kip

$M_{0}=$ major-axis bending moment at one end of the unbraced segment $=493.4 \mathrm{ft}$-kip

$M_{2}=$ major-axis bending moment at the other end of the unbraced segment $=493.4 \mathrm{ft}-\mathrm{kip}$

$C_{b}$ equals 1.0 (since $M_{m i d} / M_{2}$ is greater than 1.0)

The limit for first-order elastic analyses can now be computed as follows.

$$
L_{b} \leq 1.2 L_{p} \sqrt{\frac{C_{b} R_{b}}{M_{u} / M_{y c}}}
$$




\section{STRENGTH I:}

$240 \leq 1.2(72) \sqrt{\frac{(1.0)(1.0)}{1.25(554.7) / 1829.2}}$

$240>140.33 \therefore$ Not Satisfied

STRENGTH IV:

$240 \leq 1.2(72) \sqrt{\frac{(1.0)(1.0)}{1.50(554.7) / 1829.2}}$

$240>128.11 \therefore$ Not Satisfied

It should be noted that if the unbraced length was taken as $21.5 \mathrm{ft}$, a distance from one end of the bridge to the diaphragm, the limit would also not be met.

Therefore, a second-order analysis must be performed for the Strength I and Strength IV load combinations. Article 6.10.1.6 provides an approximate method for computing secondorder compression-flange lateral bending stresses by multiplying first-order values by an amplification factor (this calculation is not required for tensile stresses). This amplification factor is a function of the compression flange's elastic lateral torsional buckling stress, $F_{c r}$. To compute $F_{c r}$, the height between the centerline of the flanges, $h$, and the St. Venant torsional constant, $J$, must be calculated. The AISC Steel Construction Manual provides these values for rolled shapes. For a W36 $\times 135$ :

- $h=h_{o}=34.8 \mathrm{in}$.

- $J=7.0 \mathrm{in}^{4}$

$F_{c r}$ is then computed as follows according to the provisions for Appendix A6. It should be noted that, according to Article C6.10.1.6, $F_{c r}$ is not limited to $R_{b} R_{h} F_{y c}$. 


$$
\begin{aligned}
& F_{c r}=\frac{C_{b} \pi^{2} E}{\left(\frac{L_{b}}{r_{t}}\right)^{2}} \sqrt{1+0.078 \frac{J}{S_{x c} h}\left(\frac{L_{b}}{r_{t}}\right)^{2}} \\
& F_{c r}=\frac{(1.0)\left(\pi^{2}\right)(29000)}{\left(\frac{240}{2.99}\right)^{2}} \sqrt{1+0.078 \frac{7.0}{(439)(34.8)}\left(\frac{240}{2.99}\right)^{2}} \\
& F_{c r}=49.27 \mathrm{ksi}
\end{aligned}
$$

The amplification factor for first-order lateral flange bending stresses is as follows.

$$
A F=\frac{0.85}{1-\frac{M_{u}}{F_{c r} S_{x c}}}
$$

STRENGTH I:

$$
A F=\frac{0.85}{1-\frac{1.25(554.7)(12)}{(49.27)(439)}}=1.38
$$

StRENGTH IV: $\quad A F=\frac{0.85}{1-\frac{1.50(554.7)(12)}{(49.27)(439)}}=1.58$

To compute deck overhang loads, lateral forces are computed by determining the force statically equivalent to the couple resulting from the eccentric vertical loads. This computation involves the angle, $\alpha$, between the overhang bracket and the web of the girder. The bracket is assumed to extend from the end of the overhang to the web-bottom flange junction. The angle between the web of the girder and the bracket, along with the lateral force relation, are as follows. 


$$
\begin{aligned}
& F_{l}=F \tan (\alpha) \\
& \alpha=\tan ^{-1}\left[\frac{31.0}{35.6-2(0.79)}\right]=42.34^{\circ}
\end{aligned}
$$

In addition, half of the wet concrete overhang load is assumed to act on the overhang bracket, and is computed as follows.

$$
\frac{150}{2}\left(\frac{1}{144}\right)\left[(8.5)(31.0)+\frac{1}{2}\left(31.0-\frac{12}{2}\right)(2.0)+(2.0-0.79)\left(\frac{12}{2}\right)\right]=154 \frac{\mathrm{b}}{\mathrm{ft}}
$$

The lateral forces, bending moments, and lateral stresses are summarized as follows. Lateral bending moments are computed according to the approximations discussed in C1.3.2.2. To compute lateral stresses from lateral bending moments, moments are divided by the majoraxis section modulus of the flange, or $\left(t_{f}\right)\left(b_{f}\right)^{2} / 6$.

\begin{tabular}{lccccccc}
\hline & \multicolumn{3}{c}{ Lateral Flange Bending Moments \& First-Order Stresses } & & & \\
Components & $F / P$ & $\tan (\alpha)$ & $F_{l} / P_{l}$ & $L_{b}(\mathrm{ft})$ & $M_{l}(\mathrm{k})$ & $\left.S_{l}(\mathrm{in})^{3}\right)$ & $f_{l}(\mathrm{ksi})$ \\
\hline Deck Weight (lb/ft) & 154 & 0.911 & 140.3 & 20 & 56.13 & 18.96 & 2.96 \\
Overhang Deck Forms (lb/ft) & 40 & 0.911 & 36.4 & 20 & 14.58 & 18.96 & 0.77 \\
Screed Rail (lb/ft) & 85 & 0.911 & 77.5 & 20 & 30.98 & 18.96 & 1.63 \\
Railing (lb/ft) & 25 & 0.911 & 22.8 & 20 & 9.11 & 18.96 & 0.48 \\
Walkway (lb.ft) & 125 & 0.911 & 113.9 & 20 & 45.56 & 18.96 & 2.40 \\
Finishing Machine (lb) & 3000 & 0.911 & 2733.7 & 20 & 82.01 & 18.96 & 4.33 \\
\hline
\end{tabular}

Factored lateral flange bending stresses are computed below. Note that, for the Strength IV load combination, no live loads are considered; therefore the finishing machine load is neglected. Also, the limit specified in Equation 6.10.1.6-1, which limits lateral flange bending stresses to $60 \%$ of $F_{y}$, is also met. 


\begin{tabular}{lcccc}
\hline \multicolumn{4}{c}{ Factored First-Order Lateral Flange Bending Stresses } \\
& \multicolumn{2}{c}{ Strength I } & \multicolumn{2}{c}{ Strength IV } \\
Components & $\gamma_{i}$ & $f_{l}(\mathrm{ksi})$ & $\gamma_{i}$ & $f_{l}(\mathrm{ksi})$ \\
\hline Deck Weight (lb/ft) & 1.25 & 3.70 & 1.50 & 4.44 \\
Overhang Deck Forms (lb/ft) & 1.50 & 1.15 & 1.50 & 1.15 \\
Screed Rail (lb/ft) & 1.50 & 2.45 & 1.50 & 2.45 \\
Railing (lb/ft) & 1.50 & 0.72 & 1.50 & 0.72 \\
Walkway (lb.ft) & 1.50 & 3.60 & 1.50 & 3.60 \\
Finishing Machine (lb) & 1.50 & 6.49 & - & - \\
\hline
\end{tabular}

\section{$\underline{\text { C2.6.1.3 Limit State Evaluation }}$}

The nominal bend-buckling resistance, $F_{c r w}$, shall be calculated as follows. Note that $F_{c r w}$ shall not exceed the smaller of $R_{h} F_{y c}(50 \mathrm{ksi})$ or $F_{y w} / 0.7(71.4 \mathrm{ksi})$.

$$
\begin{aligned}
& k=\frac{9}{\left(D_{c} / D\right)^{2}} \\
& k=\frac{9}{(17.01 / 34.02)^{2}} \\
& k=36.0 \\
& F_{c r w}=\frac{0.9 E k}{\left(D / t_{w}\right)^{2}} \\
& F_{c r w}=\frac{0.9(29000)(36.0)}{(34.02 / 0.600)^{2}} \\
& F_{c r w}=292.3 \mathrm{ksi}>50 \mathrm{ksi} \\
& F_{c r w}=50 \mathrm{ksi}
\end{aligned}
$$

The limit states are evaluated as follows. As shown, the girder performs satisfactorily under all applicable constructibility limit states. Note that the second order amplification factor is not applied to tensile stresses. 
COMPRESSION FLANGE YIELDING

$f_{b u}+f_{l} \leq \phi_{f} R_{h} F_{y c}$

Strength I: $\quad 18.95+1.38(18.12)<(1.00)(1.0)(50) \therefore O K($ Ratio $=0.879)$

Strength IV: $\quad 22.74+1.58(12.37)<(1.00)(1.0)(50) \therefore O K($ Ratio $=0.846)$

COMPRESSION Flange FlEXURAL RESISTANCE

$f_{b u}+\frac{1}{3} f_{l} \leq \phi_{f} F_{n c}$

Strength I: $\quad 18.95+\frac{1.38(18.12)}{3}<(1.00)(57.97) \therefore O K($ Ratio $=0.471)$

Strength IV: $\quad 22.74+\frac{1.58(12.37)}{3}<(1.00)(57.97) \therefore O K($ Ratio $=0.505)$

WEB BEND-BUCKLING RESISTANCE

$f_{b u} \leq \phi_{f} F_{c r w}$

Strength I: $\quad 18.95<(1.00)(50) \therefore O K($ Ratio $=0.379)$

Strength IV: $\quad 22.74<(1.00)(50) \therefore O K($ Ratio $=0.455)$

TENSION FLANGE YIELDING

$f_{b u}+f_{l} \leq \phi_{f} R_{h} F_{y t}$

Strength I: $\quad 18.95+18.12<(1.00)(1.0)(50) \therefore O K($ Ratio $=0.741)$

Strength IV: $\quad 22.74+12.37<(1.00)(1.0)(50) \therefore O K($ Ratio $=0.702)$

\section{C2.6.2 Service Limit State}

The service limit state is evaluated according to the provisions of Articles 6.10.4.1 (governing elastic deformations) and 6.10.4.2 (governing permanent deformations). 


\section{$\underline{\text { C2.6.2.1 Elastic Deformations }}$}

The elastic deformation limit state, as previously stated, is evaluated against a maximum deformation of $L / 800$, or 0.945 inches. From the analysis results, a maximum live load deflection of 0.461 inches was determined. Therefore, this meets elastic deformation requirements $($ Ratio $=0.488)$.

\section{C2.6.2.2 Permanent Deformations}

The first step in evaluating the girder's performance under permanent deformation limits is to determine the girder's service level stresses. This will be derived solely from gravity and vehicular loadings, as lateral loads are not being considered at the service limit state in this design evaluation.

From the analysis results, the following Service II moments were found.

$$
\begin{aligned}
& 1.00 M_{D C 1}=554.7 \mathrm{ft}-\mathrm{kip} \\
& 1.00 M_{D C 2}=19.8 \mathrm{ft}-\mathrm{kip} \\
& 1.00 M_{D W}=96.7 \mathrm{ft}-\mathrm{kip} \\
& 1.30 M_{L L+I M}=1507.7 \mathrm{ft}-\mathrm{kip}
\end{aligned}
$$

Using these moments, Service II stresses for the top and bottom flange are found as follows. Therefore, according to Equations 6.10.4.2.2-1 and 6.10.4.2.2-2, respectively, the flanges are shown to meet the requirements for permanent deformations at the service limit state. 
TOP FLANGE:

$f_{f}=\frac{(554.7)(12)}{439}+\frac{(19.8+96.7)(12)}{1986.97}+\frac{(1507.7)(12)}{10032.8}=17.67 \mathrm{ksi}$

$f_{f} \leq 0.95 R_{h} F_{y f}$

$17.67<0.95(1.0)(50) \therefore O K($ Ratio $=0.372)$

BOTTOM FLANGE:

$f_{f}=\frac{(554.7)(12)}{439}+\frac{(19.8+96.7)(12)}{609.93}+\frac{(1507.7)(12)}{675.31}=44.25 \mathrm{ksi}$

$f_{f}+\frac{f_{l}}{2} \leq 0.95 R_{h} F_{y f}$

$44.25+\frac{0}{2}<0.95(1.0)(50) \therefore O K($ Ratio $=0.931)$

\section{C2.6.3 Fatigue Limit State}

As previously discussed, the detail chosen for these design evaluations is the base metal at the weld joining the lateral bracing connection plates at interior diaphragms. These details are evaluated for the Fatigue I load combination for infinite life, with a nominal fatigue resistance of $12.0 \mathrm{ksi}$, previously determined as the constant amplitude fatigue threshold.

From the previously determined factored fatigue moments, a fatigue moment of $686.0 \mathrm{ft}-$ kip was determined (see C2.5) at the diaphragm location at midspan. Since this is a simple-span bridge, a minimum fatigue moment of zero was found. Therefore, a fatigue stress range can be found for both the top flange and bottom flange by determining the stress resulting from the calculated moment. As shown, this detail performs satisfactorily.

TOP FLANGE

$\gamma(\Delta f)=\frac{686.0(12)(1.46)}{22524.9}=0.534 \mathrm{ksi}$

$0.534 \mathrm{ksi}<12.0 \mathrm{ksi} \therefore O K($ Ratio $=0.045)$ 


\section{BOTTOM FLANGE}

$\gamma(\Delta f)=\frac{686.0(12)(32.56)}{22524.9}=11.90 \mathrm{ksi}$

$11.90 \mathrm{ksi}<12.0 \mathrm{ksi} \therefore O K($ Ratio $=0.992)$

\section{C2.6.4 Strength Limit State}

At the strength limit state, as specified in Article 6.10.6, the girder must meet requirements for flexure and shear as well as a ductility requirement. Each of these criteria will be evaluated.

\section{C2.6.4.1 Flexure}

For flexure, in order to determine a section's capacity, a determination must be made regarding whether the section is classified as compact or noncompact. For this determination, the section's plastic moment capacity must be calculated. For this evaluation, the reinforcement in the concrete slab is conservatively neglected.

The first step in determining the section's plastic moment capacity is to determine the plastic forces in each of the section's components.

$$
\begin{aligned}
& P_{s}=0.85 f_{c}^{\prime} b_{s} t_{s}=0.85(4)(83.25)(8.0)=2264.4 \mathrm{kip} \\
& P_{t}=P_{c}=F_{y} b_{f} t_{f}=(50)(12)(0.79)=474 \mathrm{kip} \\
& P_{w}=F_{y} A_{g}-2\left(P_{t}\right)=(50)(39.9)-2(474)=1047 \mathrm{kip}
\end{aligned}
$$

Next, the location of the plastic neutral axis (PNA) must be determined.

\section{Case I}

$P_{t}+P_{w} \geq P_{c}+P_{s}$

$1521 \leq 2738.4 \therefore$ PNA is not in the web 
Case II

$P_{t}+P_{w}+P_{c} \geq P_{s}$

$1995 \leq 2264.4 \therefore$ PNA is not in the top flange

Therefore, the PNA is in the concrete deck (measured from the top of the concrete deck) and $\bar{Y}$ is computed using the following equation derived from that provided in Table D6.1-1.

$$
\begin{aligned}
& \bar{Y}=\left(t_{s}\right)\left[\frac{P_{c}+P_{w}+P_{t}}{P_{s}}\right] \\
& \bar{Y}=(8.0)\left[\frac{1995}{2264.4}\right]=7.05 \mathrm{in}
\end{aligned}
$$

Next, the distances of the individual components from the location of PNA are computed.

$$
\begin{aligned}
& d_{c f}=(8.0-7.05)+2-\frac{0.79}{2}=2.56 \mathrm{in} \\
& d_{w}=(8.0-7.05)+2+\frac{(35.6-2 \times 0.79)}{2}=19.96 \mathrm{in} \\
& d_{t f}=(8.0-7.05)+2+(35.6-2 \times 0.79)+\frac{0.79}{2}=37.365 \mathrm{in}
\end{aligned}
$$

The plastic moment of the composite section, $M_{p}$, can now be evaluated.

$$
\begin{aligned}
& M_{p}=\left[\frac{\bar{Y}^{2} P_{s}}{2 t_{s}}\right]+\left(P_{c} d_{c}+P_{w} d_{w}+P_{t} d_{t}\right) \\
& M_{p}=\frac{\left[\frac{7.05^{2} \times 2264.4}{2 \times 8}\right]+(474 \times 2.56+1047 \times 19.96+474 \times 37.365)}{12} \\
& M_{p}=3904.7 \mathrm{kip}-\mathrm{ft}
\end{aligned}
$$


For a composite section in positive flexure to be considered compact, according to Article 6.10.6.2.2, the section must meet three requirements. The first states that the minimum yield strengths of the flanges must not exceed $70.0 \mathrm{ksi}$, which is met since $50 \mathrm{ksi}$ steel is used. The second is that the web satisfies the requirement of Article 6.10.2.1.1, which was evaluated earlier (see C2.2.2). The third is that the section satisfies the following web slenderness limit, where $D_{c p}$ is the depth of the web in compression at the plastic moment.

$$
\frac{2 D_{c p}}{t_{w}} \leq 3.76 \sqrt{\frac{E}{F_{y c}}}
$$

It was previously determined that the plastic neutral axis was in the concrete deck. Therefore, $D_{c p}=0$, and this third requirement is met. Since all of the aforementioned requirements have been met, this section is classified as compact.

For compact composite sections in positive flexure, Article 6.10.7.1.2 states that the nominal flexural resistance, $M_{n}$, is computed as follows.

If $D_{p} \leq 0.1 D_{t}$, then:

$$
M_{n}=M_{p}
$$

Otherwise:

$$
M_{n}=M_{p}\left(1.07-0.7 \frac{D_{p}}{D_{t}}\right)
$$

$D_{p}$, the distance from the top of the concrete deck to the plastic neutral axis, and $D_{t}$, the total depth of the composite section, are as follows:

$$
\begin{aligned}
& D_{p}=7.05 \mathrm{in} \\
& D_{t}=8.0+(2.0-0.79)+35.6=44.81 \mathrm{in} \\
& 0.1 D_{t}=4.48 \mathrm{in} \\
& D_{p}>0.1 D_{t}
\end{aligned}
$$


Therefore:

$$
M_{n}=3904.7\left(1.07-0.7 \frac{7.05}{44.81}\right)=3748.0 \mathrm{ft}-\mathrm{kip}
$$

To satisfy strength limit state requirements, the section must satisfy the following relation.

$$
M_{u}+\frac{1}{3} f_{l} S_{x t} \leq \phi_{f} M_{n}
$$

For this relation, $f_{l}=0$ as wind forces and other lateral loads are being neglected at the finished state. From the moments generated for this girder, a maximum Strength I bending moment of $2892.8 \mathrm{ft}-\mathrm{kip}$ was found (see C2.5), indicating that this girder meets strength limit state requirements for flexure.

$$
M_{u} \leq \phi_{f} M_{n}
$$

$2892.8 \mathrm{ft}-\mathrm{kip}<1.00(3748.0 \mathrm{ft}-\mathrm{kip}) \therefore O K($ Ratio $=0.772)$

\section{C2.6.4.2 Shear}

The provisions of Article 6.10.9 are applied to determine whether sections meet strength limit state requirements for shear. As previously stated, the distributed shear forces were based on the interior girder distribution factor. Therefore, the shear capacity of an interior girder is computed. However, since the interior and exterior girders are the same, their shear capacities will be identical.

The first step is to determine the plastic shear capacity of the web, which is found as follows. 


$$
V_{p}=0.58 F_{y w} D t_{w}
$$

$V_{p}=0.58(50)(34.02)(0.600)=591.95 \mathrm{kip}$

The plastic shear capacity of the web is then modified by a value, $C$, to obtain the nominal shear resistance. $C$ is simply the ratio of the shear-buckling resistance to the shear yield strength and is a function of the slenderness of the web. For this computation, a shear buckling coefficient, $k$, is introduced. However, as this web is unstiffened, the value of $k$ is taken as a constant value of 5.0. Therefore, $C$ is determined as follows.

$$
\begin{aligned}
& \frac{D}{t_{w}} \leq 1.12 \sqrt{\frac{E k}{F_{y w}}} \\
& \frac{34.02}{0.600} \leq 1.12 \sqrt{\frac{(29000)(5.0)}{(50)}}
\end{aligned}
$$

$56.7<60.3$

Therefore:

$$
C=1.0
$$

The nominal shear capacity of the web can now be determined.

$$
\begin{aligned}
& V_{n}=V_{c r}=C V_{p} \\
& V_{n}=(1.0)(591.95)=591.95 \mathrm{kip}
\end{aligned}
$$

From the shears generated for this girder, a maximum Strength I shear of 208.5 kip was found (see C2.5), indicating that this girder meets strength limit state requirements for shear.

$V_{u} \leq \phi_{v} V_{n}$

208.5 kip $<(1.0)(591.95$ kip $) \therefore O K($ Ratio $=0.352)$ 


\section{C2.6.4.3 Ductility}

An additional ductility requirement is placed on composite sections in positive flexure. Specifically, sections shall meet the requirements in the relation below. For this requirement, as shown, the section performs satisfactorily.

$D_{p} \leq 0.42 D_{t}$

Eq. 6.10.7.3-1

$7.05 \leq(0.42)(44.81)$

7.05 in $<18.82$ in $\therefore O K($ Ratio $=0.375)$

\section{C2.7 Performance Summary}

A tabulated summary of all of the girder's performance ratios is presented below. As shown, the girder performs satisfactorily under all evaluated design checks, with bottom flange base metal at connection plate weld at the fatigue limit state governing $($ Ratio $=0.992)$. 


\section{CONSTRUCTIBILITY}

\section{Compression Flange Yielding}

Strength I

0.879

Strength IV

0.846

Compression Flange Flexural Resistance

Strength I

0.471

Strength IV

0.505

Web Bend Buckling

Strength I

0.379

Strength IV

0.455

Tension Flange Yielding

Strength I

0.741

Strength IV

0.702

$\underline{\text { SERVICE Limit STATE }}$

Elastic Deformations

0.488

Permanent Deformations

Top Flange

0.372

Bottom Flange

0.931

FATIGUE LiMIT STATE

Base Metal at Connection Plate Weld

Top Flange

0.045

Bottom Flange

0.992

\section{$\underline{\text { STRENGTH LIMIT STATE }}$}

Moment

Shear

Ductility
0.772

0.352

0.375 